Paweł Majewski

\title{
Between an Animal and a Machine
}

Stanisław Lem's Technological Utopia 
Modernity in Question

Studies in Philosophy and History of Ideas 10

\section{Paweł Majewski}

\section{Between an Animal and a Machine}

The subject of this book is the philosophy of Stanisław Lem. The first part contains an analysis and interpretation of one of his early works, The Dialogues. The author tries to show how Lem used the terminology of cybernetics to create a project of sociology and anthropology. The second part examines Lem's essay Summa technologiae, which is considered as the project of human autoevolution. The term "autoevolution" is a neologism for the concept of humans taking control over their own biological evolution and form in order to improve the conditions of their being. In this interpretation, Summa is an example of a liberal utopia, based on the assumption that all human problems can be resolved by science. Various social theories, which can be linked to the project of autoevolution, are presented in the final part.

\section{The Author}

Paweł Majewski is Associate Professor at the Institute of Polish Culture at the University of Warsaw. His main areas of research are: influence of writing on the intellectual and cognitive processes in the human mind; history of communication; bias of alphabetic writing as a vehicle of cultural communication. 
Between an Animal and a Machine 


\section{MODERNITY IN QUESTION STUDIES IN PHILOSOPHY AND HISTORY OF IDEAS}

Edited by Małgorzata Kowalska

VOLUME 10

\section{PETER LANG}


Paweł Majewski

\section{Between an Animal and a Machine}

Stanisław Lem's Technological Utopia

Translation from Polish by

Olga Kaczmarek

\section{黑 \\ PETER LANG}


Bibliographic Information published by the Deutsche Nationalbibliothek The Deutsche Nationalbibliothek lists this publication in the Deutsche Nationalbibliografie; detailed bibliographic data is available in the internet at http://dnb.d-nb.de.

\title{
Library of Congress Cataloging-in-Publication Data
}

A CIP catalog record for this book has been applied for at the Library of Congress.

The Publication is founded by Ministry of Science and Higher Education of the Republic of Poland as a part of the National Programme for the Development of the Humanities. This publication reflects the views only of the authors, and the Ministry cannot be held responsible for any use which may be made of the information contained therein.

\section{NATIONAL PROGRAMME FOR THE DEVELOPMENT OF HUMANITIES}

ISSN 2193-3421

\author{
E-ISBN 978-3-653-06830-6 (E-PDF) \\ E-ISBN 978-3-631-71024-1 (EPUB) \\ E-ISBN 978-3-631-71025-8 (MOBI) \\ DOI 10.3726/978-3-653-06830-6
}

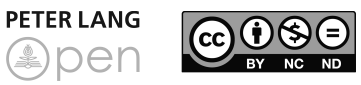

Open Access: This work is licensed under a Creative Commons Attribution Non Commercial No Derivatives 4.0 unported license. To view a copy of this license, visit https://creativecommons.org/licenses/by-nc-nd/4.0/

(C) Paweł Majewski, 2018 .

Peter Lang - Berlin · Bern · Bruxelles · New York •

Oxford · Warszawa $\cdot$ Wien

This publication has been peer reviewed.

www.peterlang.com 


\section{Contents}

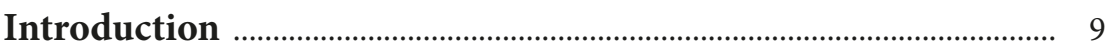

Lemology Pure and Applied .................................................................... 9

Part One Dialogues - Cybernetics as an Anthropology

1 The Genesis and Growth of Cybernetics ………………………... 15

2 Cybernetics in Poland ………………………………………………. 23

3 Philosophical Implications of Cybernetics ……………………..... 31

4 Introduction to Dialogues ………………………………………….. 39

5 The Structure of Dialogues ………………………………………... 43

6 Attempt at an Interpretation …………………………………….... 51

Part Two Summa Technologiae - Technology as Lifeworld

7 Kołakowski’s Review ............................................................................. 69

8 What Is "Lem's Essay"? ........................................................................... 73

9 Prolegomena …………………………………………………... 77

10 Evolutions …………………………………………………………… 85 
11 Taking UFO Seriously

12 Turing Body

13 Metatheory

14 Phantomatics

15 On How to Farm Information

16 Putting Pieces Together

Part Three Autoevolution and Posthumanism

17 Themes of Lampoon of Evolution

19 Introduction to Autoevolution

21 What Is Posthumanism?

22 Posthumanism as a Theoretical Discourse

23 Cyborgs, Androids and Robots 
25 Hidden Premises behind Posthumanism ...................................... 207

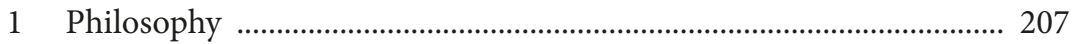

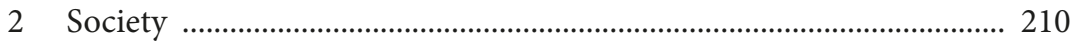

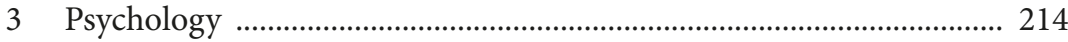

26 Posthumanism and Gender ............................................................. 217

27 Posthumanism and Bioethics ......................................................... 223

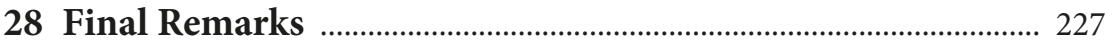

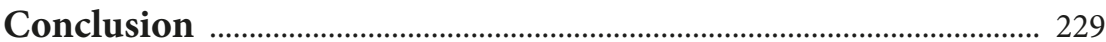

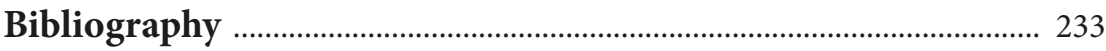

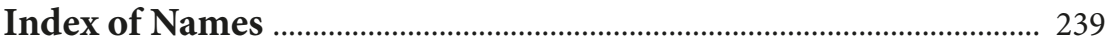





\section{Introduction}

\section{Lemology Pure and Applied}

György Lukács's book about young Hegel has 606 pages in a classic English edition, and 1,011 pages in the Polish edition. ${ }^{1}$ A book about the life and work of Faulkner by Joseph L. Blotner consists of two volumes amounting to 1,846 pages of the main text, supplemented by 269 pages of references with separate page numbering. ${ }^{2}$ A biography of Thomas Mann, written by Klaus Harpprecht in its one volume edition consists of 2,253 pages of very fine print, ${ }^{3}$ while Sartre's unfinished work on Flaubert takes up 2,801 pages (in three volumes). ${ }^{4}$ So how many pages would it take to write exhaustively about the life and works of Stanisław Lem? A comparable number perhaps. Such an exhaustive description is not what this work is after though.

The readers' response to Lem's works has gone through a number of phases. His novels and short stories started being talked about and appreciated in the 1950s in communist Poland, as well as in other countries of the Soviet Bloc, especially the USSR and East Germany. By the late 1960s they gained renown in West Germany and the United States as well. For a long time, however, he was perceived as a sci-fi author, and the genre was seen as inferior literary production by institutions in a position to determine literary value. The label did a lot of evil to Lem, because for years there would be no appreciation of intellectual values of his works. And once they eventually started being noticed, they left many critics puzzled, as the intellectual input made by Lem by far exceeded the competence of most literary scholars, while scientists representing particular disciplines explored by Lem did not deem his literary works and essays worthy of a thorough discussion.

This somewhat schizophrenic state seems to continue until today really. In the 21st century the intellectual circles appreciate Stanisław Lem, but the appreciation is often conventional. He is being praised for some vague achievements bordering on literature and science, for accurate predictions of technological

1 György Lukács, The Young Hegel: Studies in the Relations between Dialectics and Economics, trans. by R. Livingstone (Cambridge: MIT, 1977). Idem, Młody Hegel: o powiązaniach dialektyki z ekonomią, trans. by M. J. Siemek (Warszawa: PWN, 1980).

2 Joseph L. Blotner, Faulkner: A Biography (London: Chatto and Windus, 1974).

3 KlausHarpprecht, ThomasMann:eine Biographie(ReinbekbeiHamburg: Rowohlt, 1995).

4 Jean-Paul Sartre, L'idiot de la famille (Paris: Gallimard, 1971, 1975). 
development - but it is not easy to tell what that in fact meant. Every once in a while his work is still seen as "not quite serious." His situation as a writer is peculiar: his work as a whole is not "literary" enough for literary circles, and it is not "scientific" enough for scientists. Therefore, it is very difficult to classify him into any literary or philosophical current. On the other hand his work cannot be qualified as "science." From the very beginning Lem would take up topics in-between two disciplines - which has become a scientific practice only several decades later (apart from the episode of cybernetics). So to any specialists he by necessity appeared to be an amateur. The unlucky proximity with trashy sci-fi and pseudoscientific charlatans, combined with the seeming abyss separating his work from the pantheon of literature and philosophy have contributed to the unfortunate image of Lem as a sort of technology prattler. Only as late as in the 1970s have there emerged a thorough criticism and interpretation, both in Poland and abroad, which would place him among the most eminent contemporary authors. Decades of being underestimated had grown in him into a lasting sense of frustration, which only became stronger in the last years of his life.

This book will be primarily devoted to Stanisław Lem's two discursive works: Dialogues and Summa Technologiae. I will try to prove that they are the author's most significant input in the process of understanding civilizational changes in the West in the late 20th and early 21st century - even though they were in fact written several decades earlier. Lem's fiction will be referenced here often, but marginally, as a detailed analysis would complicate the argument excessively. Lem's two later theoretical treatises are wilfully omitted here: The Philosophy of Chance and Science Fiction and Futurology. They are devoted to completely different issues and employ different theoretical and interpretation methodology. They deserve a separate monograph.

Both Dialogues and Summa Technologiae are presented here against a broad theoretical background, as this approach helps unveil the intellectual sources that inspired them. Part One is devoted to Dialogues, which constitute Lem's interpretation of cybernetics. After outlining the history of the discipline and its significance in world science in the 1950s and 1960s, I proceed with an analysis of Dialogues, where I show that by writing the book Lem attempted to apply the system of categories provided by cybernetics to build his own anthropological project. However, being aware of philosophical contradictions inherent to the attempt, he could not coherently complete the plan.

Within Lem's oeuvre, Dialogues prepare the ground for a much bolder work: Summa Technologiae. The scope and the open structure of the text make it impossible to come up with unequivocal interpretation. In Part Two, I offer an interpretation according to which Summa Technologiae is an elaborate utopian 
project of autoevolution of the human species, of transition from a phase of haphazard biological evolution toward a planned phase of controlled regulation of human biological and physiological features.

Part Three, which takes up most of this book, is devoted to contemporary intellectual currents, which take up on Lem's project of autoevolution. The most important among them is posthumanism, which was established in the United States in the 1980s. ${ }^{5}$ Similarities it shares with Lem's thought, while significant, are in fact accidental. Yet, it does not change the fact that Summa Technologiae and posthumanism belong to the same intellectual process.

My main task when analyzing both Lem's texts and the works of other authors referenced here is to reconstruct their covert assumptions. By revealing and analyzing them, I offer and further prove a thesis that both Lem's and posthumanists' anthropology have traits of utopian liberalism, based on an assumption of human rationality. In order to interpret Lem in a way that will not be limited to a narrow range of linguistic and genre-related issues, I need to refer to a wide range of disciplines. Therefore, this book will invoke tools of literary criticism, sociology, history of ideas, philosophy, science studies, bioethics and a few other disciplines, which means that as a whole this work cannot be classified as belonging to any single of the disciplines listed above. It can be its disadvantage, but it may also open a broader perspective on Lem's works.

5 In this book I use the notion of "posthumanism" in a different sense that is prevalent today - I do not mean an intellectual current, which developed from a rejection of anthropocentrism in the humanities, but a technocratic ideology of sorts that allows a possibility that the human species could transcend its biological limitations with advanced technology. 



\section{Part One Dialogues - Cybernetics as an Anthropology}





\section{The Genesis and Growth of Cybernetics}

The intellectual climate of the 21st century is not particularly favorable to the so-called "grand narratives" - intellectual approaches that aim to explain the entire reality available to human mind, or at least a large portion of it. It is commonly accepted that structuralism was the last such grand narrative, which seemed to serve as a metatheory of the humanities in the 1960s and 1970s. However, its predecessor in that regard - cybernetics - is rarely mentioned, even though it was even more prevalent between the end of the 1940s and mid-1960s.

Part One of this book is to be devoted to Dialogues - the one among Lem's works in which his fascination with cybernetics is the strongest. ${ }^{6}$ In fact, Dialogues cannot be understood without referring to the swift career of the discipline. Therefore, before discussing cybernetics itself, I should outline briefly its history. This description of what cybernetics is will, however, come from an amateur. The mathematical tools and vocabulary used by the creators and proponents of cybernetics remain unavailable to me. I will be treating cybernetics as a phenomenon in the history of science and ideas, leaving mathematics in a sort of "black box," which is not to be opened, but which is being observed focusing on its location and functioning. It is justifiable, as the cyberneticists never limited themselves to producing mathematical arguments. The founding father of cybernetics himself, Norbert Wiener showed the path here (I will return to it). In fact, some branches of cybernetics detached themselves completely from science. And these branches happened to wither the earliest.

Cybernetics is commonly described as "a scientific study of control and communication in complex systems" - this is how it was defined by its creator, Norbert Wiener. ${ }^{7}$ The general character of this description is quite significant, indicating not only a broad background and a variety of sources of the discipline, but also its broad scope. Wiener gave it a name derived from Greek. ${ }^{8}$ "Kybernetes" means

6 "This book $[\ldots]$ comes from a captivation with cybernetics." Stanisław Lem, "Przedmowa do drugiego wydania," in: Dialogi, 3rd edition (Kraków: WL, 1984), 5. All translations from Dialogues, which have not been translated to English in full, have been made for this work by Olga Kaczmarek.

7 Norbert Wiener, Cybernetics: or the Control and Communication in the Animal and the Machine (Cambridge: MIT, 1965), 11.

8 Ibidem. 
"helmsman" and is derived from the verb "kybernao", meaning "to steer." The term "governor" has the same root.

Cybernetics was largely born from war-time needs and was related to technologies of building quick counting machines - in both cases the purpose was to facilitate calculating trajectories of missiles targeting bullets. In an introduction to his book Cybernetics, Second Edition: or the Control and Communication in the Animal and the Machine, ${ }^{10}$ which became the founding work of the entire discipline, Wiener describes in detail how the ideas of cybernetics were born during seminars he participated in at Harvard's Vanderbilt Hall in 1941-1944 together with mathematicians (including von Neumann), engineers, biologists and doctors. ${ }^{11}$ This interdisciplinary gathering observed that there are numerous analogies between the functioning of new calculating machines and biological organisms when it comes to mechanisms of steering and control. It turned out some processes within calculating machines and human nervous systems can be described with the same mathematical formulae - that is, processes that include feedback and oscillations. ${ }^{12}$ Research continued after the end of the war was conducted simultaneously in engineering and biology. This duality of research directions is characteristic of the entire cybernetics, and it will be important for the argument that follows.

Wiener himself played a pivotal role in shaping the new discipline - he stood behind its laws and ideology. As a child this versatile scholar and intellectual was fascinated by nature, and traces of such interests are clear in his works, which combine mathematics with physiology. It must have tickled the imagination of a young physician Stanisław Lem, when he read his books in Mieczysław Choynowski's seminar; learning English from them. ${ }^{13}$ Wiener was not only a

9 A Greek-English Lexicon compiled by Henry George Liddell and Robert Scott (LSJ) ed. 1996 s.v. (s. 1004). Both words can be found in Homer (Il. 19, 43; Od. 9, 78; 3, 283). As early as Aeschylus (Suppliants 750, "shepherd of the ship") and Plato (Phaedrus, 247 c, "charioteer"), the word "kybernetes" is used metaphorically.

10 Idem, Cybernetics: or Control and Communication in the Animal and the Machine (Cambridge: MIT Press, 1948); all quotes and references from the 2nd edition (Cambridge: MIT Press, 1961).

11 Wiener, Cybernetics, 21 and following.

12 Such processes include movement disorders in Parkinson's disease.

13 Stanisław Lem, Stanisław Bereś, Tako rzecze ... Lem (Kraków: Wydawnictwo Literackie 2001), 43. "Choynowski set up Science Seminar for Jagiellonian University Research Assistants and on behalf of the group he approached innumerable research institutions in Canada and United States requesting books for the starved Polish academia. Seeing all these treasures, unavailable to me because of the language, I sat down to learning English with utmost diligence. I cannot say this was typical science I studied, because 
mathematician, but also an engaged social critic, which can be best seen in his book The Human Use of Human Beings. Cybernetics and Society (1950), which is not a scientific work, but a collection of essays about science for a general public, oftentimes with a journalistic air to them. The fact that this particular book has become a popular guide to cybernetics shows that unlike other disciplines, cybernetics was tied to its social context from the very beginning - its creator himself has positioned it that way, and he did it on purpose. This was certainly aided by his powerful, authoritarian personality, which emanates from his determined arguments admitting no opposition and densely marking his texts, as well as from his very critical remarks about the postwar American society. ${ }^{14}$

Apart from contemporary needs and an intellectual osmosis between biologists and engineers, for Wiener the sources of cybernetics lied primarily in the development of thermodynamics and statistical mechanics in the late 19th century. He had especially great respect for one of the men behind both these disciplines - Josiah Willard Gibbs, whose long underestimated works greatly enriched statistical interpretation of energy transmission processes. ${ }^{15}$ Information transmission is part of these processes, as Wiener and his colleagues remarked and the information is treated as a physical quality here. In Cybernetics, Wiener provides basis for a mathematical description of information, ${ }^{16}$ which was then developed further by his disciple, Claude Shannon. This is where physics and biology meet: according to Wiener a biological organism is an energy and information processing system.

Later cyberneticists developed the discipline much further and found some much earlier antecedents for it. They saw all thinkers and engineers involved in combinatorics and building calculating or moving machines as early cyberneticists, from Ramon Llull and Jaquet-Droz to Pascal and Leibniz (Wiener presented the latter as the "patron saint of cybernetics"). Even cabalist mystics

it started with Wiener's Cybernetics, which I read almost like Champollion deciphering the hieroglyphs $[\ldots]$ slowly $[\ldots]$ with dictionary in my hand."

14 Cf. Norbert Wiener, The Human Use of Human Beings. Cybernetics and Society (Boston: Houghton Mifflin, 1950), Chapters 2, 7 and 9; quoted from the edition: (London: Free Association Books, 1989); idem, Cybernetics and Communication..., Chapter 8.

15 Ludwig Boltzmann is usually seen as the main creator of thermodynamics, but Wiener hardly ever mentions him. About Gibbs see The Human Use..., "Introduction," 7-15; and Cybernetics..., chapter 2, "Groups and Statistical Mechanics," 45-59.

16 Cybernetics, chapter 3, “Time Series, Information and Communication," 60-94. 
with their search for Golem were listed in that context. ${ }^{17}$ Mathematical roots of cybernetics were largely impacted by early game theory and von Neumann's theory of automata, ${ }^{18}$ Turing's works on computability and the probability theory, which was being developed at the time by thinkers such as Andrey Kolmogorov and Ronald Fisher (all these names come up both in Wiener's and Lem's texts).

It was soon observed that

certain kinds of machines and some living organisms - particularly the higher living organisms - can, as we have seen, modify their patterns of behavior on the basis of past experience so as to achieve specific antientropic ends. In these higher forms of communicative organisms the environment, considered as past experience of an individual, can modify the pattern of behavior into one which will in some sense or other will deal more effectively with the future environment. ${ }^{19}$

It was another step toward conceptually placing humans and machines on a par. A theory of "learning machines" started being developed, together with building such machines, initially quite primitive, and then increasingly complex.

In 1948 William Ross Ashby made the first Homeostat - "a physical model imitating the phenomenon of homeostasis [i.e. physiological balance in a variable environment] and the self-organizing capacities of the brain." ${ }^{20}$ The Homeostat was in fact the first practical success of cybernetics. In the 1950s and 1960s cybernetics developed swiftly and had its big entry into such disciplines as biology, economy, technical sciences (including telecommunication), sociology, political science and other. ${ }^{21}$ The marriage of cybernetics and biology gave rise to a discipline sometimes called bionics (usually biocybernetics) - and this was when for the first time there were publications on systems that combine biological and mechanical components, based on thorough research on the functioning of human nervous system. ${ }^{22}$ I emphasize that so much, because such

17 Henryk Greniewski (1903-1972), one of the Polish cyberneticists referred to the myth, labeling his own theory of machines imitating humans as "the Golems theory."

18 John von Neumann's last unfinished work was titled The Computer and the Brain (New Haven: Yale University Press, 1958).

19 The Human Use..., 48.

20 Mały słownik cybernetyczny, ed. by M. Kempisty (Warszawa: WP, 1973), 147; it includes a detailed description of Ashby's Homeostat.

21 Cf. G. R. Boulanger, "Prologue: What is Cybernetics?," in: Survey of Cybernetics. A Tribute to Dr Norbert Wiener, ed. by J. Rose (London: Illiffe Books Ltd.), 7-12. The text is one of the manifestos of the omnipotence of cybernetics.

22 Cf. Michael A. Arbib, The Metaphorical Brain. An Introduction to Cybernetics as Artificial Intelligence and Brain Theory (New York-London-Sydney-Toronto: Wiley, 1972). Two parts of this book provide a detailed description of methodological and 
systems (cyborgs) will be one of the main topics of Part Three of this book. For some time it seemed like creating a structure that would combine features of a biological organism and a machine is close. Research in economical cybernetics looked promising. New subdisciplines were formed too, such as socio- and psychocybernetics and military, medical, pedagogical and linguistic cybernetics (the latter producing the first attempts at machine translations). Researching all types of steering processes, scholars focused on problems such as the impact of steering signals and feedback on the quality and stability of control, the impact of the structure of the systems on their reliability and the resistance of steering systems to interference. It needs to be emphasized, given the liberties with terminology taken by later epigones of cybernetics, that all these notions originally had precise mathematics determinants, formed on the basis of advanced fields of the science. In the 1970s it was further enriched by linking cybernetics to the general system theory, ${ }^{23}$ which made it possible to research complex steering systems, among other things.

While creating cybernetics, Norbert Wiener saw it not only as a new, revealing discipline of science but also as a remedy to the increasing atomization of sciences ${ }^{24}$ and as a major tool shaping social life. ${ }^{25}$ Very soon, however, in the 1960 s it became clear that neither of these "metascientific" goals of cybernetics is or

scientific implications of two views: the evolutionary one according to which humans are animals, and the cybernetic one, according to which they are mechanisms.

23 It is a theory formed in 1930-1960 by an Austrian philosopher and biologist Ludwig von Bertalanffy (1901-1972), who claimed that a biological organism is not a simple sum of components, but constitutes a system characterized by unity and integrality, coordinating functions and processes, the organization of which is an important feature of life. The theory was to be an alternative to mechanistic and vitalist approaches in biology. It became an important argument for those who opposed reductionism in philosophy of science.

24 "For many years ... I had shared the conviction that the most fruitful areas of the growth of the sciences were those which had been neglected as a no-man's land between the various established fields. Since Leibniz there has perhaps been no man who has had a full command of all the intellectual activity of his day. Since that time, science has been increasingly the task of specialists, in fields, which show a tendency to grow progressively narrower. A century ago there may have been no Leibniz, but there was a Gauss, a Faraday, and a Darwin. Today there are a few scholars who can call themselves mathematicians or physicists or biologists without restriction. A man may be a topologist or an acoustician or a coleopterist." (Cybernetics..., 2)

25 Significant part of The Human Use of Human Beings is devoted to discussions of the implications of the cybernetics on social life; cf. particularly chapters 6-9, 112-162. 
can be achieved. Instead of quickly becoming a mathesis universalis, it started dividing into subdisciplines, which were losing connection with one another. The attempts to apply cybernetics to social sciences, which were in fact undertaken against Wiener's will, ${ }^{26}$ soon failed, as they turned cybernetic terminology from a precise vocabulary into a set of blurry metaphors with no heuristic value (I shall provide examples of that later). The purely technical fields of cybernetics, such as the theory of automata, of adaptive control systems and of optimal and hierarchical control, as well as the more specialized biocybernetical research, met the same fate as all other subdisciplines: this atomization and formal sophistication have made them completely inaccessible for those who specialize in slightly other fields (not to mention amateurs). What happened was exactly what Wiener was trying to save the science from.

There are innumerable texts about cybernetics. Globally there are hundreds of monographs and dozens of thousands of articles. It is impossible to pin down the moment when all this production got relegated to the margins of real science, because naturally the cyberneticists themselves have never admitted it had happened. It can be said that the 1970s brought the final fading of classic cybernetics, even though it is also the moment when Heinz von Foerster announced the end of "first-order cybernetics" and the beginning of "second-order cybernetics" in a work titled Cybernetics of Cybernetics. He defined the former as cybernetics of observed systems, while the latter as cybernetics of observing systems (which means the discipline has not avoided the self-referentiality, which became overwhelming in social sciences and the humanities at the time). This "second-order cybernetics" is now represented by sociocybernetics, which investigates the so-called autopoietic - or self-reproducing - systems. ${ }^{27}$ The

26 "Drs. Gregory Bateson and Margaret Mead have urged me, in view of the intensely pressing nature of the sociological and economic problems of the present age of confusion, to devote a large part of my energies to the discussion of this side of cybernetics ... the human sciences are very poor testing-grounds for a new mathematics technique: as poor as the statistical mechanics of gas would be to a being of the order of size of a molecule, to whom the fluctuations which we ignore form a larger standpoint would be precisely the matters of greatest interest." (Cybernetics..., 24-25).

27 The term was first introduced in the 1970s by two Chilean biologists Humberto Maturana and Francisco Varela. It is a distant consequence of the notion of homeostasis and of learning machines, as well as of the general system theory. Niklas Luhmann incorporated it into his vocabulary. For more on sociocybernetics, see under "sociocybernetics" in: International Encyclopedia of the Social and Behavioral Sciences, ed. by N. Smelser, P. B. Baltes (Amsterdam, New York: Elsevier, 2001), vol. $21,14.549-14.554$. 
highly abstract character of these inquiries situates them beyond the main scope of sociology and social sciences, although such theories did have considerable impact on, for instance, biology of ecosystems for a while (there existed a branch called cybernetic ecology).

There still exist professional associations such as the American Society for Cybernetics (www.asc-cybernetics.org, the website includes numerous links to other sites of similar character), as well as journals, such as the monthly Biological Cybernetics. ${ }^{28}$ Today's cybernetics is largely related to contemporary antireductionist theories, such as constructivism. The term includes attempts undertaken mostly by German scholars to encompass the entire human mental activity in one general theory, centered on the notion of "construction" (construction of reality in human cognitive apparatus) and employing the achievements of contemporary epistemology, system theory and system biology.

None of this means that cybernetics has not contributed anything to the mainstream world science after the period when it was one of the constituting disciplines. Fields such as IT, robotics, artificial intelligence (AI) (which cyberneticists wrote about as early as in the 1950s), the theory of automata, organization theory, telecommunication and system engineering also owe a lot to cybernetics. Economic cybernetics contributed to the development of management theory (including managing "human resources"), optimizing theory and decision theory. The specialists in neural networks, which were the thing of the time in the 1980s and 1990s, are especially indebted to cybernetics. The problem of complexity, which was in fashion at the time, investigated by both physicists (such as Stuart Kaufmann) and biologists (such as Ilya Prigogine), has a lot in common with system theory combined with an indeterminist philosophical orientation.

A detailed investigation of the growth of cybernetics in specific countries would be very time consuming. Nevertheless, it is important to glance at what happened with it in Poland, which is, I believe, a good sample, illustrating in detail the process of degeneration, which I have outlined earlier.

28 The subtitle is Communication and Control in Organisms and Automata. The editorial team is international, mostly German, and the publisher is Springer-Verlag. The examples of titles from 2001 are: "Mathematical models of the eye movements in reading," "Synergetic analysis of spatio-temporal EEG patterns: Alzheimer's disease" and "Noise-inducted transition in excitable neuron models." The profile of these articles suggests loyalty to Wiener's methods and goals. 



\section{Cybernetics in Poland}

The situation of cybernetics in Poland was peculiar. Up until 1956 it was seen as "a reactionary pseudoscience ... a form of contemporary mechanicism ... targeted against materialistic dialectics, against contemporary scientific philosophy established by I. P. Pavlov, and against a scientific approach to the laws of social life." ${ }^{29}$ After that date, the political pendulum swung to the other side and very quickly within a few years - cybernetics was made one of the main disciplines in the USSR, which was certainly connected to the utopian endeavors in social engineering undertaken there. Wiener and Ashby were translated into Russian in the 1950s. ${ }^{30}$ Many volumes of translations from Western languages were published, as well as Russian works. The boom lasted until the 1970s and it quickly spread into USSR's satellite states.

First, in 1957, a number of translations of minor books were released; in 1959 Henryk Greniewski published his Elementy cybernetyki sposobem niematematycznym wyłożone [Elements of cybernetics laid out in a nonmathematical manner], ${ }^{31}$ in 1960 Wiener's Human Use of Human Beings came

29 Krótki słownik filozoficzny, ed. by M. Rozental and P. Judin (Warszawa: Książka i Wiedza, 1955), 76-77.

30 For example: Wiener's Kibernetika i obshchestvo, 1958, and Ashby's, Vvedenie v kibernetiku, 1959, with an introduction by Kolmogorov; Wiener's autobiography was also translated, as well as his minor essays, such as "God and Golem, Inc. A Comment on Certain Points where Cybernetics Impinges on Religion," was translated as: "Tvorets i robot. Obnizdenie niekotorych problem, v kotorych kibernetika stalkivaetsja s religiej."

31 Henryk Greniewski (1903-1972) was a logician and a mathematician, a professor at the University of Warsaw, a disciple of Tadeusz Kotarbiński; cf. Elementy... (Warszawa: PWN, 1959); his other books on cybernetics include Cybernetyka $z$ lotu ptaka (Warszawa: KiW, 1959), 2nd edition amended and co-authored by Maria Kempisty (Warszawa: KiW, 1962); or Cybernetyka niematematyczna (Warszawa: PWN, 1969). In the latter book, part one repeats the text of Elementy..., while part two consists of Greniewski's original input to the theory of complex systems, while part three includes his theory of Golems, that is, "models imitating humans in at least one of the following areas: (1) imagination and dreams; (2) mastering language or languages; (3) conceptual thinking (especially deduction); (4) introspection"; this part is accompanied by a rich "Historical background" section. Greniewski's works are elegant, clear and precise. 
out, and in 1961 - Ashby's Introduction to Cybernetics. ${ }^{32}$ The dates are important: they clearly show that Lem's Dialogues, which were first published in 1957 and were largely based on works by Wiener and Ashby, which Lem read in original English, were bound to fall on deaf ears. ${ }^{33}$ It could hardly have been otherwise in a country where a year earlier the word "cybernetics" would have been used in the context defined by Krótki słownik filozoficzny ["A short dictionary of philosophy"] ${ }^{34}$ - if at all. In Lem's essay Niebezpieczne zwiazki ["Dangerous liaisons"] (1962), devoted to vain attempts to apply Shannon's theory of information in the humanities, there is a following remark: "Eleven years ago I sat in the Czytelnik café in front of a learned gathering who were to decide about the publishing of The Magellan Nebula. This harmless book aimed for teenagers, was accused of smuggling, among other things, cybernetics, which I have not managed to successfully camouflage with a pompous term 'mechaneuristics." ${ }^{35}$ Moreover, as usual, Lem never provided any of the most basic explanations, instead dropping the reader right into the middle of his own observations, which constituted a very unorthodox approach to cybernetics. I shall try to prove how unorthodox it was later, for now suffice it to say that it could not have made understanding Dialogues any easier for the readers of their first edition (or the following ones).

32 William Ross Ashby, Wstęp do cybernetyki, trans. by B. Osuchowska and A. Gosiewski (Warszawa: PWN, 1961); 2nd edition 1963 [original edition: An Introduction to Cybernetics (London: Chapman \& Hall, 1958)]. It is an extensive, formal description of the functioning of a general model of a machine as a complex system (automaton), with a transition to biological systems in part three; it includes numerous references to Shannon's mathematical theory of information.

33 "I have probably written this book too early, so all these issues seemed outworldly and did not resonate as a whole, it went to waste completely" (Tako rzecze ... Lem, 84).

34 It is telling to read Dialogi o cybernetyce ["Dialogues on cybernetics"] by Stanisław Bogusławski, Henryk Greniewski and Jerzy Szapiro from that perspective. The text was published in a quarterly Myśl filozoficzna [no. 4 (1954), 158-212]. In the introduction the authors write: "Dialogues are between a supporter of cybernetics - Z., and its critic - K. They are both conceived as members of the contemporary academic circles of the Polish People's Republic. The critic wants to subject cybernetics to a judgment from a Marxist point of view, whereas the supporter is a person of good will who wants to follow the progress of science, but he does not always choose the right path." The last sentence from Z. is: "After all, you are inviting an ex-follower of cybernetics [to join you in a thorough research - PM]." There are six dialogues. Lem probably read them and they might have influenced the form of his own Dialogues to some extent, but certainly not their content.

35 Trans. by Olga Kaczmarek from the Polish edition: Stanisław Lem, Mój pogląd na literaturę (Kraków: WL, 2003), 15. 
Lem should then be located outside the entire Polish cybernetics - and it needs to be emphasized right away here. It is telling that one would search in vain for references to texts by Polish cyberneticists in his works, or even for their names. From the Annexes to Dialogues, it is clear that Lem saw the fall of cybernetics a few years before others saw its greatness.

Let us not get ahead of ourselves though. In 1962 the Polish Society of Cybernetics (PTC) was set up; its first chairman was Oskar Lange. The same year, he published a treaty titled Calość i rozwój w świetle cybernetyki ["Totality and development in light of cybernetics"], which includes an attempt at a cybernetic interpretation of Marxist laws of social development. ${ }^{36}$ Summing up his very mathematical arguments, Lange suggests that cybernetics allows for discarding earlier philosophical interpretations of development processes:

All these qualities, characteristic of biological processes, occur in a variety of physical and chemical processes, as well as sociological and economic ones. They occur in automata built by humans too. The intellectual apparatus provided by cybernetics allows us to explain them without recourse to the notion of an immaterial being, which would regulate the dynamics of nature and social development: to any "life force," "entelechy," "elan vital," "soul", "spirit of the time" or "spirit of a nation," Adam Smith's "invisible hand," etc. At the same time this explanation does not negate the empirical fact that systems have a way of operating which cannot be derived from the ways of operating characteristic of its constitutive elements; they have their own law of development, and, finally, under certain conditions the development of any system is an ergodic process, ${ }^{37}$ in which developmental disorders disappear with time, and the period of a process's ergodicity may be limited, the pace of disorders retraction and their scale which does not affect the system, can change over time, etc. ${ }^{38}$

This passage follows the same line as other attempts at determining the philosophical context of cybernetics (to which I will return later), and it is certainly the most intellectually thorough among Polish authors (Lem excluded).

After Lange's death (1965), Henryk Greniewski took over as a chairman of PTC - the most famous popularizer of cybernetics at the time. PTC initiated

36 It was included in the last volume of Lange's collected works: Oskar Lange, Dzieła, vol. 7, Cybernetics (Warszawa: Państwowe Wydawnictwo Ekonomiczne, 1977), 375; part one: Cybernetyka a filozofia ["Cybernetics and philosophy"] and part two: Cybernetyka i ekonomia ["Cybernetics and economy"].

37 Ergodic process - a process during which information about the system's initial state disappears; ergodic theory, one of the fields of statistical mechanics, studies ergodic processes.

38 Oskar Lange, Dzieła (Warszawa: PWE, 1977), vol. 7, 84-85. 
a publishing series at PWN titled Information and Control. A Series Devoted to Cybernetics. Wiener's first Cybernetics was published in the series in 1971. A year earlier it published a book by Józef Konieczny titled Cybernetyka walki ["Cybernetics of combat"]. The conclusions of chapter two (Łańcuch niszczenia ["Chain of destruction"]) are as follows:

Summing up all that has been said so far about the chain, system and destruction, one can provide a few precise conclusions that will be pertinent for a military cyberneticist.

(1) Targeted destruction is a peculiar kind of action, which can only take place as part of a chain of destruction.

(2) A destroyer consisting of a shooter, crew, weapon and missiles is a crucial component of any chain of destruction.

(3) A theory of destruction based on at least four axioms: self-destruction, common sense, shield and sword, as well as universal destructibility seems close to reality ...

(6) Any object belonging to the chain of destruction can be in any state among three categories: vitality, readiness or activity ...

(8) Connections between elements are an important immaterial element of any chain; connections human-human and human-machine have a primary role.

(9) History of any chain of destruction can be divided into three separate phases: composition, implementation and use ...

(11) Chains and their surroundings form systems of destruction, among which we can distinguish specifically destroying and destroyed systems ... (78-79)

The author defined each notion in the fragment quoted above (such as "destroyer," "weapon," "shooter") precisely, using algebraic formulae. However, the explanatory power of these definitions is no bigger than that of the "conclusions" I have quoted here. The fact that works of Wiener and Józef Konieczny fill the same shelf is a clear symptom of the backwardness of Polish cybernetics.

In 1973 Maly stownik cybernetyczny ["A small dictionary of cybernetics"] was published, resembling similar publications in the USSR and East Germany. ${ }^{39}$ It brought together the knowledge about complex systems and controlling them available at the time. It included information about computers available at that point, about neurophysiological processes (to the extent to which they had been researched by then) numerous entries on the theory of probability and game theory, as well as a mention that Norbert Wiener had family roots in Poland. ${ }^{40}$

In 1978 PTC started publishing a quarterly Postępy Cybernetyki ["Developments in Cybernetics"], which would come out up until 1993. The Institute for Research

39 Maly słownik cybernetyczny, ed. by M. Kempisty (Warszawa: Wiedza Powszechna, 1973), 533.

40 Maty stownik ..., 504. 
on Systems at the Polish Academy of Sciences still publishes a quarterly Control and Cybernetics. Both periodicals mostly consist of detailed expert treaties on various aspects of control in technical systems.

Oskar Lange and Henryk Greniewski treated cybernetics the way scientists usually treat their fields: as a tool to describe reality, but not as a key to the ultimate truth and theory of everything. Unfortunately, other Polish cyberneticists failed to follow this path.

The most famous among them at some point was Marian Mazur (1909-1983). He was an engineer by training, and a professor at the Warsaw University of Technology, who created a system of cybernetic psychology, laid out in his big oeuvre, Cybernetyka i charakter ["Cybernetics and character"]. ${ }^{41}$ The book reiterates words like "homeostat," "feedback," "information" and system as a mundane mantra; it is replete with mathematical formulae and diagrams that are supposed to depict the functioning of human psyche, and it is permeated with the author's devotion to scientific precision. The first chapter includes - a very accurate - list of sixteen differences between a scientist and a doctrinarian. The problem is, though, that his own theory and the way he lays it out makes it seem like a doctrine much more than a science in light of his own argument, which makes it ironic. Most of the book is taken up by enunciations about the advantages of cybernetics over other sciences and a discussion of the functioning of human psyche in cybernetic terms. The latter, however, has nothing to do with Wiener and his colleagues' research on nervous system, as Mazur is not interested in the physiological aspects of psychology. His arguments are merely a transposition of one terminology to another: classic (not to say common sense) psychological notions (such as character, temperament, emotions and impulses) are translated into cybernetic concepts. The entire operation remains unrelated to any empirical data, but it relies heavily on "life truths" that are scattered among innumerable prepositions, formulae and graphs. The crowning moment of Mazur's argument is the concept of five "dynamic types of character" (exodynamic, exostatic, static, endostatic and endodynamic), which, combined, can produce hundreds of configurations. Mazur is convinced it constitutes an absolute sum of knowledge about human character, grounded in unshakeable foundations of cybernetics and mathematics. Each type is illustrated with examples from literature and

41 1st edition (Warsaw: PIW, 1976); amended 2nd edition came out with a subtitle Psychologia XXI wieku ["Psychology of the 21st century"] (Podkowa Leśna: Wydawnictwo Aula, 1996); 3rd edition (Warszawa: Wyższa Szkoła Zarządzania i Przedsiębiorczości im. Bogdana Jańskiego w Warszawie, 1999). 
history: Horace, Caligula, Proust and Carmen represent the exodynamic character; Petronius from Henryk Sienkiewicz's Quo Vadis serves as an example of an exostatic character, while Caesar and Cromwell - endodynamic and so forth.

Mazur's work is one of the countless attempts to overcome humanities' perennial weaknesses: blurriness of notions. It is an attempt, which sees cybernetics as a remedy to this ailment - a science combining physics and biology, which in Mazur's view consequently included mathematics and psychology. The attempt ended the same way as all other endeavors of the kind: confirming an old truth that in the humanities precision in terminology is paid for with their meaning. The book's reviews published by scholars in the humanities basically all boiled down to this one point. ${ }^{42}$ Nevertheless it became quite popular with technicians and engineers, and the author spent the last few years surrounded by a circle of loyal followers (the so-called "Mazurians"). Traces of Mazur's influence can be seen in writings of an eminent Polish scholar of religions, Andrzej Wierciński.

Lange applied cybernetics to economy, Mazur - to psychology, and Józef Kossecki undertook an ambitious attempt to apply it in social sciences. Kossecki saw himself as Mazur's disciple and had a passion for quoting him extensively. He accepted Mazur's theory of psychological types. His most important achievements include two books: Cybernetyka kultury ["Cybernetics of culture"] ${ }^{43}$ and Cybernetyka społeczna ["Social cybernetics"]. ${ }^{44}$ The first one discusses history and culture - globally - in terms of cybernetics. Here, too, those terms have no connection to their homonyms known from the works of Wiener, Ashby and their forerunners. When analyzing history, Kossecki relies on syntheses and popular works about foreign cultures written by other specialists. The result is a "third-degree essay" of sorts - a text based on texts that are already a rewriting of other texts, but which are treated as source material. The distance from any actual sources, historical, cultural or even cybernetic is monstrous. I will quote a passage about the history and culture of Poland. It is representative of the whole work.

Analogous processes are observed in the history of the Polish nation. During feudalism we had strong nobility, which served as a homeostat. However, as capitalism developed the nobility was growing weaker, becoming less and less capable of serving as a nation's homeostat, while the Polish bourgeoisie was not strong enough. It is no surprise that this is the period when the country was partitioned - the absence of a strong social class

42 Cf. Małgorzata Szpakowska, “Z życia żółwi,” Twórczość, no. 4 (1977), 119-122.

43 Józef Kossecki, Cybernetyka kultury (Warszawa: PIW, 1974).

44 Józef Kossecki, Cybernetyka społeczna (Warszawa: PWN, 1981); amended 2nd edition. 
serving as the nation's homeostat at that time increased the likelihood of the fall of the entire state - although, of course, this was not the sole reason of the fall. (81)

In the later work, Cybernetyka społeczna, Kossecki's ambitions have grown and the contents of the previous book are elaborated upon extensively. The author produced detailed analyses of economic and historical processes, focusing on modern Europe and introducing his periodization (whereas earlier he would only roughly separate epochs). For example, chapter 13 is titled "Cybernetic Analysis of International Politics," and its section 13.3 is "Cybernetic analysis of international politics between the Congress of Vienna and the First World War." For each of the periods, the author calculates the percentage of "control factors" for each country in the global political scene. A yet newer work by Józef Kossecki featuring cybernetics (but also discussing the role of secret organizations in history and politics) has an extremely long title, which is nevertheless worth quoting in full: Elementy nowoczesnej wiedzy o sterowaniu ludźmi. Socjotechnika, socjocybernetyka, psychocybernetyka. Skrypt dla oficerów policji ["Elements of modern science of human control. Social engineering, sociocybernetics and psychocybernetics. A manual for police officers"]. He recommends Marian Mazur's theory as a modern useful tool for police investigators.

One could expect that Józef Kossecki is the last link in the intellectual chain of Polish social cybernetics. That is not the case however. In 1986 the "Książka i Wiedza" publishing house released a book by Olgierd Cetwiński, titled Między buntem a pokora ["Between revolt and submissiveness"]. In the introduction the author declares himself indebted to Mazur and Kossecki's achievements. It is a study of cybernetic psychology and political sciences, in which the terminology of cybernetics (or rather, by then, merely cybernetic imagery) has become even blurrier than in the writings of Cetwiński's idols. The last chapter ("Quo vadis, Polonia?") contains a cybernetic account of Polish history between 1795 and 1981. Here is an excerpt:

... the Polish Enlightenment is a period when a dynamic template of correlational homeostasis developed. The process was powerful: even though the Polish society had been incorporated into other typically homeostatic systems (the dynamic Prussian one, and the more stagnant Russian and Austrian ones), it managed to retain its own type of homeostasis, and even grew its own homeostat and its own battery to some extent. The invaders realized that. Hence their later efforts - coming after the failed uprisings aimed at disempowering the Polish correlator ... The nation's survival through the partitions was largely - if not solely - made possible by the fact that it retained a correlational system of homeostasis. It will not be an exaggeration to compare it to the type known from Athens. (298-299) 
The above gives an idea about the Polish works on social cybernetics. It is worth adding that in 1988 Piotr Sienkiewicz - the editor-in-chief of Postepy Cybernetyki - published a book Poszukiwanie Golema. O cybernetyce $i$ cybernetykach ["Searching for Golem. On cybernetics and cyberneticists"]. ${ }^{45}$ It is an intelligent and thorough overview of the history and themes of the field. The author writes: "If I were to point to one of the living authors as 'the father' of social cybernetics, I would point to Stanisław Lem with no hesitation" (118). I fear, however, that Lem would not approve of the idea that he might have been the spiritual father to Marian Mazur and Józef Kossecki - nor would they likely be satisfied with the concept.

This overview of Polish social cybernetics should not be treated as a full picture of the discipline as a whole, not in Poland, and certainly not in the world in general. It would be an extremely distorted image. Technical cybernetics and bionics developed quite differently; they never lacked precision, quite the opposite: precision and narrow subject matters locate them at the other end of the spectrum than the lucubrations I have quoted. It proves the diversity within the field of cybernetics, which I have pointed out before. Where did it come from?

The answer requires that I produce an interpretation of the phenomenon of cybernetics in the science and culture of the 20th century. I will make such an attempt - preliminary, of course - and it will be the final part of my introduction to an analysis of Lem's Dialogues.

45 Piotr Sienkiewicz, Poszukiwanie Golema. O cybernetyce $i$ cybernetykach (Warszawa: KAW, 1988), 258. 


\section{Philosophical Implications of Cybernetics}

The philosophical positioning of cybernetics was never clearly delineated. While explaining the place of his new field within the intellectual history, Wiener mentioned Leibniz, as well as Augustine and the Manicheans, ${ }^{46}$ but he was never particularly interested in the consequences of the emergence of cybernetics for contemporary philosophy. Cybernetics strongly, albeit misleadingly, resembles the 18th-century mechanicism. It is misleading because Descartes and La Mettrie sought to apply mechanistic interpretation to a physical and mental whole that is a human, which means they saw consciousness as correlative to mechanistic processes as well. ${ }^{47}$ The cyberneticists - and I mean the early ones - never shared that view. ${ }^{48}$ They would not touch on the problem of consciousness at all. ${ }^{49}$ Human body was interesting to them on the level of

46 Human Use of Human Beings..., 11, 34-35. It includes a juxtaposition of two basic perspectives: Augustinian and Manichean. Modern science exemplifies the Augustinian view, as it assumes intelligibility of nature, its "goodness" (the "bad," Manichean nature would interfere with the cognitive process, through arbitrary changes in the laws of physics for example).

47 About Descartes, cf. Cybernetics: or Control..., chapter 1: "Newtonian and Bergsonian Time," 40-41.

48 Of course, many of the proponents of cyberneticists were - likely unconsciously mechanicists. Karl Steinbuch, for example, the author of Automat und Mensch (Berlin: Springer Verlag, 1961; 4th edition 1971), declares in the very first chapter, titled "Cybernetic Anthropology" (!): “The main thesis of this book is as follows: What can be observed in intellectual functions, are introducing, processing, storing and exporting information. In no case is it proven or even likely that explicating intellectual functions requires accepting assumptions that go beyond physics."

49 Here is a sample of Wiener's style of dealing with what is today phrased as the mindbody problem: "We have already spoken of the computing machine, and consequently the brain, as a logical machine. It is by no means trivial to consider the light cast on logic by such machine, both natural and artificial. Here the chief work is that of Turing. We have said before that the machina ratiocinatrix is nothing but the calculus ratiocinator of Leibniz with an engine in it; and just as modern mathematical logic begins with this calculus, so it is inevitable that its present engineering development should cast a new light on logic. The science of today is operational; that is, it considers every statement as essentially concerned with possible experiments or observable processes. According to this, the study of logic must become a study of the logical machine, whether nervous or mechanical, with all its nonremovable limitations and imperfections. It may be said by some readers that this reduces logic to psychology, 
neurophysiological processes, of nervous impulses - they were not interested in consciousness and subjecthood. They were careful to avoid metaphysical speculation, aiming for the discipline to exhibit scientific precision. In his work The Computer and the Brain (1958), which was mentioned here earlier, von Neumann gave a description of logical operations in a computer and nervous impulses (in accordance with contemporary level of technology and knowledge) and wrote: "the most immediate observation regarding the nervous system is that its functioning is prima facie digital" $(40,44)$. Later, however, it turns out that the analogy is merely superficial (so, literally, prima facie), as in fact "the language of the brain is not the language of mathematics" (81). There is no declaration of the kind that "human is a machine." von Neumann cannot be counted among cyberneticists, but Wiener, too, writes at the beginning of chapter 7 of Cybernetics: or Control... titled "Cybernetics and Psychopathology": "I therefore wish to disclaim in advance any assertion that any particular entity in psychopathology ... is due to a specific type of defect in the organization of the brain as a computing machine. Those who may draw such specific conclusions from the consideration of this book do so at their own risk" (144). And elsewhere in the same book (chapter 5: "Computing machines and the nervous system") he observes: "The mechanical brain does not secrete thought 'as the liver does bile,' as the earlier materialists claimed, nor does it put it out in the form of energy, as the muscle puts out its activity. Information is information, not matter or energy. No materialism which does not admit this can survive at the present day" (132).

Cyberneticists were not particularly interested in the ethical implications of their research either. Another quote from Wiener is probably the strongest statement on the subject:

Those of us who have contributed to the new science of cybernetics thus stand in a moral position which is, to say the least, not very comfortable. We have contributed to the initiation of a new science which, as I have said, embraces technical developments with great possibilities for good and for evil. We can only hand it over into the world that exists about us, and this is the world of Belsen and Hiroshima. We do not even have the

and that the two sciences are observably and demonstrably different. This is true in the sense that many psychological states and sequences of thought do not conform to the canons of logic. Psychology contains much that is foreign to logic, but - and this is the important fact - any logic that means anything to us can contain nothing which the human mind - and hence the human nervous system - is unable to encompass (Cybernetics: or Control..., 124-125). 
choice of suppressing these new technical developments. They belong to the age, and the most any of us can do by suppression is to put the development of the subject into the hands of the most irresponsible and most venal of our engineers. The best we can do is to see that a large public understands the trend and the bearing of the present work, and to confine our personal efforts to those fields, such as physiology and psychology, most remote from war and exploitation. ... I write in 1947, and I am compelled to say that it is a very slight hope. (28-29)

Wiener's persona of a public intellectual kept struggling with his soul of an academic. The former would draw powerful visions of social change brought about by cybernetics, while the latter - as we have seen - rejected the possibility of investigating society with the use of cybernetics, even though he never concealed his interest in social sciences:

As to sociology and anthropology, it is manifest that the importance of information and communication as mechanisms of organization proceeds beyond the individual into the community. On the one hand, it is completely impossible to understand social communities such as those of ants without a thorough investigation of their means of communication, and we were fortunate enough to have the aid of Dr. Schneirla in this matter. For the similar problems of human organization, we sought help from the anthropologists Drs. Bateson and Margaret Mead; while Dr. Morgenstern of the Institute for Advanced Study was our adviser in the significant field of social organization belonging to economic theory. His very important joint book on games with Dr. von Neumann, by the way, represents a most interesting study of social organization from the point of view of methods closely related to, although distinct from, the subject matter of cybernetics. (Cybernetics: or Control..., 18-19)

Yet, elsewhere in the same book he states:

It may be that there is a mass sociology of the human animalcule, observed like the populations of Drosophila in a bottle, but this is not a sociology in which we, who are human animalcules ourselves, are particularly interested. We are not much concerned about human rises and falls, pleasures and agonies, sub specie aeternitatis. Your anthropologist reports the customs associated with the life, education, career, and death of people whose life scale is much the same as his own. Your economist is most interested in predicting such business cycles as run in their course in less than a generation or, at least, has repercussions which affect a man differentially at different stages of his career. Few philosophers of politics nowadays care to confine their investigations to the world of Ideas of Plato. (Cybernetics: or Control..., 163-164)

Social cybernetics emerged, grew and captivated many. To what effect I have shown on the Polish example. Why was it so? Why cybernetics had such a huge impact, incomparable to the impact of any of the natural sciences? Of course, thermodynamics, for example, developed rapidly in the 19th century and inspired a philosophical metaphor of the world as a heat engine that became 
quite popular in the humanities in the late 19th and early 20 th century. ${ }^{50}$ But neither in this nor any other case can we observe such an overwhelming adoption on an entire vocabulary of a discipline. There has never been any social thermodynamics, which would inspire someone to calculate loops of hysteresis for the French Revolution.

Cybernetics offered something more though than any other discipline - or so it seemed at the time; it combined two fields of basic research: physics and biology. It focused on human body, human nervous system on a par with machines and their circuits and control systems. All these objects of study are categorized with the same terminology, but without vulgar mechanicism. Cybernetics was then a way to go beyond the nature-culture dichotomy, beyond the question about a qualitative difference between humans with their symbolic world and the rest of the natural world. Or at least it very much seemed like such a third way is possible, a way between arts and science, which were just then definitively parting ways, a phenomenon powerfully described in C. P. Snow's essay Two Cultures. ${ }^{51}$ Certainly, there was something extremely appealing in the idea that a human, an animal and a machine are equal as systems primarily determined by the circulation of information in their control centers. The impression was that both scientists and humanities scholars received a universal shared model for all the phenomena they were dealing with. There was no reductionism involved - a human was not seen as a mere type of a machine, but as an entity equivalent to it, differing in structure and possibly some aspects of functioning.

Things could have seemed that way for those who first encountered cybernetics soon after it was created, in the 1950s, reading Wiener and Ashby - this is what the first wave of enthusiasm for the field looked like. This is also how later people such as Mazur and Kossecki saw cybernetics. However, a close reading of cybernetics' foundational texts reveals that this universality was in fact an

50 Cf. J. David Bolter, Turing's Man: Western Culture in the Computer Age (Chapel Hill: The University of North Carolina Press, 2014), 31-32. Bolter's remarks on philosophical and scientific metaphors prevalent in particular periods in the history of Europe (clock, steam engine, heat engine and computer) repeat and elaborate on Wiener's observations from Cybernetics: or Control... (cf. chapter 1: "Newtonian and Bergsonian Time," 38-39). The whole period of positivism of the 19th century is an arena of mutual interactions between science and philosophy too.

51 The essay constituted the text of a lecture given by Sir Charles Percy Snow (1905-1980), a physicist and novelist, in 1959. It started a long and turbulent discussion about the role of the humanities and science in the society and culture of the second half of the 20th century. 


\section{illusion. Cybernetics did not combine physics and biology in full; it only com-} bined some narrow areas of these fields. It did not explain either humans or any other complex systems completely in their actions and functions - it was in fact only interested in some of their very abstract characteristics. Henryk Greniewski described it as follows:

Speaking in a bit of a joke (and one should not underestimate the didactic value of jokes): cybernetics does investigate animals, humans and telegraphs, but only in the way in which elementary geometry investigates both tree cutting, stone splitting and cutting metals. The same thought can be phrased "seriously" (for sticklers among the readers, of course): cybernetics investigates what is common in the process of communication for human nervous system and a telegraphic line in a highly abstract manner; similarly elementary geometry (or, more precisely, solid geometry) does deal with analyzing solid figures into its components, "forgetting" that they are approximate idealizations of actual solids, and remaining quite "uninterested" in whether the solid is actually a piece of wood, a stone or a metal. The applicability of cybernetic tools to all kinds of matter is neither new nor unique in science. The same quality applies to the arithmetical terminology for example, or the aforementioned geometry and probability theory. You can count stones, just as well as animals, humans or social bodies. Probability theory is equally applicable to decay of atoms in a radioactive body, and to the death rate of animals and people, and to draws and lotteries. (Elementy..., chapter 3.3: "Comparative Remarks on Terminology," 57)

It is a great shame that the Polish social cyberneticists never took these words to their hearts. Their colleagues from other countries similarly ignored Wiener's remarks about the risk related to applying cybernetic notions together with the methodology of the sciences in general to the object of social sciences. Here is one more of those remarks:

I mention this matter because of the considerable, and I think false, hopes which some of my friends have built for the social efficacy of whatever new ways of thinking this book may contain. They are certain that our control over our material environment has far outgrown our control over our social environment and our understanding thereof. Therefore, they consider that the main task of the immediate future is to extend to the fields of anthropology, of sociology, of economics, the methods of the natural sciences, in the hope of achieving a like measure of success in the social fields. From believing this necessary, they come to believe it possible. In this, I maintain, they show an excessive optimism and a misunderstanding of the nature of all scientific achievement.

All the great successes in precise science have been made in fields where there is a certain high degree of isolation of the phenomenon from the observer...

It is in the social sciences that the coupling between the observed phenomenon and the observer is the hardest to minimize. On the one hand, the observer is able to exert a considerable influence on the phenomena that come to his attention. With all respect to the intelligence, skill, and honesty of purpose of my anthropologist friends, I cannot think 
that any community which they have investigated will ever be quite the same afterward. ... There is much in the social habits of a people which is dispersed and distorted by the mere act of making inquiries about it. In another sense from that in which it is usually stated, traduttore traditore. (Cybernetics: or Control..., chapter 8: "Information, Language, and Society," 162-163)

Claude Shannon said in an interview: "Somehow people think it [mathematical theory of information] can tell you things about meaning, but it can't and wasn't intended to." 52

There was no shortage of skeptical voices either, doubting cybernetics as a whole. For example John R. Pierce wrote in 1961 with a shade of subtle irony:

Some words have a heady quality; they conjure up strong feelings of awe, mystery, or romance. ... I don't believe that cybernetics is quite such a word, but it does have an elusive quality as well as a romantic aura. ...

The trouble is that each of the many fields that Wiener drew intro cybernetics has a considerable scope in itself. It would take many thousands of words to explain the history, content, and prospects of any one of them. Lumped together, they constitute not so much an exciting country as a diverse universe of overwhelming magnitude and importance.

Thus, few men of science regard themselves as cyberneticists. Should you set out to ask, one after another, each person listed in American Men of Science what his field is, I think that few would reply cybernetics. If you persisted and asked, "Do you work in the field of cybernetics?" a man concerned with communication, or with complicated automatic machines such as computers, or with some parts of experimental psychology or neurophysiology would look at you and speculate on your background and intentions. If he decided that you were a sincere and innocent outsider, who would in any event never get more than a vague idea of his work, he might well reply, "yes."

So far, in this country the word cybernetics has been used most extensively in the press and in popular and semi-literary, if not semiliterate, magazines. I cannot compete with these in discussing the grander aspects of cybernetics. Perhaps Wiener has done that best himself in I Am a Mathematician. Even the more narrowly technical content of the fields ordinarily associated with the word cybernetics is so extensive that I certainly would never try to explain it all in one book, even a much larger book than this. ... cybernetics includes most of the essence of modern technology, excluding the brute production and use of power. It includes our knowledge of the organization and function of man as well. Cybernetics almost becomes another word for all of the most intriguing problems of the world. ... Thus, even if a man acknowledged being a cyberneticist, that wouldn't give us much of a clue concerning his field of competence, unless he was a universal genius....

52 The interview was made in November 1989 by John Horgan, quoted in: Idem, The End of Science. Facing the Limits of Knowledge in the Twilight of the Scientific Age (New York: Basic Books, 2015), 213. 
Happily, as I have noted, few scientists would acknowledge themselves as cyberneticists, save perhaps in talking to those whom they regard as hopelessly uninformed. Thus, if cybernetics is overextensive or vague, the overextension or vagueness will do no real harm. Indeed, cybernetics is a very useful word, for it can help to add a little glamor to a person, to a subject, or even to a book. I certainly hope that its presence here will add a little glamor to this one. ${ }^{53}$

Pierce mildly suggests that cybernetics is really an all-encompassing word, that can mean nearly anything, and it certainly is a scientific utopia. Was not the same written 15 years later about structuralism, and then, 30 years later - about postmodernism, the subsequent potential "universal perspectives"?

On the other hand, David Jay Bolter in his Turing's Man... - which is a remarkable attempt to root the computer technology within the Western culture as a whole - writes about cybernetics:

Wiener's work with servomechanisms to aim antiaircraft guns and to do much else besides had convinced him that forms of life could be understood not as Cartesian clockwork, which was too crude and rigid, but rather as electromechanical or even electronic devices. ... he stressed direct contact with the world - experiments with the muscles of the cat, improved prostheses for amputees, sensing equipment, and so on. Current workers in artificial intelligence show less interest in such direct contact with the world and more interest in abstract thought. Wiener was still only halfway along the line from Descartes to Turing. He wanted machines to imitate the man who acts in the world as well as the man who reasons, to explain muscle action in terms of feedback loops as well as chess in terms of digital program. He relied on hardware devices for his metaphor of man and demanded a close correspondence between man and the machine made to imitate him. Vacuum tubes were meant to be a physical substitute for neurons, servomechanisms for nerves acting upon muscles. This line of thinking was forthright and compelling, and led do attempts to build a brain (in theory, seldom in practice) using simple electronic components. Those following Wiener's approach spoke of creating artificial brain cells and neutral networks and allowing the machine to learn as a baby was presumed to do - presuming with Locke that the baby's mind was a tabula rasa at birth. But the theory of neural networks, which was developed mathematically, met with little or no practical success. In general, Wiener's preferences gave way to others in the 1950's, as computer hardware and especially programming languages became more sophisticated. Unfortunately, the elegant name of cybernetics ... smacking perhaps of the antiquated technology of the war years, also gave way to "artificial intelligence." (192-193)

53 John R. Pierce, An Introduction to Information Theory. Symbols, Signals \& Noise (New York: Dover Publications, Inc., 1980), 208-210, 227-228. The book is in fact an extensive layman's manual introducing Shannon's theory and its derivates. 
Bolter is locating Wiener in the development plan of information and computer technology, which is not entirely true about the history of cybernetics, and this bias is particularly clear in the statement that artificial intelligence is simply a different name for cybernetics (Bolter apparently does not know that many institutions still use the name). It is equally unacceptable to say about the first Cybernetics, as Bolter does in his annotated bibliography to Turing's Man, that it contains a "notion of identity of man and machine" - it's clearly simplifying things too much. What is important for us here is that Bolter, too, sees cybernetics as a sort of scientific utopia.

Summing up what has been said and quoted here before, I could say that cybernetics is an example of a process where the intentions of the creators have little to do with those of their successors. The former have great ambitions hoping the latter would put them to life. The latter put them to life the way they see fit and the way that is possible given the available materials. The scenario repeats itself continuously throughout the history of science and culture, producing results of varying quality. In the case of Norbert Wiener the very creator was torn by mutually contradictory tendencies: scientific precision and the visionary scale.

It is quite possible that cybernetics was one of the great myths of the 20th century science. Its extraordinarily broad perspectives drew hordes of enthusiasts, believers and maniacs, who eventually dragged the discipline far from its origins, close to conspiracy theories and would-be-universalisms, and all the areas of human intellectual activity where doctrinaire shibboleths prevail over genuine curiosity, and the Ultimate Certainty produces deep thinking but neutralizes brains. 


\section{Introduction to Dialogues}

Lem's Dialogues, just as many other of his works, underwent significant transformations. The first edition ${ }^{54}$ included eight dialogues, between Hylas and Philonus, written between 1954 and 1956. The second edition ${ }^{55}$ was supplemented with two annexes, each consisting of two separate texts. The first annex ("Dialogues" after 16 years) is strictly about cybernetics, the second one contains two sizeable treaties, originally published in Studia Filozoficzne. ${ }^{56}$ Their content, although going beyond cybernetics, should be discussed separately in this chapter, as it connects cybernetics with other fields Lem is interested in.

The full title of the first edition is Dialogi o zmartwychwstaniu atomowym, teorii niemożności, filozoficznych korzyściach ludożerstwa, smutku w probówce, psychoanalizie cybernetycznej, elektrycznej metempsychozie, sprzężeniach zwrotnych ewolucji, eschatologii cybernetycznej, osobowości sieci elektrycznych, przewrotności elektromózgów, życiu wiecznym w skrzyni, konstruowaniu geniuszów, epilepsi kapitalizmu, maszynach do rzadzenia, projektowaniu systemów społecznych ["Dialogues on atomic resurrection, theory of impossibility, philosophical advantages to cannibalism, test-tubes sadness, cybernetic psychoanalysis, electric metempsychosis, evolution's feedback, cybernetic eschatology, personalities of electrical networks, deceitful electronic brains, eternal life in a chest, constructing geniuses, capitalism's epilepsy, management machines, designing social systems"]. The readers could easily feel overwhelmed just opening the book. The fact that it was not understood is best testified to by the number of reviews that came out: a note in Nowa Kultura ${ }^{57}$ (describing it as a "read for the select audience") a summary in Nowe Ksiażkij8 and a review by

54 Kraków: WL, 1957.

55 Kraków: WL, 1972; reprinted in 1984.

56 "Etyka technologii i technologia etyki," Studia Filozoficzne, no. 3 (1967), 107-142; "Biologia i wartości," Studia Filozoficzne, no. 3-4 (1968), 35-78.

57 Nowa Kultura, no. 29 (1957), 25.

58 Danuta Kępczyńska, Nowe Książki, no. 17 (1957), 1054-1055. The author traces the sources of Dialogues back to the ancient forms of the genre. The obvious statement will be equally clear to other critics, but it does not seem like any major conclusions could be drawn from it. And "invoking Philonous and Hylas is obviously a joke, which is best in the first dialogue, made so archaic, so it 'exudes' the smell of agora and ancient Greece" (Tako rzecze... Lem, 84). Of course, the long title itself is styled in an archaic manner characteristic of the early print era. 
Wacław Sadkowski in Trybuna $L u d u,{ }^{59}$ including statements such as "Philonous's long rants become boring and pointless"; and the conclusion "[Dialogues are] completely devoid of excitement, creative anxiety and - so to speak - the pathos of seeking the truth." It is hard to imagine a more inaccurate judgment about this or any other of Lem's works. And that is about it when it comes to the response the first edition of Dialogues received in the Polish press, although it needs to be said that journalists at the time were very accustomed to saying things in an indirect manner (which is what Sadkowski might have been doing there), and cybernetics (especially as it was presented in Dialogues) was not a subject that could be praised openly. To be precise I should add that the second edition was met with complete silence, while the only (but thorough) review of the third one was written by Marek Oramus. ${ }^{60}$ As to the Annexes, their reception boils down to texts such as a few sentences' long mention in a press review in Twórczość $c^{61}$ where the author (Andrzej Kijowski) states: "No dictionary of foreign words will be enough to translate Lem's scientific and philosophical code into a layman's parlance." Until now Dialogues have also been very carefully omitted from Polish monographs on Lem's works. ${ }^{62}$

The causes of the situation are rather clear. The subject of Dialogues was foreign to most Polish readers, and the author - as I have mentioned earlier - did not include any basic explanations in the book, employing (consciously or unwillingly?) a method that Oramus later described as "natural selection of readers." ${ }^{63}$ Dialogues surprised the readers of Lem the novelist,

59 Trybuna Ludu, no. 223 (1957), 6. Lem wrote about this review: "I cannot quite understand, because it is as if someone said: this omelette does not fulfill the criteria for a beefsteak. It does not, because it was not meant to be literature" (Tako rzecze... Lem, 84).

60 “Entuzjasta w sieci sprzężeń,” Przegląd Techniczny, no. 26 (1985), 44.

61 Dedal (i.e., Andrzej Kijowski), Twórczość, no. 2 (1969), 142.

62 Passages from Małgorzata Szpakowska’s Dyskusje ze Stanisławem Lemem ["Discussions with Stanisław Lem”] (amended 2nd edition, Warszawa: OPEN 1997, 93-99, 155-168, which include a detailed analysis of Dialogue 7) and Jerzy Jarzębski's Wszechświat Lema ["Lem's universe"] (Kraków: WL 2003, 37, 137, 162-163) are exceptions from the rule. See also: Marian M. Leś, Stanisław Lem wobec utopii [“Stanisław Lem on utopia”] (Białystok: Towarzystwo Literackie im. Adama Mickiewicza, 1998), 72-80 (on Dialogue 7's relation to Eden).

63 Marek Oramus. "Entuzjasta..."; Umberto Eco admits to a similar approach in his "Postcript" to The Name of the Rose. Joyce's remarks about "the ideal reader suffering from an ideal insomnia" are generally known. This opens up possibilities to interpret 
the humanities never understood them and the scientists - just never noticed them. ${ }^{64}$

It does not mean that Lem's earlier works: The Astronauts, The Magellan Nebula, Time Not Lost trilogy containing Hospital of the Transfiguration and a number of short stories were praised by the critics. The reviews, while much more numerous, were characterized by a lack of understanding of these works comparable to the reviews of Dialogues quoted earlier. The history of Lem's reception is one of the sad themes of the Polish culture after 1945. Following it highlights a number of issues: from the backwardness of the Polish humanities and science in regard to world trends, to an old man's frustration and author's bitterness (he was never particularly easy-tempered, as can be seen in the Letters published in Polish in 2002). This not being my main subject here, I have to limit myself to these remarks, returning to them occasionally, as I will be discussing Lem's works.

Undoubtedly Lem has been somewhere between the humanities and science from the beginning, and even though (or perhaps because) he was moving between the two areas with bigger ease than most specialists can boast in their respective fields, he remained an outsider in both. In literature, he was perceived as the storyteller whose fantastic narratives were freckled with weird terms; the scientists were suspicious of his way of turning their professionalized knowledge into stories. It was only in the 1970s that critics such as Małgorzata Szpakowska, Jerzy Jarzębski and Stanisław Bereś undertook successful attempts to build a strategy to read Lem.

Dialogues is the one work by Lem that lost most of their appeal with time. I do not want to say they are obsolete. But the thing is cybernetics, their main subject, is obsolete - which Lem himself admitted in the first annex. I will try to analyze whether they can be read today. I assume here that cybernetics as presented in Dialogues is the first stage of Lem's anthropology, and the specificity of how it is laid out in the book is that it goes beyond purely technological issues. I do not have to add that Lem extended the scope of cybernetics' relevance in a way that is quite unlike what Polish social cyberneticists did.

Lem's writing as erudite and hermetic in a manner characteristic of some of the currents of modernism.

64 After the first edition, the only reaction in the field came from Greniewski, who mentioned Dialogues in his Elementy cybernetyki... 
In the later, "mature" criticism of Lem, insofar as it is, to a very limited extent, devoted to Dialogues, they are notoriously read through a political lens. ${ }^{65}$ The entire terminology is supposed to serve as a smokescreen, and the first six dialogues would allegedly serve as a misleadingly long introduction to the main component of the work - Dialogue 7 devoted to a critique of the socialist political system and the centrally planned economy. This is an acceptable interpretation of course, but limited; it turns Dialogues into a political pamphlet and dooms it - this time inevitably - to historical oblivion, as any pamphlet would be. It is also difficult to believe that Lem could write this whole book only to smuggle in an attack on the political system.

In order to look at Dialogues from a broader perspective, it is necessary to start by determining the most obvious textual links. The form of the book relates back to Plato and Lucian in the history of literature - they picked the form to emphasize some fundamental aspects of their philosophical and literary thought. But there is also a more immediate reference - Three Dialogues between Hylas and Philonous by Berkeley, which is where Lem found the names of his interlocutors: Hylas and Philonous. The first of these names means "bodily," "material," "concrete," metaphorically also "earthly"; the second one means "thought liking," "cerebral," "intellectual." Both for the English bishop and for Lem, in accordance with the meanings of the names, Hylas is a naive enthusiast, while Philonous a thoughtful sage, which has obvious consequences in the disproportionate structure of the dialogues.

65 Cf. Jerzy Jarzębski, “Lata młodzieńcze i dojrzałość cybernetyki”, in: Stanisław Lem, Dialogi, Collected works (Kraków: WL, 2001), 486. Małgorzata Szpakowska, Dyskusje ..., 155 and following. 


\section{The Structure of Dialogues}

Let us investigate the text of the Dialogues themselves. Discussing it seems appropriate here, because this is the one book by Lem that is extremely poorly known to contemporary readers and, it seems, rarely read. Even in this summary I will be introducing elements of interpretation.

The first dialogue includes a discussion of paradoxes of achieving physical immortality through copying an organism's molecular structure. Philonous proves to Hylas that copying a living organism necessitates rejecting the classic notion of personal identity, as the duplicated individual is identical with the original, but it is not the same, not even if the original individual ceases to exist the moment the copy is formed (the word "moment" is itself impossible to determine with any precision). It is closely related to the question of consciousness. This particular dialogue can now be brought up in the context of the current discussions about ethical and philosophical aspects of cloning. The issue of "multiplied identities" is one of Lem's favorites and is taken up on numerous occasions in Summa Technologiae.

The second dialogue is a short outline of what would then in the 1960s be called the mind-body problem, and which, on the other hand, is just a phase of the perennial philosophical problem: the problem of consciousness and its relationship with matter. At least one sentence from the dialogue merits quoting: "It is highly probable, that if atoms were not such complex objects, characterized by such peculiar qualities as the uncertainty principle, if instead they were, say, tiny hard balls, then the world made of them would look quite different from the real one - and it seems very likely that no living creature could be made of such atoms, nor any neuronal structures that could be basis of psychological processes" (page 38 of the Polish edition from 1984). In this sentence, Lem anticipates the consciousness theory developed 25 years later by Roger Penrose, according to whom consciousness theory is correlated with quantum processes in the microtubules of human neurons. ${ }^{66}$ The critics of the theory emphasize that Penrose made a logical error of ignotum per ignotum while building it, as the

66 Cf. Roger Penrose. The Emperor's New Mind: Concerning Computers, Minds and the Laws of Physics (London: Vintage, 1990). Idem, Shadows of the Mind. A Search for the Missing Science of Consciousness (Oxford: Oxford University Press, 1994). See also: The Large, the Small and the Human Mind (Cambridge: Cambridge University Press, 1997). 
impact of the quantum processes on the human nervous system is just as much of a riddle for us as consciousness.

The fifth chapter of Wiener's Human Use of Human Beings might have been an inspiration for the initial two dialogues. In it Wiener considers biological organism as an information processing system and he writes for example:

In other words, the fact that we cannot telegraph the pattern of a man from one place to another seems to be due to technical difficulties, and in particular, to the difficulty of keeping an organism in being during such a radical reconstruction. The idea itself is highly plausible. As for the problem of the radical reconstruction of the living organism, it would be hard to find any such reconstruction much more radical than that of a butterfly during its period as a pupa. (103-104)

It is significant that Lem adopted Wiener's scientific and cognitive optimism, and he ignored his warnings and dark visions of the future and nature of our species. He would later surpass Wiener's pessimism though.

The third dialogue presents Lem's original approach to Shannon's notion of information (mathematically described as the opposite of entropy), as he tries to describe the human ontogenesis (the development of the fetus) in terms of information processing. Lem emphasizes that ontogenesis seems to contradict the second law of thermodynamics: the degree of the order in a system increases with time instead of decreasing; and then he argues that this is in fact an illusion. He introduces key cybernetic notions here: "feedback" (64), "the threshold of minimum complexity", beyond which "the system becomes capable of producing other systems of equal complexity" (63). ${ }^{67}$

The fourth dialogue touches on some more issues related to defining consciousness (or more precisely the impossibility of defining it). It then discusses the immense difficulties of reproducing human sensorium and motility in machine systems. Lem reveals deep understanding of these complications - a kind of understanding, which the robotics experts only gained 20 years later.

The fifth dialogue continues the subtle discussion of the essence of consciousness. Lem investigates the subject with a determination that derives from the difficulties that arise from the cybernetic interpretation of life, especially an intelligent life, and even more specifically life of a human being understood as a biological entity with consciousness that cannot be reduced to biological terms.

It needs to be pointed out here that generally speaking, the first six dialogues revolve around two major issues:

67 This is really an early cybernetic concept of what will then become "information farming"; cf. Chapter 15 of this book. 
- an attempt at defining consciousness for the purpose of machine construction (mind-body problem);

- an attempt at defining biological evolution in terms of building complex systems.

However, the main subject of the conversations between Philonous and Hylas is in fact confirming the impossibility of succeeding in these attempts, at least insofar as they are based on the set of notions currently in use within our culture. Even though it is not stated explicitly anywhere, the entire intellectual work done by the interlocutors is only proving how ineffective it is. We may presume this was not Lem's original intent while setting about writing Dialogues. It does not mean that Dialogues are intellectually shallow. Their internal contradictions are like the aporiae that dismantle the grand philosophical systems from within, with the only exception being that the author and his protagonists realize it fully and are not trying to deny it, while the big authors of philosophical systems were always striving to prove the coherence of their systems. Lem is usually reluctant to claim that cybernetics solves the issues discussed in Dialogues.

All these problems, so thoroughly discussed by Hylas and Philonous, nearly overlap with the issues analyzed by experts in artificial intelligence (AI). The term is never mentioned in Dialogues, but the field itself was only being born at the time when he was writing them. I will discuss the links between Lem's thought and AI in Part Two of this book, while analyzing relevant sections of Summa Technologiae.

I should return now to the discussion of the fifth dialogue. At its core there is the attempt to define a physiological correlate of consciousness as a type of network. Such neuronal networks were the object of cyberneticists' study from the very beginning of the discipline; they created their mechanical models, which were an approximation of a real network of the brain of humans and higher animals. It was assumed that the mechanism of brain's functioning boils down to interconnections within such a network; and the only reason why we cannot explain it in full is that it is unimaginably complex. This is where the popular saying that human brain is the most complicated structure in the universe came from. It turned out to be even more correct than it was originally thought - after a period of enthusiasm in research on neuronal networks, the developments in neurophysiology led to a discovery that the functioning of a brain relies on many other mechanisms, and cannot be reduced to neuronal connections.

Philonous uses the moment to dismiss a suspicion that cybernetics, which treats consciousness as a correlate of mechanical processes (i.e., that a neuronal network is a type of a mechanism), is in fact a new version of mechanicism: 
[The older, 18th century] concept of 'mechanicism' had the following characteristics: that the whole can be reduced to a sum of its parts, that every process can go either forward or back and a mechanism is ahistorical, i.e. it is not shaped by its past. You can dismantle it freely, and then put back together - it will not affect its functioning. You can reverse it, and it will go back to its starting point. Based on the knowledge of how far along in the process one of the parts is, you can always predict where it shall be at any given moment in the future, as long as you know all the forces that influence the mechanism. The point is such statements are only valid for systems such as a watch or steam engine, but they cannot be applied to biological or quantum phenomena. (114-115)

The notion of a network that has an entry, an exit, a control center and feedback is then extended to include counting machines, defense systems and animals with their behavior. Lem supplements this purely cybernetic approach with a semiotic aspect. He does not stop at the statement that information circulates within networks, he also points out that problems can arise from disruptions in circulation, especially if there is an excess of information or if the functioning of feedback mechanisms is flawed. He will return to the issue in the seventh dialogue. When Hylas asks: "Pray, tell me, what is the purpose of the very complicated way in which you describe processes and phenomena that have been studied by psychology so thoroughly?" (128), Philonous responds with a lecture on how the description of a model of a network is in fact identical with the model itself, 68 and concludes the lecture, saying: "We find ourselves in an astonishing situation in which the simplest logical description of the network turns out to be the network itself, in which logic begins to be transformed, to grow into neurology" (130). It is an echo of Turing's idea of "logic incarnated in a machine," although tilted toward biology. ${ }^{69}$ Lem will develop the thought further in Summa Technologiae, when writing about "information farming."

At the end of the fifth dialogue, Lem makes a brave attempt to define free will in cybernetic terms. The result is as follows:

In this sense network acquires information in a twofold manner: firstly, from the outside, and secondly through a recombination of symbols, which have not been connected in a given way before within the network. "The internal richness" and the "integrity of

68 It is in fact but a version of the old problem of the representation of reality in its model; one that was probably best summed up by Borges in the short story in which a ruler of an empire orders a 1:1 map of his state from cartographers. The problem of "map and territory" will return in Summa Technologiae with the description of "pantocreatic" methods.

69 It will not hurt to mention that Turing's last work, to which he only managed to create notes, was supposed to be an extensive book about morphogenesis. 
the network" define its character. Such network operates on "free will," thus manifesting its "character."

The above entails that the network is responsible for each of its acts, as it is "free" in its decisions. It is responsible for its character shaped in previous decisions since it first came into existence. No decision was fully predetermined; it could have been ("accidentally" or not) modified. (144)

And so the free will of this particular network commonly known as mind or soul is a matter of stochastics, the probability mechanisms in the processes of distribution of information. This could be seen as Lem's idee fixe: his fascination with probability theory. His later works, and especially The Philosophy of Chance will be permeated by it.

The sixth dialogue considers the possibilities of building a network, which would be an exact equivalent of a real human brain. So again, it belongs to the field we now call AI. In order to strengthen the image of difficulties involved in reproducing consciousness and psychological content in a machine, Lem begins the dialogue with a reference to Dostoyevsky's Notes from Underground. Philonous says: "It is extraordinary, unheard of and thus particularly difficult, verging on laughable, to speak about the tragic and sublime sides of human essence and psyche in the language of a physicist or a designer" (147). He then discusses in detail the technicalities of the project of transplanting a brain to a network built specifically for that purpose. Such an artificial brain, it is claimed here, might be many times more effective than the biological one. Hylas's objections to this view represent - ahead of the time - the opponents of AI, who are afraid of the possibility that humans would be dominated by "smarter" machines. Philonous's replica could be descried as a "critique of computer fetishism," that is of the uncritical attitude to machines' alleged omnipotence (166-168). Lem states (which turned out to be prophetic) that progress in building "artificial brains" is mostly threatening to the society insofar as it pushes people into thoughtless consumption. ${ }^{70}$

For Lem the possibility of reproducing human brain in an artificial structure, based on an assumption that both are structurally and functionally equivalent,

70 Already in the 1950s, Lem knew that the notion that digital computers might become "smarter" than people is absurd. The title story in the Sesame collection masterfully showed the falsity of the belief that computer could think creatively. (The collection only had two editions, in 1953 and 1954. Lem never agreed for it to be published again because of the political connotations and naivety of the plots in most of the short stories.) One can add, in the spirit of Lem, that perhaps one day we shall build machines that can outgrow us intellectually, but these will not be digital computers. The motif would return in Summa Technologiae. 
is, as Philonous phrases it on Lem's behalf, the only form of immortality available to people. So the problem put forth at the beginning of the book - whether we can attain physical immortality - is finally solved here, although with many restrictions. The idea will return later in the project of autoevolution that is Summa Technologiae. Lem will develop some of his bolder vision there, again being ahead of his time and other authors.

Clearly, cybernetics is merely a basis for Lem (even though he considered this to be the best basis) that he uses to take his thinking beyond technology and science - toward philosophy or even eschatology, but nowhere in his thinking does he delve into speculative, immaterial metaphysics.

On to dialogue seventh, the longest one, which Lem devoted fully to the project of cybernetic sociology, and an original critique of the socialist system and the centrally planned economy. It is introduced by Philonous: "The society is paradoxically more alike to an electronic brain than a living organism as a system (an organized set) of elements connected through feedback" (172). The first instrument of analysis is the notion of "delayed reaction to stimulus," which in processes analyzed cybernetically leads to oscillation in subsequent stages of these processes, regulated by feedback.

The phenomenon has been known to physics and technology, as well as economy for a long time. Lem is trying to prove that the same notions can be used to analyze processes of biological evolution and social processes as well. Both are nonlinear in his view. In natural sciences, the term is used to describe a type of processes, the variability of which cannot be described in a universal way, which means the rules of these processes change in time, unpredictably, in a stochastic manner. The dynamic of change in biological and sociological systems is very different. Philonous described it as follows:

When we juxtapose the rules of dynamic for biological populations and social systems, we see, that the former can exist long-term in an unchanged form only if they achieve dynamic balance, if they are internally durable, whereas the latter can exist long-term also if they lack internal stability. It derives from the fact that social system can be stabilized forcefully. This is why changes in social systems have historically mostly been violent, and would take up the form of coups or revolts, as opposed to the non-violent dynamic of biological evolution.

In social systems numerous parameters oscillate, with the economic oscillation being mostly primary, while political and cultural ones are secondary. These secondary oscillations, which lead to changes in human behavior through changes in psychological attitudes, impact the primary ones, which shows the cyclical, feedback-related character of the phenomena. Oscillation of social systems known from history generally had a tendency to increase its amplitude, which after a series of hard perturbations usually led 
to destruction of the old system by revolutionary forces, targeted against forces striving to save and preserve the existing structure unchanged. (184)

The argument may seem worryingly similar to Kossecki's revelations from Cybernetyka społeczna, but Lem is careful to avoid illustrating his theses with specific historical examples, either here or elsewhere. It is not only for the fear of political censorship, but also - perhaps primarily from the point of view of the point of the text - because of the huge difficulty of translating his highly abstract statements into the language of specifics. We might recall here the quote from Greniewski's popular lecture on the perils of abstract cybernetic notions.

On the many subsequent pages Philonous is developing an interpretation of two main socioeconomic systems in front of his patient interlocutor: capitalism and socialism. He interprets them in terms of systems, feedbacks, oscillations, focusing on methods preventing oscillations that are harmful for the system. Lem smuggles in his critique of socialism here, which is emphasized by the critics. Philonous talks about a tendency for "decision to flee up" (206), a phenomenon that social theorists often call "flotation of responsibility." For Lem it looks as follows:

... within the relatively limited group of those in power there gradually grows such a concentration of feedbacks regulating production, that "the information capacity" of the group is exceeded and there arises a necessity to expand the central management. This would be equivalent to an organism devoid of automatisms, i.e. automatic reactions. It would have to consciously, with concentration control, the heartbeat, blood pressure and chemistry, breathing, tissue transformation processes, etc. Such an organism could not do anything other than working to retain relative balance in its life processes.

Centralization involving increasing the number of feedbacks, blocks (or limits the transfer) of information, while extending its paths. Instead of short connections between supply and demand, there are layered "switching stations" in the systems. As a result of extending the paths of information transfer there occur significant delays between stimulus and reaction ... Above all the delay in production processes, i.e. the time elapsing between changes in demand and the resulting changes in supply, significantly impacts oscillation in capitalism.

In the socialist model the most important delay is caused by extended feedback loops (perimeter - center - perimeter). (208-209)

In later interviews Philonous engages in a detailed analysis of a whole range of consequences of this delay process for the social system, from economic to psychological. However, no specific name, fact or description of authentic situations is mentioned. In the final stage of the conversation, Philonous outlines a project of "a cybernetic social utopia," explaining to Hylas what mechanisms should be improved and how in order for "a properly functioning" social system, that 
is, one without harmful delays and oscillations, to be created. When Hylas asks: "Can you present to me the relationship between cybernetic sociology and the kind of sociology and economy that is generally known today?", Philonous responds: "As of yet, there is no cybernetic sociology in a real sense; there are only early beginnings, individual discoveries and methodological research guidelines. The discipline will only emerge, when the general information theory, the most important and the most complex part of cybernetics, develops its mathematical tools enough and when there has been enough observational and experiential facts to produce generalizations" (237). However, for the reasons I have described earlier, the discipline has never in fact emerged. ${ }^{71}$

The last, eighth dialogue is devoted to a preliminary venture into social psychology from the cybernetic perspective. Lem is trying to determine the impact of individual variability within a population on the functioning of a social system - and vice versa. The attempts conclude in the statement:

Simplifying and shortening the matter, we can say that all occurrences within the social system that happen through force, repression, and prohibition have in fact one aim: of turning a non-linear system into a linear, in the simplest way, that is by decreasing the number of degrees of liberty offered to individuals who are elements of the system ... In other case, the more liberty is offered to individuals, the more unlimited disturbances to collective processes ensue, because the range of occurrences on the social scale increases; there occur new contradictory opinions, changeable individual reactions, radically opposed views and actions; as these phenomena progress, the systems is less and less linear and it is more and more difficult to retain its internal coherence and to predict future developments. (263-264)

At the end of the work, Lem many times and strongly emphasizes his confidence about the possibility of creating an optimum social system through scientific means - cybernetic, of course. Philonous characteristically states: "Politicians are, from the point of view of academic sociology, a sort of healers of social ailments, practical institutionalists without education in the area at best" (275); and his last words are: "Despite all disappointments, failures and tragic mistakes, people will build a better world. If they were not to act with that thought, we would lose all faith in humanity and its potential, in which case it would be better not to live at all my friends" (287).

71 Małgorzata Szpakowska gives a much more detailed analysis of Dialogue 7 in her book. 


\section{Attempt at an Interpretation}

What does it all lead to? I should perhaps start with a commentary to the last dialogue. Similarly to Lem's early novels, it is a declaration of faith in our species' auto-creative power. Yes, we are all capable of making a leap into the realm of enlightened happiness. Science would be our stepping stone. If we read what Lem had to say about human nature in the last years of his life - in his column Rozważania sylwiczne ["Silva rerum deliberations"] - it will turn out that with age he turned from a noble progressive to a determined conservatist, as one would be hard pressed to find anything other than bitter rants on the unchangeability of human vices in his late texts. With time he himself thought that "Dialogues are characterized by an excessive hope and faith in cybernetics." 72

The observation is only an aside, although it would be possible to write an interpretation of his entire work along this evolutionary line, with the intermediary stage of moderate skepticism, when his best novels were written. ${ }^{73}$ This modest vision could also be compared to the grand project of autoevolution from Summa Technologiae, which I will analyze in Part Two of this book and which was created still at the "optimist" stage of Lem's thought. At this point, however, I am primarily interested in what can be learned from Dialogues in the 21 st century.

Lem's plan was ambitious to say the least. Dialogues seem to be a preliminary project of a total anthropology based on the fundamentals of cybernetics, a project outlined with a great care for methodological moderation. ${ }^{74}$ That this is "an anthropology," and not merely "a sociology" is visible from the range of the problematic, which is not limited to social issues only, but which in fact ranges from metaphysics to psychology. Lem clearly made it his goal to summarize all the most fundamental problems of the human world, and especially those, which ensue from the rapid intrusion of technology into it.

72 Tako rzecze ... Lem, 85.

73 The last two dialogues could also be seen as a "metautopia" - a way of considering "the conditions of possibility of all future societies, which could be scientifically (i.e., cyberneticially) organized."

74 A more malicious critic could write that Dialogues really contain anything the author was interested in at the time. Indeed, Dialogues could be described as somewhat incoherent in structure and excessively complicated in arguments presented, but the qualities do not really occur frequently enough to disqualify the work as a whole. 
The scope makes it hard to produce an interpretation of Dialogues. In Chapters 1 and 2, I suggested that cybernetics split into two heterogeneous branches: the very technical science and the vague social commentary. Dialogues do not really belong to either. They are too general for the technological cybernetics, and too detailed for its social counterpart. They are an intellectual project of their own.

How valuable is the project really though? The critique of the socialist system was certainly accurate, but, just as many other such critiques, expressed in a more common language, it had no actual effect. The futurological visions in Dialogue 7 and 8 did not come true in the least bit (Lem himself would mock the formerly trendy futurology in the 1970s and 1980s). The philosophical issues caused by the introduction of information technology into the living world (e.g., mind-body problem, and the philosophical foundations of artificial intelligence, AI) were described in Dialogues with rare precision and insight, but in 2017 we are, it seems, equally removed from their solutions as we were back in 1957. It seems that if Lem planned Dialogues that would actively contribute to the social practice - the intention was not fulfilled.

Dialogues could also be treated as a purely intellectual endeavor, a survey showing that cybernetics could be effectively applied as a tool for analyzing the social world. It requires turning a blind eye on the explicitly interventionist tone of the two final dialogues. However, even in this case it turns out that they have not achieved this goal to a satisfactory degree. Not because they were trivial or derivative - quite the opposite - but because the cybernetics itself has been removed into the archives of ideas and science. In their basic shape Dialogues (sauf the annexes) are a fortress built for a lost army. It is a sad paradox - as Lem saw the imminent failure earlier than others, and yet he wrote the book that exceeded the achievements of the other Polish cyberneticists (and likely foreign, too) many times, while the others continued to defend the position of their discipline, when it was already marginalized.

It begs notice that Dialogues prove that there is a full analogy between the universe of cybernetic notions and the world of human problems; or - in other words - that it is possible to translate the old system of notions describing the world into the system of cybernetic notions, and that it would lead into an at least partial solving of social and philosophical issues. Mazur's Cybernetyka $i$ społeczeństwo was a similar attempt, but intellectually infinitely more primitive. I need to point out that the attempts to frame the social world from a cybernetic perspective are not explanatory in character - either scientifically, or philosophically. Similarly to structuralism, for example, cybernetics did not explain reality; 
it described it. This description seemed so revelatory for more than a decade that it was expected to explain everything.

This analogy positions Lem when writing Dialogues beyond the opposition of naturalism and culturalism. This, too, should be emphasized, because the question about the type of view he held on human nature surfaces often in the critical texts. His view on the matter was by no means unchangeable and coherent, as Lem is neither a meliorist nor a pejorist, just as he is not merely a naturalist or merely a culturalist - in this latter case the methodology and theory he took up in Dialogues place him beyond this particular opposition. For the interlocutors of Dialogues, human is a creature biologically constituted - the evolution process, itself shaped by the laws of physics, determines "the boundary conditions" of our existence and growth. Yet within this frame our growth goes beyond the materialist concept of nature. From the very beginning Lem assumes that there is a nonbiological element in us as well. ${ }^{75}$ His penchant for social engineering, which is clear in Dialogues for the first time, is a constant quality in his work. It will keep coming back in Summa Technologiae as well (although only in a limited way), and in many other works of fiction, from Eden to The Star Diaries.

One could ask here, whether the phrase "cybernetics as an anthropology" is not internally contradictory, derived from the fact that the former is a science, while the other belongs to the realm of Geisteswissenschaften and in some its variants has nothing to do with any kind of scientific character. ${ }^{76}$ Indeed, there is a fundamental aporia here, but it does not lie in the terminology, but in its deepest premises behind the very foundations of the book. Lem tries to explain human there using terms that were coined for a very different purpose. Because he is treating cybernetics as the foundation for a specific anthropology, none of the problems taken up by the interlocutors in Dialogues is fully solved. The subject of the conversations and the method of considering it are heterogeneous, but not in the hundreds of details, which are discussed accurately and fruitfully, but in the most general plan of the whole, when it turns out, that all arguments are entangled like the geoglyphs on the Nazca desert, the patterns of which can only be seen from the bird's eye view.

75 Which I would not want to describe as "spiritual," "transcendent" or in any other way at this point. The theme of Lem's anthropology and its place between naturalism and culturalism will be a recurrent one in later parts of this work.

76 I am thinking here of German philosophical anthropology for example (Scheler, Plessner, Gehlen). On the other hand I am not discussing here the science par excellence, that is physical anthropology, and the positivist versions of cultural anthropology. 
If Dialogues cannot be treated as "a manual of society building," or as "a treaty on the first principles" - then there is one more, third way to interpret it. They can be seen as an important stage in the author's intellectual development. I believe Dialogues cannot be understood without the knowledge of what cybernetics used to be, just as Lem's later works cannot really be understood without knowing about Dialogues. The themes that will be important in Summa Technologiae, The Philosophy of Chance, Science Fiction and Futurology, not to mention the less prominent theoretical texts and fictions, were first taken up in Dialogues. The author took them up, and then critically recapitulated them in the annexes, to which I shall now turn.

The first annex, Dialogues after 16 years, includes two texts: Losing Illusions: From Intelectronics to Information Technology, and Applied Cybernetics: An Example from the Field of Sociology. In the first one, Lem summarizes the history of cybernetics between 1957 and 1971 in detail, pointing out how it diverges from cybernetic predictions of it. The overview includes the links between cybernetics and the theory of information, information technology conceived as a study of building and programming computers, semiotics, neurophysiology and genetics. Emphasizing again the huge difficulties of trying to conceive of all these disciplines coherently together, he admits that he has fallen short of this task. On the other hand, the growing problems with reproducing the working of the brain in machine systems - problems that were rarely foreseen by anyone apart from Lem back in the 1950s (such as the technical difficulties in building systems freely imitating human motile capacity, spacial orientation, shape recognition, etc.) - led to this particular trend in the development of cybernetics, which was most interesting to Lem, being largely slowed down. But even this failure leads Lem to some valuable conclusions. He asks: "if indeed we build computers, but we are incapable of building brain simulators, because the first task proved to be immeasurably easier than the latter one, then why did the natural evolution choose the more difficult of these two tasks?" (317-318). The answer contains one of the most fundamental theses of Lem's all philosophical writings: it happened so because the biological evolution is a stochastic process, not targeting any particular goal, and therefore testing innumerable variants throughout hundreds of millions of years - whereas human projects and products nearly always have a specific goal, and hence, in comparison with the products of biological evolution, they are highly narrowly specialized. The statement is trivial and obvious to any student of biology when phrased this way, but Lem will draw far-reaching conclusions from it. I will discuss them further throughout this work. The rest of the annex 
is devoted to some of the most important problems troubling contemporary cybernetic and computer technology. ${ }^{77}$

The text about "applied cybernetics," on the other hand, develops in Dialogue 7 - it is an in-depth analysis of the pathologies of the system of centrally planned economy in communist Poland. By the time Lem wrote Dialogue 7, these pathologies have become striking - here he only pointed out the increasing "undercurrent" of informal relations that underlay the failing state machine. ${ }^{78}$ The cybernetic terminology he uses to describe these phenomena departs considerably from correspondence with the technical terminology of Wiener, Ashby and other forefathers of the discipline, and it becomes more and more similar to the elaborate imagery I wrote about when discussing Mazur and Kossecki ${ }^{79}$ - but, of course, Lem uses the terms with intellectual mastery that cannot be compared to what those authors were capable of. The pertinent quotation would be:

When the central authority loses the view of the existing state of things, because it unknowingly set in motion pathological steering circuits, which, abusing the regulative cycles, cause disturbances on other levels, gradually the entire economic organism of the society falls into tracks of unpredictable changes. A superficial judgment might lead to a conclusion that the emergence of informal managing groups is a positive phenomenon as a spontaneously born form (sic!) allowing for overcoming the obstacles. From this point of view the only alternative to such groups being formed are completely haphazard actions: when an excessive and physically impossible plan cannot be carried out in full, the options are to carry out a part of it, with the part either chosen haphazardly, or by choosing a part that is privileged through a silent agreement of "informal management." This type of argument, however, is essentially false. There is no such alternative. The plan is never carried out haphazardly, because those who implement it are not logically

77 Among other issues it includes the sentence: "But if as a result of gradual merging of computing machines and memory banks there emerge national, continental, and later even planetary computer network, which is a realistic direction of development, the whole system, constituted by humans and these networks, may take up a dynamic trajectory, quite divergent from the civilizational hopes" (321). This is the earliest harbinger of the Internet that can be found in Lem's writings.

78 Cf. Małgorzata Szpakowska, Dyskusje..., 166-167. Szpakowska points out that a society relying on a network of informal relations following the principle of do ut des was satirized by Lem in his short story Profesor A. Dońda, never translated into English.

79 Metaphors like that can already be found in the main body of Dialogues. Philonous speaks of "a crisis which is analogous to 'a short circuit' in a neuronal network - an epileptic attack," to which Hylas exclaims: "Oh, then crises are the epilepsy of capitalism?"; to which Philonous responds: "With a grain of salt, one could say that" (187). The metaphor is given by Hylas, who is naïve, so it is not necessarily to be treated seriously. 
programmed automata, but humans. Each of them is at first trying to act in accordance with the accepted procedures, but since they encounter resistance - the infamous objective difficulties - those who formally are still partners become, in fact, rivals, just as they would be in a free market economy, with the one significant difference that the situation of competition, i.e. of colliding efforts from individual managers, not foreseen in the plan, is simply illegal. Yet, it exists; if not everything will be carried out, the fulfillment of specific parts is determined based on criteria and circumstances previously unaccounted for: personal relationships and connections. (339)

It is hard not to admire such an insightful analysis. In an essay from the early 1980s (Mój pogląd na literaturę) $)^{80}$ Lem wrote that "the diagnosis of our ailments with elements of forecast, which I gave in the 2nd edition of Dialogues, turned out to be terribly true" (199). And in the collection of interviews with Stanisław Bereś, Lem said: "I was myself astonished, how much of what I have written [in Dialogues] was confirmed." ${ }^{81}$ However, this critique of the communist Poland contained in Dialogue 7 and the essay Cybernetyka stosowana lost its power with the fall of communism, and it only continued to make sense as an example of excellent social critique.

Annex 2 consists of two essays, which have little to do with cybernetics, but a lot with Summa Technologiae - they were published after its first edition. By discussing them here, I will introduce the second part of this work, which will be devoted to Lem's Summa Technologiae.

Ethics of Technology and Technology of Ethics was originally a paper delivered at a conference on moral dilemmas in science, held by the Department of Philosophical Questions in Natural Science of the Institute of Philosophy and Sociology of the Polish Academy of Science (December 24-25, 1966). It is an attempt to determine the mutual influence between two evolutionary lines of the contemporary civilization: the technological progress and the transformation of ethical norms. It seems that the issue has not lost its pertinence, and in fact, at the beginning of the 21 st century it only became more burning than it was in the 1960s; a mention of cloning, euthanasia and of the constant progress in the technologies of genetic modifications should be enough to prove it (I will return to these issues at the end of Part Three). For Lem, other illustrations of the problem included the prevalence of drugs and other addictive substances - which were no less a problem then than they are now - the introduction of the contraceptive pill and the generally increasing ease of life in the Western societies. He summed it

80 Reprinted in amended version in Teksty Drugie, no. 2 (1990), and in the collection Mój poglad na literaturę..., 193-214.

81 Tako rzecze Lem..., 84. 
up in the following pithy words: "The forceful implementation of 'improvements' can set off an 'axiological implosion' - i.e. a collapse of the system of values: it may lead to a situation in which living is very easy, but not really worth it" (371); and "The task of technology cannot be to constantly aim for a 'short circuit' of all the possible needs, desires or directives with their objects, because where one can obtain everything immediately, nothing has value, which derives from a certain hierarchy of goals and various degrees of difficulty in overcoming them" (373).

For Lem, the very notion of ethics is devoid of any transcendental connotations - he is coherently a rationalist in that regard. He states:

By ethics we shall mean a vaguely delineated set of rules of "the social game." Some of these rules are certainly instrumental in character, and their occasional ethical aspect depends, among other things, on the whole set of rules, i.e. the entire culture. We believe that it is the situations of interpersonal contacts that have an ethical aspect. Determining which of these situations have an ethical aspect to them and how they can be judged in that regard is the clearest when we look at a given case from the perspective of a particular culture; the range of situations classified as ethical and the very criteria turn out to be variable (although not infinitely variable!), when looked at from various cultures. Judgments about interpersonal situations within a particular culture are especially divergent when they are made by observers positioned outside the given cultural environment, which implies an observer who grew up in a different culture. (379)

It implies that there are no universal values, but for Lem it also means that the emergence and development of ethical systems is independent from the biological foundations of the human species; otherwise there would have to be some ethical universals, because the biological diversity within the human population is too limited to justify the diversity in symbolic systems. Anthropological research has not yielded a discovery of a principle, value or norm that would be present in all human cultures. Thus, Lem rejects sociobiology avant la lettre, as Richard Dawkins and Edward O. Wilson had not even written their major works by then. So, again: neither naturalism nor culturalism. What is it then?

In the summary that concludes the text there is a following passage:

According to the hypothesis presented here, "the ethical" constitutes a component of how group behavior is controlled, with maximum probability of occurring in particular situations; this component - together with how group behavior is programmed as a whole - can be seen as a result of three sequential processes combining to instill these behaviors: accidental events (such as fluctuation of climate), Markov processes (which perpetuate effects of a random deviation from the initial state through positive feedback) and cumulative processes (e.g. techno-evolutionary processes). These processes produce a model of "human nature" characteristic of a particular culture, and they determine a corresponding system of norms and ethical judgments, which from 
the perspective of a participant of the culture is not merely a product of certain probabilistic references, but is endowed with a symbolic meaning. (419-420)

What would that mean? Above all it means that for Lem, ethics, or, more precisely, the emergence and development of ethical systems and norms for societies, constitute a stochastic process, a random and unpredictable one. This sentence of mine expresses in a colloquial language what the quoted excerpt stated with utmost precision. The notion of "Markov processes" plays a fundamental part in this essay and in Lem's thought on culture in general, so it calls for a closer explanation. Markov processes or Markov chains ${ }^{82}$ are a type of stochastic process characterized by a principle that stage $n$ of such a process depends only on the stage directly preceding it $n-1$, and no other earlier stage. Systems that undergo Markov processes are hence systems that "forget the past," in a sense that from the current stage and state of the system one cannot derive anything about its earlier stages, and vice versa: no later stage can be determined from it (with the exception of the one following it directly). In nature an example of a Markov process would be the motion of a particle suspended in a fluid called the Brownian motion. For an amateur such motion is completely random, but mathematicians have developed an elaborate formalism to describe it. Surprisingly, Markov processes can yield results that seem orderly to a human mind. A computer generating sequences of letters following the rule "to $x$ add a letter which most often follows it in Polish," will produce sequences of letters imitating words of the language, but prevalently meaningless. ${ }^{83}$ This is exactly a Markov process.

In Lem's view the development of ethics in societies is such a process, and in fact the entire culture and history of the humankind can be interpreted in this manner. The Philosophy of Chance will largely be devoted to proving this claim. In Ethics of Technology..., he draws further conclusions from it about creating models of societies' evolution, and this is what he is mostly interested in (social engineering again). He pays no attention to the philosophical consequences of this position, even though they are just as interesting and unprecedented in the Western philosophy. Following the spirit of the 20th century, Lem dispels

82 Andrey (Andrei) Andreyevich Markov (1856-1922) was a Russian mathematician and one of the authors of the probability theory; he was a professor at a university in Petersburg and a member of the Petersburg Academy of Science. His research on processes that were later named after him started from a study of sequences of letters in Pushkin's Eugene Onegin.

83 Similar processes are in play in The Cyberiad, in the short story The First Sally (A), or Trurl's Electronic Bard, where the Electronic Bard - a poetry producing machine - recites a poem during its trial run, which starts from: "Pev't o' tay merlong gumin gots..." 
any illusions we may have about an overarching meaning of our existence and actions; the absence of such meaning is obvious to him, which he makes it the implicit underlying premise of his argument. And it is not merely an unjustified statement of absurdity of existence that so many other philosophers made. The absurdity of our existence is not pure nonsense for Lem. The fate, which steers our existence, is not blind. Our randomness is not completely random - it is governed by mathematics.

Can it make us feel any better? ${ }^{84}$ It depends on one's personal attitude. For many there will likely be no perceptible difference between randomness governed by the laws of stochastics and randomness that has no justification. Yet, for some, perhaps even many, an attempt to make our condition, in itself lacking external roots, a part of a mathematical formula, an attempt undertaken by Lem not only, and not even primarily in this essay, can be a sort of consolation, as Jerzy Jarzębski put it. ${ }^{85}$

For example, in Ethics of Technology..., there is a noticeable shift in Lem's worldview since writing Dialogues. It is no longer an expression of joy of planning a perfect society, the cognitive optimism, which allowed him to manipulate the cybernetic terminology for the purpose of producing a new anthropology, is gone. Instead there is a careful skepticism, and his reflection on the links between the human world and the rest of the reality has become much sharper.

Lem did not take the stochastic model of culture and ethics out of thin air. It has been proven on a broad empirical basis, ${ }^{86}$ but, of course, it does not go beyond being a hypothesis, and one that is not easily subjected to verifying procedures. The two-part title becomes understandable only after the model has been outlined. While "ethics of technology" seems like an almost self-evident concept and it certainly was not foreign to people in the second half of the 20th century, as it is not at the beginning of the 21 st century, "technology of ethics"

84 Lem would never ask this question. He would likely say that the purpose of thinking is not to make us feel better. Nevertheless I want to point to this trace of existentialist interpretation, at least tentatively, as many such themes of coping with absurdity come up in his novels, including Solaris and The Magellan Nebula.

85 Cf. Jarzębski, Kosmogonia i konsolacja, in: Wszechświat Lema..., 68-102. The term "consolation" here, drawn from classical rhetorics, is justified by the assonance between it and the word "cosmogony" in the title of the essay ["Cosmogony and consolation"], but it probably also points to the fact that, perhaps against the author's will, Lem's whole argument is somehow elitist.

86 Cf. Dialogi, 383 and following. The issue is taken up more thoroughly in The Philosophy of Chance and Science Fiction and Futurology. 
becomes understandable only if we allow for a possibility of modeling the development of societies using mathematical tools. This is not something we know - it is a part of Lem's vision of the future. We are aware that the technological progress is not concordant with the changes in ethical norms, which do not follow immediately. But we are still far away from these processes happening simultaneously, not to mention from modeling ethics a priori.

"Technology of ethics," however, is not a naïve science fiction that would describe people who are completely dependent on psychotropic drugs or virtual projections (Lem offers a grotesque image of such a reality in The Futurological Congress). This is about something else: we are at the beginning of this writer's next major narrative. He starts questioning the very distinction between the natural and the artificial here. ${ }^{87}$ I will discuss the details in Part Two of this book. Here I would only point out that within "technology of ethics" this distinction loses its meaning, because Lem considers the possibility of controlling societies' ethical views not through any kind of repressions (be it political, ideological, physiological or symbolical), but on the basis of the stochastic model through which technologically advanced civilizations are capable of deciding about the fundamental parameters of their development to some extent; and this is exactly due to the stochastic nature of the process. Lem, however, is very clear about this potential being minimal and very restricted by various factors, among which neglecting individual human qualities of members of the given civilization is the least significant. He is not thinking about totalitarian Gleichschaltung here, but about reducing the number of parameters that need to be included in the model. Thus, he admits that the entire model is a mathematical construct rather than a sociological one, or, in fact just a preliminary attempt at producing such a construct, because no formalism has been proposed in the end.

The essay Biology and Values touches upon ethics from a slightly different angle, although still within the perimeters of the probability theory and close to cybernetics. It begins with a distinction between autonomous values, nonrelational values (treated as facts) and non-autonomous values, that is, instrumental, relative to something (treated as qualities) (426-427). In the first chapter, "Axiology and Physics," he asks "when and how instrumental values are formed, where do they come from" (437), to which

one has to respond that the difference between presence and absence of axiology, just as the difference between a real goal and absence of a goal, can be conceived of with use of the same method that would allow us to understand a difference between a bald

87 Cf. Jarzębski, Wszechświat Lema..., 97 and following. 
head and a head full of hair. When a stone falls due to gravity, we do not ask whether it made a decision about accelerating its speed during the fall. When a virus approaches a cell, we are in a sphere of classificatory instability ... If we assume the virus does not make a decision in the axiological sense of the word ... we fall into trouble with amoebas ... etc. In fact the point is: if we can grasp the whole model of functioning of a given homeostat with the same precision with which we can grasp the working of, say, an electrical doorbell, then "decisions taken" will need to be replaced with causal relations, possibly involving a feedback loop, and the "goals of actions" will be replaced with probability chains, producing structures which in borderline cases (mouse, monkey, human) achieve a status of models of homeostat's environment. "Values" turn out to be simply a kind of relations between physical states, relations that statistically determine the behavior of the given system. (437)

Here Lem is trying to explain the notion of instrumental value in terms of biological cybernetics, which has been very problematic for other philosophers. The "relations" he mentions are transfers of information between elements of a system in his view. The system and the "homeostat" are signs of this being another attempt to produce anthropological cybernetics. This time Lem is trying to use it to solve a classic problem of philosophical ethics.

What is next? When analyzing the links between physics and semantics (discussing the case of influence of symbolic meanings on human physiology in taboo), in passing Lem produces a thesis about the relationship between the emergence of language and the emergence of regularities in human behavior:

So, when random occurrences turn into a regularity, semantics emerge as invariable. Hence, clearly, the meaning of "taboo" cannot be found in a physical section of brains, just as no other meaning can, because we are speaking of something that has not existed as a physical phenomenon (as ergodics of language creation) since primeval times. In their dynamic stillness we can only observe late results of primeval causes ... So the program of "physicalizing culture" will likely by utopian forever. If it were to become a reality, values would turn out to be "superfluous" entities, like Laplace's demon (entia praeter necessitatem). (440-441)

After this strong statement Lem returns to the question of the genesis of instrumental values. He explains the homeostatic functioning of living organisms and then writes - and here comes the core of the argument - that "instrumental values" are qualities of objects of states that contribute to retaining the balance within homeostats (both in humans and other living creatures). The definition is based on the fact that all homeostats and only they can be defined as systems that have a goal (i.e., retaining balance in a changeable environment), and a presence of a goal is what Lem sees as the necessary condition of an instrumental value.

On the other hand, he interprets autonomous values as a special type of information that has a strong influence on the system; so strong that in extreme cases 
the system can disrupt or even destroy its homeostasis (as in a case of "dying for one's faith"). Lem does not explain where the special information comes from or what exactly is its influence. The problem of links between physics and semantics comes up again. And the immediately occurring question of how to distinguish between a value-producing homeostat from one that does not necessitates an answer that: "the decision is determined by the cumulative conclusion from long periods of observation" (450). There is no general rule, a law of nature, that would determine the presence of either type of values for a particular homeostat, be it a human or a clam. Concluding, Lem points out certain logical difficulties deriving from a consideration of complex, multilevel homeostatic sets (451-454) and finishes by saying:

If active orientation on values ends up amounting to optimalization of ultra-stable states, the science will develop toward biology and physics meeting half-way: the former will dump the ballast of completely anachronic axiological terms that goes beyond the instrumental, and the latter will absorb the sphere of instrumental values in parts of its theory of anti-entropic systems, as an element of the general theory of physical systems. (454-455)

Lem is trying to combine anthropology, biology and cybernetics here, implying that the former will disappear when the latter two are merged. He is very close to pure naturalism here, but he is careful to avoid any open declaration that would reduce humans to a purely biological species. If he did so, his entire argument would become pointless, because the notion of ethical "value" would lose its meaning altogether. He is still in trouble here, because he is trying to bridge heterogeneous disciplines and discourses. He is in the shadow of cybernetics as a mathesis universalis.

The entire second chapter of Biology and Values, "Biology and Technology," is a discussion of another such bridging attempt. It is devoted to a study of biological evolution in technological terms, with some axiometrics added for good measure. In short: does questions about the value of evolutionary solutions make sense, and hence can evolution be described as a construct? The problem remains unsolved though.

In the third chapter, "Intermittent and Continuous Evolution," Lem discusses certain aspect of biological evolution as a Markov process and as a game (as in game theory) and compares them to technological evolution. Finally, in the fourth chapter, "Biology and Non-instrumental Values," Lem considers whether biology can contain the notion of autonomous value, which is "a typically cultural phenomenon, very well known to anthropologists, for example, as scholars who practically devote all their efforts to trace and compare them" (482-483; 
Lem's view on what cultural anthropology is was already a bit obsolete). He claims such values can be traced in these qualities of biological organisms that are not capable of survival and reproduction, that is, in "redundant" information, such as the plumage of some of the bird species. It could perform the same functions it has in a more modest version. However, there is caveat here: we do not actually know, and we will not any time soon, where exactly the threshold of "system's information utility" lies. If it makes sense at all to speak of autonomous values in nature, they only be derivative to more fundamental phenomena (484485). It is a clear contradiction that Lem does not even mention: by definition autonomous value cannot be derivative to anything. The question of consciousness through which and for which such value can be constituted is completely omitted here. If, however, for Lem this notion is completely independent from its original anthropological sense, he never provides a new definition. It is another example of contradictions that come from juxtaposing divergent vocabularies.

The last chapter of the essay, titled "Axiometrics of Progress" is another failed attempt, and Lem admits that in the very first paragraph: "The cumulative effect of how far evolution went from a single cell to a human seems obvious with this range as an expression of progress. But when we want to evaluate this huge improvement with some sort of axiological measurements, we encounter insurmountable obstacles" (486). The point is we can meaningfully show progress within certain evolutionary lines, groups, organs or physiological systems. However, the method fails us when applied to evolution as a whole.

"J. Huxley, for example, juxtaposes an eagle with a tapeworm, demanding that the reader realizes the amazing 'progress', between the two forms. Who is to judge it critically? It is only our aesthetical criteria that lead us to believe that an eagle's existence is beautiful and heroic, whereas a tapeworm's is opportunistic and ugly" (491). The same applies to comparisons between people and insects for example. It is not about aesthetics though, but about adaptability and specialization. And what about culture, this very human product? Indeed, Lem would say, we have achieved more than any other species with it, but we have no guarantee whatsoever that these achievements will last. He expresses a view here that could almost be seen as a manifesto of culturalism:

The rules of cultural development are not bioevolutionary and therefore evolution cannot be a source of knowledge about cultural obligation - nor the other way round: cultural criteria cannot be applied to evolution. Consequently, the place where the evolutionary process extends beyond its natural monoselective (i.e. solely biological) stochastics, the "anthropogenetic locus of evolution," cannot be located at the top of value ladder used by a biologist interested in axiometrics. This place serves purposes that cannot be measured on a biological scale. It is the very place where scale itself is 
being reevaluated: it is the moment when biology is being evaluated from the point of view of culture. (501-502)

For Lem "culture" is by essence different from "civilization" or "technology", because he can see no way of describing it with the same language as the one he used in Dialogues to discuss the latter concepts together with "machine" and "nature".

Why did Lem actually write that essay? He poses questions in it to which he has no answers, as he himself admits. He proposes theses that are based on contradictory premises, he is hesitating between a naturalist and culturalist anthropology, and at times he seems to question the point of anthropology all together. What is the purpose of it all?

I believe his intention can be described as follows. Evolutionary biology has been entangled in a prevailing contradiction from the very beginning of its existence, ever since On the Origin of Species by Means of Natural Selection, or even earlier, starting with Buffon and Lamarck. Evolution understood the way Darwin suggested is a nondirectional process, nontheological and governed by impersonal laws. Living creatures are subject to such evolution, and especially we, humans, are. Evolutionary biology as a science should follow its own basic premises and describe evolutionary processes without judgment. Moreover, it is not supposed to (or the scholars in evolutionary biology, to be more precise and avoid the hypostasis, are not supposed to) describe the evolutionary process as a process in the common understanding of the term, as a sequence of events, with a beginning and an end, and consequently with its causes, values and goals. This is how evolutionary biology ought to be studied. This is how its texts ought to be written. In reality, however, this was never so. Up until our times the greatest biologists who wrote synthetic and popular accounts of their field, have not been able to refrain from a teleological narrative, presenting evolution as a sensible, directed process, the aim of which (and let us not even mention causes here) is us, of course. Using the terms of literary analysis (and I will not be the only one to do so), one can say that the narrative and rhetoric of evolutionary biology have always contradicted the discipline's basic premises. It is hardly surprising though; it not only shows the unwavering vanity of the "crown jewel of creation" - it also proves Roland Barthes' remark that "human is a story-telling creature." Darwin's revolution produced a general model of biological reality, but in practice it turned out to be impossible to follow its premises, and an evolutionary biologist cannot help but tell the story of the discipline, just as a historian does. Except that in biology this rule has bigger impact on the results of research. A historian studies the human world and by presenting sequences of events in 
various configurations, he or she makes sense of the historical process, but telling it does not contradict the very premises of the discipline, as is the case for a biologist who theoretically cannot tell the story of evolution and judge it. But how else can it be described, especially from the bird's-eye view?

No need to add that these remarks apply only to a limited number of authors, both in biology and history. But they do apply to those among them who had the greatest impact on the shape of both fields. Biologists themselves have noticed the problematic character of the discourse of evolutionary biology a long time ago, and ever since the 1960s the discipline is striving to avoid value judgments, as does history. I would claim that Lem's essay Biology and Values was his attempt to deal with those contradictions. Having recourse, once again, to cybernetics and systems theory, Lem tried to combine three disciplines here: biology, cybernetics and anthropology (its axiological variety), expecting to succeed in eliminating the problem of value judgments about facts of evolution by reducing the very notion of value, via cybernetics, to a category of evolutionary biology. However, he must have realized success is impossible in this case - and perhaps hence the culturalist tinge in the conclusion. Lem's failure may (again perhaps) be partially caused by the fact he did not draw a clear enough line between the discourse of biology, with its narrative and rhetoric, and its object: the reality itself. If such suggestion is true, it could be explained by his fascination with Turing's vision of unified physics and logic: such a vision, applied more broadly, makes the very notion of scientific discourse pointless. Logics becomes incarnate in computers, and similarly biological theories could be identified with a practice of programmed evolution, in which case the very distinction between theory and practice, the artificial and the natural would be dismantled. Lem was deeply fascinated by such a possibility, as will be seen when I analyze Summa Technologiae. In Biology and Value this fascination might have turned against him. ${ }^{88}$

Both essays from the second annex to Dialogues went completely unnoticed. Philosophers of ethics were not interested, understandably, because Lem's

88 In his philosophy of science Lem pays little attention to scientific discourses, paradigms or the entire problematic of the impact of the language of science on its content and methodology. When he was writing his main works such issues were not being discussed. However, it is tempting to say that had Lem become interested in these issues when they became popular, he could have given more precise answers to many of his own questions. 
arguments have nothing to do with the 20th-century philosophical ethics. They had no influence of its further development either. ${ }^{89}$

Dialogues with the annexes are both a complex and heterogeneous structure. The leitmotif is the conviction that cybernetics can be a cure to the ailments of science, and also, something Lem does not say explicitly anywhere, that cybernetics will help build a holistic anthropology that would combine computer science, sociology and genetics. Even then, however, at the early stage of his philosophical development, Lem was too subtle a thinker to believe his own vision without reservations. If Dialogues can be of any interest today, it is because they carry the whole history of a certain illusion - from feisty parades, through harsh combat to capitulation.

As I have mentioned a few times before, Dialogues are the first stage in the development of Lem's philosophical thought. The second stage is Summa Technologiae. Part Two of my book is devoted to this work.

89 In an interview Lem admitted: "I never read anything on ethics, I know nothing about it." (Zbigniew Taranienko, "O biosferyczny parlament świata. Rozmowa ze Stanisławem Lemem," Argumenty, 1970, 38.) Assuming we believe this statement to be true, there would be a mutual lack of interest between Lem and philosophical ethics. 


\title{
Part Two Summa Technologiae - Technology as Lifeworld
}

\author{
Of course, if I knew how to write analytically, starting \\ with dictionaries, I would never have written a single \\ book - everything was just mixing in this terrible brain \\ of mine.
}

From a letter to Michael Kandel, May 8, $1972^{90}$

90 The excerpt refers to The Cyberiad. All quotations from Lem's letters used in this chapter as motto-interludes are from: Stanisław Lem. Listy albo opór materii. Ed. and Introduction by Jerzy Jarzębski (Kraków: WL, 2002). 



\section{Kołakowski’s Review}

In the November 1964 issue of the monthly Twórczość (which was then the most important Polish literary journal), in the regular "Book of the Month" column, there appeared an extensive review of Stanisław Lem's newest work. The work was Summa Technologiae, ${ }^{91}$ and the review was penned by Leszek Kołakowski. ${ }^{92}$ Kołakowski admits in it that he has not been able to evaluate the book properly. He not only emphasizes the remarkable intellectual qualities of the book, but also points out that Lem mixes up science and futurology so completely that

the work ... merges a huge amount of concrete information and observations with fantastic ideas about the future of the world of technology into an indistinguishable alloy; consequently these ideas become as realistic, as if they were merely plans to build a new bridge over the Vistula River, and certainly more realistic than new water filters for Warsaw. (116)

The bold visions for the future presented in ST must have seem grotesque and ill-suited for the realities of the Polish People's Republic, which he ironically expressed in the following sentence:

I think ... that the observations about transgalactic transportation can be useful even in our world, where real technological dreams lead us to imagine that one day people will invent phones that connect between Warsaw and Pruszków [a suburb of Warsaw] without interruption; that one day there will be elevators working without errors for weeks at a time, or a glue that glues things and razor blades that actually shave beards. (117)

But the main target of his criticism was different. The author of what would later become Horroris Metaphysicus held it against the author of Summa Technologiae that he was excessively prone to reduce human metaphysical needs to physiology and cybernetics and he believed firmly in the rational progress of technology. He wrote:

His predictions are guarded with many "maybes" and "ifs". Yet, I do not hesitate to call him a brilliant ideologist of scientist technocracy, that is a person who is convinced that there is no real human problem that cannot be solved with technological means, without assuming, of course, that people will effectively find solutions to everything. (117)

91 In order to avoid the stylistic difficulties of declension of a Latin title, from now on I will mostly abbreviate the title as ST.

92 Leszek Kołakowski, “Informacja i Utopia," Twórczość, no. 11 (1964), 115-123. 
Stanisław Lem would never forget Leszek Kołakowski's this sentence. ${ }^{93}$ In 1991, 27 years after this review, he published an article titled "Trzydzieści lat później”94 [Thirty years later] in Wiedza $i \dot{Z} y c i e$ journal, in which he was extensively showing that "the virtual reality," which was then the fresh and highly publicized achievement of technology, was a faithful fulfillment of his own predictions from ST about phantomatics. ${ }^{95}$ This was exactly the part of ST that Kołakowski considered pure fiction. Lem responded:

Kołakowski censured completely the very core of the predictions contained in Summa, by stating that the reader would have difficulty distinguishing fairy tales from information in it. He did honey the author with some compliments but they went completely sour when he accused me in conclusion of "intending to liquidate" the real of philosophy, and most particularly he blamed me for presuming that one day in the future this realm could be invaded by products of technology. He then broke the camel's back by saying: "Hence one could answer Merleau-Ponty's question about what was left of philosophy after the results of modern science by simply repeating: everything that had been there before." (12)

He then added some quite straightforward allusions about the meanders of his adversary's intellectual development (Kołakowski was enthusiastic about the communist system in Poland in the 1950s) and accused him that he never made the effort to get acquainted with the effects of technological progress, and that "infallibilitas philosophica remained the corner stone of his position" (13). In

93 He produced a replica in a discussion about ST published in Studia Filozoficzne journal, where Lem wrote: "Does the book express a position that could be described as 'apologetic to technology'? I do not think so; I have too many reservations about the mighty forces we have ourselves set in motion. Am I the ideologist of a 'scientistic technocracy'? As much as a person in a dinghy in the middle of the sea can be an ideologist or an avid follower of a faith that states that if they do not make the best possible use of oars, sail and mast, this journey will not end well for them. If I kept repeating in the book that the only cure for technology (its terrible effects) is another technology, it was because I was convinced this is the actual state of affairs; not out of some enthusiasm" (Studia Filozoficzne, no. 2 [1991], 97).

94 Stanisław Lem, “Trzydzieści lat później," Wiedza i Życie, no. 6 (1991), 10-23.

95 A little later in one of the articles in PC Magazine, which were then collected in the volume Tajemnica chińskiego pokoju, he admitted that he had got carried away by the enthusiastic media reports: 'I sinned with triumphalism, because my 'phantomatics' is to the technologies of Virtual Reality what perhaps a new Mercedes model is to a steam-engined three wheeler, built in 1769 by an engineer called N[icolas] J[oseph] Cugnot" (Tajemnica chińskiego pokoju, Kraków: Znak, 1996, 33). 
conclusion of the text, half of which basically consists of excerpts from ST, Lem sums it up as follows:

What then does a philosopher do when preparing a selection of his essays from 30 years earlier? Following the title of the anthology of these reprints Pochwała niekonsekwencji ["Praise of inconsequence"] [which is the title of the collection in which the text about ST was reprinted - PM] he calmly repeats that everything Lem made up about phantomatics back in 1963/64 is sham. (23)

Kołakowski responded in a letter to Wiedza $i \dot{Z} y c i e,{ }^{96}$ in which he wrote, among other things:

Lem states with triumph that - as opposed to all other futurologists - he was the real prophet, because "phantomatics," i.e. creating perfect illusions, came true, while he had been teased when 30 years earlier, rather than a year or two ahead of the time, he accurately predicted the future, and "fame and fortune" do not come to the early prophet, endowed with a special sense to scientifically look into the future, but to the poorer one, who comes on time; well, indeed, sad is the fate of minds too sharp ... (71)

What follows is a polemic with the charge of ignorance about the realm of virtual reality, but in nearly every sentence Kołakowski suggests mockingly that Lem is suffering from an "omitted prophet syndrome." Finally he writes simply:

Lem's resentment leads him even to an observation that "infallibiltas philosophica' remained the corner stone of his [i.e. my] position" - the very absurd view that I have mocked so many times ... he claims that my 1964 review was a barely honeyed criticism; I thought the proportion was reverse; but who could measure that accurately! ... It seems, however, as an author of a review of his book in Times Literary Supplement remarked a few years ago, that he feels hurt that the humankind does not admire him as much as it should. ... Vanitati creatura est subiecta, as the Scripture puts it; vanity is common, but the art of vanity lies in not showing it; it is not difficult - all it takes is a sense of when one becomes absurd. $(72)^{97}$

Great people tend to have great memory and a sharp tongue. I daresay, however, that this conflict may seem pointless, as it is stems from a basic misunderstanding. Kołakowski’s review did not condemn Lem completely, and yet this is all Lem saw in it. The reviewer's torn position was not merely caused by ambivalent impressions, but had roots in the book's inherent qualities. What were they?

96 Leszek Kołakowski, “Lemowi,” Wiedza i Życie, no. 12 (1991), 71-72.

97 An echo of the letter returns in Lem's article "Fantomatyka (II)"; cf. Tajemnice chińskiego pokoju..., 51 . 



\section{What Is "Lem's Essay"?}

Lem's four big discursive works: Dialogues, Summa Technologiae, The Philosophy of Chance and Science Fiction ad Futurology tend to be described by critics as "essays." The term is not quite accurate in so far as a typical essay would not be more than a few dozen pages long, whereas all four of Lem's "essays" are hundreds of pages long, with Science Fiction and Futurology nearing a thousand. They do however fulfill other criteria of essays in the Polish sense of the word: they follow a fairly liberal line of argument and include very limited academic references and tools (i.e., notes and references, bibliography). These features, however, which sometimes work perfectly for a "typical," short essay, can have a very different effect in a text exceeding 700 pages, or even just 300. Such a huge essay, a hybrid form in size and text structure, becomes difficult to grasp and categorize, especially if the author had large aspirations, and the text subject touches on science and both are definitely the case with Lem. Lem uses both the right that authors of informal essays have to construct his argument with a degree of liberty, and the right of a scholar to produce a synthesis of his subject matter. It is particularly troubling for someone trying to analyze ST and to grasp what theses the author is actually striving to prove. The richness of knowledge contained in it and the very peculiar structuring make ST a typical example of "an open text," which can be subjected to divergent interpretations. That's why Kołakowski could find in it a proof of "scientist technology" and Lem could feel offended by it. ${ }^{98}$

Before I undertake my attempt at an analysis of ST, a few words about the title. Kołakowski wrote about it that: "if Aquinas' Summa Theologica were to the heritage of theology what Lem's Summa is to technology, it should contain hypotheses and information about quaternizing trinities, perspectives for cherubinizing humans and about pseudo-pandemonic mercy" (116). Jerzy Jarzębski believes that the title is a sign that God has been replaced by Reason as the principle

98 Another difficulty are the changes that Lem introduced in ST in subsequent editions. My interpretation is based on the 4th amended edition (Lublin: Wydawnictwo Lubelskie, 1984), 352. The quotations and references in English come from the translation by Joanna Zylinska (Minneapolis, London: University of Minnesota Press, 2013). It does not, however, include the afterword "Dwadzieścia lat później” [Twenty years later] which is included in the 4th edition in Polish. Neither includes the original first chapter "Sztuka i technologia" ["Art and technology"], which the author removed from it after the 1st edition. In the subsequent editions Lem would expand on certain chapters. 
ordering the world, "as a power which had agency and is independent from biology, aiming in its evolution in its own uncharted directions." 99 The problem is that for Aquinas God is the only and the absolute principle, and the entire gigantic intellectual structure of Summa Theologica, with its clockwork precision of questions, arguments and counterarguments, is unconditionally subordinate to this one principle. Meanwhile, in ST the Reason has a primary role, as it does throughout Lem's philosophy, but it is not an Absolute and it cannot be in light of the views of the author, who always avoided seeing anything as an Absolute. And when it comes to the formal qualities of the two works: one would be hard pressed to find two texts as different as Aquinas' Summa Theologica and Stanisław Lem's Summa Technologiae, the reasons being the ones I have listed before (rigorous treaty vs. liberties of an informal essay). Therefore, I believe the choice of Lem's title was really determined by aesthetics and ambition rather than any precise idea of analogy.

What is the subject matter of ST, how can it be defined? Or rather, what answer can be given to this question based on the context of the work and author's intentions? If I wanted to outline the historical context for ST, as I did for the Dialogues before, I would need to write a history of the entire 20th-century science, with the history of its first half as the background of Lem's book, and the history of the second - a verification of his predictions. Perhaps it is exactly when analyzing ST that a Lem scholar has the strongest sense of his or her incapacity to handle the task fully and of the task's immense scope; when writing about Lem it is hard not to write about everything. And it is because he writes about everything.

But how does he do it? Only a naive reader could believe that Lem really mustered the entire human knowledge, more than any expert in any discipline. $\mathrm{He}$ has indeed exceeded most of them in creativity of his thought on science and the world in general, but his method of navigating the seas of scientific knowledge is somewhat different from the typical scientific methodology. It could not be otherwise, given that his ambition is to grasp those seas from shore to shore, sail high seas and not just stride along coastlines. In short, Lem's method is to write scientific informal essays. He has amazing knowledge, certainly vaster than most of his contemporaries, but he juxtaposes different elements in a way that is neither scientific nor unscientific. It is something in-between, which translates into the convention of an informal essay causing not small a headache for someone

99 Jerzy Jarzębski, “Summa technologiae i jej potomstwo. Posłowie," in: Stanisław Lem, Summa Technologiae. Dzieła zebrane (Kraków: WL, 2000), 494. 
who strives to interpret him. The latter's level of scientific immersion is usually very different still. Lem is the genius amateur, while a Lem scholar - just an amateur. These three levels of thought raise great problems in categorizing any "lemological" research: they are neither literary criticism, not science studies, but it should combine the best in both. If it could succeed, the interdisciplinary character of this three-level structure (science-Lem's works-research on Lem's works) would undoubtedly yield remarkable results.

The unscientific character of ST can be seen not only in the liberty of arguments (which still form a subtle structure), but also, it would seem, in its main objective. It is an elaborate prediction of how technology and science would develop; it is a type of futurology - but a very peculiar one, as I shall show soon. And predicting future on a scale undertaken by Lem in ST is very foreign to science, which does formulate predictions based on research into the current state of affairs and theory (and some threads of positivism and contemporary philosophy of science assume that this is its main goal), but certainly in a much more limited way.

This is enough at this point about the metaproblems with analyzing ST. It needs to be added that Lem was hardly ever interested in sociology of science and knowledge, or their social context. He was wholeheartedly a scientist, convinced about the absolute independence of science and technology from anything outside their realm. Małgorzata Szpakowska has laid out this quality of his thought very accurately. ${ }^{100}$ Interestingly enough, however, he did see the social context of science in his literary works, especially in His Master's Voice.

100 Dyskusje ze Stanisławem Lemem..., 73-74. There is a sentence about it in ST: "Even though it may seem strange [emphasis mine - PM], there are many contradictory viewpoints with regard to what a scientific theory actually is" (382). Lem put the sentence in one of the notes, not in the main body of text. 



\title{
9 Prolegomena
}

\author{
I have always found human oscillation within the \\ boundaries determined by elementary provisions of little \\ intellectual interest and therefore I was more eager to \\ deal with utterly extreme possibilities (as in S[umma] \\ Techn[ologiae] for instance), without being concerned \\ with how realistic they might be. But then I was never \\ involved in futurology as it is conceived today, which is \\ sort of descriptive, but I preferred being a normativist... \\ and I never claimed otherwise, did I...
}

Letter to an unidentified addressee, September 29, 1972

Yet, Summa Technologiae is a work of futurology, albeit not a typical one. Without a doubt. This is how the author planned it and it can be read from its content and structure. It is sometimes considered to be a project in philosophy of science and technology, and such themes can be traced in it, whenever Lem is pondering on the ontological status of his observations and indulges in methodological digressions. ${ }^{101}$ However, treating ST as belonging entirely to philosophy of science and technology prevents an analysis of other aspects of it, which are much more significant in my view.

The spirit of cybernetics hovers over the entire ST. It needs to be remembered that the book was written at a time of unfading enthusiasm about science. It is particularly clear in chapter 4 ("Intelectronics"), containing predictions on the development of "artificial brains." There, Lem employs conceptual tours and arguments that are close to the ones we saw in Dialogues, including the specter of "cybernetic sociology." It seems that this part of ST stood the test of time the least, as the growth of computers - both technologically and socially ended up going in a completely different direction, which we can see quite clearly today. But even this chapter contains important points that require some scrutiny.

"Futurology," "philosophy of science and technology," "cybernetics." These are the key words in ST. Before I proceed to outlining the general principles of its structure, I need to point out that the first of these terms is particularly

101 Kołakowski identified ST as a work belonging to the field of philosophy of technology, which was, too, refuted by Lem in their dispute. 
important in this chapter. And this is because if the author really intended this work as a prediction, as a set of visions for the future (and Lem states such intention explicitly in many places), then someone venturing to interpret the work has every right to compare this type of prognosis with the current state of affairs. And most of Part Two of my book will be devoted to such a comparison. Going through subsequent chapters of ST, I shall try to show in what ways the notions and predictions formulated by Lem relate to the contemporary state not of science and technology, as I lack competence in that regard, but to the contemporary state of thought about them. And that seems to be an acceptable approach, as ST itself is a type of such thought, and not a handbook or a synthesis. Some of the books Lem published in the 1990s are his own responses to these predictions. ${ }^{102}$ However, he focuses only on the negative consequences of the dynamic progress of technology, discussing them with little interest though, which, one may assume, is a result of his feeling of disappointment that his main idea that should govern the progress of technology - that is, rationality and proportional growth of the potential of technology and ethical pragmatics of its use - did not come true at all.

The central subject that ST circles around, according to the author, is "a slogan which through its associations sounds rather amusing, that is the call to 'catch up to and even overtake Nature." 103 Our species, according to Lem, should go beyond limitations imposed by evolution and physical conditions of growth, but Nature should help with that, suggesting the best solutions. ${ }^{104}$ This is how one could summarize the book, which includes the following passage in one of the initial chapters:

The end of this road does not lie, as some claim, in the "duplication" of the human design or the design of some other living organisms, inside the electrical circuits of digital machines. For now, life's technology is far ahead of us. We have to catch up with it - not to ape its results but to exceed its seemingly unmatched perfection. (25)

102 Cf. Jerzy Jarzębski, "Summa Technologiae i jej potomstwo." This refers mostly to Tajmenica chińskiego pokoju, Bomba megabitowa and Okamgnienie. Numerous remarks about the accuracy of his predictions in ST are scattered throughout Lem's writings starting with the early 1990s.

103 "Discussion [on ST]", Studia Filozoficzne, no. 2 (1995), 95.

104 It is telling that Lem generally ignores one of the basic qualities of the Western culture - that people aim to go beyond Nature through Culture. Instead he proposes a paradox of "going beyond Nature through Nature," the meaning of which will be thoroughly analyzed here. 
It only becomes clear at the end of the book that this is where Lem states his intention according to which ST is to become not only a general prediction for the development of civilization, but also a project of autoevolution of the humankind - the central element of the civilization's growth. This is how - as a utopian project of autoevolution - I will treat ST throughout this book. I am emphasizing it here in order to avoid misunderstandings in the parts that will follow, especially as the main subject of ST is built up with numerous preliminary studies, each requiring a separate analysis. My following chapters will then run parallel to the development of the text of ST, without merely summarizing it, but instead offering an extensive commentary, which will be concluded with an attempt to synthesize the meaning of this complex work. Then, in Part Three, I shall try to contextualize Lem's project of autoevolution with broad reference to contemporary intellectual tendencies.

A peculiar quality of Lem's style in ST needs to be pointed out here. Words such as "Nature," "Machine," "Reason," 105 "Designer," "Science," "Culture" appear on nearly every page, usually capitalized. For Lem they are the fundamental notions around which he weaves his entire discourse, and not only in ST. But they are not explained anywhere. Lem does not provide precise definitions of them (with the exception of a relatively precise definition of "Machine" at the beginning of the fifth chapter), but he does often contextualize them. They are not scientific terms then, but metaphors rather, figures, which Lem uses to map out the scope of his thought. They are indefinable, probably partly because he sees them all as self-evident, and partly because these are his primary notions. It resembles some old philosophical systems with their fundamental concepts such as "God," "being," "spirit" - to the explanation of which a whole system would be devoted, while they themselves were to guarantee its coherence by marking the very core of reality, "the transcendental signified." In that sense, Lem is closer to the tradition of the Western metaphysics than he is to "the ideology of scientist technocracy" - assuming we do not treat the latter as a type of metaphysics as well (and what would an absolutization of Reason and Nature be?).

105 In the English translation of ST, Joanna Zylinska chose to translate the Polish word "Rozum" as "Intelligence," which has some merit, but it seems that the connotations related to the Enlightenment are more pertinent in this case, so the word "Reason" would be more accurate here. I leave Zylinska's translations unchanged in that regard, but translate "Rozum" and "Reason" whenever the author references the term outside quotations (Olga Kaczmarek). 
ST was not analyzed more often than Dialogues - hundreds of phrases such as "personoclastic cerebromatization," 106 would scare off humanists, while scientists would be put off by the bold "fantastic" prediction and the "vagueness" of an informal essay. In the few interpretations that have been published, ST was mostly seen - if not simply as glorifying science and technology, then at least as an important stage in thinking about them. ${ }^{107}$ The reviewers did notice that in ST Lem was in fact modifying the meaning of those notions as they were known before. It was only Małgorzata Szpakowska and Jerzy Jarzębski who, starting in the late 1980s, began to notice that Lem was in fact subverting the very distinction between what is scientific and what is not, and what is natural or artificial. However, these two most eminent Polish Lem scholars differ radically in their interpretation of the fact. In her Dyskusje..., Szpakowska wrote: "Lem is convinced about the continuity between the behavior of human as a biological creature and human technological efforts mediated through conscious actions" (66). And immediately after: "From the point of view of an individual human subject technoevolution is something external, independent and unavoidable, as bioevolution is for an individual creature, which at best is capable of looking for the best tactic in struggle for survival." For Szpakowska, technoevolution, just as most other themes in Lem's discursive works (as opposed to his fictions), has no metaphysical connotations. Jarzębski has a radically different approach and he devoted a lot more attention to neutralizing the Natural/Artificial distinction. In the article Naturalne, sztuczne i dziura w kosmosie ["The Natural, the Artificial and a Hole in the Universe"], ${ }^{108}$ he claims obliterating this distinction in Lem's thought correlates with the anxiety about the superior meaning of human existence in the Universe, and the notion of Reason is a factor that can help dispel this anxiety.

106 On page 217. It means a mechanical, invasive transformation of human brain, which irrevocably changes the personality of the person subjected to this procedure. The notion appears in the context of social engineering.

107 Kołakowski, "Lemowi," Studia Filozoficzne, no. 2 (1965). Apart from that one, four Polish editions inspired altogether twelve press reviews (based on relevant volumes of the annual Polish Literary Bibliography). The 1st edition (Kraków: WL, 1964, 470) - 6 reviews; the 2nd amended edition (Kraków: WL, 1967, 97) - 2 reviews; 3rd edition (Kraków: WL, 1974, 505) - 2 reviews; 4th amended edition (Lublin: Wydawnictwo Lubelskie, 1984, 352) - 2 reviews. So far ST has been translated to Russian (1968), Hungarian (1972, 1977), Serbo-Croation (1977), German (1974, reprinted in 1978, 1980, 1981, 1986), Latvian (1987), Czech (1995) and English (2013).

108 Jerzy Jarzębski, Wszechświat Lema..., 278-297. 
Lem's writing shows that there is no way out of this dilemma [of desiring meaning in a meaningless world - PM]. Perhaps then there is faith in the existence of transcendence not a religious one, but rather a philosophical one: as the space where the laws of our evolution are rooted (perhaps by some kind of superior consciousness) and hence their impersonal and unconditional character is redeemed. This is also where Reason can escape the trap of a closed universe with its antinomies. (297)

According to Jarzębski in Lem's works Reason:

becomes only something like a passenger, who temporarily settles inside the body of the evolving humankind in order to use this habitat to its biological limit and make a leap into another reality, move into the environment of increasingly complex machines. Once it mounts mechanisms, Reason will likely again exploit their potential to the limit in order to then move onto another horse - and so on. ${ }^{109}$

This type of Hegelian vision of Reason seems to me to be too far-fetched a hypostasis, as Lem probably never accepted Reason as an entity with such a degree of ontological independence. I believe it would be too "metaphysical" a leap for an author who usually avoided any metaphysics. On the other hand though Jarzębski's view corresponds well with his interpretation of the title of ST.

Jarzębski also points to the themes in Lem's fiction that refer to lifting the opposition between the Natural and the Artificial. It is one of the subjects of Observation on the Spot - the lifting of this distinction surfaces there as the ethicsphere of Entia, permeated with microscopic particles, "quickies," which make it impossible for Entians to commit acts that are forbidden by their law or harmful to others. Jarzębski writes: "It is about bringing the designer's work to a level where differentiating between the artificial and the natural would no longer be possible, and hence the very matter itself (to a certain degree) - 'the laws of nature' - would fall into the scope of engineer's skills... The very idea of obliterating the differences between the artificial and the natural becomes important here and it triumphs. As a result the entire universe becomes an arena of technological mechanisms and is (potentially) permeated by rational will." ${ }^{110}$ Jarzębski also points out that countercultural movements in the second half of the 20th century opposed just such a model of the world: "A human surrounded with technological devices, enhanced through them and enriched by them, is no longer the same human as before. So this modification could be rejected." ${ }^{111}$ It

109 "Literackie przygody uniwersalnego Rozumu," in: Wszechświat Lema..., 143; see also further on page 144 and following.

110 “Kosmogonia i konsolacja”..., 97, 98.

111 "Literackie przygody uniwersalnego Rozumu”..., 164. 
turns out, however, as I shall try to show, that in the context of Lem's thought on technology such arguments lose meaning.

Now, in the 21st century, this destruction of scientist and positivist oppositions becomes clearer and clearer. Let us read the author's words more closely:

We shall also, by way of speculation, consider the domains in which man's enhanced activity of this kind will match Nature's work. Even then will man remain subject to limitations, the material aspect of which - conditioned, as they will be by the technology of the future - we cannot predict, but the psychological effects of which we can at least partially grasp because we are ourselves human. The thread of such understanding will only be broken when man, in a thousand or a million years' time, gives up his entire animal heritage, his imperfect and impermanent body, for the sake of a more perfect design, and when he turns into a being so much higher than us that it will become alien to us. Our preview of the future will thus have to stop at sketching out the beginnings of this autoevolution of the species. (40)

Lem "outlines the beginnings of autoevolution of the species" on the hundreds of pages of ST that follow. The analysis leads again, as in Dialogues, on a high level of abstraction, carefully avoiding any specifics. Jerzy Jarzębski mentions that he was surprised by the lack of descriptions of everyday life of the people of the future. ${ }^{112}$ Lem does not include them because he knows it is easier to predict the general progress of civilization than the details of it, and moreover one can presume he has little interest for the everyday of the future. He is interested in thorough transformations of human world, global or even cosmic changes - and not what we would eat and how we would spend our free time. He described it in his novels (most broadly in Return from the Stars - and he considered this the poorest of his novels). The everyday life of normal people seems repulsive to Lem, which can be confirmed by his disgust with contemporary technology, stemming to an extent from it having become "common," from computers descending from the highs of science to business and pop culture, which started with the introduction of personal computers, and intensified with culture 2.0.

The "absence of the everyday," which was so astonishing to Jarzębski, is a symptom of a more general "absence" or "lack" in ST. Lem is hardly interested with general social processes at all there - on any level. He almost does not mention the question of the influence of the great technological changes, which he describes passionately in the book, on the social, cultural and political life. There are only a few remarks about social cybernetics in ST, a faint echo of the subject extensively treated in Dialogues, and a very limited analysis of psychological and social consequences of phantomatics. ST is suspended in "social vacuum." Here it is interestingly

112 “Summa technologiae i jej potomstwo"..., 483-494. 
different from the contemporary philosophy of technology, which mostly focuses on rationality of the technological progress in the social context and on the human responsibility for this progress and its impact on the habitable zone and future generations. ${ }^{113}$ It is easy to explain Lem's perspective in ST. First, and that is an accidental reason, hoping to predict the social development, he would immediately end up in conflict with the contemporary political ideology, risking, at best, censorship, and in the worst case scenario - putting the entire ST to rest. Second, and this is a much sounder reason intellectually, Lem probably decided that predicting technological and scientific changes, while risky, can still be sensible, as the range of these changes is somehow conditioned by the laws of physics, mathematics and logic, whereas any prediction about social changes (even if they are related to the former) is completely random, as the development of society and culture cannot be contained by any rules or any theoretical model - so one can predict anything there. ${ }^{114}$ Omitting the domain of social communication has a huge unwarranted impact on the whole of Lem's project of future civilization, as it practically prevents any thought on culture - if culture is to be understood as a correlate and center of this communication. Therefore, the entire issue of human autoevolution, which is the subject of ST, is located beyond culture and beyond the sphere of the social.

In the interpretation of Summa Technologiae, which I present on the following pages, I describe "technology as life world" - Lebenswelt. This concept, derived from phenomenology, described well the function of technology in the future civilization, both according to Lem, and according to the numerous contemporary theoreticians, whose views will be discussed here. Technology and its products have been taking over the world of our experience since at least the beginning of the 20th century. Most of the contemporary cultural studies is focused on the consequences of the "real" world being mediated by its technological replicas and representations. ST is also analyzed here as an original attempt to grasp this process of takeover and its possible implications.

113 In the notes to ST following sentences: can be found "All of this does not, of course, amount to suggesting an equivalence between man and any material object to be constructed or any technical product to be improved. The aura of moral responsibility must envelop the field of bioconstructionism - which is an area of great risk (but also perhaps of equally great hope)" (321). These sentences remain unrelated to the whole of the book though.

114 If that supposition is correct, it means that while writing ST, Lem had to give up his conviction about the possibility of cybernetically regulating the social system, which he widely promoted in Dialogues. Hence, the sparsity of remarks on the subject in ST. See also the next note. 



\title{
10 Evolutions
}

\begin{abstract}
Nihilism? In my books? There might be something to it, you may be in on a secret here. I would call it - futility... it is careful about the décor, which denies it on the surface. Saying terrible things, quite innocently, as if in play...
\end{abstract}

Letter to Michael Kandel, July 1, 1972

ST starts with a description of analogy between two evolutions: biological and technological. ${ }^{115}$ Listing similarities and differences between them, Lem suggests that the Designer - the symbolic figure personifying the human technological potential - should consciously replicate the solutions unconsciously applied by Evolution. In ST the differences stemming from the targeted character of conscious actions of a temporal Designer and the undirected, impersonal process of Evolution lasting billions of years are subjected to a very detailed analysis. I am interested in something else though. The 19th- and 20th-century science, affected by the myth of the omnipotent non-Natural Reason, separated so much from its capacity to adopt bioevolutionary solutions in technology that the occasional suppositions about, for example, the perfection of spider nets (perfection from the point of view of human technological needs) were formulated as surprising and remarkable. More or less when Lem was writing ST, the theme of "peeking on nature" appeared in scientific and popularizing discourse. Its initially modest impact was a result of prevalence of the type of thinking, which prevented forming any kind of connections between Technology and Nature.

115 Małgorzata Szpakowska adds another one - evolution of culture, discussed in The Philosophy of Chance and Science Fiction and Futurology. From the point of view of this work that juxtaposition is not coherent, as ST does not discuss culture at all. Culture is not a part of the concept of autoevolution as Lem understands it. But autoevolution can be interpreted in cultural terms and this is what I will be interested in. Szpakowska makes one important remark: “in Stanisław Lem’s views two notions play a key role: evolution and accident" (Dyskusje..., 54). Dialogues and ST - both devoted to technology and science - are governed by the former of the two concepts, while The Philosophy of Chance and Science Fiction and Futurology devoted to culture - are subordinate to the latter. This would mean that in the later stage of his philosophical development, Lem decided statistics is the model of cultural reality that none of the other fields of mathematics and natural sciences could provide. 
Cybernetics, the history of which was outlined in the previous part, was one of the first attempts at a methodological synthesis of Nature and Technology. Before that these were two separate worlds, between which there was Science, studying Nature, on the one hand, and providing theories as bases for growth of Technology, on the other. ${ }^{116}$ This would be called "stealing Nature's secrets" - of course in order to discover the truth about the world and subject it to humans, but not to use the rules of Nature in the products of Technology. When the Wright brothers were designing the first airplane, they did not connect the design of wings with an analysis of the dynamics of bird flight. When radar was invented, it was not associated with bats in any way. Positivism and scientism contributed greatly to solidifying this distinction. Even though the same laws of physics and chemistry describe the functioning of living organisms and technical machines, since La Mettrie no one ever thought that these two worlds could be linked with ties other than theoretical. This is when a distinction between an invention and a discovery became popular - the distinction which, I should emphasize strongly, has nearly lost its meaning, at least within the domain of biotechnology, but also in sciences such as molecular physics, where the objects of observation and discoveries are mostly constructed theoretically. The emergence of this distinction was of course connected to the model of man, popularized by the Enlightenment, as a creature independent from Nature, and endowed with a Reason independent from Nature. The remains of the Christian view of Man as the lord of creation went even deeper. In the 19th century in the collective imagination, shaped by the early mass media, "a discovery" was associated with an image of a fearless white pioneer, fighting his way through a wild jungle or an ice desert, whereas "an invention" would convey an image of an engineer or a scholar, working in the quiet of his studio or in an orderly lab. In the late 19th and early 20th century such figures of collective imagination included Henry Morton Stanley, Edward Peary or Nils Nordenskjöld as discoverers, and Thomas Alva Edison and the Wright brothers as inventors. ${ }^{117}$ They were presented as heroes of civilization, inspired by the project of progress and growth, which determined the shape of collective imagination of the Western civilization between the end of the 18th century and the first half of the 20th century. The epoch preferred discoveries and inventions that would bring immediate benefits to the society at large or that would strengthen the

116 This generalization does not refer to the group of great discoverers and inventors without formal education (the most famous among them being Faraday and Edison).

117 Pasteur takes a middle position in such a typology as a discoverer working in a lab. 
position of the European biggest political powers (the impact of the British imperialism on the dynamics of exploration in Africa cannot be overestimated). Perhaps this is the reason why the 19th-century discoverers of the fundamental laws of nature, such as Dmitri Mendeleev, never became great heroes of mass imagination. It was only changed by the discoveries made by Roentgen, and Skłodowska-Curie, who attracted large "media" attention. The fact that Albert Einstein became a pop icon has its roots in a completely different cultural context, and mostly in the processes of mass culture.

The revolutionary character of Lem's thought is becoming more readily apparent, I believe. Despite the metaphorical vagueness of the analogy between two types of evolution, the heuristic potential of the juxtaposition was huge. It was nothing less than questioning the very distinction between the Natural and the Artificial, Nature and Technology, discovery and invention - and the questioning was coming just when these oppositions seemed completely undoubtable. Lem rejects them - and the entire Summa Technologiae is built on this refutation. ${ }^{118}$

The thesis that bioevolution and technoevolution run parallel may imply that Lem is continuing the old Spencerian evolutionism. This would be utterly wrong though. Lem never used this metaphor to describe the structure and functioning of the society, which, as we remember, he preferred to describe in terms of cybernetics. His terminology might be vague, but he never adopts narrowly defined biological terms to science. And above all evolutionary metaphors are not related to progress and teleological growth in his thought - neither in biology, nor in technology. He never claims that autoevolution is the most perfect form of being, but only that it is an inevitable consequence of how humankind has been developing so far. If one wanted to look for fathers of this type of thinking, creatively combining biology and science, one should point to Sir D'Arcy Wentworth Thompson (1860-1948). The British mathematician, biologist and classicist is the author of a monumental work On Growth and Form (1st edition 1917, 2nd edition 1942), where, in a nearly Pythagorean manner, he describes, how the laws of physics and mathematics determine the morphogenesis and ontogenesis of living creatures. ${ }^{119} \mathrm{He}$ answers such questions as (and who does not ask

118 Jacques Monod also proposed rejecting the opposition between the natural and the artificial in his famous 1970 book Le Hasard et la Nécessité (Paris: Seuil, 1970, 17-18).

119 Thompson's thought remains outside the mainstream evolutionary biology, but the most eminent representatives of the discipline speak about him with highest regard. In his foreword to an abbreviated edition of On growth and Form (Cambridge: Cambridge University Press, 1992, XXII+346), Stephen Jay Gould emphasizes the extraordinary erudition presented by Thompson, who quotes Leonardo da Vinci and Dante in the 
themselves that?): why the spirals on snail shells are so precisely drawn or where does the shape of pelvic bone come from in mammals. ${ }^{120}$ Lem never mentions Thompson's name, but there are many passages in ST that resemble his style, when Lem discusses the impact of the shape of our body, or - on a lower level of the cell metabolism, on our life and technology; and all this, as Lem does not fail to emphasize, depends on external physical conditions. Both authors are not only characterized by interdisciplinary thinking and a certain intellectual gigantism, but also enjoyed little popularity with their contemporaries and for the same reasons: Oxford humanists thought Thompson was a renegade (as he occupied himself with the unworthy field of biology!), while biologists and mathematicians took him for an odd amateur (he was the author of Glossary of Greek Birds, which combined philology with ornithology). Thompson's intellectual biography could be an inspiration to think about the problem of "two cultures" - and we should remember both the term and all its consequences were originally born at British universities. Perhaps Lem's intellectual biography could be an incentive to understand changes within "the third culture" better. ${ }^{121}$

first sentence of his work. It is telling that Gould - shaped by the paradigm of specialized science - is amazed by the "renaissance" quality of Thompson's thought.

120 Turing's works on morphogenesis was in some ways inspired by Thompson's views. In the recent years Thompson's way of thinking about nature has been returning in the ideas of Stephen Wolfram or Adrian Bejan, who build general models of mechanisms structuring complex biological forms basing them on contemporary laws of mathematical physics.

121 This is the term used to describe the shift of culturally creative functions from the humanities to natural sciences, which has been popularized since the early 1990s, mostly by American scholars. Cf. The Third Culture, ed. by J. Brockman (New York: Simon \& Schuster, 1995). 


\section{Taking UFO Seriously}

The first problem Lem discusses in ST after the initial chapter about "two evolutions" is the existence of two civilizations in the universe. For a contemporary reader this may be somewhat surprising and an argument for a view that Lem is only a sci-fi author. However, beginning ST with this subject is a very conscious and justified move. It needs to be remembered that in the 1960s the question of extraterrestrial intelligent forms of life was raised by serious scholars. ${ }^{122}$ This is the time of the vast SETI program (Search for Extraterrestrial Intelligence), all of which that was left 20 years later was E.T. in Spielberg's blockbuster. In Soviet Byurakan an international symposium on extraterrestrial life was held, and Lem was an active participant. A study of contemporary writings on the subject could help determine the borders between the scientific treatment of the issue and the popular media news about unidentified flying object (UFO). ${ }^{123}$ In the 1970s the complete lack of positive results of the search for signals from other intelligent creatures (the so-called Silencium Universi) led to decreasing interest

122 Including especially Carl Sagan (1934-1996), Francis Crick (1916-2004) and Sir Fred Hoyle (1915-2001).

123 Ufology and the concept of ancient astronauts (i.e., that aliens were actively involved in the emergence of ancient cultures and civilizations) merit a careful analysis as parascientific discourses. Reading the writings in the field (especially the works of Erich von Daeniken) shows complex functioning of elements of language and scientific methodology. In short it can be said that the authors of such works reject the authority of "the officially accepted science," but they employ its tools (or, strictly speaking, their simplified copies) to build their own theses in order to paradoxically add to their authority, based on "scientific precision." Such authors are usually unaware of the paradox and the fact that their arguments notoriously violate the most basic principles of scientific thinking (including the principle of reproducibility of experiments). Lem often emphasizes that science cannot deal with one-time phenomena (in ST he writes about it in the chapter "Extrasensory Phenomena," 354358). A more thorough analysis of ufological texts would require a separate study. Many have criticized ufology and the concept of ancient astronauts (cf., e.g.: Wiktor Stoczkowski, Des hommes, des dieux et des extraterrestres. Ethnologie d'une croyance moderne [Paris: Flammarion, 1999]). A psychoanalytic take on the UFO phenomenon can be found in Carl Gustav Jung's essay Flying Saucers: A Modern Myth of Things Seen in the Skies. So far, however, there have been no analyses (at least not in Poland) of the language of the discourse on ufology and ancient aliens that would approach the subject in the way I suggest in this note. 
in the issue among scientists and eventually its shift into the mass culture, where it has flourished ever since, for example, in the X-Files series. ${ }^{124}$ The Silencium Universi is a serious problem in itself, but philosophical rather than scientific. It inspired Lem, both in ST and elsewhere, to think about whether potential intelligent aliens could be intentionally concealing their presence in the Universe. ${ }^{125}$

This would be reason enough for Lem to treat the problem of extraterrestrial civilizations as a pertinent one. Moreover, the problem has its justified place within the structure of ST. Lem starts with a premise that if he is to predict the development of our civilization, he first has to compare it with other civilizations. Or it should be done - but we know no other. From this lack Lem derives conclusions about what he believes the hypothetical civilizations have to be like. Rejecting the famous hypothesis formulated by von Hoerner about common self-destructive tendencies among cosmic civilizations, ${ }^{126}$ Lem points out that "the Intelligence we shall discover one day will possibly be so different from our ideas of it that we shall not even want to call it Intelligence" (68-69). This is a recurring theme of many of his novels, especially Solaris, His Master's Voice and The Invincible: man is trapped in the solipsism of his own thinking and perception, and he can only feel it, when faced with an alien intelligence. Other forms of life may be too different for us to start a contact and understand their thinking - just as we cannot grasp how animals see the world ${ }^{127}$ (although Lem fails to see the analogy), or even the details of other people's consciousness, especially if they are removed from us in time and space, or belong to other cultures. Of course, when it comes to contact with Aliens these differences would have been much bigger and more intense.

This is the chapter when for the first time in ST there is a suggestion that intelligent forms of life may not only transform their environment to adopt it to their

124 The SETI program is still in operation though and it is dynamic, as can be seen on its rich website: http://setiathome.ssl.berkeley.edu/. Many personal computers connected to the Internet also analyze the radio data. In the 1990s both NASA and its European counterpart European Space Agency (ESA) renewed their interest in the subject, now as "astrobiology," which does not look for intelligent forms of life but for bacteria.

125 Cf. especially The New Cosmogony in: A Perfect Vacuum.

126 It is the time of the most intense arms race. Von Hoerner's hypothesis, which was formulated to explain Silencium Universi, assumes that every or nearly every civilization destroys itself once it reaches the technological stage - and therefore it never has enough time to broadcast signals of its existence into the universe.

127 Cf. Thomas Nagel, "What Is It Like To Be a Bat?," in: Mortal Questions (Cambridge: Cambridge University Press, 1979). 
needs, but they can also take up the task of transforming themselves through autoevolution (70-71). In such a case observing the traces of such creatures would be even more difficult for us, people. We are used to Reason, meaning "a heroic attack on surrounding matter" (70). But this, as I wrote before, is a positivist conviction. We can already see that autoevolution as conceived by Lem renders the opposition of the artificial and the natural meaningless. Looking for traces of intelligent life in the universe, we are looking for the type of transformations in Nature, which could be seen as a result of intentional acts of Reason (e.g., radio signals, which could not have been produced "naturally"). How are we convinced about such distinctions though, Lem asks? How do we know what is Nature and what is an effect of intentional action? Those distinctions are merely a result of the biological and later historical development of our species. Perhaps what we take to be nature is a product of some intelligent Designer. Such a view, once described as theism, known in modern physics in certain types of anthropic principle, and surfacing in ideological debates in the simplified form of "theory of intelligent design" is formulated by Lem in one of his fake reviews in A Perfect Vacuum, in New Cosmogony. Unconstrained by the seriousness of the essay form or a discursive text, he expresses a view that laws of physics are rules of a game played by great civilizations. Whether in its extreme form, or as old theism, or even the moderate versions to be found in ST - the thesis is clear: the distinction between Nature and Artificiality loses its meaning when we start asking for its criteria. If living creatures - humans or aliens - subject their own bodies to the kind of transformative practices to which they subject their environment, "the nature" and "the artificial" distinction becomes null. Why?

Once again I return to the distinction between "a discovery" and "an invention." You can only "discover something" that existed before that, independently from its discoverer; "invention" is an act of creating something that did not exist in real life before. Uranus the planet certainly had existed before Herschel discovered it. A phonograph had certainly never existed before Edison built it. However, these common sense notions become more complicated in the discourse of the Natural and the Artificial. One could assume that the distinction has something to do with one of the fundamental qualities of the Western thought - its focus on the subject. The distinction between the subject - "I" - and the external world, which serves as the field of perception and activity of the subject but materially independent from it, has been in our thinking at least since Descartes. The body is the link between the "I" and the world - this will become very important for my analysis of posthumanism in the later part of the book. This sharp distinction is the reason why people of the West have had such trouble understanding Indian philosophical systems, for example, as they do not have a 
concept of an individual subject cognizing the world as external to it. The impact of the post-Cartesian philosophy of the subject is significant but a detailed analysis would be unnecessarily subtle for the purpose of this work. Here it is enough to suggest that the post-Cartesian subjectivity became the foundation of distinctions that I am describing here: the artificial, creativity and invention have been located on the side of the "I," whereas the natural, transformation and discovery are all on the side of the world. ${ }^{128}$ It seems pertinent to remark that the philosophical romanticism strived to overcome these distinctions as early as the first half of the 19th century, but it had no practical impact on the hegemony of the enlightenment and positivism within the social praxis. Our time on the other hand really did bring a breakthrough in that regard. I want to show that ST is in fact a harbinger of this breakthrough, and in Part Three of this book I will try to prove that currently we are witnessing it actually happening, with utopian vision of further changes in that direction becoming intellectually available as well. "Autoevolution" is the key term here. The way Lem understands it means transplanting the category of "transformation" into the sphere of the subject. The subject (or, as Lem calls it, the Designer) begins to apply strategies to itself to its own body - that were only applied to the external world before. And this, let me emphasize again, effectively obliterates the differences between the Natural and the Artificial, a discovery and an invention.

Of course, the concept of autoevolution needs to be thoroughly discussed and I shall do that in Part Three. Its understanding depends on technological solutions but largely also on the way the world is conceived of. It is closely linked with the notion of the body as well. That is why I will need to refer to phenomenology and gender studies, for example.

Writing about the question of extraterrestrial life as Lem saw it, one has to mention one more thing, or in fact one more fundamental philosophical problem related to progress in science and technology, which Lem writes about in ST. Up until the 20th century there had been no issue of the limits to human knowledge because human knowledge could grasp only the immediate human surroundings, a limited scope from the perspective of the universe: planet Earth, its solar system and what is contained within it. It could be said that the scope of scientific research was limited to the Lebenswelt. But in the 20th century it changed rapidly with the dynamic progress in physics and astronomy, which produced the theory of relativity and quantum mechanics and cosmology, leading to the

128 For a somewhat different approach to the same problem, cf. Jerzy Jarzębski, Wszechświat Lema..., 279-280. 
burning question of the relationship between the cognized world and the perceptive tools and capacities. Theories and disciplines mentioned in the previous sentence have become deeply unintuitive. History of science tells us that their authors were in fact astonished by the results they reached - as exemplified in the many years of discussion between Einstein and Bohr about interpreting quantum mechanics or Einstein's saying, repeated ad nauseam by scholars: Raffiniert ist der Herrgott, aber boshaft ist Er nicht. ["Subtle is the Lord, but He is not malicious"]. ${ }^{129}$ It means that even though the laws of Nature are extremely hard to grasp and discover for a human mind, the world is ultimately knowable. (This is exactly what Wiener claims when he writes about the "Augustinian" vision of the world.) The developments in science in the second half of the 20th century have put that claim into question. ${ }^{130}$ Lem phrases the problem as follows: can people as creatures shaped through evolutionary biology, so with a brain and senses which are primarily supposed to help them survive in the physical conditions of planet Earth - use the ultimately fairly random sensorium to really discover and understand all the laws of the world, both in micro- and macroscale? To put it both shortly and loftily: can our brain encompass the universe? Lem claims it cannot, as the biological and evolutionary heritage of our species limits us to a narrow scope of time and space. The fact that we can in no way represent sensually either the world of elementary particles, or the grand scale of the structure of the universe speaks in favor of that thesis. On the other hand though, the fact that we have been able to figure out the existence of these two levels of being based solely on abstract reasonings and that this knowledge is coherent, with slight incoherencies in its very basics (if "only" is the right word here) - this very fact shows that the human mind does have surprisingly large capacities. The knowledge we have about processes within the atomic nucleus or the dynamics of galaxy clusters is useless from the point of view of evolution (unless we treat building nuclear power plants as an element of a strategy of acquiring energy for the purpose of efficient survival, but even the most radical sociobiologists

129 The sentence appears in ST (173) in English as "God is sophisticated, but he is not malicious."

130 In Dyskusje..., Małgorzata Szpakowska quotes a sentence from Fritjof Capra: "in the 20th century for the first time the human capacity to understand the universe has been put into question;" and comments: "Lem does not draw such radical conclusions; the very thought that the world could turn out to be essentially un-understandable is completely foreign to him" (68). In this chapter I claim it is quite the opposite: in ST, Lem does admit such a possibility and this is the cause of one of the important aporiae in the structure of the work. 
do not go that far). And yet - we reached it. It can be a sign of a huge excessive potential of our brains that the evolution gave us - and this is how it is generally interpreted, and Lem shares the view. Our main problem is we shall never be able to understand the limits of this knowledge. It is as if Pascal and Wittgenstein shook hands: the former with his sentence about the eternal silence of these infinite spaces; the latter with the thesis about the eye that cannot see itself. It is a paradox - one of many in Lem's thinking - that when the human brain reaches a level of abstraction so extreme, that the senses have long stayed behind, suddenly the biological heritage intervenes with great force to remind us that we did not appear in this world for the purpose of learning the First Principles.

We can certainly surprise ourselves. One of the last sentences Comte, the father of positivism, uttered before his death is a telling testimony to that: he said man would never learn the chemical structure of stars. How ironic that only two years later (1859) Bunsen and Kirchhoff built the first spectroscope. The very existence of culture, art, religion, philosophy and literature is undoubtedly a miracle of sorts in that context. Stanisław Lem was aware of that. But in his own thinking, both in ST and elsewhere, he always reminds us where we come from. Many would rather forget the inglorious roots. As we shall see soon, Stanisław Lem has something special to offer to them as well.

The universe does not help us in our musings on our future, but we can speculate using arguments ex silentium and ex nihilo. This is how chapter three of ST concludes. Then, Lem returns to Earth to deal with Homo sapiens as a species. It is pertinent to quote his own self-commentary in a discussion published in Studia Filozoficzne. There he speaks about some of the implicit anthropological premises made in ST:

it is possible to equate the products of man with products of Nature in their efficiency, reliability, durability, universality, etc. It is also possible to try and differentiate between stages of such rivalry; it would have to start with the stage of regulation, i.e. of optimalizing stages of what is, or what is given (society, our brain, our body); the second stage would be that of creation (involving a transition from what is given to creating new solutions). (95)

The distinction is not kept everywhere in ST, but chapter four, which I will discuss shortly, does describe some improvements in the external reality of human life - the transition to the actual autoevolution will come later. Lem also expresses his view on human nature at that time, which is very important for our understanding of his intellectual route. Despite his self-proclaimed "skepticism" (Studia Filozoficzne..., 96), he is in fact still close to the unconditional optimism of Dialogues: 
The book [ST] assumes a certain kind of human and a certain kind of culture - "maximally rational." It is premised on a historical development that will make this kind of human and culture more prevalent, more and more universal. That is the optimism which can be found in Summa. Without that direction of cultural development there would be no optimalization in actions, nor any rationality of efforts, nor the highest pace of growth or the best choice - to everyone's benefit - among many possibilities.

Those premises have not been explicitly articulated - they can be read between the lines. Societies and individuals, which we know from history behave so splendidly only very rarely. My book turns these exceptions into a norm. It is a bold move, but I believe it is not entirely utopian. $(97-98)^{131}$

131 The utopian character of Lem's predictions and projects will be analyzed in the next part of this book. 



\section{Turing Body}

The title of the fourth chapter is "Intelectronics," but one would be disappointed looking for the history of microprocessors (Intel company was established 4 years after the first edition of ST). Instead it is a compound of "intelligent electronics" (the founders of Intel were probably working with the same idea). This is the chapter that most clearly continues the themes from Dialogues. Lem writes a lot about "intelligence amplifiers" (e.g., 93-96; the idea comes from Ashby) and the projects of "a radical restructuring of science as a system that acquires and transmits information" (86). The restructuring is forced by the "megabyte bomb" (81-85), that is, the exponential increase of knowledge, which no one can grasp, not only as a whole (it is no point even dreaming about it anymore, as Lem points out often and with regret), but even within one discipline.

The restructuring of science is to be made possible by the creation of cybernetic systems (we would say computer systems today): systems of acquiring, selecting and distributing information. Such systems, which for Lem are the first stage of technology of "information farming," have not been created yet, although the existing algorithms for searching information on the Internet, which are constantly being improved, are getting closer to this vision. The ideas of machines that are transformers of knowledge again include Lem's utopian belief in the rationality of technology and its products. One can imagine how disappointed he must have been with the early Internet with its practically infinite space of chaotic information that did not become knowledge (i.e., an ordered structure). The increase in knowledge is gaining pace, and if Lem was anxious about the amount of it half a century ago, the situation is certainly far more dramatic now. ${ }^{132}$ The so-called Lem's law is partially true then; he formulated it in one of his columns in the 1990s: (1) No one reads. (2) If someone reads, they do not understand anything. (3) If they understand, they forget immediately. I bring up this aphorism not as an element of my analysis of Lem's discourse, but to demonstrate, how bitter and disillusioned he was at the end of his life.

132 In his later novel, Wizja lokalna ["Observation on the Spot”], there is an extensive description of "ignorantics" and "ariadnology" - disciplines devoted solely to determining the level of ignorance (stemming from excess of information, and not from epistemological limitations) and methods of finding information in a nearly infinite set. Even in the description of solaristics in Solaris there are similar themes. 
The functioning of "intelligence amplifiers," Lem says, will inevitably become incomprehensible for people from a certain level of complexity. It is a consequence of their purpose: to process the amounts of information that humans can no longer process. Lem uses the notion of "a black box" here, as known in behaviorist psychology. He points out that we should not be worried that we will not understand the rules and functioning of such a machine, because our brain is a similar "black box." We do not know the precise mechanism behind it, as the "self-referentiality" of the brain would not have any use in the evolution process (99). ${ }^{133}$ "The uniqueness of the cybernetic solution, whereby a machine is completely alienated from the domain of human knowledge, has actually already been used by Nature for a long time now" (99). We can now observe the "uniqueness" on everyday basis, working on our computers, tablets and smartphones no one other than IT and electronics experts can ever understand the rules of how these devices work. They are nearly what Lem meant as "black boxes," but they are not "intelligence amplifiers."

At this point I find myself dangerously close to the old fear of "machines smarter than humans," "breaking free" from our power and becoming unpredictable. Such a view is of little interest to Lem though, as he is too attached to humanism, to the motif of the sorcerer's apprentice and such other ideas. (The motif itself is actually quite fascinating and I will return to it when discussing posthumanism.) That does not mean, however, that Lem never asks about the consequences of "the black box" for the social practice, only limiting himself to epistemological problems.

For Lem intelectronics is not primarily a way to build "smarter machines" or "artificial brains" - they are but an intermediary stage. Constantly drawing parallels between Technology and Nature, he writes:

... such a new technology will mean a completely new type of control man will gain over himself, that is, over his organism. This will in turn enable the fulfillment of some age-long dreams, such as the desire for immortality, or even perhaps the reversal of processes that are considered irreversible today (biological processes in particular, especially aging). Yet those goals may turn out to be a fantasy, just as the alchemists' gold

133 Here and in other places Lem's argument is only congruent with some varieties of contemporary evolutionism, that is, the ones which assume that the evolution process exhibits a preference for beneficial solutions only, and it rejects solutions that are not beneficial or that are neutral from the point of view of survival. However, elsewhere in Lem's work we would find statements about the "excess" of evolutionary solutions, which would mean that he does not side entirely with any type of evolutionism and only draws from them depending on the needs of his own discourse. 
was. Even if man is indeed capable of anything, he surely cannot achieve it in just any way. He will eventually achieve every goal if he so desires, but he will understand before that that the price he would have to pay for achieving such a goal would reduce this goal to absurdity.

It is because even if we ourselves choose the end point, our way of getting there is chosen by Nature. We can fly, but not by flapping our arms. We can walk on water, but not in the way it is depicted in the Bible. Perhaps we will eventually gain a kind of longevity that will practically amount to immortality, but to do this, we will have to give up on the bodily form that nature gave us. (91)

Intelectronics is the first step on the way to autoevolution. We need to remember that for Lem both computer and human brain are cybernetic systems. Equating them as a category allows him to believe that the growth of technology of constructing "thinking machines" will sooner or later translate into autoevolution technology - that there will occur a process that is reverse to what some artificial intelligence (AI) experts are predicting today, when they strive to build an artificial brain seeing it as the ultimate task of technology. One could say for Lem this is the penultimate task.

Before I proceed with a discussion of the social implications of intelectronics, I need to make one important digression. The whole chapter of ST I am discussing now is deeply related to a discipline now most commonly known as AI, even though Lem never uses the name. The term was first used by John McCarthy in 1956. Nowadays AI is really a separate discipline of science, combining computer technology, logic, neurophysiology and neuroscience, philosophy of language and mind, as well as cognitive and developmental psychology. Its object is "the capacity of a digital computer or computer-controlled robot to perform tasks commonly associated with intelligent beings. The term is frequently applied to the project of developing systems capable of intellectual processes characteristic of humans, such as the ability to reason, discover meaning, generalize, or learn from past experience."134 The main area of exploration in AI right now is building devices that could engage in logical games (especially chess), devices that could prove logical and mathematical theorems, recognize images and understand natural languages. Specialists in AI also write about constructing "artificial brain" (neuronal networks) and robots with advanced locomotory capacities. The discipline's foundational text is an article by Alan Mathison Turing Computing Machinery and Intelligence, published in 1950 in a prestigious British journal

134 Encyclopaedia Britannica, ed. 1996, vol. 1, 605. The definition is based on the views of Marvin Minsky, who is generally seen as the most distinguished contemporary theoretician in the areas of AI. 
Mind. The article contains a description and a discussion of "Turing test," a procedure aiming to determine whether a machine subjected to it can imitate human intellectual processes. One would be hard pressed to find any description of the AI problematic today where the author would not be respectfully referring to this piece and Turing's name in the very first words. AI is a hugely controversial field, provoking radically diverging philosophical views. I have no intention of recounting those arguments, instead hoping to point to some of the unobvious convergences in Turing's and Lem's thinking.

At the roots of all disputes around AI there is the problem of vagueness of two key terms. Turing's question about whether "a machine can think" makes sense only if we know exactly what the terms "machine" and "think" mean. And this is not clear, especially with the latter word. Naturally, Turing realized these difficulties and took them into account, but the definitions he proposed are not obvious at all, and the never-ending discussion surrounding them is the main evidence of that. While the notion of "machine" is fairly clearly defined at least in the strictly technical sense (there are precise definitions of "Turing machine" - the general technological model of a counting machine - and of "von Neumann machine" - the general technological model of a digital computer), we still cannot find agreement on what "thinking" means. Hence the numerous polemics with Turing test and his definition of thinking. ${ }^{135}$ There are

135 The most famous among them is likely the "Chinese room argument" formulated by John Searle [John Searle, Minds, Brains and Programs, in: Behavioral and Brain Sciences, no. 3 (1980), 417-457]. Searle presents a situation in which an English person who does not know Chinese receives a set of Chinese ideograms with instructions in English on how to use them. The person then generates output of correctly formed Chinese phrases, even though he or she does not understand them. According to Searle it is a proof that there is no connection between correct use of linguistic signs and intentionality of using them, and hence that the notion of "thinking" cannot be correctly applied to digital machines. Lem refers to this thought experiment in the title essay of his volume Tajemnica chińskiego pokoju [“The Chinese Room Secret"] (1996), where he rejects Searle's arguments against Turing test. Lem included his own version of the test in ST (130). In The Magellan Nebula there is a "Turing tale" (245-247, in the 1955 Polish edition; unavailable in English).

It is worth mentioning also Hilary Putnam's essay Brains in a Vat. The essay contains evidence about conventional character of reference in linguistic signs and belongs mostly to philosophy of language. However, Putnam invokes Turing test in his argument, emphasizing that linguistic expressions used by a computer have no reference to the external world (which is a way of saying they are unintentional). From the point of view of my work it is interesting that the thought experiment on which Putnam 
two ways to approach the problem. If thinking is defined as a process consisting of logical and mathematical operations (as "the strong AI" would assume), then machines do think. However, if thinking is defined as a process dependent on human sensorium, on the whole of sensual and mental experiences that make up our consciousness, then we cannot determine unequivocally whether machines can think, for the same reason why we do not have access to anyone else's consciousness. The only difference is that when A says to B "I have a toothache" and both are people, then while B cannot feel the same pain as A, he can represent the pain to himself, using what he has stored in his own memory (unless he has never had a toothache before). But if A said to B "I am having a short circuit" and $A$ were a machine, while $B$ a human, then $B$ would have no way of representing the content of that from A statement to himself. But then the question whether "a machine can think" no longer has meaning. ${ }^{136}$

Turing knew perfectly well that the phenomenological and sensual approach to thinking makes the whole problem irrelevant and this is one of the reasons why he designed his test (which he himself called "an imitation game") in such a way as to make it impossible to phrase the problem this way. ${ }^{137}$ Hardly anyone

builds the main line of his argument (the "brains in a vat" from the title, isolated from the external, physical reality, but retaining an illusion of contact through a connection to a computer) is fully identical with the Lem's short story about Professor Corcoran (Further Reminiscences of Ijon Tichy Part One) in Memoirs of a Space Traveler: Further Reminiscences of Ijon Tichy (1966, first published in English in 1991). The astonishing congruence has its sources in Berkeley's philosophy of course, which both Lem and Putnam reinterpret.

136 It is a fundamentally lemological problem. This is yet another example of reaching the very limits of human mind's ability to conceptualize, which according to Lem are the reason why any attempt at contact between people and other forms of intelligence fail. This case is unique though as this alien form is the product of human activity. This paradox is a source of anxiety, which, I believe, is at the roots of most emotionally biased views on AI.

137 The example I gave above takes into account only one variety of the thinking question within AI. Yet invoking pain is frequent in discussions about the relationship between intersubjective thinking and individual consciousness within the philosophy of mind in general; for example, cf. Wittgenstein's Philosophical Investigations, par. 281-287. (I leave out here advanced discussions that take place within the contemporary philosophy of mind about the very existence, characteristics and cognitive availability of subjective psychic experiences.) Apart from "the strong version of AI" and the "phenomenological" approach I have just outlined, there is also "a weak version of AI," according to which human thought processes are unpredictable (in a mathematical sense) or depend on factors unknown to science and therefore cannot be modeled 
notices that Turing test actually precludes presence of the creature, which passes it. The communication happens solely through text. The only criterion is syntax and semantics of the enunciation. This makes the questions of the conditions that shaped it, of whether it is a result of "mathematical" or "phenomenological" thinking, or some other type still, in short the question of intentionality behind the enunciation, irrelevant. All that matters is an artifact of text.

The original version of the Turing test may seem rather surprising. It actually starts not with how to distinguish between a human and a machine but with distinguishing between a man (A) and a woman (B); and the man can intentionally mislead the interrogator by offering confusing answers, whereas for the woman "[t]he best strategy ... is probably to give truthful answers." ${ }^{138}$ Authors writing about AI usually omit this passage and proceed to the main argument. This bit is in fact incomprehensible unless we take into account Turing's homosexuality, which implicitly dominated his life and led to his death at the early age of $42 .{ }^{139}$

I suggest that this peculiar opening of the "imitation game" from Turing may be related to his personal life - or rather the lack thereof, ${ }^{140}$ not in a sense that the whole issue of AI could be sensibly explained through the author's personal issues, but they could be behind Turing's thought, directing it toward machines as an alternative to people. But that is not all. Going deeper into Turing's text (not merely the test) one can notice that it is highly emotional, and intellectually incredibly dense. Turing writes:

The new problem [introducing a machine into the test] has the advantage of drawing a fairly sharp line between the physical and the intellectual capacities of a man. No

in a machine. "Spiritualism" - a conviction that there is an immaterial soul - is an extreme variety of the weak AI.

138 Turing, “Computing Machines and Intelligence," Mind, no. 236 (1950), 433-460.

139 Cf. Andrew Hodges, Alan Turing: The Enigma (London: Burnett Books, 1983). It is a huge biography with an extensive source base, a product of 7 years of research that the author started practically from scratch. Turing poisoned himself with cyanide as a result of serious depression caused by enforced hormonal treatment that he was sentenced to in court. He turned himself in to the police after a random sexual partner started stealing from him and blackmailing him. Homosexuality was punishable by law in the United Kingdom at that time.

140 Hodges makes similar suggestions: "He painted the pages of this journey into cyberspace with the awkward eroticism and encyclopaedic curiosity of his personality. Modern cultural critics have jumped with delight to psychoanalyse its surprises. ... the subtext is full of provocative references to his own person ..." Andrew Hodges, Turing (New York: Routledge, 1999), 38. It is an abbreviated version of the full biography. Unfortunately, Hodges does not provide specific examples of such analyses. 
engineer or chemist claims to be able to produce a material which is indistinguishable from the human skin. It is possible that at some time this might be done, but even supposing this invention available we should feel there was little point in trying to make a "thinking machine" more human by dressing it up in such artificial flesh. The form in which we have set the problem reflects this fact in the condition which prevents the interrogator from seeing or touching the other competitors, or hearing their voices. (434; emphasis PM)

Clearly, Turing wants to make sure there is no possibility of physical contact between participants of the test. If this were only about making it harder to distinguish between a machine and a man (which up until today tend to have very different physiques), it would be pragmatically understandable. But Turing writes that "it would not make sense" to make a machine resemble a man externally (i.e., to produce an android). Apparently retaining the physical difference is better in his view for some reason. Right before this passage there are sentences that have been quoted here before:

The best strategy for her is probably to give truthful answers. She can add such things as "I am the woman, don't listen to him!" to her answers, but it will avail nothing as the man can make similar remarks.

We now ask the question, "What will happen when a machine takes the part of A in this game?" (434)

A man can imitate a woman. He can also be replaced by a machine, which would not resemble a human at all, and then the machine would imitate either a man or a woman, but a human in general - regardless of gender. I believe Turing is striving to liberate the creature taking the test from all issues related to gender and sexuality. Some of the commentators wrote that a machine could replace a man, while others would see it as a mistake caused by "unfortunate" phrasing. In my view the phrasing is careful and purposeful. This is what follows:

The question and answer method seems to be suitable for introducing almost any one of the fields of human endeavour that we wish to include. We do not wish to penalise the machine for its inability to shine in beauty competitions, nor to penalise a man for losing in a race against an aeroplane. The conditions of our game make these disabilities irrelevant. The "witnesses" can brag as much as they please, if they consider it advisable, about their charms, strength or heroism, but the interrogator cannot demand practical demonstrations. (435)

Machine is to have nothing in common with human apart from intelligence that can be verified through text. It does not have to prove it has any other qualities; it does not need to "shine in beauty competitions." It need not be penalized for not fulfilling such norms in a way some people were then penalized for not conforming to other norms. 
A bit further on Turing discusses the definition of "a machine" and writes bitterly:

Finally, we wish to exclude from the machines men born in the usual manner. It is difficult to frame the definitions so as to satisfy these three conditions. One might for instance insist that the team of engineers should be all of one sex, but this would not really be satisfactory, for it is probably possible to rear a complete individual from a single cell of the skin (say) of a man. (435-436)

This is an extraordinary passage and, I need to add, very much in Lem's spirit in how it speaks of the "nonmachine" people "born in the usual manner." But something else is striking here: Turing's argument and the way he carries out his reasoning are very different from the standard academic discourse. This was not how people wrote in the mid-20th century. (It is equally extraordinary that Turing predicts cloning in passing.) At this point again behind the scientific arguments there seems to lurk Turing's exasperation with gender.

In the following part of the text there is a description of a digital computer and the famous discussion with arguments contradicting Turing's theses. Let us look at the fifth argument ("from various disabilities"):

These arguments take the form, "I grant you that you can make machines do all the things you have mentioned but you will never be able to make one to do X." Numerous features $\mathrm{X}$ are suggested in this connexion. I offer a selection: Be kind, resourceful, beautiful, friendly, have initiative, have a sense of humour, tell right from wrong, make mistakes, fall in love, enjoy strawberries and cream, make someone fall in love with it, learn from experience, use words properly, be the subject of its own thought, have as much diversity of behaviour as a man, do something really new. (447, emphasis PM)

This enumeration is food for thought here as well, especially the passage I have put in bold. Listing "strawberries and cream" between "fall in love" and "make someone fall in love with it" - and with all three preceded by "making mistakes" is peculiar in itself. Moreover, further on Turing discusses some of these charges and writes:

There are, however, special remarks to be made about many of the disabilities that have been mentioned. The inability to enjoy strawberries and cream may have struck the reader as frivolous. Possibly a machine might be made to enjoy this delicious dish, but any attempt to make one do so would be idiotic. What is important about this disability is that it contributes to some of the other disabilities, e.g., to the difficulty of the same kind of friendliness occurring between man and machine as between white man and white man, or between black man and black man. (448, emphasis PM)

I believe that Turing's commentary on the inability to enjoy strawberries and cream in truth refers to the two qualities listed before and after that one in the 
enumeration above. For a psychoanalyst this would be completely obvious. Appreciating "delicious dish" by a machine is "idiotic." A machine is meant to do something else. There is to be a different "kind of friendliness" between machine and man. Honestly, it is hard to not notice elements of personal engagement here.

There are a few other such passages in Turing's text. I have only listed the most telling ones. A poem Turing included in his letter to Dr. N. A. Routledge after his arrest is another sign that he did connect his personal issues with his research: Turing believes machines think / Turing lies with men / Therefore machines do not think." 141 Irony turns into despair here, and the entire life work is being put into question.

This is enough when it comes to analyzing Turing's article. ${ }^{142}$ Let us read this sentence again: "We now ask the question, "What will happen when a machine takes the part of A [i.e. man] in this game?'” This is when the actual Turing test begins, the one that has been described and analyzed too often for it to be sensibly repeated here. Instead I preferred focusing on the personal issues that Turing hid in his text. I am asking: why did Turing want machine to replace man? I repeat again: I am not suggesting that the objective, scientific meaning of his research is determined by his personal, individual disposition. I am not claiming that Turing test is the product of heteronormative oppression. I am trying to answer the question why of all the infinite aspect of the physical reality he chose to study this one - the swop of machine for man - and why he treated it the way he did? Why did he hide body? Why did he choose machine?

One could say I have answered the question myself writing about the "nonphenomenal" presence of machine, justified by the nonintentional character of the enunciation it produced. But such explanation (apart from being not necessarily satisfactory from the philosophical and scientific point of view) remains on the methodological level. Why should I not ask about the psychological reason? In fact the explicitly personal tones included, as I have shown, in Turing's article actually provoke such a question. So why did Turing write the way he did?

Perhaps because he valued the peacefulness of machine higher than the anxiety of a homosexual body. Machine is predictable, it causes no surprises, it does not disappoint or fail the way man does - such statements can often be heard

141 Hodges, Turing..., 54.

142 Similar arguments can be found in N. Katherine Hayles' introduction to How We Became Posthuman and Slavoj Žižek in his essay Please, No Sex, We're Posthuman (2001). 
from technocrats. They are theoretically true, but in practice any user of a personal computer would beg to differ. Perhaps, however, Turing meant something more. Machine has no sex; it has no lust, no desires; it does not yearn for anything the way man does.

For one reason or another Turing was clearly fascinated by the vision of machines replacing humans. It is time to ask: what does it all have to do with Lem? This is a fascination the two of them have in common. Again, to answer the question why would Lem share it (leaving aside the question of whether this question makes sense in the first place), one needs to engage in risky speculation, ${ }^{143}$ but on a very different subject. No one suspects Lem of sexual inversion, even though there are texts about his misogyny. ${ }^{144}$ But Lem has disgust for human body. He abhors physiology and sexuality, which he sees as connected with abject secretions more than with anything else. It is a persevering motif in his writings: disgust with human physiology. It is another paradox: the writer looking to deify man in Nature, evolution and biology describes his own species as "paleface" or "mucilids," and composes insulting verses:

What Nature's charge

Constitutes the fate of the unhappy Earthlings

Who in the price of love

The outlets of metabolism have,

Taken with pity the whole Universe

Extends its hands to you people

Who locate the perfect feelings

In the ugliest parts of the body

..

Knowing where they hold their ideals

With no way of escaping the trap,

Taken with pity the whole Universe

Wrings its tentacles in horror

$\cdots$

143 It brings to mind a comparison with a passage from The Magellan Nebula. One of the characters, who has just been through a heartbreak, asks a robot to kill him. Machine does not understand the order and the misunderstanding provokes a fascinating dialogue between them. I believe the scene can be interpreted as a fictionalization of Turing's views on the difference between man and machine (it is unlikely this is what Lem had in mind, although it is not impossible Lem knew Turing's works by the time he was writing The Magellan Nebula).

144 There are quasi-homoerotic themes in his early works that usually come from an emphasis on the ethos of male friendship. 
When in a hurry my girl I pollintae;

I write verses full of dancing

Bees, roses and butterflies

But you, unhappy human nation,

Which loving its females

Have to mate obsessively

Alas, with their plumbing,

Dost you praise it - in verses? ${ }^{145}$

Can anyone still doubt that for Lem body was disgusting? ${ }^{146}$ The near-absence of love themes or scenes in his novels would seem to confirm this diagnosis. ${ }^{147}$ On the other hand, one could list a catalogue of passages from Lem's grotesque short stories from The Cyberiad and The Star Diaries where the disgust with body and sexuality is ostentatious. ${ }^{148}$ I am trying to offer an explanation of the lack that would situate Lem not only within the scope of the contemporary question of sexuality, but actually at the very center of it, albeit not overtly. The most important issues do not have to be shown in their closest anatomy. We saw that with Turing as well. In Lem's case the implicit reason pushing him away from the body may likely be his traumatic wartime experience. ${ }^{149}$

145 Wizja lokalna, [“Observation on the Spot”] (Kraków: WL, 1983), 118 (trans. by Olga Kaczmarek). Names such as "paleface," "mucilids," "sticky Albuminids" and similar come up many times in The Cyberiad - the volume of short stories that have robots as narrators and as inner audience.

146 Treating judgments formulated in a piece of fiction, and a grotesque one, as an expression of author's views can be seen as a sign of methodological naivety. But it is sensible to treat author's views as formulated in his fiction and in his discursive works as elements of one metadiscourse. Of course, I do not assume that the views of Lem the author are necessarily identical with the views of Lem the person.

147 It brings Harey from Solaris to mind. Harey is and is not human. Lem carefully emphasizes her superhuman qualities in the scene in which Kelvin is testing her blood and discovers that Harey is made of different particles than people. It is a strong manifestation of Harey's "bodily inhumanity," even though on the "macroscope" level she seems human.

148 Lem's grotesque writings are a litmus test of his worldview: he articulated in them his most extreme opinions about the human nature and the future of man. In his autocommentaries from the 1990s, he often admitted that he had hoped these particular visions would remain fantasies, but they seemed to have been fulfilled most literally. The Cyberiad and The Star Diaries deserve an interpretation which would show that they hyperbolize "serious" discourses and fictions Lem wrote, and that they all make up a coherent whole.

149 I wrote about it in details in an article Lem fantastyczny czy makabryczny? O możliwym źródle pisarstwa nie-realistycznego ["Lem: Fantastic or Macabre? On the Possible 
Instead Lem dives into the world of machines. Nearly all of his novels include extensive detailed descriptions of all sorts of mechanisms. Sometimes he pays more attention to screws, pegs and steering systems than to his character's psyche. In Eden an amazing description of "factory" becomes emblematic of this theme, in which machine and the organic combine very closely, with the organic element dominated by machine. Lem's machines are not lifeless, in a sense in which weird objects in Locus Solus by Raymond Roussel are, or in a sense in which the mechanisms Vern's characters use to order the world are lifeless. Lem's machines are not dead, despite the fact that Michael Kandel translated The Cyberiad as Mortal Engines. They are not dead, because for Lem, just as for Turing, machines are better than people. Both ethically and aesthetically better.

Let me return to chapter four of ST. After outlining the "black box" idea, Lem writes:

It is time to introduce moral issues into our cybernetic deliberations. But it is in fact the other way around: it is not we who are introducing questions of ethics into cybernetics; it is cybernetics that, as it expands, envelops with its consequences all that which we understand as morality, that is, a system of criteria that evaluate behavior in a way that, from a purely objective perspective, looks arbitrary. Morality is arbitrary just as mathematics is, because both are deduced from accepted axioms by means of logical reasoning. (99-100)

We know these views already from Dialogues and the consequences of promoting them further come with the same contradictions. As long as Lem writes about "electrocracy," that is, the possibility to delegate some of the decision processes within a society to "intelligence amplifiers," he himself sees the aporiae and admits that treating a society as homeostat or a predictable processing information system unavoidably leads to a collapse of the entire model (99-107). In short: the strict rationality of "the cybernetic ruler" combined with the irrationality of men and the practically infinite number of parameters affecting the system soon ends in disaster. Comparison with the centrally planned economy is hard to resist, but this time it does not seem to be intentional.

Later, however, Lem goes further and tries to refer the idea of "thinking machines" to problems of faith and metaphysics, which means taking up a challenge which AI experts usually avoid. This boldness is impressive, but the execution is controversial, to say the least. This part of ST (107-129) contains a mix of extreme epistemological reductionism and bold thought experiments, as

Source of Non-Realistic Writing"], Przeglad Filozoficzno-Literacki, no. 1 (2009). I wrote about it also in the third chapter of my book The Speaking Lion. 
well as very complex attempts to bring together such issues as the possibility of grounding religious faith in rationality, the question of the contents of faith in terms of theory of information, hypotheses about the physiology of metaphysical experience, the cognitive status of revelation, the impact of religion on social life and "the ghost in the machine" (i.e., AI - this is where we can find Lem's version of the Turing test). Of the whole ST this section is most like an informal essay, in a negative sense; to disentangle all the threads Lem combined on these pages would require a whole separate treaty. It includes statements such as:

No religion can do anything for humanity, because it is not an empirical knowledge. It does reduce the "existential pain" of individuals, but at the same time, it increases the sum total of calamities affecting whole populations precisely owing to its helplessness and idleness in the face of social problems. It cannot thus be defended as a useful tool, one that remains helpless in the face of the fundamental problems of the world. $(122-123)$

This is a moment when Lem becomes a real, ahistorical, scientistic technocrat. If his entire work consisted of such statements, there would be no value in striving to analyze it. ${ }^{150}$ Soon after, however, he describes a fascinating project of building "a believing machine," one that would have metaphysical beliefs about, say, life after death programmed into it. He then elaborated on the project in Non Serviam, one of fake reviews in A Perfect Vacuum. It will also return later in ST.

This intellectual Gordian knot ends, as is often the case with Lem, in a statement about the impossibility of a conclusion. At the end of this part of ST, he proceeds directly to take up the problem of consciousness in a machine (which is the key issue for AI), comparing it to "the bald man paradox" (we do not know from which point we can speak of "consciousness" as correlate to the degree of complexity of mathematical processes carried out), and then eventually he repeats his thesis from Dialogues, that consciousness is “'disseminated' across the whole of the homeostat across its activity network. We cannot say anything else on this matter if we want to remain both sensible and cautious" (132). And this conclusion proved to be true - the contemporary neuroscience accepts similar positions.

Lem's views on reducing faith to physiology and on the social function of religion certainly had the biggest impact on the tone of Kołakowski's review. It

150 It needs to be pointed out that in other works Lem takes up the issues of religion with a lot more understanding. Szpakowska devotes a whole chapter in her monograph to it (Lem i Pan Bóg), and Jarzębski is even trying to present his oeuvre in general as a quasi-religious in a way. 
needs to be added that they fell on a deaf ear as theoreticians and practitionersconstructors of AI are generally careful to avoid getting involved in such topics or simply are not aware of them; and even Lem himself did a much better job marrying religion with intelectronics in The Cyberiad, The Star Diaries and A Perfect Vacuum. The impact of technology on spiritual life was and still is being raised though, albeit on a different level. Suffice it to mention the notion of "cybernetic religion" proposed by Fromm, ${ }^{151}$ the powerful metaphor of "Turing man" offered by Bolter, or Henri Lefebrve's "cybernanthrope."152 Today many authors attempt to redefine basic philosophical categories due to the influence of technology (i.e., redefining the notion of "individual identity" in the context of cloning), but such discussions belong to a different field.

The last part of "Intelectronics" is "Doubts and Antinomies" (137-153). In it Lem sums up the unsolved conceptual problems related to AI in a way that remains useful today. He discusses the philosophical paradoxes of "thinking machines," their "consciousness" and "personality," their potential "wisdom" and so on clearly and precisely. The conclusion of the chapter is:

Those systems will not be trying to "dominate over humanity" in any anthropomorphic sense because, not being human, they will not manifest any signs of egoism or desire for power - which obviously can only be meaningfully ascribed to "persons." Yet humans could personify those machines by ascribing to them intentions and sensations that are not in them, on the basis of a new mythology of an intelectric age. I am not trying to demonize those impersonal regulators; I am only presenting a surprising situation when, like in the cave of Polyphemus, no one is making a move on us - but this time for our own good. Final decision can remain in human hands forever, yet any attempts to exercise this freedom will show us that alternative decisions made by the machine (had they indeed been alternative) would have been more beneficial because they would have been taken from a more comprehensive perspective. After several painful lessons, humanity could turn into a well-behaved child, always ready to listen to (No One's) good advice. In this version, the Regulator is much weaker than in the Ruler version because it never imposes anything; it only provides advice - yet does its weakness become our strength? (152-153)

Michel Foucault would certainly appreciate these sentences - Lem described Power without Subject, without Man. The impersonal power of machine.

151 Erich Fromm, To Have or To Be? (New York: Bloomsbury, 2013), 120-132, especially 131-132. "Man has made himself into a god because he has acquired the technical capacity for 'a second creation' ... We can also formulate: We have made the machine into a god and have become godlike by serving the machine."

152 Henri Lefebvre, Vers le Cybernantrope. Contres les technocrates (Paris: DenoëlGonthier, 1971). "It is a man who defines himself in terms of an artificial brain, lives in a symbiosis with machine, and discovers a double, schizoic reality." 


\section{Metatheory}

Of course, I belong to the Enlightenment and I am a rationalist, albeit a little desperate. A desperate rationalist can turn out to be closely related to a fool.

Letter to Michael Kandel, July 1, 1972

The fifth chapter of ST, "Prolegomena to Omnipotence," serves as a metatheory for the entire work. It is located midway through the book and it divides it into two symmetrical parts. The first one is about issues of autoevolution unrelated to biology (the hypothetical reference to extraterrestrial civilization and intelectronics, that is, the capacity to build intelligent machines without organic components) - and this is the part that has been discussed here already. The other part of ST is devoted to those aspects of autoevolution that are directly connected with biology and Nature. Those include phantomology, information farming and autoevolution in a strict sense, that is, reconstruction of the human species. Before Lem discusses them though, he first outlines a sort of classification of autoevolution and tries to impose a conceptual order on his own reflections on the subject, which is necessary given how different his thought is from what was accepted earlier, as I have emphasized on many occasions.

At the beginning Lem writes:

It is only when we are eventually able to compete with Nature on the level of creation, when we have learned to copy it so that we can discover all of its limitations as a Designer, that we shall enter the realm of freedom, of being able to work out a creative strategy subordinated to our goals. ... we can turn Nature's infinity against it, so to speak, by working, as Technologists, on uncountable sets ... We can remove the difference between "the artificial" and "the natural" - which will happen once the "artificial" first becomes indistinguishable from the natural and then exceeds it. We shall discuss later on how this is going to happen. But how should we understand this moment of "exceeding" the natural? It stands for carrying out with Nature's help what it cannot do itself. (156)

Soon after he defines the notion of "Machine." I will quote an extensive passage here, as it is one of the most important ones in ST and Lem's way of thinking about technology cannot be fully understood without it.

$\mathrm{OK}$, then, someone will say, all these lofty phrases were just intended to elevate human artifacts, all those various machines that Nature does not create. 
Everything depends on what we understand by a "machine." It can, of course, refer just to what we have learned to construct so far. Yet if by "machine" we understand something that displays regularity, the situation will change. From such a broad perspective, it is not important anymore whether a "machine" has been constructed from existing matter, from those one hundred elements discovered by physics, or from air showers, or even from gravitational fields. It is also not important whether and how a "machine" uses, or even "creates" energy. It would, of course, be possible to construct a system consisting of intelligent beings and their environment in which our laws of thermodynamics would not apply. Someone will respond that this system would be "artificial" and that we would secretly have to provide it with energy from outside, in a way that would be unnoticeable to its inhabitants. Yet we do not know whether the Metagalaxy does not have any external energy sources that would be "connected" to this system from outside. Maybe it does; maybe its eternal supply of energy results from the infinity of the Universe. If that was the case, would this mean that the Metagalaxy was "artificial"? As we can see, everything depends on the scale of phenomena under discussion. A machine is thus a system that manifests some kind of regularity of behavior: statistical, probabilistic, or deterministic. From this point of view an atom, an apple tree, a star system, or a supernatural world is a machine. Everything we construct, and that behaves in a certain way, is a machine: everything that has inner states and outer states, while the relations between sets of those states are subject to certain laws. (156-157)

This is how Lem neutralizes the significance of distinguishing between the Natural and the Artificial. "Artificiality" for him does not imply intentionality of creation, and "naturality" - a lack of such intentionality (this is roughly how the difference between the two notions could be described in their regular sense). It is not about that; it is about regularity in functioning. The thesis is: Designer can create every system (be it a computer, a tree, a cyborg or a galaxy - the technical capacity is of no bearing here) under the sole condition, that the structure and functioning of the system can be described with precision. The criterion is purely pragmatic then, but very different from the earlier one. Even something previously considered natural can in fact be an "artificial" product. The fact that we still distinguish between these two categories is merely a matter of how backward we are technologically. We make "artificial flowers" from the artificial material - plastic. ${ }^{153}$ Once we learn to produce them from the same material that real flowers are made of, the distinction will no longer be applicable. When

153 That is from polymers that do not occur in living organisms. But the proteins we are largely made of are a type of polymers too, albeit with an incredibly complex structure. It means that on the level of molecular engineering we are dealing with the same class of substances, but the simple polymers are to proteins what a barrow is to a limousine - also when it comes to how difficult they are to build. 
everything can be "artificial" in that sense, nothing is either artificial or natural, because a product of Nature is indistinguishable from something produced by Designer. Moreover, the broadening of human knowledge from the planet Earth to the Universe, which took place in the scope of the last hundred years, again deprives the opposition of Natural and Artificial of its meaning. It used to be possible to claim that the Amazon Jungle is natural, and the office of a dean at All Souls College - artificial. But a question of whether a star cluster is natural or artificial is just badly put. ${ }^{154}$

Lem is certain those changes will happen; we just do not know when that will be. Speaking of "imitology" - this is the general term Lem coins for the problematic - he does not touch upon the question of "when."155

The condition of predictability of designed system is crucial for Lem, as he remains faithful to cybernetics and science in general, even this late in his intellectual journey. And it is not a symptom of some archaic scientism. The position that a Designer cannot build objects that could not be theoretically described stems from the assumption that any reality, not only the one we inhabit now, but also all the ones we could create ourselves, needs to have a set of laws that describe it. Otherwise we would not only be stepping into the realm of pure fantasy, where despite appearances Lem does not like being, but we would also be stepping beyond the realm of our cognition as a reality without laws of physics governing it is impossible to imagine for us, and impossible to figure out through abstract reasoning, and therefore we can say nothing meaningful about it, even though we can formulate any preposition about it (e.g., "kangaroos are made of exhausted cottage cheese"). This is not the type of writing Lem is interested in ST.

The statement about "regularity" as the essential feature of Machine is another element of an implicit "critique of the body" - Lem clearly suggests that human body is an irregular structure, subject to numerous aberrations in functioning and to many errors, one that cannot be described precisely and, hence, controlled. It is then another reason to reject it.

This is roughly Lem's main metatheoretical position. One could ask now whether there is place for man at all within this model - after all, so far we have

154 The Natural/Artificial opposition in ST is not identical with the opposition Nature/ Culture, and hence the difficulty in applying all these notions. As long as we stay on the planet Earth, "Artificial" is more or less the same as "Culture," but in the lengthy passage I have quoted above Lem definitely goes beyond such limits.

155 Which, we should point out, makes him a utopist. I will discuss the utopian character of ST in the next part of this book. 
not been able to describe ourselves with regular theories and to most of us it is highly doubtful that we ever will. But Lem does not ask that question and the very notion of autoevolution leads eventually, I believe, to making such a task impossible.

In the chapter "Chaos and Order" another very important question is posed though: does any of the models of reality devised by men describe it with absolute precision? This is one of the most fundamental questions for philosophy of science and it is usually answered in a negative - a theoretical model is never identical with the phenomena it describes, it exists in the realm of mediated symbols determined by the historically formed cultural communication - so it cannot render it with complete precision. Of course, in the contemporary science these questions become very complex, especially when the reality is only accessible through a mathematical model describing it or through very indirect observations (as is the case in particle physics and cosmology). Lem solves the problem in the most radical way imaginable:

What are we left with then? With considering the phenomenon itself its most perfect representation, and with replacing analytical with creative activity. In other words - with imitological practice. (164)

As the only perfect model of any phenomenon is the phenomenon itself, Lem in fact identifies theory with practice. The strategy he offers is both, as we shall see later when discussing information farming and autoevolution. Thus, Lem rejects another dogma of our thinking, separating scientific theory from engineering, or more generally, Science from Technology.

If we now ask how the Designer knows what he is to create if the theoretical model is identical with the practical object being designed, Lem responds:

I have said that restraint on the level of design will serve as a compass in our navigation between the abyss of knowledge and the chasm of stupidity. Such restraint stands for belief in the possibility of acting effectively and in the need to give up on certain things. It means first of all giving up on asking "definitive" questions. This is not a silence of someone pretending to be deaf but rather active silence. We know far more about the fact that it is possible to act than about how it happens. The designer is not a narrow pragmatist, like a builder who is constructing his house from bricks, uninterested in where these bricks came from and what they are, as long as the house gets built. The designer knows everything about his bricks - except for what they look like when no one is looking at them. (168)

It is a bit of an evasion, which stems from our uncertainty about the nature of the world. No one knows if the world we inhabit is fully cognizable, not only for us, which I have discussed earlier, but also "in general." It is primarily a matter 
of whether it can be described mathematically, whether every level and aspect of reality can be modeled mathematically. Lem and other authors writing on the subject are careful to not mention the problematic status of the humanities. The question can be reversed too: Does every mathematical theory describe some physical entity? Some scholars, such as James Jeans and Arthur Stanley Eddington would answer in affirmative, but today, even though many mathematical theories that used to be seen as absolutely "pure" found practical use, such view is generally described as "mathematical mysticism," as there is no logical or scientific evidence for it - and this is where we return to the starting point. Lem offers an excellent metaphor here, which presents mathematician as

a mad tailor who makes all sorts of clothes. He does not know anything about people, birds, or plants. He is not interested in the world; he does not examine it. He makes clothes but does not know for whom. He does not think about it ... He takes the finished clothes to a massive warehouse. If we could enter it, we would discover that some of the clothes fit an octopus, others fit trees, butterflies, or people. We would find clothes for a centaur and a unicorn as well as for creatures that have not even been imagined yet. $(171-172)$

All these metatheoretical reasonings have an implicit meaning. Lem's Designer has the utmost degree of liberty. He is not limited by culture, politics, society, and history, not even by biology. He is only limited by the laws of physics hence the title of the chapter: "Prolegomena to Omnipotence." The Designer's main problem is the eternal question of "what to do?" which here carries the broadest possible meaning, as the Designer can do nearly anything. Lem is trying to outline a code, a set of rules, or a method. At the same time he himself, as the author of ST, enjoys a virtually unlimited theoretical field, which is, however, determined by the fairly strict perimeter of the laws of physics and his own assumptions, especially regarding the (un)knowability of the world. $\mathrm{He}$ at least sees himself as unrestricted by the constraints of the past, of culture and society, but somehow obliged to correspond with them, as he is writing for his contemporaries, and not for those about whom he is writing. His task is extremely difficult, which is where the complexity of the thought in ST comes from, especially in this particular chapter.

The section titled modestly "A New Linnaeus: About Systematics"156 presents a set of notions that Lem uses referring to the main directions of development

156 Lem's lofty diction in ST would itself merit some interest. Perhaps it is not so much a product of author's (lack of) modesty, as of irony, which he then lost in the 1980s at the latest, when he also lost his anthropological optimism. 
for future technology, which will grow from combining scientific theory, technology and bio- and technoevolution. Lem emphasizes many times that the terms describe something that does not exist yet, and will not for a long time, so they have to be somewhat vague. He writes:

"Pantocreatics" refers to everything man or another intelligent being can achieve. It refers to gathering information and using it with a particular goal in mind. Such separation also exists today to some extent; it can be seen in the differentiation between science and technology. In the future, the situation will change in that information gathering will have become automated ... The part of pantocreatics that deals with information use, and that has emerged from the combination of the general theory of physical and mathematical systems, can be divided into two fields. For the sake of brevity, and also to provide a kind of overview, we shall call the first of these Imitology and the second Phantomology. They overlap with each other to some extent. We could, of course, try to be more precise and say, for example, that imitology is a design theory based on the mathematics and algorithms that can be identified in Nature, while phantomology stands for actualizing in the real world mathematical structures that have no equivalent in Nature. Yet this would already mean assuming that Nature basically has a mathematical character - while we do not want to make such an assumption. This would also involve accepting algorithmic universalism - which is highly dubious in itself. It is therefore more sensible to leave our definitions partially open. (178)

The metaphorical style - difficult to avoid when writing about omnipotence makes it hard to get a general understanding of the project. Lem constantly oscillates between Nature and Design, obliterating the borders between the two notions. Since he cannot produce precise descriptions of "pantocreatic technologies," he finds recourse in an almost poetic strategy - he purposefully dissolves the semantics of his own discourse.

Lem's view on the difference between imitology and phantomology is also significant here:

Imitology is an earlier stage of pantocreatics. It is derived from the modeling of real phenomena in scientific theories, digital machines, and so on, which is already practiced today. Imitology involves launching probable material processes (a star, a volcanic explosion) as well as improbable ones (a microfusion cell, a civilization). A perfect imitologist is someone who is capable of repeating any natural phenomenon, or a phenomenon whose emergence is enabled by Nature, even though it itself has not been created spontaneously by Nature ... There is no sharp boundary between imitology and phantomology. As a later, more advanced phase of imitology, phantomology involves constructing ever less likely processes, all the way to entirely impossible ones, that is, processes than cannot take place under any circumstances, because they contradict the laws of Nature. It seems to be an empty class because the unrealizable cannot be realized. We shall attempt to demonstrate, albeit only briefly and rather crudely, that such an "impossibility" does not have to be absolute. (178-179) 
We can see that, again, phenomenon becomes identical with its model. And again, this identity happens in both types of scholastic suppositions, de re and de dicto. Lem employs a rhetorical device whereby he manipulates notions as if he were doing so on these notions' referents. There is a reason why Lem constantly uses the hypostases of Science, Technology, Nature and a few other entities. It would be unacceptable in a strictly academic text and they are usually the cause of some grotesque misunderstandings in postmodern texts. They are, however, necessary and justified in Lem's writings - how else could he speak of these issues, so removed from any past or present reality?

Lem's main aim is to show that Designer-Pantocreatic and Nature can be the same. To make such a possibility seem more likely, he quotes examples from genetic engineering, which were completely fantastic in 1964, but which are quite practical in 2017, ${ }^{157}$ and he interprets that as a seamless transition from "plagiarism" from Nature to "creation." He writes:

As we can see, our actions blur the boundary between what is "natural" and what is "artificial." Modeling thus allows us to cross the boundary between plagiarism and creation because our comprehensive knowledge of the genetic code obviously allows us to introduce all kinds of changes into it ... Evidently, we do not need to be familiar with the entire evolutionary road that Nature has traveled to construct a human being. We do not need millions of bits of information about particular stages of development, about Sinanthropus, about Mustier or Aurignacian civilizations. On having produced a "model" of a sperm or an egg that "matches" the original, we will have obtained a genotype that is more perfect than all the originals (owing to the accumulation of valuable genetic traits) - thanks to which we will have opened a "side entrance" into the process of creating human organisms for ourselves. (185)

This is the essence of imitology: it is about repeating the best achievements of Nature without repeating the whole blind process that led Nature to such results. This, I believe, makes the sense of the model becoming the same as the modeled phenomenon clearer. Imitology is to be an "extension" of Nature steered by Reason - without the sharp cut that separated Science from Technology in modern science.

157 The contradiction with the preceding sentence is an illusion. The fact that some of Lem's project became real does not mean that we have got closer to "pantocreatics" or "autoevolution." We are still just as distant from reaching the point of identity between Technology and Nature as we were half a century ago. In light of the strategic plans laid out in ST our achievements are but early attempts. See more on this in Chapter 27 of this book. 
In the passage quoted above there emerges also a theme that will return later - albeit implicitly - in a discussion about reconstruction of species in the last chapter of ST. In order to reconstruct human organism the Designer does not need the history of the development of our species. And similarly, he will not need the history of its culture in order to reshape it. I will discuss this conclusion, as sad as it might be for humanists, later.

To provide even stronger arguments in favor of his metatheoretical theses about the possibility of "pantocreatic modeling" of reality, Lem offers another fascinating metaphor:

Yet maybe it is only today that we need theories and models of phenomena? Maybe, on being asked such a question, a wise man from another planet would silently hand out a piece of an old shoe sole picked up from the ground to us, communicating in this way that the whole truth of the Universe can be read from this piece of matter? ... Does Matter by any chance not have all of its potential transformations "inscribed" in it ... Then, taking the basic building block of Nature, the hydrogen atom, we could "deduce" all those possibilities from it (modestly starting from the possibility of constructing systems that are a trillion times more spiritual than man). We could also deduce all that is unrealizable from it (sweet kitchen salt $\mathrm{NaCl}$, stars whose diameter equals a quadrillion of miles, etc.). From this perspective, matter already entails as its foundational assumptions all those possibilities as well as impossibilities (or prohibitions); we are just unable to crack its "code." ... What we have just said is nothing else than tautological ontology ... (182-183)

If it were indeed possible to deduce a description of the entire universe from an old shoe sole (the idea is somewhat like Zen kōans reflecting the most profound sense of the world in striking absurdities), the problem of setting rules of pantocreatics, as well as the problem of correspondence between a model and a phenomenon, between a word and a thing, between a notion and an object, would cease to exist. The matter itself - unmediated by any kind of conceptual arguments - would imply nearly infinite possibilities of shaping it. It is now clear that most of the difficulties in creating pantocreatics ensue from the problem of representation that troubles the entire Western thought. Lem is no pioneer in such approach. This passage of ST puts him in a long line of thinkers dreaming of discovering a Grand Principle in the reality itself, outside any conceptual systems. "Tautological ontology" is nothing else as Leibniz's mathesis universalis. Leibniz wanted to create a language in which words-things would encompass all features of the objects they refer to. Lem wants objects themselves to determine their own features and relations - so the Designer would not have to use any words, any notions. Any humanists, trapped under the burden of forty centuries of interpretation would applaud such a dream of a thoughtless pinnacle of wisdom. 


\title{
14 Phantomatics
}

\author{
Stanisław Lem's prophecies (or, simply, Lem's Visions) are \\ characterized by the fact that he himself does not take \\ them in the least bit seriously, but NEVERTHELESS \\ they come true completely within about a year. \\ Dangerous, right?
}

Letter to Szymon Kobyliński, March 14, 1974

Lem brings up chapter six in ST, "Phantomology," whenever he wants to prove how sharp a prophet he is. The chapter contains a description of something that, perhaps somewhat hastily, came to be identified with the so-called virtual reality (VR). I do not intend to compare Lem's prediction with the contemporary state of VR technology. It would be doubly pointless: because of my ignorance with regard to technological details of VR, and because Lem's prediction is less about technological aspects of phantomology and more about its psychological and social consequences. And they should be the object of interest here, again, as was the case with cybernetics, considering the science and the technology from the point of view of their cultural significance.

Why did Lem come up with phantomatics in the first place? What is its place within the structure of ST? The chapter starts with the following statements:

We are faced with the following problem: how do we create realities for the intelligent beings that exist in them, realities that are absolutely indistinguishable from the standard reality but that are subject to different laws? ... We shall ask, Is it possible to create an artificial reality that is very similar to the actual one yet that cannot be distinguished from it in any way? The first topic focuses on the creation of worlds, the second on the creation of illusions. But we are talking about perfect illusions. I do not even know whether they can be called just illusions. Please, judge for yourselves. (191)

So for Lem phantomatics ${ }^{158}$ is an introduction to "pantocreatics," "a steppingstone to creative engineering" (191), something of a training ground to study

158 A terminological remark: the text of ST suggests that "phantomology" is a theory, and "phantomatics" - a practice of creating "illusionary worlds." The distinction is not sharp as the entire ST - as a prediction and a manifesto of autoevolution - is a piece of purely theoretical discourse about phenomena that do not exist yet, and, moreover, if they ever occur, they will make the distinction between theory discourse and practice irrelevant. 
people's reactions to an "artificial-natural" reality. It is a rehearsal before the proper act of "second creation," a rehearsal of an illusion of a "new world." Lem describes the technical details of "phantomatic machine" and sensual experiences of a phantomatized person with utmost precision, and he introduces a distinction between peripheral and central phantomatics, as well as between teletaxy and phantoplication. We shall now look into the meaning of those terms.

Peripheral phantomatics involves stimulating senses externally - the contemporary VR is the closest to it, with its helmets and gloves sets. Central phantomatics involves stimulating directly the areas in the brain responsible for particular kinds of experiences. Interestingly, Lem, who is usually not keen to make excursions into the past, points to ecstatic shamanistic practices and strong intoxicants, such as drugs, as "prephantomatics" of the first type. The remark leads him to a conclusion, which he repeats a few times, that perhaps the real application of phantomatics will in fact be limited to pleasure. Given what an average Internet user and unprofessional user of VR technology is mostly interested in today, one has to admit that Lem was actually completely right in his predictions here, even though he was quite saddened by this particular achievement of his. ${ }^{159}$

"Central phantomatics," with its capacity to provoke strong pleasure and pain by stimulating the brain directly, omitting the senses - something that has already been tested on animals - leads Lem to ask about the possibility of creating "artificial paradise and heaven." It is a question of significant philosophical and sociological weight, but in this case Lem only flags the problem.

Lem's dictionary includes also "cerebromatics," which means "changes to the dynamic structure of the brain's neural network," so all actions connected with central phantomatics, with far-reaching psychological implications. Lem considers the possibility of a transformation of an individual identity that would not be "illusionary" (e.g., by placing a person in a phantomata simulating the court of Bonaparte with the phantomatized person cast as "Napoleon"), but real, transforming a personality so deeply that the person subjected to it would in fact become Napoleon, with all his biographical experience and all the personality traits the emperor of the French had. By discussing this possibility, Lem is unusually careful about the historical and temporal aspect of human identity. Emphasizing that identity is determined not only by psychological processes, but also by external circumstances in a broad historical and social context, he

159 For an anthropologist, the identification of shamanistic practices with simple drug intoxication is a glaring simplification. It is a reflection of how little Lem cared about the past. 
concludes that it is impossible to cerebromatically turn Mr. Smith into Napoleon. It is equally impossible in peripheral phantomatics as it only produces an illusion of surroundings, without the phantomatized person ever ceasing to be himself or herself. Lem rightly stresses that:

the more the character one wishes to impersonate differs in personality traits and historical period from his own, the more fictitious, naïve, or even primitive his behavior and the whole vision will be. Because, to be crowned a king or receive the Pope's emissaries, one has to be familiar with the whole court protocol. (209)

We are dealing with the issue of artificiality here, but not the one that we encounter in the project of autoevolution, but a regular, primitive artificiality of a badly defined situation. ${ }^{160}$ It is the first argument supporting a thesis that phantomatics is actually incoherent. All these reflections resemble conversation between Hylas and Philonous about transmitting personal identity, except in Dialogues they referred to mechanical replication and teleportation of people, whereas here it is the issue of radical transformations of external reality. The continuity of this theme is a testimony not only to Lem's long-lasting interest in the problem, but also to the inevitable influence of technological changes on conceptual standards regarding individual identity.

Phantomatization is generally risky for Lem from the social perspective. There is the issue of "yearning for authenticity" - the phantomatized individual is always aware that even the most perfect illusion is merely an illusion. He is then torn between the phantomatic reality and the authentic one; this duplicity cannot be avoided, as there is no way for a copy to become the original, which is particularly striking in case of Lebenswelt. Lem suggests, however, just as the Wachowski brothers (now sisters) do later on, in The Matrix, that phantomatized people could be purposefully misled about the status of the world they are in. He designs something resembling a "VR Turing test" and claims the only way to verify the "reality of the real" is through presence of material correlates of the most intimate content of one's consciousness, such as damaged home appliances, which only the phantomatized person knows about - and he or she knows they are the only one who knows that. These complex and seemingly fantastic ideas actually resemble The Matrix plot, a film that became a manifesto of cyber-pop

160 Gruppenfuehrer Louis XVI in A Perfect Vacuum is a macabre version of this idea, in which Nazi refugees from Europe create a replica of Versailles in the Amazon Jungle. In light of these analyses, it seems ironical that Lem received an offer to film this story, which he mentions in his conversations with Stanisław Bereś. 
culture in $1999 .{ }^{161}$ Even here, however, Lem draws some very serious conclusions. A phantomatized person acts in isolation:

It is because any act of turning to other people for help is, or rather can actually be, an act of feeding the machine with strategically valuable information ... This is why the person undergoing the experience cannot trust anyone but himself - which severely narrows down his options. He acts defensively to an extent, as he is surrounded from all sides. This also means that a phantomatic world is a world of total solitude. There cannot be more than one person in it at any one time, just as it is impossible for two real persons to find themselves in the same dream.

No civilization can become "fully phantomatized." If all its members were to start experiencing phantomatic visions from a certain point on, the real world of this civilization would come to a halt and die out. (202)

The diagnosis is clear: complete "artificiality" of the surrounding world, with the exception of the "natural" human body and mind amounts to a suicide of a civilization. A moment later Lem states the same even more strongly:

Of course, it is possible to envisage some kind of omniplanetary "Superphantomat," to which the inhabitants of a given planet have been connected "forever," that is for as long as they have been alive, while their bodies' vegetative processes are being supported by automatic devices ... This civilization would only exist for the duration of one generation - the one that remains connected to the "Superphantomat." This would thus be a peculiar form of euthanasia, a kind of pleasant suicide of a civilization. For this reason, we consider its implementation to be impossible. (202-203)

In the context of the project of autoevolution as it is presented in the whole of ST, the conclusion is as follows: phantomatics is but a half-measure, with harmful results, as it does not eliminate the Natural/Artificial dichotomy entirely, it only disrupts the ontology of Lebenswelt. Later in ST we shall see that only a reconstruction of the human species in its physicality, a shift in the category of transformation, which I discussed earlier, can in fact guarantee a coherent process of autoevolution.

This does not exhaust the subject matter of the chapter devoted to phantomatics, but before I proceed with that discussion, I want to briefly point to congruencies between phantomatics and some of the contemporary intellectual trends.

All things considered, phantomatics is flawed for Lem, as it either leads to cognitive dissonance or to extinction of the human species. Neither of these

161 In some ways the plot of The Matrix reflects Lem's description of phantomatics quite faithfully. It is based on the idea of machines dominating people - something that will never happen according to Lem and most other artificial intelligence (AI) theoreticians. 
threats discouraged people from it though, as in the last decade of the 20th century they not only accepted phantomatization as a possibility, but also actually started to desire it, although in a shape that is somewhat different from what Lem described in ST.

When in the 1990s Internet was rapidly popularized globally, it immediately became clear how many human dreams and phantasms find their expression in the digital cyberspace. In February 1996 John Perry Barlow, one of the gurus of the IT world, published The Declaration of Independence of the Cyberspace - on the Internet, naturally. Here is a passage from it:

Governments of the Industrial World, you weary giants of flesh and steel, I come from Cyberspace, the new home of Mind. On behalf of the future, I ask you of the past to leave us alone. You are not welcome among us. You have no sovereignty where we gather. ... Cyberspace ... is an act of nature and it grows itself through our collective actions ... Cyberspace consists of transactions, relationships, and thought itself, arrayed like a standing wave in the web of our communications. Ours is a world that is both everywhere and nowhere, but it is not where bodies live ... Your legal concepts of property, expression, identity, movement, and context do not apply to us. They are based on matter. There is no matter here. ${ }^{162}$

The statement that cyberspace is an act of nature is of particular importance here - it fits perfectly in Lem's project of autoevolution. Erik Davis, from whose book I quote Barlow, emphasizes rightly that the exuberant rhetoric of the text carries a clear ideological message: Internet is to become a sphere of unrestricted freedom. Such view fueled the "web anarchism" at the turn of the centuries and it still is a support for all those who react violently to any attempts at ordering or controlling the web, even after it became clear that the web functions, mostly thanks to big corporations and not selfless activists. Here, however, I'm interested not so much in analyzing social and political aspects of the cyberspace, but its role in the ideas of autoevolution. ${ }^{163}$

In the early 1990s there emerged a group in Los Angeles, which came to be known as "extropians." They were enthusiastic about new technologies and drew

162 Quoted from: Erik Davis, TechGnosis: Myth, Magic and Mysticism in the Age of Information (London: Serpents Tail, 2004), 132-133. This book, written by an IT specialist with some interest in the humanities, includes a lot of useful information about relationships between technology and magical or mystical thinking. However, it is extremely chaotic that makes it difficult to use it.

163 A vast, panoramic view of global transformations of the last decade of the 20th century, with particular emphasis on the role of Internet, can be found in Manuel Castells's trilogy: The Information Age: Economy, Society and Culture, vol. 1: The Rise of the Network Society, vol. 2: The Power of Identity, vol. 3: End of Millennium (2nd ed; 
bold visions of their further growth, which would help people acquire unlimited capacities. In their own, somewhat mystical way, they prophesied the same project of autoevolution and exceeding the limits of humanity that Lem presented in ST. It is particularly interesting that they also assumed that in the future people would move their brains from bodies to computer networks. Max More, the President of Extropy Institute, wrote:

Shrugging off the limits imposed on us by our natural heritage, we apply the evolutionary gift of our rational, empirical intelligence to surpass the confines of our humanity, crossing the threshold into the transhuman and posthuman stages that await us ... When technology allows us to reconstitute ourselves physiologically, genetically, and neurologically, we who have become transhuman will be primed to transform ourselves into posthumans - persons of unprecedented physical, intellectual, and psychological capacity, self-programming, potentially immortal, unlimited individuals. (Quoted from: Davis, 143-145)

Which is exactly what Lem prophesies in ST. Stepping ahead of myself here a little, I will add that the same views are developed in the last chapter of ST and then, more than a decade later, in Golem XIV. Moreover, we encounter here words that remained foreign to Lem: "transhumanism" and "posthumanism," to which I shall return later. At this point I just want to show that the cyberspace, which Lem and his commentators associated mostly with phantomatics, comes close to his thinking in other areas as well - or perhaps above all elsewhere. The passage I have quoted is a good example of the functions of the Internet and cyberspace in the culture of the early years of the 21 st century. The heights of technology overlap with heights of mysticism. Davis invokes Nietzsche and his thesis about Übermensch as a result of rejecting the earlier model of humanity. I believe in the context of autoevolutionary projects this is only an intellectual convergence, but in Part Three I will try to search for a line that would connect these areas of Western thought more directly.

Extropians accuse the human kind of the same things as Stanisław Lem and in the same way, with the same justifications. I will try to show that the solutions offered to human problems are also largely similar in these two cases.

The thesis about moving human brains to computer networks is not just a sci-fi idea. It is one of those elements of contemporary thought, in which it is hard to distinguish between what is scientifically and technologically viable and

Oxford: Blackwell, 2000, XXIX+594, XV+461, XV+448). However, the level of detail of the book, combined with the pace of developments since its publication led to the work losing a lot of its relevance very quickly. 
what is but wishful thinking emerging from cultural anxieties. "The presence of myth" in science, which Leszek Kołakowski sought deep underneath the positivist paradigm is very clear now, and not only in computer technologies, but also in physics and biology, for example. Authors such as Marvin Minsky and Hans Moravec - widely respected in the area of AI and IT - were very interested in the idea, even though clearly it is completely unrealistic at this point. ${ }^{164}$ (It is only different from Lem's phantomatics in that Lem does not allow for rejecting the body, which by the way, as I have pointed out earlier, is an internal contradiction of phantomatics as part of the autoevolution project. This idea, however, highly resembles Lem's "cosmogonic engineering," which will be discussed later.) It is again a certain concept, less scientific or technological than resulting from many people's state of mind at the beginning of the 21 st century.

Another important cultural correlate of cyberspace would be cyberpunk. It is a literary genre inaugurated by a novel by a Canadian, William Gibson, titled Neuromancer (1984), which is often quoted and analyzed by media theorists. The novel is set largely in virtual space generated by computer systems. By now the motif has been largely exhausted, but taking into account that Gibson published Neuromancer when personal computers were still a technological novelty, one cannot help but admire his pioneering position. Cyberpunk is a literary genre in its own right now, with hundreds of works. Cyberpunk novels are usually set in environments dominated by computer systems, very much like the world outlined by Lem in ST, especially in the chapter I am currently discussing here. In Poland the most eminent representative of cyberpunk is certainly Jacek Dukaj (born in 1974). There are formal similarities between his works and Lem's novels insofar as both contain numerous descriptions of alien ("inhuman") worlds (such as VR or other planets), and those descriptions equal Lem's best ones from Eden and Solaris in how vivid and powerful they are. ${ }^{165}$

Taking into account the length and the subject matter of my book, I have to limit my discussion of the cultural role of the Internet and cyberspace to these few side notes. Let us return to Lem's phantomatics now.

I have mentioned "teletaxy" and "phantoplication" earlier. Having discussed the psychological and social consequences of phantomatics, Lem then remarks:

164 Moravec, a professor in robotics at Carnegie Mellon University, presented an operational vision of moving human personality into a machine in his book Mind Children (1988).

165 On Dukaj, see more in Chapter 25. 
The categorical statement with which we closed the previous section - that it is only possible to be either oneself or nobody - does not contravene phantomatics' potential ... We mentioned earlier that this lack of authenticity in a phantomatic vision, the fact that it represents a biotechnologically executed escapism, is a big problem. Cybernetics offers two ways of overcoming such inauthenticity of experience ... we shall call them teletaxy and phantoplication. (217-218)

"Teletaxy" means "connecting someone to a machine that only functions as a link between him and the real world ... Teletaxy connects a person to a randomly chosen fragment of reality, as a result of which he experiences the reality as if he were really placed inside it" (218). The machine would be a "remote-I," connected with the senses of the person steering it. Lem points to an astronomical telescope as a prototype of such a teletactor.

"Phantoplication" means something very similar, with the one difference that instead of a machine remote-I there is a real person. Specifically, it is about

connecting one person's neural pathways to those of another person. Thanks to this procedure ... a thousand people can simultaneously "take part" in a marathon ... However, this method only involves a unidirectional information transfer, since those "connected" to the runner are not all able to command his movements. (219)

Lem only devotes one paragraph to each of these ideas, after which he again returns to the issue of personality in the context of phantomology, which, as we already know, he finds extremely fascinating. ${ }^{166}$ Earlier, he described personality problems caused by phantomatics, and now, in the penultimate section of the chapter ("Personality and Information") he focuses on paradoxes of "multiplied identities."

Before I proceed to discuss them, I need to point to one more aspect of phantomatics, or, more precisely, a lack thereof. In his analyses Lem pays very little attention to phenomenological approaches to perception. He implicitly accepts that human consciousness and the external world are strictly separated,

166 In a letter to Michael Kandel on October 19, 1974, he wrote: "As to PHILOSOPHY now, I am quite rational and fairly clear in gnosiology, but it is not the same with ontology, because I think there is an inexplicable mystery there: the Ego (I) - physics, biology and other empirical sciences can sufficiently explain the emergence and existence of "others", i.e. "third parties", but we can NEVER count on them to explain where I come from. There is no clear link between "they" and "I" at all in the natural sciences, because "I" is existentially a unique point through its "unleaveability" (you cannot "leave" your I, you cannot go beyond it) and HEREIN FOR ME LIES THE GREATEST MYSTERY OF BEING, while the rest are merely the consequences of IT... (Hence, the "amazement with being", etc.)." (Listy..., 218-219) 
and the transfer of data via the body (or sensual impulses) is clear. Such approach is obviously reductive, but perhaps it was necessary to accept it in order to speak of phantomatics as a technology, and not just a vague idea.

In "Personality and Information" Lem takes up a theme of "multiplied identity," which came up earlier in Dialogues; this time it is connected to the issue of teleportation. Lem is considering a possibility of framing human personality in terms of theory of information, and accepts implicitly that "personality" can be fully reduced to physiological and mathematical data. Such assumption is necessary in order to meaningfully discuss teleportation at all. ${ }^{167}$ The attempts to explicate the notion of personality in terms of cybernetics again lead him into paradoxes we saw earlier in Dialogues, all the more complicated by the fact that in ST there is the additional element of genetics (identity as a derivate of phenotype). Here again from his complex argument Lem draws a conclusion that a "copied" or "telegraphed" individual would not be identical with the "original," even if it had the same atomic structure (that disregarding the influence of quantum uncertainty). To explain this surprising lack of identity, Lem vaguely refers to extraphysical factors, while also stressing it has nothing to do with spiritualism.

I believe this issue could have been a bit clearer, if arguments about the historicity of our existence were used. Lem nearly always disregards history, cultural tradition and those ways of thinking about people, which take into account the past, such as hermeneutics. In light of his autoevolutionary projects in ST it is understandable, because autoevolution - to which I will return in Part Three means, among other things, rejecting historicity. But there are points in Lem's thinking that would benefit from including history in the view. This is one of such moments. In order to explain the nonidentity between the "copied" man (just as the nonidentity of a clone) and the "original," it is enough to explain clearly that each human being is unique due to its own history and - in a broader context - due to how differently every human is affected by the history of culture. Even the "way of creation" of a human - be it conception, artificial insemination,

167 Teleportation is the means of transport of choice for the protagonists of the American sci-fi series Star Trek, which was one of the icons of the 1980s mass culture. It inspired a distinguished physicist Lawrence M. Krauss to write a book The Physics of Star Trek (1995), where he discusses the possibility of really implementing some of the "fantastic" technological solutions known from the series, including teleportation. However, as a physicist he pays little attention to the issue of personality and consciousness, which, apart from the technological issues, seems crucial to the question of human teleportation. 
"copying" or cloning - is, of course, an element of one's biography and as such it influences individual identity, shaping it in ways very different from any other individual. The "artificial" methods are perhaps not as different from the "natural" ones as Lem and contemporary commentators of the issue of cloning claim - and this is what leads them to engage in a heated discussion of the question of identity. Is the difference between a clone and a human born "naturally" bigger than between a Wall Street broker and an Indian pariah? (I need to point here again to Lem's obliteration of the Natural/Artificial distinction.) We are all equal in face of history in a sense that it shapes each of us differently than everyone else. The problem of copying people, and cloning, is telling in a sense that it juxtaposes - and violently, too - the presence of the historical dimension of culture and the absence of it in technology. Perhaps the problem of the individual identity of clones can be reduced to that juxtaposition. Such a juxtaposition would also be a symptom of a major breakthrough in the history of our species, which ST describes, I believe. It describes a shift from history to autoevolution, transgressing the limits of humanity.

Lem would disapprove of such an approach to the issue mainly because it presents human identity as dependent not on eternal, or at least unambiguous laws of Nature, but on something as appallingly random and incoherent as history and culture. Given the mutual influence of culture and technology within "the technologies of producing people," one could also ask whether a human (a person) has a humanistic coefficient. Florian Znaniecki applied the notion only to objects in human environment. But autoevolution, with its obliteration of the distinction between the Natural and the Artificial, allows us to ask it also about human - because for Lem we become our own products, and not in a "spiritual" sense, as it had been earlier, but in a material sense, as we produce and modify our bodies. It seems to me though that Lem would respond in a negative, assuming he would even see the question as valid. However, I would claim that at the current stage in our civilization's development (before autoevolution) the only way to avoid the paradox of "multiplied identities" is by assuming that every member of our species, no matter how he or she was created, has an individual, unique humanistic coefficient - a set of meanings ascribed to him by others and him or herself. The incoherence of this solution within the project of autoevolution stems from the fact that "copying" people is just a half measure in light of this project, just as phantomatics is a half measure. Only a full autoevolution - a complete reconstruction of the human species, a full detachment from the form of humanity we have known so far - will allow us to avoid such incoherences or contradictions. Lem does not say that explicitly, but I believe it is a conclusion 
that can be drawn from ST as a whole; ST contains a lot of implicit assumptions, which I am trying to bring to light here.

A curious reader, still remembering some of the more recent intellectual trends, might ask what is the relationship between phantomatics and Baudrillard's simulacra. The answer is: there is none. For a very simple reason: Lem's phantomatics is not only an element of the project of autoevolution, but it is also based on an intervention into the human sensorium. And Baudrillard's metaphor of simulacra refers only to the internal circuits of culture; it has no links with issues of biotechnology. However, it is true that Baudrillard's thought, whatever our judgment about its content and precision, does describe in its own way the same phenomenon that Lem focuses on in ST: the destruction of the Natural/Artificial opposition. ${ }^{168}$

168 Baudrillard locates the opposition inside culture as opposition between original and copy. See especially his description of replicas of prehistoric cave paintings in The Precession of Simulacra essay and the entire argument presented there. 



\title{
15 On How to Farm Information
}

\author{
Of course, I am always right, how exhausting! \\ Letter to Michael Kandel, [month unknown] 22, 1974
}

The penultimate chapter of ST is titled "The Creation of Worlds." It contains an outline of a radical transformation of external reality of human life - but still only the external one. It is the penultimate stage of autoevolution.

To totally restructure reality, a total method is needed. In this chapter Lem seems to be taking a step back from his thesis about theory and practice being the same, which he stated in the fifth chapter, and returns to modeling a scientific theory. He is clearly irritated by the fact that science develops randomly and chaotically, not only because it is belittling to his vision of man, but also because it limits the Designer's "omnipotence." In short, there is a need for an "applied metascience":

Human civilization is like a ship that has been built without any design plans. The construction process was extremely successful ... Yet this ship is still rudderless. Civilization lacks knowledge that would allow it to choose a path knowingly from the many possible ones, instead of drifting in random tides of discoveries ... Science is playing a game with Nature, and even though it wins every time, it allows itself to be drawn into the consequences of this victory and exploit it, as a result of which, instead of developing a strategy, it ends up just practicing tactics ... We have to learn how to regulate scientific progress too; otherwise the random character of any future developments will only increase. (235)

Had Lem had a chance to read Kuhn's The Structure of Scientific Revolutions, published two years before ST, he would have likely agreed with his analysis of progress in science. But Kuhn only described the world of science - Lem wanted to change it. ${ }^{169}$

The change would amount to so much as transforming the process of science's evolution from a chaotic one into a strictly determined process. Just as pantocreatics is meant to be a "rational" replica of Nature, and autoevolution a rational replica of bioevolution, "information farming" is to give as full control

169 It might be worth noting here that in the passage I have quoted Lem repeats - intentionally or not - one of the oldest topoi of European literature, that is, the image of society as a ship on a rough sea, threatened by destruction. 
over the increase of knowledge through science. And all this so that civilization gains "the freedom of strategic maneuvering to be able to control its path" (236).

What is information farming? In ST we read:

We are supposed to go all the way toward automatizing Science. This is a terrifying task ... We are to invent a device that will gather information, generalize it in the same way the scientist does, and present the results of this inquiry to experts ... Our device thus produces theories. (242)

Information farming is then something like a programmed metascience. On the following pages Lem discusses philosophy of science and links between information processing and biology (in human brain). This discussion remains unrelated to any "official" currents in philosophy of science and they do not include anything that would not have been said in the preceding chapter already. Generally, in his version of philosophy of science, Lem leans toward a conventionalist orientation. The main part of the chapter is devoted to the technology of information farming. The description includes elements of cybernetics, theory of information, biochemistry, embryology and genetics. The main idea is:

Could we not take up "information farming," cross-breed bits of information with one another, and initiate their "growth" so that we eventually obtain a "mature organism" in the form of scientific theory? (251)

The procedure would as it were repeat the development of living organisms. Every complex living organism grows out of a very simple nucleus, for example, a spermatozoid and an egg cell. The transition from this simple stage to the phenomenally complex grown-up organisms is an object of amazement and fascination (and studies) for many scholars - and of Lem. He remarks that the process of ontogenesis, which enables such a vast multiplication of information in an organism, must be subjected to a set of some very precise laws. But if that is the case, then we could, Lem says, design a quasi-biological system, whose initial structure would have some scientific information built in, and a set of instructions of development. The system would then fulfill those instructions, just as a human embryo and fetus do, resulting in a "mature organism - scientific theory."

This idea from Lem may seem completely fantastic. I will try, however, to treat it as a serious idea, with its own place in the project of autoevolution. The idea of inscribing information inside the molecular structure of matter, or even on a yet lower level, has particular intellectual bearing. We can immediately notice that it eliminates the problem of representation mentioned before. 
The questions of adequacy of linguistic signs and the objects they describe simply disappear when the language of theory becomes a tool of practice just as performatives work in magic. Lem believes here that the language of scientific theory could operationally be the same as genetic code. To prove it, he produces lengthy arguments about the essence of natural languages (section titled "Linguistic engineering," 267-282). Lem's philosophy of language is, so to say, just as "private" as his philosophy of science, that is, it has just as little connection with any known philosophical currents, and it is just as deeply permeated with imagery derived from biology. In short, his theses can be summarized as follows: the meaning of a genetic code is its performativity in the process of ontogenesis (so, eventually, a mature organism), and the veracity or falsity of its "statements" is determined by natural selection. It is assumed that the same model can be applied to the relationship between the language of theory and molecular structures, which makes "information farming" possible in a sense that the evolving system will eventually result in complexity of information that will exceed the initial set - as is the case in ontogenesis. Similar parallels between natural language and genetic code are drawn in a book Das Spiel - Naturgesetze steuern den Zufall by Mandfred Eigen and Ruthild Winkler, which was published a decade after ST (Polish edition released in 1983).

I mentioned that Lem "seemingly" withdrew from the idea to identify theory with practice. The problem lies in a sort of conceptual split, which Lem apparently does not notice. "Information farming" is indeed an example of such identification, as logical and intellectual operations are replaced here with physical and chemical processes. However, - and that is the key problem - the processes result in another theory, albeit expressed not through a set of formulae and theorems, but rather as lumps of matter of complex molecular structure from which a theory can be deciphered. It is then a sort of intermediate stage between "pure theory" and "pure practice." The author's aim, as he emphasizes, is "automatizing Science," thanks to which the Designer will know "what to do." But "information farming" is not itself a construction, it is only a building instruction. Its advantage is that it eliminates the chaotic heuristics from the scientific process. However, the price is that even though theory becomes practice, the practice remains a theory. Lem, too, cannot see this contradiction or he glides over it on purpose.

We should remember that for Lem the project of "information farming" is merely a remedy to "megabyte bomb" and the chaotic increase in knowledge, so 
it is only an intermediary step toward autoevolution, and not an element constituting autoevolution. As we can clearly see now, ST mostly consists of such "introductions," and this is why it has to be very generic about the questions of the impact of technology on human life. Only the last chapter will show that technology is to change it through and through, all the way to its biological foundations.

Could these ideas from Lem be fulfilled in any way? The idea of coding linguistic meanings in material systems is of course fulfilled by every computer, in its integrated circuits or chips, memory and logic gates. But Lem's project is much more advanced. Computers based on von Neumann's classic architectural design operate only in a binary system, and all data they process have to be expressed in the binary code. Lem has something very different in mind: expressing a language of scientific theory in a representation of biological molecular structures, the way genetic code is represented in DNA sequences. Contemporary technologies are slowly getting closer to such options, or similar ones. I am speaking of quantum computers and biocomputers here.

In the late 1970s Richard Feynman was the first to put forward the idea of bringing mathematical processes to the lowest, quantum level of matter. He has been building such systems since the 1990s. In quantum computers information is inscribed and processed not as bits but quantum bits, that is, quantum states of individual atoms and their superpositions. It increases the computing power by many orders of magnitude and it is a tremendous qualitative change in comparison to digital computers. If quantum computers were popularized, it would probably get us closer to the idea of "information farming," although it seems unlikely that even those machines would be able to add new data to their databases on their own. Biocomputers are much closer to Lem's ideas, that is, machines that combine mechanical systems with living matter. Future research on these systems and a technology of inscribing data expressed in human natural languages into DNA sequences (DNA digital data storage) will allow us to see to what extent it is a fulfillment of the idea of information farming.

Apart from these technologies, there are also theories describing reality in a way that make "information farming" possible. These are self-organizing systems theories, which have been developed since the 1960s by Humberto Maturana, Francisco Varela and Niklas Luhmann - I have mentioned them in Part One as the late (and somewhat alienated) offspring of cybernetics. These theories often employ the notion of "autopoiesis," which means the ability of complex systems (organic or inorganic) to transform their own structure and qualities. Such theories have a lot in common with emergentism, a view that a system as a whole has qualities that cannot be reduced to the sum of its parts and relations 
between them. This position has been mostly shaped in opposition to contemporary reductionism in natural sciences. All these currents resemble the premises of Lem's project of "information farming" to some degree. ${ }^{170}$

And what is the relationship between "information farming" and "the creation of worlds"? It seems that in this case it is quite simple. Again, Lem seamlessly oscillates between his "theory" and "practice." The project of automatized science is a "user manual" for the Designer, a set of practical tips. It was discussed in "Prolegomena to Omnipotence" as well, but there it was about something else: Lem focused on a set of general rules for the Designer to follow, something like a "constitution," setting the terms of "omnipotence."

The two final sections of "The Creation of Worlds" are "The Engineering of Transcendence" and "Cosmogonic Engineering." Lem reaches the limits of his own technological imagination here. The connection of these passages of ST with the rest of the book seems rather feeble, even though the author claims they are a description of "another possibility of taming the information deluge" (282). This is not so much about the "megabyte bomb" though, as it is about the human yearning for faith, for irrational metaphysics - which Lem sometimes notices, but does not approve (we have already seen, what he is capable of saying about religion) and tries to frame the issue in terms of technology. So it is like mixing fire with ice.

The way he does it is impressive. He begins by pointing out the futility of consumerism:

It is often said that the separation of the present reality from transcendence, so commonplace today, is pernicious in that it underlines the universe of fixed values. Because life on Earth is the only thing that exists, because it is only in this life that we can seek fulfillment, the only kind of happiness that can be offered to us is purely carnal. Heavens have not revealed anything to us; there are no signs that would indicate the need to devote ourselves to some higher, nonmaterial goals. We furnish our lives ever more comfortably; ... we invent more and more ephemeral trends, dances, one-season stars; ... Entertainment derived from a nineteenth-century funfair is today becoming

170 From here it is close to scientific mysticism of, for example, "the gnosis of Princeton," which has been the position of many scholars from Princeton since the 1970s (with the most eminent among them being Fritjof Capra). "The Gnosis of Princeton" involved a conviction, that every element of matter, all the way to atoms and elementary particles, is endowed with some kind of consciousness. This shows that Lem's thought does occasionally, against his will, get close to the border between scientific thinking and magical and mystical one. For more on "the gnosis of Princeton", see: Raymond Ruyer, La Gnose de Princeton (Paris: Fayard, 1974). 
an industry underpinned by an ever more perfect technology ... At the same time, a feeling of emptiness, superficiality, and sham sets in, one that is particularly dominant in civilizations that have left the majority of primitive troubles, such as hunger and poverty, behind them. Surrounded by underwater-lit swimming pools and chrome and plastic surfaces, we are suddenly struck by the thought that the last remaining beggar, having accepted his fate willingly, thus turning it into an ascetic act, was incomparably richer than man is today, with his mind fed TV nonsense ... The beggar believed in eternal happiness ... looking as he did into the vast transcendence ahead of him. Free time is now becoming ... actually a vacuum, because dreams can be divided into those that can be realized immediately ... and those that cannot be realized by any means. Our own body, with its youth, is the last remaining god on the ever emptying altars; ... yet even those wonders of civilization turn out to be of no use. Nothing shows him what to do, what to aim for, what to dream about, what hope to have. (283-284)

It might be hard to believe this was written in Gomułka's Poland. The passage sounds more like a text by an American conservative commentator such as Allan Bloom, and written in the 1990s, or it could be a blurb for one of Houellebecq's novels. Again, it shows how perceptive Lem was about the role of technology in human life (which was increasing at a much lower pace then than it is now). In the last years of his life, he would also make similar statements, but in a much grumpier tone. This passage is actually quite unique in ST, because, as I have mentioned, Lem was not interested in the social aspects of technology. Perhaps because already then he saw more negatives than positives to it. Why then, we could ask, did he put so much emphasis on technology - so much so, that he was often accused of scientism? I will try to partially answer that question once I have looked into his response to "vacuum of transcendence."

What is Lem's response to it? The same as extropians have today, even though they seem not to notice the vacuum. Lem describes "machine," inside which there is a whole world, peopled with rational creatures - it is a product of the Designer, and it is made of electrical impulses. It is also a huge digital computer simulating a highly complex global physical reality. Part of the machine is "the Other World" - a place, where the residents go after their death. It can be programmed so that it can realize any type of transcendence that has ever appeared in human thought - from the Christian paradise and hell to Buddhist nirvana. Lem emphasizes - and it is an important methodological remark for him - that he is using the term "machine" only for the lack of a better one, which would be more fitting for the entity he has in mind. Today we could call it cyberspace. As Lem writes later, the designers of such world, suffering from "withering of transcendence" in their own reality, could at some point decide that it is possible and advisable to make an "Exodus" to the other, "artificial" world - as it does admit transcendence, which they know for sure, having programmed it that way. 
We can see that from the technological point of view this is the same idea as the ones presented by extropians, which I have presented when discussing phantomology. ${ }^{171}$ But Lem, more attuned to philosophical questions, immediately renders it meaningless. In the sketch of a dialogue between a Designer and a skeptic (286-287), he proves that the contradiction does not lie in the "artificiality" of such a world (and we have already showed that the notion itself is meaningless in Lem's thought), not in its "limits" (as it is no more limited to its inhabitants than ours is to us), but in the fact that for its inhabitants the transcendence it offers can be just a matter of faith, just as it is for us. Living inside such a world they cannot prove the existence of "afterlife," without depriving it of its meaning. And it is also ontologically impossible, because the line between life and death is just as strict for them as it is for us - this is how the Designer programmed it, exactly so that they can only believe in their afterlife, and not know it. Only an external observer of such a world (i.e., the Designer) knows that the afterlife exists. The vast difference between faith and knowledge or science is absolutely clear for Lem here, despite his commitment to Reason. His Designer says:

Belief without after-death fulfillment means incomparably more to mortals than fulfillment or transcendence not preceded by belief... this is a highly interesting problem. It is real, that is, soluble, only for an observer who is positioned outside that world ... When it comes to ... suggestion that we introduce miracles into this "new world," we have to reject it ... Miracles are not a confirmation of belief. They are a transformation of the latter into knowledge because knowledge is based on observable facts - which the "miracles" would then become. Scientists would make them part of physics ... to prove belief is to destroy it as it only exists in its full absurdity and groundlessness, in its rebellion against empiricism ... Put briefly, a world in possession of the current knowledge about transcendence and what it looks like is a world without belief. (287-288)

171 Perhaps it is worth mentioning here that the source of all ideas of transferring human minds to cyberspace can be traced back the notions of noosphere and Omega Point established by Pierre Teilhard de Chardin. The cyberspace itself, for example, the web, is sometimes seen as an incarnation of the noosphere, although one might doubt whether Teilhard would agree. An American cosmologist Frank Tipler is the author of an idea that the human kind, threatened by implosion of the universe (assuming the process will last long enough to be witnessed and that it will follow the scenario of expansion and then contraction) might make a "leap" into an artificially created dimension of time and space. Such concept is also akin to the ideas of Lem, Teilhard and the extropians. 
This sums up one of the most important problems of the Western philosophy: the question of validity of unprovable statements about the world. There are many people who need a superior, outworldly justification for the world, but such a justification can only be effective according to Lem if it is arbitrary. Credo, quia absurdum, as Tertullian put it. ${ }^{172}$ This dilemma could only be eliminated if we could place ourselves outside this world and remain permanently "in-between worlds."

Thus, a seemingly purely technological idea seems to become a center of purely philosophical thinking for Lem. ${ }^{173} \mathrm{He}$ finishes with the following sentences:

The conclusion is that the source of Great Anxiety, and of the equally dangerous mindlessness, lies not in the "amputation" of transcendence by materialism in man but rather in the present social dynamics. It is not a renaissance of transcendence that is needed but rather a renaissance of society. (288)

With this sentence Lem takes a step toward philosophy and social practice, but faithful to his convictions - he does not go any further down that road. He is convinced that while technology can be a correlate of social issues (which can be clearly seen in all the social meanings ascribed to the web), but it almost certainly cannot be a remedy to them. Technoevolution progresses independently from the development of society. These are two separate currents. This view, which can be traced throughout ST, is one of the arguments in favor of the utopian character of Lem's thinking, as it necessitates assuming that human kind will somehow "grow up on its own" to benefit from all the amazing technological possibilities described in ST. Lem knows about this utopianism, but he does not like admitting it (as in the already quoted passage from Studia Filozoficzne). So far, however, there is no reason to believe that the technological growth has anything to do with the ethical progress in users. This chasm is quite problematic

172 This is one of Lem's favorite Latin quotes. His view on faith is quite different from contemporary theology. Lem seems to have especially valued Tertullian, PseudoDionysius the Areopagite, Nicholas of Cusa or Pascal - so thinkers representing negative theology.

173 Again, I need to invoke the piece Non Serviam from Perfect Vacuum. Its "author" and protagonist, Professor Alfred Dobb, is giving an account of a discussion between two "personoids" he has created on a computer. They are discussing the genesis of their world, and they conclude with an accusation that its potential creator (i.e., Dobb) has entangled them in insolvable philosophical dilemmas (highly resembling ours). Ironically, Lem makes Dobb close the account with a statement that he feels responsible for the being of these creatures, so, as long as he can, he will not turn off the computer, despite appalling electricity bills. 
for the project of the species' autoevolution, as I will show in the next part of this book.

The section "Cosmogonic Engineering" develops the idea of "creation of a world," but without the issue of transcendence. Lem simply (?) proves the technological possibility of such occurrence, again being a quarter of a century ahead of extropians and other authors who were only inspired to think this way by the rapid growth of IT in the 1980s and 1990s. Lem imagines such a world as a cosmic-sized computer system, powered by star energy and simulating all "natural" phenomena in its circuits. No need to add here that the terms "natural" and "artificial" lose all their meaning by now. ${ }^{174}$

At this point, however, Lem get trapped in the paradox he has just thoroughly analyzed a moment earlier:

Equally, they [inhabitants of the world built by the Designer-Cosmogonist] are unable to establish whether someone created them and the cosmic habitat they freely roam, and, if so, who it was. Yet even though we have not been created by anyone (or at least by any personified being), there are plenty of philosophies that claim the contrary, declaring that our world is not all there is. But people who have pronounced such things have the same senses and brains that we do - sometimes rather sharp brains! (293-294)

This is somewhat surprising. One is tempted to ask where from the author draws his unshakable certitude that there is no creator of our world, given that on the preceding pages he has described nothing short of a creation of a world. How can we know that the building material of our universe - matter, energy and information - is not a "set of building blocks" available to the Designer in a higherorder world? The author himself admits that the sequence of such creations can be very long (292-293). This contradiction in Lem's thinking is an illustration of a fairly persistent conflict in his work between the scientist and empiricist conviction about the superiority of Reason and Science over other human ways of experiencing reality on one hand, and a strong "sense of mystery," a metaphysical yearning for a Great Dream to be hidden somewhere behind the facade of reality on the other. This clash of conviction actually has its own separate, thorough

174 Here we should invoke New Cosmogony from the Perfect Vacuum volume, which is a quasi-fiction developing the idea. Lem's apocryphs are usually read as intertextual games of the type Borges engaged in. However, they include a lot of autocommentaries on Lem's discursive texts. It would be advisable to write an analysis that would give a detailed idea of all such links, just as I suggested earlier for links between his discursive and grotesque writings. The thesis about close links between Lem's discursive works and his fictions is commonly accepted in Lemology, but it rarely produces thorough and precise analyses of the subject. 
description within Lem's oeuvre. It is the narrator's words in His Master's Voice, which express the conflict between amazement at the impersonal absolute of the laws of science on the one hand - and the impact of cumulated individual life experience, the psychological capacity of a scholar, his private fears or obsessions. It all clashes inside Peter Hogarth's consciousness. While generally Lem remains insensitive to the relationship between science and society, he does seem to understand the relationship between science and the scholar's personality very deeply. Generalizing a little, one could say that he cares about the adventures of an individual and the universe - and nothing less, nothing in-between. It is nearly certain that his interests were shaped in this way by his early war and Holocaust trauma. ${ }^{175}$

Later in the section "Cosmogonic Engineering" Lem points out that

The physicists from that world would only be able to discover the fact of creation (or rather of "having been created") by comparing our real world with their own. It is only then that they would be able to see that our world is one level of Reality short when compared with theirs ... Figuratively speaking, a created world [by the Designer] is perhaps like a very stable, very long, and internally coherent dream that no one is dreaming but that rather "is dreaming itself" - inside a "digital machine." (294-295)

"Cosmogonic engineering" would then be free of the contradictions that phantomatics is flawed with, and in this sense it would be the "correct" variant of autoevolution. It is, however, a variant, which exceeds the project contained in ST as a whole. Lem sees it as a "deviation" and concludes the chapter with the following:

Someone could ask whether I believe it is at least a little bit likely that humans will one day make such - or similar - plans ... I do not think so. Yet, if we take into account all those countless intelligent worlds revolving inside those enormous galaxies, while the number of those galaxies is incomparably higher than the number of ... the grains of sand in a desert, this very number makes any improbability possible ... Yet for no one in this whole abyss of stardust to arrive at an idea about such an undertaking, to try to bite more than it seems possible to chew - this indeed seems rather improbable to me. Before someone categorically disagrees, please, take a moment: July nights, during which the sky is so starry and beautiful, really encourage such contemplation. (296)

We already know what Lem thinks about a starry sky. In Part Three I will try to show what it entails for the moral law.

175 I try to prove this thesis in the article I have already invoked here, Lem fantastyczny czy makabryczny? 
Since following Lem's thought has led me here to issues of utmost fantasy (although still rooted in science), I will quote one more passage from this chapter:

Pantocreatics does not thus create eternity because this is impossible. Fortunately, it is also unnecessary. We have nothing in common with a rather peculiar being who would want to exist for billions of years on an individual level and who would realize what such an existence means. (No human being is ever going to be able to imagine that.) (290)

It seems to be an accurate statement. But even this immeasurable difference has not prevented scholars from considering the existence of such forms. It was undertaken in the context of the "heat death" of the universe - a scenario of universe's development based on constant expansion until nearly all thermodynamic processes cease. Universe would then become a practically infinite, empty space, with rare individual elementary particles. (And the word "rare" is to be understood as broadly as possible. It has been calculated as one electron per a volume exceeding the universe observable today by many orders of magnitude.) There are people who dare to speculate about possible forms of life in such conditions. These would have to be forms with radically slow life processes (due to the lack of energy in their environment), and so their life span would be counted not even in billions of years, but in billions of billions of years (we find ourselves in the world of big numbers were the cumulated exponents deprive imagination of all its capacities). An article on the subject was once published by Freeman Dyson, ${ }^{176}$ which was then taken up by Paul Davies in The Last Three Minutes, ${ }^{177}$ and eventually found an exciting and well written rendition in a book of two American cosmologists Fred Adams and Greg Laughlin titled The Five Ages of the Universe. ${ }^{178}$ It is one more evidence how far scientific deduction can take us, although in this case it is pure fiction, not a description or a prediction. Perhaps this is just the kind of sci-fi Lem dreamt about. ${ }^{179}$

176 Freeman John Dyson, "Time Without End: Physics and Biology in an Open Universe," Review of Modern Physics, no. 51 (1979), 447. Dyson's main goal was a polemic with Steven Weinberg's statement in his famous book The First Three Minutes: A Modern View of the Origin of the Universe: "The more the universe seems comprehensible, the more it also seems pointless."

177 Paul Davies, The Last Three Minutes: Conjectures about the Ultimate Fate of the Universe (London: Weidenfeld \& Nicolson, 1994).

178 Frank Adams, Greg Laughlin, The Five Ages of the Universe: Inside the Physics of the Eternity (New York: Free Press, 1999).

179 Fred Hoyle, who probably has similar intellectual leanings, wrote a novel about an intelligent form of life of extraplanetary size (The Black Cloud, 1957). Lem mentions 
After this digression into the most remote domain still available to our mind's reach (although too distant for our imagination to grasp it), in the last chapter of ST Lem returns to the project of autoevolution of our species. The project - or its interpretation I am about to present - involves a number of ideas that have been circulating in the late 20 th and early 21 st century.

the novel in ST on page 318. Hoyle, however, is more interested in the links between science and politics than in the features of the entity. 


\section{Putting Pieces Together}

The plethora of themes in ST may confuse - and it does confuse the general meaning of the work, which I wanted to bring out here. So I will now summarize it briefly.

Summa Technologiae develops the kind of thinking about the role of technology in the human world, which Lem started to work on in Dialogues. Just as in Dialogues his discourse can be accused of being somewhat chaotic - he put in it everything he was interested in at the time. Even if that is the case, it has no bearing on my analyses. I believe ST is a global prediction of how our civilization will develop technologically, and it includes an elaborate project of autoevolution of our species, based on a set of assumptions pertinent to philosophy, anthropology and social practice. Some of these assumptions have already been discussed in this part of my book. These are, above all: eliminating the opposition between the Natural and the Artificial and the conviction about the progressive character of autoevolution and about its independence from social processes running parallel to it.

I have been trying to show to what extent the stylistic and formal devices Lem used in ST affect the overall shape of his project, especially the fact he does not differentiate between a scientific text and an informal essay. Lem's thinking in ST develops as follows: first, he considers the possibility of existence of intelligent forms of life different from us, treating it as an initial point of departure for the autoevolutionary project. He then moves on to what is now known as Artificial Intelligence. Its potential can be a step in acquiring control over production and distribution of information and knowledge, and it has the side effect of making "mechanical social control" possible. In the fifth out of eight chapters, he presents a metatheoretical discussion of the scope and methods of the Designer's actions - in ST it is a symbolic figure representing the human technological potential, which can be used in autoevolution. He talks about "phantomology," the "early version" of reality subjected to radical technological transformation. In the penultimate chapter, Lem offers a project of "information farming," which is to be a response to chaotic increase in knowledge, allowing for practical fulfillment of far-reaching autoevolutionary plans presented in the last chapter, which shall be the subject of my analysis on the following pages.

As its final result autoevolution is to lead to rejecting the earlier form of human existence, both its spiritual and physical aspects. The totalizing character of the autoevolutionary projects and Lem's partially concealed meliorist anthropology 
give utopian qualities to the whole idea. From a humanist's point of view, its most striking feature is complete rejection of human historicity and neglecting the impact of social processes on technological evolution and autoevolution. Yet those features are justified given other premises Lem accepts. In his vision, technology replaces culture in its function of a reservoir of symbolic meanings and values and thus technology interferes with every sphere of life, completely permeating human material environment - it becomes what philosophers used to call Lebenswelt.

This summary makes the structure of ST seem fairly clear, but Lem's argument is constantly interrupted with dozens of digressions and side notes, which may give an impression of the whole being quite chaotic, especially to a reader unaccustomed to this kind of broad intellectual gestures that are so typical for this particular author. Moreover, he himself is frequently skeptical about his arguments and interrupts himself with self-commentaries, doubts or methodological remarks. As a result ST is a very layered text that renders itself very easily to diverging interpretations. By no means am I claiming that the attempt at interpretation that I am presenting here is the final one. 
Part Three Autoevolution and Posthumanism 



\section{Themes of Lampoon of Evolution}

In Part Three of this book I will discuss the last chapter of ST, and then some of the currents in contemporary philosophy and sociology, which in one way or another seem to be akin to Lem's project of autoevolution. These are mostly convergences rather than any kind of genetic affinities, and will partly be constructed through my interpretations. The aim is to show that Lem's work, especially ST, has great albeit so far unacknowledged significance for the contemporary problems of our civilization.

The last chapter of ST is titled "Lampoon of Evolution." It includes a description of the project of autoevolution of human species, the very description to which the rest of ST is but a set of introductory studies, as I have suggested earlier. The word "lampoon" ought to be taken with a grain of salt, just as other rhetorical devices Lem uses in the titles of his chapters and sections of ST. It is a testimony to Lem's personal and internally diverse attitude to bioevolution. He both admires the phenomenon, which he often hypostatizes, and is critical and hostile to it. The admiration comes from the fact that bioevolution has produced such amazing beings as a biological cell and rational humans. ${ }^{180}$ The criticism and hostility stem from the fact that for Lem the rationalist the process is unbearable in how blindly random it is. This randomness has had a huge impact on the emergence of our species, on its physical and physiological shape and, more implicitly, on our minds, our culture and our history.

Autoevolution is to be, among other things, our response to this randomness. The fate, incarnated in stochastic mutation and selection processes, led to a situation where we, as the only form of life to our knowledge, have the ability to transform our mode of existence. It can be seen as the highest form of autarky.

The difference between "the artificial" and "the natural" thus begins to blur because "the artificial" is capable of exceeding "the natural" within any range of parameters that are of importance to the Designer ... Man [as a bodily creature - PM] remains the last relic of Nature, the last "authentic product of Nature" inside the world he himself is creating. This state of events cannot last for an indefinite period of time. The invasion of technology created by man into his body is inevitable. (299-300)

180 In ST as in other texts Lem sings praises of the genius with which organelles are designed and how they can adapt. In Lampoon, in the section titled "In the Eyes of the Designer" (335-346) there is a whole catalogue of Evolution's flaws as seen by Lem. 
Lem is again giving voice to his credo, as heavy as it is with implicit anthropological assumptions: we do not choose autoevolution; it is an inevitable result of a choice made centuries earlier. As it happened many times before in history, chance becomes necessity.

How will the process develop? In "Reconstructing the Species" section there are three alternative scenarios offered. In the first one autoevolution happens "only" through biotechnology - in its stage we already know today.

In this case, biotechnology's tasks will consist in eliminating diseases or preventing them and also in replacing waning functions or defective organs with their biological substitutes (such as transplants, tissue grafts) or with technical ones (prostheses). (300)

According to Lem "this is the most traditional and shortsighted approach" (300), and it is based on an assumption that "the human organism is given and thus fixed in its overall design" (300). This entails accepting the basic postulate - in the context of the public debate on biotechnology - presented by contemporary social and political humanism, that is, the inviolability of the biological structure of our species. But even this "traditional and shortsighted approach" already represents an excessive intervention into the human condition for many scholars and commentators today. The contrast is a clear testimony of how foreign all forms of humanism are to Lem, whether right-wing/conservative or left-wing/ liberal. This issue will be discussed separately later.

The second option is "a plan for creating 'the next model' of Homo sapiens" (301), in which "while doing everything as described earlier [i.e. in the first option] it is possible to combine those actions with a superior one, which will involve replacing Nature's evolutionary gradients with man's purposefully regulatory activity" (300). This variant is then all about replacing evolution with construction, and chance with a plan. Describing those scenarios, Lem was constantly aware how controversial every sentence is from the point of view of standard humanist and anthropological values. In the early 21 st century this tension between the humanist framework and projects of autoevolution did not decrease, but it actually became stronger - as we shall see when analyzing contemporary discussion on the subject. It is because now the potential for actually realizing these ideas is much bigger than when Lem wrote ST. This means that "the threat to humanity" - as the defenders of status quo put it - became more imminent. So it is necessary to look very carefully at how Lem referred to potential criticism directed at his ideas.

To the question about the purpose of the autoevolutionary activities described in option two, Lem offers the following answer: 
It may focus on eliminating all those harmful consequences caused by the absence of natural selection, which destroys the inadequately adapted, from the artificial environment of that civilization. Alternatively, it may replace a modest program with a comprehensive one: that of biological autoevolution. The aim of the latter is to form an ever greater number of perfect human types (through scientifically changing hereditary parameters, e.g., mutability, susceptibility to cancers, body shape, inner- and cross-tissue correlations, and, last but not least, parameters that regulate life span or even the size and complexity of the brain). In other words, this would be a plan for creating the next model' of Homo sapiens extended in time over hundreds or perhaps even thousands of years. It would take place through slow and gradual changes rather than a sudden leap which would smooth out intergenerational differences. (300-301)

The first two sentences of the passage describe an alternative. The first segment seems to be a declaration from a supporter of aggressively eugenic practices this is what the mention of "eliminating all those harmful consequences caused by the absence of natural selection" might suggest. I believe, however, that this is simply an effect produced by the clumsy structure of the sentence. Its actual meaning would be: "a moderate" version of autoevolution should eliminate those factors from human biology that cause diseases and feebleness of the body - so it would not so much replace natural selection in its eliminating function, but rather finally free the human species from qualities that this selection would be eliminating in the past. This way we would get rid of dilemmas of keeping alive people who are fully paralyzed or incurable and suffering, or the elderly, or children with serious developmental defects. In natural conditions, or even as late as in the first half of the last century, all these people would have no chance of survival. However, the progress in medicine and other sciences led to a situation in which the possibility (and medical obligation) to keep them alive begins to clash with other ethical principles, resulting in the discussion about euthanasia (I will be discussing that later). “The second scenario" Lem presents has a strictly utilitarian goal: engineering human bodies, independently from their biological heritage in order to improve them, so that no flaw in our bodies interferes with us benefiting from the fruits of scientific growth.

This second scenario is "the maximum program" (the first one is "the modest option"). It goes beyond even the most liberal contemporary criteria regulating biotechnology, but for Lem this is not the last word. Soon after he writes:

Third, perhaps the whole problem should be treated in a far more radical way. We can consider as inadequate both Nature's design solution to the problem of 'What is an Intelligent Being to be like?' and the solution that could be reached by autoevolutionary means learned from Nature. Instead of improving or 'patching up' the model that exists within a certain set of parameters, it is possible to set some new arbitrary values for them. Instead of a relatively modest biological life span, we could demand quasi-immortality. 
Instead of strengthening the design provided by Nature within the constraints set by its building material, we could demand the highest strength that the existing technology can offer. In other words, we could replace reconstruction with a total rejection of the existing solution and then design a completely new one. (301)

This passage carries a barely concealed postulate to reject humanity. People who would be so radically transformed, so completely designed anew on their own, would no longer be people. They would become a form of intelligent life completely foreign to us. I suggest that for now we put aside the most immediate reactions to such an idea: shock, laughter or indifference. Let us focus on this "foreignness." Here and further on Lem sees it mostly as a physical difference. Posthumans would be tougher, stronger, more immune to things. Yet, it is also possible - and, I think, necessary - to ask about the intellectual difference. It is true that we cannot say anything about it with certainty - even if we assume this is all more than just an irresponsible vision of an intellectual suffering from ennui. However, on behalf of the possible future posthuman, we can consider those trends in our human world and the way we think about the world, which seem to lead toward the posthuman condition. This part of my book will be devoted to those trends exactly.

Very aware of how unobvious his vision is, Lem devotes subsequent pages to a critique of it. He begins with the arguments in support of his position, mostly repeating what he has said earlier (301-303). And then, he gives the floor to an opponent of autoevolution. It is worth quoting his opinion in its entirety, as it proves that, despite the appearances, Lem was actually very sensitive to humanism - even though he rejected it.

In reply, we say that the supporter of the revolution in human redesign does not probably realize what the consequences of his postulates may be. We are not just talking about some narrowly conceived attachment to man's present body. The whole of culture and art, including some of its most abstract theories, is saturated with corporeality the way it was formed and shaped by Nature. Corporeality has informed the canons of every historical aesthetic, of every existing language, and, through that, of the totality of human thought. Our spirit is corporeal too: it is not that this word derives from respiration. Contrary to what it may seem, there are no values that could have emerged without the presence of the corporeal factor. Love itself is entirely corporeal-in its least physiological sense. It would be an act of extreme madness if man really was to undergo a transformation owing to the technologies that he himself has created and if he would consider a robot with a perfect crystalline brain his successor. It would actually amount to a collective suicide of the human race, even though such a suicide would be covered up by the apparent continuation of humanity in thinking machines - which are part of the technology created by man. In this way, man would ultimately allow the technology he himself has brought about to push him out of his place of existence, of his ecological 
niche. Having removed a less adapted species from the stage of history, technology would thus become a new synthetic species. (303)

No opponent of biotechnology and autoevolution could put it better. This passage also shows Lem's attitude to body, albeit from different angle than in the analyses I presented earlier. Here it is clear that Lem's hatred of the body stems not only from aesthetical criteria, but also from his view of the omnipotence of body and corporeality over human existence as a whole. Therefore his reference to humanism is quite peculiar, as no version of humanism in the European culture has ever emphasized the corporeal character of our existence quite so much, even though, as I shall show later, there are numerous covert similarities between the autoevolutionary project and some versions of humanism. Lem is not a naturalist here though, as for him "Body" is not identical with genotype or phenotype, or with any other physiological factor, which contemporary naturalist reductionists see as the factor, that determines our lives in full. "Body" is just a figure here, as "Designer" or "Nature" were in the earlier chapter. It expresses Lem's rejection of this particular element of our being that is painfully limiting, as it does not allow us to reach the heights of existence, which we have discovered through our minds. It could be said that at this point in his thinking - paradoxically - Lem is something of a "technological spiritualist," awaiting not the enslavement of the soul in a machine, but a liberation of it from the body by machine.

The terms "robot" and "thinking machines" that Lem uses are not exactly accurate here - they are meant to emphasize that the opponent is an amateur. As I have already shown, the thing is not to transform people into copies of C3PO from Star Wars, nor to move human minds into computer networks the way extropians suggested. If we are to analyze Lem "seriously," it is necessary to remember that a robot is one thing, an android is another, and a cyborg yet another type of entity - and none of these has much to do with computers. These terminological differences will be clarified in Chapter 23.

The response from the supporter of the project of reconstructing the species (303-305) is based on negating the importance of the past, so if we were to locate the discussion on a scale between conservatism and liberalism, this position would be on the liberal side. So what, he says, that our biological body determines our being, experience and understanding of the world? So what, given that the body itself, born from a million of accidental mutations and selections, has multiple flaws and disadvantages? Evolution shaped them for the sole purpose of survival, while we have long been pursuing other goals. "I do not believe in any solutions that would be final" (305) - which means: it is merely 
accepted custom and our limited imagination that lead us to believe that our current material form is the only one possible. And anyway, this form - Lem repeats his favorite theme - is a source of constant suffering for us, because, for instance, the proximity of sexuality and the excretory system disgust and shame us, giving rise to numerous dilemmas of our culture. Its defender would say that this is why it is valuable. But is it worth it to pay such a high price for this value? - Lem asks.

Today we believe that it is possible to create a symphony ... via a conscious mental effort. At the same time, the thought of "composing" a successor for ourselves ... seems like a terrible heresy. Yet the desire to fly ... also used to be seen as heresies in the past ... If we are to behave like intellectual cowards, we can, of course, remain silent on the topic of any probable future developments. But in that case, we should at least make it clear that we are behaving like cowards. Man cannot change the world without changing himself. We can take the first steps on a given path while pretending we do not know where it leads. Yet this is not the best strategy. (305)

"Yes," the defender would say, "but is this exploration from flying to autoevolution always legitimate, or are there limits to it?" In other words, is there a point beyond which a thought of change does become a heresy? Heart transplant was supposed to be it, and then artificial insemination - but after the fact we have accepted them. Now we are facing the possibility of cloning and label it a "heresy." What about radical autoevolution? Lem does not see the objection because he is an ardent supporter of progress, a true child of Europe, with its mysterious desire to constantly exceed its limits. It has to be said very clearly here, that writing about "culture" and "civilization," and their transformations inspired by the posthuman utopia, I am only writing about the culture and civilization of the West; I would not get into a discussion about how it could affect the whole world through globalization, which, by the way, has become problematic, to say the least, in light of the events of the first 15 years of the 21st century. The utopian character of Lem's utopia is based on the fact that it is really a u-topia, as we do not know where it will be fulfilled (if it is to be fulfilled): on the entire planet, or in one of its parts. In short, Lem's whole thinking about technology is deeply rooted in the type of thinking that is characteristic of the Western culture, as its fundamental premise is that people will always aim to fulfill their whole potential, following the credo "if something can be done, let us do it." The cultures of the East, of Mesoamerica or Africa, did not know this type of thinking. But for Lem the richness of cultures and their philosophical and anthropological foundations have no significance. It is important because he treats the Western thought especially in the realm of technological progress - as the only possible way of approaching these issues. For him a culture whose members would consciously refuse to fulfill their entire technological potential would likely be flawed. Those 
supercivilizations that have been mentioned here before, which are concealing their presence in the universe, have not and would not withhold progress, they simply hid its results, or would hide them.

His position can then be categorized as "Eurocentric liberalism" - if we were to measure Lem against the contemporary spectrum of worldviews. However, looking at it from a different angle, at no point does Lem want to pass for a hardheaded anti-humanist; he knows this would make him an adherent of the "ideology of scientist technocracy," as Kołakowski labeled him. So, before he responds to the charge of lack of specifics laid by his imaginary opponent with a detailed presentation of biotechnological parameters of autoevolution, he again expresses some general opinions about his own bold project:

[The autoevolutionist] before he moves on to discuss the position adopted by his rationalist opponent, ${ }^{181}$ he reveals that the first standpoint is actually not that alien to him. It is because, deep down, he feels the same strong objection to any plans for species reconstruction that the person who has condemned it in absolute terms does. But the autoevolutionist sees such future transformation as inevitable, which is why he is looking for all kinds of reasons that would support it, so that the necessary action overlaps with the outcome of the decision made. He is not an a priori opportunist; he does not think that what is necessary must at the same time be good. At the same time, he hopes that it at least may turn out to be good. (307)

One is almost tempted to add: freedom is the recognition of necessity. There is a degree of fatalism in Lem's thinking that finds expression in this sort of declarations. But perhaps it should rather be called intellectual heroism, as it is also true that it takes great courage to look into the future of our species. So far it seems that there is indeed no escaping technology, no stopping its progress. We need to be thinking about what is next; otherwise we will just be carried by it. We shall soon see, though, that for Lem there is apparently no difference between thinking and doing.

To bring out the opposition between bioevolution and autoevolution even more, Lem writes at the beginning of the next chapter ("Constructing Life"):

To design a dynamo machine, one does not need to know the history of its invention process. A young engineer can do very well without it. The historical circumstances that

181 Calling the defender of humanity "a rationalist" is quite a perfidious device, which allows Lem to, on the one hand, emphasize the specificity of the charges against autoevolution, but, on the other hand, to suggest that his opponent is somehow too earthly. Lem seems to be using the colloquial understanding of the word, which he would have probably used with a different meaning when referring to himself. 
shaped the first generations are, or at least can be completely irrelevant to him ... This kind of separation from developmental history is unknown in biology. (307)

It is unknown in biology - and therefore the process of bioevolution is inevitably burdened with the past, largely affecting our physicality. Our mind is also historical, albeit for somewhat different reasons. "Separation from history" will be an advantage of autoevolution - which is nothing less than an engineered construction. This is another reason why humanism, burdened with history, ${ }^{182}$ is so irrelevant to projects of autoevolution.

It needs to be added here that historicity of bioevolution and historicity of humanism are two very different phenomena, which can be put next to each other here only because, as I have shown, Lem seems to have a tendency to identify reality with discourse about it, and he does so permanently for the reality of bioevolution. Bioevolutionary processes are historical insofar as each subsequent form of life retains certain qualities of its predecessors. Historicity of humanism is based on a system of values established within the Western culture and accepted throughout most of its existence. One of its major characteristics is the desire to remember the past (which is a characteristic the West happens to share with most human cultures). Both types of historicity lose their meaning in the face of autoevolution. It will explain why a bit later.

On the following pages of ST, Lem discusses those aspects of biological evolution, which can be perfected in autoevolution. The long section "Constructing Life" (307-319) includes a description of the basics of the "species technology," which again subtly weaves together the discourses of biology and engineering, while the author uses cybernetic notions for instance to explain processes of cellular metabolism. A detailed analysis of this section of ST is not necessary for the purposes of this book. Lem uses rhetorical devices here that I have already discussed in the context of the entire ST, producing the same effect: a strong suggestion that it is possible to identify biotechnological engineering with the process of bioevolution, or at least an easy shift from bioevolution to bioconstruction is possible. The following paragraph merits particular attention:

Seen in this way, human evolution deserves both a positive and a negative evaluation. Negative, since ... it deprived its final and highest products, that is, us, [emphasis - PM]

182 I am not invoking the title of Hayden White's famous essay (The Burden of History) by accident. Narrativist historians pay great attention to the very process of accumulation of narratives making up "history." This accumulation leads to increasing difficulties in grasping the possible meanings organizing history and human culture on all levels. Yet humanism cannot reject "the burden of history," without rendering itself meaningless. 
of the opportunity to continue in a steady manner the work of progress on the biological level. Biotechnological as well as moral aspects stop us from simply continuing with the evolutionary methods: biotechnological because we are too determined as a particular design solution by Nature's causal forces, and moral because we reject the method of blind trials and that of blind selection. (314)

The passage I have quoted in bold above should probably be treated as a lapsus calami, as it is a mark of a teleological approach to bioevolution, which was something science started being accused of in the mid-20th century at the latest, and which Lem usually carefully avoids. ${ }^{183}$ It is quite possible though that this "crack in the text" actually reveals Lem's belief in human superiority over other forms of life. This would fit his utopian anthropological assumptions and would be yet another proof of his implicit humanism that he is striving to eradicate from his discourse on technology. The rest of the passage on the other hand is about the qualitative change that the shift from bioevolution to bioconstruction necessitates. Lem does not describe the character of the change precisely; it is related, however, to all of the premises of the autoevolution project.

Later in the text, especially in the section "Constructing Consciousness" (322327) Lem again returns to problems he has already discussed, above all the issue of consciousness and the theory of information in the context of bioconstruction. After a number of detailed remarks on these subjects he produces another powerful general declaration. It is as follows:

One of the Nobel laureates, who received the prize precisely for his studies on heredity, and thus may be said to be directly interested in similar [i.e. biotechnological] achievements, declared that he would not want to live to see them actualized owing to the terrifying responsibility man would then have to take on.

Although creators of science deserve the greatest respect, it seems to me that the preceding point of view is not worthy of a scientist. One cannot simultaneously make discoveries and avoid taking responsibility for their consequences ... The scientist tries in vain to narrow down his research so that it takes the form of information gathering, which is protected with a thick wall against problems to be covered by its application. Evolution ... acts ruthlessly. In gradually getting to know its engineering activities, man cannot pretend that he is gathering solely theoretical knowledge. (335)

"The Nobel laureate" is James Watson, and his words are a leading theme in discussions on bioethics today. Lem's commentary on one hand justifies autoevolution (but in what sense?), but on the other it contradicts the separation between science and social practice that has been articulated many times throughout ST. It is another point when Lem's persona as a scholar is in conflict

183 See Chapter 6 about narrative in evolutionary biology. 
with his persona as a utopian humanist. And as to the sense of justification of autoevolution - I have put it into question in the parentheses above as Lem does not distinguish - here or elsewhere - between predictions about autoevolution from the practice of it. That is, he does not see that in the context of the social role of thinking there is a difference between thinking about a possibility of a certain development leading to autoevolution and thinking about autoevolution as if it were certain to happen. Confusing those two modes is another feature of Lem's discourse, which locates it in the utopian realm.

The last paragraph from the section "Reconstructing Man" is a testimony of to what extent Lem's thinking remains determined by implicit assumptions that are fundamentally "Western":

What is therefore possible? Almost everything, with just one exception. Having considered in advance, people could decide one day, many thousands of years from now, "Enough! Let things be the way they are now; let them remain like this forever. Let us not change, seek, or discover anything new, since things cannot be better than they are now, and even if they could, we do not want it."

Even though I have outlined many unlikely things in this book, this one seems to me the most unlikely of them all. (348)

It is clear: we do not stop discovering and creating, because this is just what we are, and it is so obvious that we do not even ask why we are like that. Contemplative attitudes are fundamentally alien to Lem. ${ }^{184}$ This conviction of his, which he does not seem to be aware of, but treats it as a given of reality, is the same one as the conviction that is the foundation of the entire posthumanist utopia, which I will be analyzing on the following pages.

In the eighth chapter of ST, Lem mentions cyborgs in passing as well. A short section "Cyborgization" (348-350) begins with a statement that:

Separate consideration needs to be given to the only project of human reconstruction proposed by scientists with which we are familiar today - a project that is still purely hypothetical. Yet this is not a project for universal reconstruction. It is supposed to serve some particular goals, that is, an adaptation to the Universe as an "ecological niche." It goes under the name of "cyborg" (which is an abbreviation of the term "cybernetic organization"). (348-349)

Lem certainly has in mind the first scientific text about cyborgs, which is now the classic article on the subject by two Americans, Manfred E. Clynes and Nathan S. Kline, "Cyborgs and Space," which was published in Astronautics journal in

184 Yet, see later the discussion of "The Twenty-First Voyage" in my chapter "Introduction to Autoevolution." 
1960. (I will discuss it in more detail in Chapter 23.) Approaching the idea of cyborgs as a purely technological concept is characteristic of the early discourse on the subject. For Lem, it is only one of the possible routes autoevolution could take (but the only one explicitly articulated at the time). In today's discussions it plays a much more eminent role, as we shall see soon.

This is really where ST ends. ${ }^{185}$ The final two sections of "A Lampoon..." "“The Autoevolutionary Machine" and "Extrasensory Phenomena", 351-358) contain only side notes to the main theme. The first one is devoted to a peculiar kind of eugenics. Lem floats an idea of a machine that would match couples to marry each other in such a way that they produce offspring with the best possible phenotype. Those critics, who mentioned the idea, approached it with skepticism, to say the least. ${ }^{186}$ For Lem, however, it seems not to have had any ethically dubious qualities, as the last sentence of the passage states:

"Cutting up people's brains and bodies" [i.e. "strong" autoevolution] evokes disgust, whereas "machinic marriage counseling" seems to be quite an innocent intervention - yet these are just two paths of different lengths that can both lead to analogous results. (354)

In the conclusion of ST, the author emphasizes how important it is to focus the autoevolutionary activity on the molecular level of life and he again invokes comparisons between "natural language" and "language of the genetic code":

From twenty letters of amino acids Nature constructed a "pure" language, which expresses - via a slight rearrangement of nucleotide syllables - plagues, viruses, bacteria, T-rexes, termites, hummingbirds, forests, and nations, as long as it has bought time at its disposal. This language, so perfectly atheoretical, anticipates not only the conditions at the bottom of the oceans ... but also the quantum character of light, thermodynamics, electrochemistry, echolocation, hydrostatics - and many other things we still know nothing about. It does so only "practically," because, though it causes everything, it does not understand anything - yet its lack of intelligence is much more productive than our wisdom. ${ }^{187} \ldots$ It truly makes sense to learn such a language - because it constructs philosophers, while ours constructs only philosophies. (360-361)

This declaration would explain why Lem paid so little attention to cyborgs whose possible construction happens on the level of entire bodies and organs, not molecules. Lem was a real enthusiast of biotechnology, and if one wanted to

185 I am not including here the "Afterword. Twenty years later," which was added to the fourth Polish edition of ST. I do not think it adds anything new to the whole work.

186 Cf., for example, Szpakowska..., 75-76.

187 Cf. the conclusion of Chapter 13. 
follow his path, a history of genetic engineering and discussions about it should be written. I will do something different though. I have been trying to show here that $\mathrm{ST}$ as a whole is a project of autoevolution. According to Lem autoevolution can happen in different ways. I am most interested in the one, which entails far-reaching spiritual consequences. Even the most advanced uses of biotechnology do not, I believe, lead to a qualitative change in the human condition. People do not cease to be people. Cyborgization does cause such a leap. I will present the arguments in favor of these strong theses later in the text. At this point I just want to preliminarily explain my choice. Moreover, I have suggested many times that ST is a utopia, but the ideas regarding cyborgs today are no less utopian (as opposed to bioethical discussions), and that is another link here. I want to focus now on the utopianism of ST and Lem's thinking about technology as a whole. 


\section{Utopia in ST}

While describing and analyzing the content of ST, I pointed to those qualities of the work that can be seen as utopian. It is important because if it can be proved that ST is a kind of utopia, it would have bearing on all types of thinking about social practice that repeat the model of ST - that is, autoevolutionary ideas. Again, I have to emphasize methodological difficulties one encounters studying (not to mention producing) a discourse that is somewhere in between four different domains: humanism and posthumanism; theory and social practice. It is extremely difficult to determine the relationship between such a discourse and its subject. It is hard to tell where a description ends and a manifesto begins; what is a theoretical concept and what is an actual plan of action.

I treat the utopianism of ST as one of the implicit anthropological assumptions Lem accepts. He rarely and marginally formulates them overtly (and I have quoted many of such passages here). A deep conviction about human rationality is a recurring thread. The thought is usually an axiom for Lem, which does not need to be justified. It does come into conflict though with the opposite view, which he has been articulating from the very beginning of his writing and which is the dominating one. However, we can omit that contradiction here, as it has no bearing on the current argument. It is an element of conflict between naturalism and culturalism in Lem's thought. ${ }^{188}$

Human rationality is the necessary condition for autoevolution. Science and technology, which make autoevolution possible and, in fact, necessary due to unstoppable progress, ${ }^{189}$ have no necessary rationale for themselves. Even "information farming" does not produce one for itself, and "pantocreatics" is but a set of Designer's internal rules, which have nothing to do with the "User." In short, science and technology can never answer what it is that they exist for and what the purpose of their products is. Therefore, if there is no obvious pragmatic

188 Commentators have been pointing out for a long time that Lem's fictions and discursive texts are swarmed with contradictory assumptions. See, for example, N. Katherine Hayles, "Chaos as Dialectic: Stanisław Lem and the Space of Writing," in: idem, Chaos Bound: Orderly Disorder in Contemporary Literature and Science (Ithaca and London: Cornell University Press, 1990). The author (who is one of the leading theoreticians of posthumanism) outlines an interpretation of Lem's work as constant attempts to marry various contradictory statements about man and the world.

189 The conviction about the "inevitability of progress," which has been discussed here before, is another element of his discourse that contributes to its utopianism. 
criterion (applicability of medications, practical usefulness of technical devices), the question of purpose becomes problematic. What makes it even more difficult is that the availability of a pragmatic criterion entails a question about whether the achievements of science and technology are always used for a common good (and we know they are not). Lem rarely says any of these things, as they are problematic from his point of view. He would rather that the meaning of science was implicit to it, as is the case with art that is separated from social issues. However, he knows this is not the case, he assumes human rationality is what gives meaning to science. ${ }^{190}$ Rational people - and only they - can make such a use of the fruits of the growth of technology based on science, that it will not turn against them and will not degrade the progress itself. Lem realizes how risky such a thesis is - and that is why he conceals it beneath the surface of the text of ST.

Yet, the social reality contradicted this thesis already when ST was being written. Today this contradiction is even more striking. And I do not just mean those versions of thoughtlessness, stupidity and bad intentions, which we witness daily on the web, nor am I thinking about the deep separation between pragmatics and ethics in how technology is used. The thing is also that - despite the claims of "third culture" enthusiasts - science and technology do not help introduce order into the exponentially increasing amounts of meanings available in our culture, while they themselves keep adding on meanings. One of the diseases that destroy the Western culture today is semiotitis ${ }^{191}$ - excessive growth of chaotic meaning, which cannot be put into "grand narratives." A thoughtful person is drifting today on the surface of an infinite and bottomless ocean of meanings, with no navigation tools, and with every move or gesture, every word, even accidentally dropped, immediately becoming meaningful in any number of ways. Scholars and intellectuals work compulsively producing new meanings. But this whole infinitely chaotic field of meanings makes no sense. (And the distinction between sense and meaning comes more from Sartre than Frege here.) Lem understood that a long time ago - I believe that his Memoirs Found in a Bathtub (1961) is one of the most powerful descriptions of semiotitis, if we only go beyond the level of political readings. Memoirs... are a startling description of

190 I am using the term "rationality" in its standard meaning, as shaped by the thought of the Enlightenment and Positivism.

191 By creating this neologism, I am referring to the book by Constantin Noica Six Maladies of the Contemporary Spirit, where the Romanian intellectual described catholitis, horeitis and todetitis and their opposites: acatholia, ahoretia, atodetia - they are an original diagnosis of the crisis of culture in the second half of the 20th century. 
a desperate work on sense, a futile work with no grounding in any kind of lasting foundations.

Autoevolution, seen as a product of science and technology, is devoid of sense, even if we assume that it does include a pragmatic criterion, which is not self-evident at all. To give it sense, Lem has to introduce an anthropological premise. And it is the thesis about human rationality. It is a utopian thesis. This means that the idea of autoevolution is utopian itself.

But what are we speaking about when we use the word "utopia"? Studying two of the best discussions of the problem that have been written in Polish, ${ }^{192}$ one could come to a conclusion that nearly every conceptual system referring to social and cultural reality, which is not a straightforward description, is a utopia. Any such discourse includes either certain assumptions about human nature or postulates about how the social world should be arranged. Wishing to avoid getting into vague discussions, I accept the understanding of the concept of utopia presented by Karl Manheim: utopia is a system of thought, discourse or narrative, which calls for a change of the existing social order; as opposed to ideology, the aim of which is to preserve such order. The important point is that Manheim does not assume that utopia describes the perfect state - which was a characteristic of old utopias, from Plato's republic, through More, to Wells's positivist projects.

I believe ST is a utopia, which does not assume perfection of the project it presents, but its inevitability. Lem emphasizes that on many occasions. The utopianism here is not about claiming that autoevolution is a telos for the humanity, a paradise or any other such ultimate point of arrival. (It is different in some of the newer concepts, e.g., for the extropians, but that's another story.) At its core, however, there lies an assumption of human rationality that in fact makes ST similar to projects of enlightenment, positivism and liberalism (the differences between Lem's thought and the former two has already been analyzed here). There are two options then: Manheim's utopia of change and liberal utopia of rationality. They are complementary with each another. Lem believes that any description of future changes of humanity is only justified when one accepts some basic assumptions about human nature, which would inform the

192 These are: Aleksander Świętochowski, Utopie $w$ rozwoju historycznym (Warszawa: Gebethner i S-ka, 1910), 347; and Jerzy Szacki, Spotkanie z utopiq (Warszawa: Sic!, 2000), 240 (new edition). Świętochowski is of course outdated now in his interpretations, but most of the book is a description of tens of utopian systems, and it has lost no value as a compendium. 
changes. Otherwise such description would be pure fantasy. We have already seen how the view materialized in "metatheory of autoevolution," which determined its technological scope. Now I am trying to show that the utopian assumption of rationality is what determines the autoevolutionary pragmatics in Lem's discourse. Pantocreatics determines the Designer; rationality determines "the User." However, while the former is "real" as an essential component of the autoevolutionary project, the latter is an ad hoc assumption with a status of an axiom, which cannot be treated as a practical rule.

The difference between the two can be illustrated as follows: let us imagine that a computer at an IT store comes with two user's manuals. The first one is a regular manual on how to use it, install software and so on; while the latter is a manual of virtuous use of the computer, which, for example, includes a directive that the computer cannot be used to browse pornographic websites, and anyone who does that will be naughty. In the autoevolutionary project pantocreatics is the manual of the first kind, whereas rationality - of the second. Pantocreatics is essential for autoevolution to happen, rationality - unfortunately is not. And that is also a reason why rationality is what makes the project utopian.

It is a complex issue. We have here: Lem's explicit discourse in ST and other "essays," with all its difficulties; Lem's fiction, which largely corresponds with the discourse ${ }^{193}$; Lem's project of autoevolution; we have the twofold utopian character of the project as I am presenting it; the implicit and contradictory anthropological assumptions accepted by Lem; the evolution of his thinking between the 1960s and the end of his life; and finally there is the issue of how it all relates to the social and political practice, especially the contemporary state of biotechnology and surrounding debates. It is a conundrum that is difficult to analyze and I shall not disentangle it on every possible level. However, later in this chapter I will be describing sections of the contemporary (post)humanist discourse that have something to do with Lem's utopia. I want to emphasize here that the thesis about the utopian character of the autoevolutionary project is applicable to all concept I will be referring to on the following pages.

A few more general remarks need to be made about the utopian character of autoevolution. We already know that the main ethical condition for

193 I am only referring to those connections marginally so as not to make my own analyses even more complicated. Lem's novels, especially Wizja lokalna ["Observation on the Spot"] and Eden have been studied in search of their utopianism both by Szpakowska and Jarzębski. Cf. also Mariusz M. Leś, Stanistaw Lem wobec utopii (Białystok: Towarzystwo Literackie Im. Adama Mickiewicza, Oddział Białostocki, 1998). 
autoevolution is human rationality. Without it, autoevolution may become what Internet can be: a trifle for entertainment only. Yet, this liberal and meliorist assumption that makes Lem resemble many of the "old" utopians drawing visions of humanity without law and violence, governed by natural virtues, conflicts with another assumption, equally, if not more important than this one. As the author of the autoevolutionary project, Lem rejects - he wants to and has to reject - the entire humanism. Autoevolution is unhistorical, as it reveals the entire past of the species, not only biological past, but historical and cultural too. This may seem not to contradict the earlier characteristic, especially as it is shared by most liberal social theories that assume people are independent from the past and are almost infinitely malleable in their humanity. However, therein lies the problem: such thinking requires that we reject the notion of "human nature," and treat it as a "naturalistic fallacy." Meanwhile, the assumption of rationality does imply the existence of human nature - one that would include rationality. If I am right in seeing an aporia here, it is one that Lem shares with most liberal and posthumanist thinkers - it will be evident as I discuss the notion of identity in contemporary (post)humanist discourse.

The fact that in ST, Lem almost never ponders on whether people will actually want to subject themselves to autoevolution may be an evidence that he does not deem the notion of "human nature" necessary. It clearly does not cross his mind that people could be willing to retain their current condition. Most likely it is simply because he sees this condition as extremely meager, but partly also because he shares a liberal conviction that this condition can be freely shaped, that it is independent from all that is past - and so that there are no imponderables that used to be seen as "human nature."

A psychoanalyst would certainly wonder about the impulse that leads Lem to change everything. But even in this case our author is not consistent. In 1978 the monthly Znak asked scholars and intellectuals about their views on science and faith. Here is an excerpt from Lem's response:

The newer extremists on the other hand dream about a real "etorevolution" involving redesigning a human that would be in every respect "better" than Homo sapiens. The biggest risk lies in the fact that this whole designing endeavor unwittingly goes beyond real history of the humanity. The thing is that every social or philosophical system, every religion, every historical time accepted and assumed all the qualities and values present in the natural man. The natural man was and is "a constant," an unchangeable element in its own history. It is easy to speak generally about a "better human," but in no tradition of earthly cultures, no philosophical and religious systems, no ethical codes can one find any directives what would suggest what this "perfected" man would be like. By stepping beyond the state of things we have, we are losing any normative, legal, axiological and 
theological ground, we are left with no compass - this whole meliorist concept is left in a vacuum. But one day it will be possible to carry out psychological and bodily changes of great scope, and there may be no shortage of fanatic supporters of the process then. This is likely the biggest threat ahead of us. ${ }^{194}$

It looks like Lem in 1978 is criticizing Lem's ideas from 1964. It will not seem odd if we take into account how unstable his anthropological views were. However, the evolution of Lem's anthropology is not my concern here - it would make my argument too complicated. In the quoted excerpt Lem emphasizes the problem that has now become the main argument for the opponents of biotechnology: the rejection of history as a road sign, and of ethics grounded in history - even though he did not mind it back in ST at all. It needs to be added that the issue itself is still valid, because, as I shall try to show later, posthumanism is the first period in our history when the content of the past in no way helps us understand the present. The disconnect is too radical.

In another short text, written somewhat earlier, Lem described various "effects" occurring within futurology. Among them there is "Archimedes effect."

The ARCHIMEDES EFFECT is the search for support for thought. It is nonsensical to claim that full freedom, that is, lack of limits, is what gives wings to thought. Weightlessness only seems to give cosmonauts full freedom of movement (if they weigh nothing, they do not pull, so they have no limitations), because in reality it paralyzes orientation and turns man like a wriggling baby; similarly thought with no support in known templates does not fly infinitely but it holds on to anything it can, at random.

Our era invalidates all the traditional supports, including the experience of previous generations, customary prohibitions and the belief in unconditional benefits of economic growth, and thus it takes away the tested structure that the thought ruling action could lean on. That is why the Archimedes effect occurs so spasmodically today. The more things happen, that even yesterday seemed impossible, the more dramatically thought turns to the past, searching for directions.

Hence the popularity of historical parallels, hence the imposing tendency to remind us we come from apes, hence the discussions about the inescapability of inborn qualities - and hence the sudden interest in history and ethology. Perhaps we can be saved by studying the behavior of Romans at the time of the fading empire? Or maybe rather we should focus on anthropoids? Maybe the behavior of rats, lemmings and predators will be our compass? Or maybe man is

194 Stanisław Lem, [A response], Znak, no. 291 (1978), 1148. 
a domesticated animal that domesticated itself? And we should look for a solution in a cow or a ram? Why does the enlightened audience now read all the bestsellers on its apish qualities, while a century ago similar revelations would provoke anti-Darwinian fury? Because the limits posed by apes are better than none. ${ }^{195}$

Here is yet another approach to the matter: the past (biological rather than cultural, but not only) is a remedy to the instability of an era of great changes. But it is not a sure remedy, it is straw that a drowning man clutches at. It can fail us because the connection with the past is no longer organic, the past is, so to say, brought back artificially. The wave of sociobiological books on "ape roots" of human social institutions, which started in the 1990s, confirms Lem's thesis. The remark about "cosmonaut's baby-like helplessness" coincides with his normative attempts in ST ("pantocreatics") and Lem's dislike of "wild sci-fi."

All these different views Lem expressed about the past share one thing: the past as understood by the classical, 19th- and 20th-century humanism, that is, the past that contains the meaning of the present, is irretrievably gone.

195 Stanisław Lem, “Refleksje 1974,” in: Rozprawy i szkice (Kraków: Wyd. Literackie, 1975), 335. 



\section{Introduction to Autoevolution}

Małgorzata Szpakowska titled one of the chapters in her book "Lem i trzy ewolucje" ["Lem and three evolutions"]. ${ }^{196}$ In it she discussed his views on biological evolution, evolution of technology and evolution of culture. She skipped a fourth evolution though, which is the most important one for this work: autoevolution.

The word occurs in ST the same way "Nature" and "Designer" do - as a primary notion, which is never defined with any precision. Until today it has gained no strong presence in the language of science and humanities. It is therefore necessary to attempt to define it and its scope. What is human autoevolution, what can it be? Is it just an idea, or is it a tangible process, or one that is close to becoming tangible?

In light of ST, the main theme of which, as has been shown earlier, is the call to "rationally exceed Nature," autoevolution is a rational, planned process of transforming human genotype and phenotype, as well as his sensorium until biological forms of existence are completely rejected; the aim of the process is to achieve physical and intellectual prowess that is higher than a human can ever achieve within the potential provided by the random process of biological evolution. Going beyond the discourse of ST, it also needs to be said that the theoretical reflection on autoevolution has to include an analysis of its possible implications for human and posthuman spiritual, social and political life. Posthumanism is the discursive correlate of autoevolution. The analysis that follows here will be based on this definition.

In Lem's fiction there are two scenarios of autoevolution present: serious and grotesque. The former can be found in Golem XIV (1981), the latter in "The Twenty-First Voyage" in The Star Diaries (1971).

Golem, a supercomputer built by people, which achieved intellectual independence and became something of an oracle, in its Inaugural lecture discusses in brief the entire history of life on Earth and the human species from the point of view of Lem's interpretation of biological evolution. It predicts the further development of humans, claiming that unsolved contradictions that torment us and our cultures will eventually push us to reject the current form of existence the body - and to transition to other forms of existence ${ }^{197}$ :

196 Dyskusje..., 54-89.

197 Here and further on I skip the issues of the nature of the relationship between consciousness and body (mind-body problem, self-awareness, etc.), which have not been 
Can you remain in place standing stubbornly at the crossroads? But then you will lapse into stagnation, and that can be no refuge for you! ... So you will embark on the expansion of Intelligence, abandoning your bodies, or you will become blind men led by one who can see, or - ultimately - you will come to a halt in sterile despondency.

The prospects are not encouraging, but that will not hold you back. Nothing holds you back. Today a disembodied Intelligence seems to you just as much a catastrophe as a disminded body, for this act of resignation entails the totality of human values and not merely man's material form. This act must be to you the most terrible downfall possible, the utter end, the annihilation of humanity, inasmuch as it is a casting off, a turning into dust and ashes of twenty thousand years of achievements - everything that Prometheus attained in his struggle with Caliban.

I do not know if this will comfort you, but the gradualness of the change will take away the monumentally tragic - and at the same time repellent and terrible - significance contained in my words. It will occur far more normally, and to a certain degree it is already happening: areas of tradition are beginning to bother you, they are falling away and withering, and this is what so bewilders you ...

You will manage to neither perish not triumph as of old.

I feel that you are entering an age of metamorphosis; that you will decide to cast aside your entire history, your entire heritage and all that remains of natural humanity whose image, magnified into beautiful tragedy, is the focus of the mirrors of your beliefs; that you will advance (for there is no other way), and in this, which for you is now only a leap into the abyss, you will find a challenge, if not a beauty; and that you will proceed in your own way after all, since in casting off man, man will save himself. ${ }^{198}$

Golem's words resemble contemporary posthumanist manifestos (see Chapters 21 and 22 here), but have much higher artistic and intellectual standing. The description of autoevolution in "The Twenty-First Voyage" is much more elaborate, if a lot less lofty. Here ${ }^{199}$ again, as in other grotesque writings by Lem, he describes "the other side of the coin," mirroring his own "serious" texts, but with a lot less serious effect.

definitively solved and to which Lem devoted a significant part of Dialogues. Within the radical approaches I am discussing now, it is assumed that this problem will be solved through technology, or that it is merely a result of the limited humanistic imagination, or an erroneous interpretation of reality (i.e., the so-called Cartesian mistake). In fact, if it is to be taken as a real problem (i.e., if the human consciousness is really essentially and inextricably related to human body and senses), there could be no moving or extracting the mind out of the body.

198 Stanisław Lem, "Golem XIV," in: Imaginary Magnitude, trans. by M. E. Heine (San Diego-New York-London: A Harvest Book, A Helen and Kurt Wolff Book, Harcourt Brace \& Company, 1984), 41-43.

199 Stanisław Lem, The Star Diaries, trans. by M. Kandel (London: Secker \& Warburg, 1976), 66-219; paging further on follows this edition. 
Golem's version of autoevolution is similar to the extropians' idea, although unlike them Lem's Golem knows what shock it would be to culture. And this is one of the main conceivable versions of autoevolution. Ijon Tichy, on the other hand, having arrived on the planet of Dichotica, has a chance to learn about a new version in which humans ${ }^{200}$ do not abandon their bodies, but begin to radically transform them.

Szpakowska meticulously analyzed one of the themes in "The Twenty-First Voyage": the religiosity of monks-machines, which are the last creatures on this planet who believe in transcendence. Yet, she completely ignored autoevolution, even though the two topics are complementary. The name of the planet resembles the word "dichotomy" - and the very dichotomy in this case lies in the growing "transcendental spirituality" of machine on one hand and "wild" autoevolution of humans, devoid of any higher meaning on the other.

Tichy makes no contact with the Dichoticans. He learns about the autoevolution which has been going on for more than ten centuries from books, provided by Demolitian Friars living in hiding (they and the Prognosites are two orders of machines). The autoevolution on Dichotica started with a rejection of mortality, which was turned into action through the progress of technology. It started modestly with biotechnology and intelectronics, which spread cloning, designing and resurrecting people, quickly leading to deconstruction of the truth and dogmas of the (Christian) faith, especially the immortal soul and the personal identity. Then

I learned that in the year 2401 Byg Brogar, Dyrr Daagard and Merr Drr threw open the gates to limitless autoevolutionary freedom; these scholars earnestly believed that Homo Autofac Sapens, the Self-made Man, made possible by their discovery, would achieve the ultimate in harmony and happiness, endowing himself with those aspects of form and qualities of spirit he judged to be most perfect ... For such hopes usually attend the appearance of any great and new technology.

At first autoevolutionary engineering, or - as they called it - the Fetalistic Movement, burgeoned in a way that seemed to accord with the expectations of its illustrious inventors. Ideals in health, congruity, spiritual and physical beauty became universalized, by constitutional law every citizen was guaranteed the right to acquire whatever psychic or somatic attributes were deemed the most desirable ... But progress has this about it, that it is driven ever onward by its own advance, hence things did not stop there. The transformations that followed seemed innocent enough at the outset. Young women

200 Actually it is Dichoticans but the masque is very transparent in this case. The drawings that Lem places in the text and the words of the narrator make it very clear what species the author had in mind. 
beautified themselves by the cultivation of epidermal jewelry and other efflorescences of the flesh ... young men sported side and back beards, cockscomb crests, jaws with double bites, etc.

Twenty years later the first majority parties came into being. It took a while before I realized, reading, that "majority party" meant something different on Dichotica that it did to us. In opposition to the majority party platform, they called for the proliferation of anatomies, there was the minority group, which advocated reductionism, that is, the elimination of those organs considered by the minority leaders of various factions to be non-vital. (180)

Biopolitics is thus born on Dichotica - political views and programs are linked with autoevolutionary practices. We should add that people on Earth are close to this stage, even though they are not there yet in terms of technology. What else are the discussions on euthanasia, cloning and applied genetics that have been growing since the early 1990s if not just such biopolitics? Later in his readings, ${ }^{201}$ Tichy learns the details of autoevolutionary propaganda and the subsequent stages of autoevolution, its meandering development and its gradual degeneration, which produces changing trends in increasingly odd transformations of bodies; a state institution called SOPSYLABD (the Soma and Psyche Planning Board), itself disintegrating into bureaucratic subinstitutions such as LA (Lip Administration), BUFF (Beautiful Figure Foundation) and NIFTY (the National Institute of Fingers and Toes) is striving in vain to control such tendencies. Without renouncing the grotesque aesthetics, Lem also shows that autoevolution can fall prey to the same social, political and bureaucratic processes that harmed all utopian and revolutionary ideas of transforming existence.

Later on in the process of autoevolution the existing notions of gender and sexuality are destroyed. This grotesque destruction seems today like a caricature of the discourse of gender and queer studies:

201 In the structure of the text of "The Twenty-First Voyage" two motifs, human autoevolution and machines' faith, correspond with two different layers of the plot. Tichy's reading of books on autoevolution is interrupted by conversations on faith which he is having with Fathers-Robots. There are also some external interruptions as well. A detailed analysis of the structure of the plot is not my subject here, although one could make some interesting observations about it, for example, that Tichy's contact with Dichoticans is almost entirely mediated by text, while his contact with machines is direct (bringing to mind a Turing test in a rebours). The scene in which friars are checked by a Dichotican patrol is equally subversive: people play the part of heartless oppressors, while machines are presented as the delicate, spiritual victims. 
Showing their contempt for all things utilitarian, they set eyes in their armpits, and one group of young biotic activists made use of innumerable sound organs ... Then came the fashion - the mania rather - for long tentacles ... And, since no one could lift those piles of coils by himself, so called processionals were attached, caudalettes ... In the textbook I found illustrations depicting men of fashion, behind whom walked tentacle-bearing processionals on parade; but this was already the decline of the protest movement, or more precisely its complete bankruptcy, because it had failed to pursue any goals of its own, being solely a rebellious reaction against the orgiastic baroque of the age.

The baroque had its apologists ... who maintained that the body existed for the purpose of deriving the greatest amount of pleasure from the greatest number of sites simultaneously. Merg Brb, its leading exponents, argued that Nature had situated - and stingily at that - centers of pleasurable sensation in the body for the purpose of survival only ... Brb received the enthusiastic support of a group of talented young designers from SOPSYPLABD, who invented brippets and gnools ... ecstasy centers, of course, were implanted in the brain ... Thus were created the brippive and gnoolial drives, also activities corresponding to those instincts, activities which a highly rich and varied range, for one could gnool and brip alternately or at the same time, alone, in pairs, trios and later - after noffles were tacked on - in groups of several dozen individuals as well. Also new forms of art came into being, master brippers appeared, and gnool artists, but that was only the beginning; towards the end of the 26th century you had the mannerism of the marchpusses ... and the celebrated Ondor Stert, who could simultaneously gnool, brip and surpostulate while flying through the air on spinal wings, became the idol of millions. (194-196)

Behind the mocking style of the passage, we can read a certain vision of a continued Copernican revolution. In the process of the increasingly allencompassing autoevolution the very notion of what it means to be human - at least in a physiological sense, which, as we know, is particularly important for Lem and the contemporary anthropological thought - begins to lose its uniqueness. It becomes relative by being placed on a broad scale of forms of existence that can be designed or assumed. Our planet is not in the center of the universe, nor is our galaxy, we are not the ultimate goal of creation, and our universe is not the only universe - and if that were not enough, it turns out that body and sex, through which we define our humanity, are not the only possible option of corporeality and sexuality, but only one of the possible options drawn from a nearly unlimited spectrum. It is one of the possible consequences of autoevolution in its "somatic" version, especially when there no longer is any hierarchy of higher values. The writings of Judith Butler, describing "a gender continuum" replacing the binary opposition of "masculinity-femininity," contains a similar thought, except articulated in all seriousness.

Further on in "The Twenty-First Voyage" there is a scene that corresponds even better with gender studies, and that also feeds into Lem's taste for the 
macabre. ${ }^{202}$ Tichy and the friars go out on the surface of the planet. They come across a small building, and then Tichy says:

I heard groans issuing from that place, and a throaty rattle so dreadful, my hair stood on end. The voice, undeniably human, chokes and moaned in turn. I knew for a certainty that this was the cry of someone being tortured, being murdered perhaps; I looked at my companions, but they paid absolutely no attention to those grisly sounds ... There on a blood-spattered table lay a naked figure, surrounded by machines that had sunk gleaming tubes or tongs into its body, which was now dead, and so contorted by the final throes, I couldn't tell arms from legs ... I stood, overcome by the horror, the ghastliness, the mystery of the scene, for the corpse was alone - I could look into all the corners of that mechanized torture chamber ...

The shining bell lifted and I beheld a face, an inhuman face; by now all the machines were working at once, and so rapidly, that I saw only a blur and the motion of glass pump beneath the table, inside which a red liquid churned, till finally in the middle of this confusion the chest of the corpse began to rise and fall; before my eyes his wounds sealed up, he twitched all over, he yawned.

"He's come back to life?" I asked in a whisper.

"Yes," said the prior. "In order to die once more."

The one lying flat looked around and with a limp, seemingly boneless palm gripped a handle that stuck out on the side, gave a pull, and the bell slid back over his head, the slanting pincers, emerging from their sheaths, clutched the body, and a scream rang out, the same scream as before ...

it was the prior explaining that the pavilion was a special service station, where one could live and relive one's own death. The purpose here is to experience sensations as powerful as possible, and not necessarily suffering, for with the aid of the stimuli transformers pain becomes an excruciating pleasure. All this derives from the fact that thanks to certain types of automorphosis Dichoticans can enjoy even the pangs of death ... This particular method bears the name of "Agonanism." (204-206)

The description of the execution of Robert Damiens, which opens Foucault's Discipline and Punish, is very similar. In both cases we are dealing with a typical sadomasochist phantasm: surrendering to pain and torture till death. Except in the autoevolutionary world of Dichotica such dream can be fulfilled more than once, while in our world it can happen only once. ${ }^{203}$ For Lem this image is a

202 Such themes can be found in nearly every work of fiction that Lem produced, starting with the collection of monstrous fetuses in Kauters's apartment (Hospital of the Transfiguration), to the pornographic X-rays in Imaginary Magnitude (which are perhaps a distant echo of the exchange of X-rays between Castorp and Clavdia Chauchat in The Magic Mountain). I have pointed to possible reasons behind this tendency in the article "Lem fantastyczny czy makabryczny?"

203 In 2001 in Germany 40-year-old Armin Meiwes used an Internet forum for cannibals to contact Bernd Brandes, who agreed that Meiwes would kill him (by cutting off his 
testimony to the degeneration of the Dichoticans. Absolutizing the bodily and sensual experiences is a substitute for the lost faith in transcendence. Again, it is impossible not to notice such substitution today. The entire huge realm of gender studies, largely shaped by Foucault's influence and the feminist thought, focuses on the very question of the body - the problems of older metaphysics are considered musty and irrelevant. The body and gender perform the function of a center of thought - detached from their biological qualities and reduced to symbols of their social functions. Moreover, such theory of gender favors all these forms of the bodily and the sexual, which were previously not mentioned, were repressed as "nonnormative," beginning with the trivial homosexuality, through all forms of transgender to sadomasochism and other highly nonnormative phenomena. By making them the center of its attention, gender studies largely contribute to the destruction of the existing way of understanding the issues of bodily and sexual identity, and hence to the rise of posthumanism.

However, if in "The Twenty-First Voyage" we can find so many traces of our contemporary reality of the 21 st century, does it make sense to treat the text as a description of future autoevolution? Perhaps autoevolution is only one of the grotesque masks that Lem gave to our world, so the description of our problems becomes less straightforward? Yes and no. Yes, because "The TwentyFirst Voyage" can be read as a critique of the current situation, just as any other of Lem's grotesque texts. No, if we assume that the autoevolution in "The TwentyFirst Voyage" is the same autoevolution that he discussed in ST, seen from a different point of view. These interpretations are equally acceptable and are not contradictory. In light of the latter it is visible that autoevolution of the "somatic"

genitals and bleeding to death) and eat him. In 2004 Meiwes was sentenced to 8 years in jail, but his trial triggered a hot discussion whether he should be punished for killing and eating someone who expressly wished that to happen. And it is by no means the only such case.

A desire for extreme sensual experiences and absolute domination and submission have the main role in S\&M phantasms. Such practices are usually highly conventional and can take up the form of a ritual or highly complicated and staged game. The emotional bond is absent or reduced to a minimum, while pure, depersonalized bodily experience is absolutized. Having such practices performed by machines, as it happens in Lem's writing, might be a well-conceived literary idea. It can be put in the same realm as other mass culture products that raise the issue of sex between men and machines or cyborgs - for instance David Cronenberg's films or video clips made by Chris Cunningham. 
type will not liberate us from the problems of the body and gender, or other social issues.

The following stage of autoevolution on Dichotica focused on the mind and produced wisdomites, who settled down due to the size of their brains. Later, it turned to another extreme:

The reaction, when it came, was violent. Our medieval woodcuts, offering representations of dragons and monstrosities from other lands, are child's play alongside the physical abandonment that then beset the globe ... This was also when agonanism came into vogue. Civilization retrogressed ... In the parks all overgrown with table weeds and wild china there lay basking, between clumps of napkill, hullocks - veritable mountains of breathing meat. The majority of these monstrous forms did not arise through conscious choice and planning, but rather were the ghastly consequence of breakdowns in the body-building machinery: it produced not what had been ordered, but degenerate and crippled freaks. (207-208)

Even though in the 20th century, dictator Dzomber Glaubon temporarily introduced "unification, normalization and bodily standardization," as well as desexualization, soon after the Dichoticans returned to autoevolutionary practices, biopolitics and multiplicity of sexes. As a result, during Ijon Tichy's stay on Dichotica the only humanoid creatures were Fathers-Robots. In his last conversation Tichy finds out that their credo is "non agam" ("I will not act"). This point reveals the radical difference between the Dichoticans who were in the process of constant autoevolution and the machines-believers, as the covert credo of the Dichoticans is the opposite sentence: "semper agam," and they share the attitude of people that I mentioned in the previous part of this book: "if we can do it, let us do it!"

So it turns out that Lem can criticize even the most fundamental of his own beliefs. While analyzing the implicit assumptions behind the ST, I emphasized on many occasions, that one of the necessary conditions for the project of autoevolution to make sense is the assumption that people sooner or later will fulfill their entire intellectual and technological potential. In Lem's discursive works this assumption is unquestionable. Meanwhile in his grotesque texts this very assumption is questioned, which implies that they can be understood as an internal critique within Lem's work. ${ }^{204}$

204 "The Twenty-first Voyage" is similar in that regard to the short story "Altruizine" in The Cyberiad. In this story Trurl sets off to the planet of H.P.L.D. (Highest Possible Level of Development; in Polish, however, the creatures are described as N.F.R., abbreviation from Najwyższa Forma Rozumu, but with clear political allusion to German Federal Republic, in Polish Republika Federalna Niemiec), where he deals with creatures 
The analyses presented so far show that Lem allows for three types of autoevolution, which I here call: "somatic," "cyborg" and "mental." Somatic autoevolution is a biological manipulation of the form of the body through genetic engineering ("The Twenty-First Voyage"; "the weak variant" in ST); the cyborg autoevolution is about a far-reaching synthesis between body and machine (cyborgization in ST); the mental autoevolution is about radical separation of mind from the body and placing it in another "vehiculum," for example, a computer network (Golem XIV, "the strong variant" in ST). Further on I shall trace those themes in contemporary culture, which include these three types of autoevolution in one way or another.

There is also a short text by Lem from 1969 called "Autoewolucja." ${ }^{205}$ The theme of the text is as follows: any autoevolutionary practices (which for Lem include, e.g., contraceptives) are "a clash between faith and empirical knowledge." The autoevolution itself - a thorough transformation of the entire species - will be the biggest of those clashes and religion (at least Roman Catholicism) will never come to terms with that. In broader terms the question about the possibility and acceptability of autoevolution is for Lem a question about the limits of human freedom. He sees here the problem of discrepancy between the performative power of technology and its sensible use. But, as I have mentioned before, such doubts only come up marginally in his works. They are completely absent from ST.

degenerated by their own omnipotence. It includes a discussion of the contradiction entailed by the notion of omnipotence for a human being who is finite in time and space (Borges's short story The Immortal has the same message). The sentence from "Altruizine": "whether one thinks in metal or jelly is completely irrelevant," is a paraphrase of Turing's thought.

205 Argumenty, no. 34 (1969), 7, 14. 



\section{Around Autoevolution}

It is easy to trace themes that anticipate autoevolution within the culture of the West. Of course, we cannot speak of autoevolution up until the end of the 20th century in a sense in which it was discussed in Chapter 19. Nevertheless it is possible to consider which of the persisting themes in history do pertain to a radical transformation of humans.

It needs to be said that physical transformations of the body - which lie at the center of one of the variants of autoevolution - have been performed by people from the very beginning of the existence of the species. In this perspective, all beautifying techniques have a lot to do with autoevolution. This includes deformations of the body known in many cultures, including changing the shape of feet in Chinese culture, transforming skulls among the Maya, transforming necks among the SubSaharan tribes, permanent forms of skin decoration among the native tribes of the Amazonian jungle (as well as permanent makeup and piercing in the contemporary Western culture), the entire art of tattoos, from the Maori culture to subcultures of today - the list goes on and on. If we disregard the differences in the symbolic meanings of such practices, what they have in common is that they all involve applying various forms of mechanical techniques to the surface of human body, in order to change its "natural" shape. They differ from the "real" autoevolution insofar as they do not involve manipulating the very biological process of producing bodies. The procedures are "superficial" in that sense.

If we consider other effects of human desire for beautification and improvement, we should include here the entire history of fashion and clothing, as well as, for example, the contemporary cult of youth, beauty and physical fitness, which is a significant element of the mass culture. It would not be sensible to engage in such a broad search for harbingers of autoevolution. Similarly, it would be interesting but hard to treat various improvements in everyday life, deriving from the centuries of progress in technology and medicine (such as cars and vaccines) as "autoevolutionary" phenomena.

When it comes to cultural topoi that correspond with autoevolution, three in particular seem important: the cabalistic topos of Golem, the alchemical topos of a homunculus and the romantic topos of Frankenstein. All three of these are versions of the myth of an artificial human, which has been present in the Western culture since antiquity (Daedalus and Talos, ${ }^{206}$ Pygmalion and Galatea,

206 Talos - a robot made of bronze by Daedalus (or Hephaestus) for Minos. As a sentinel of Crete, he would make rounds of it thrice every day in full armor, catching intruders 
Prometheus and Pandora). "The artificial man" of the past tends to be linked with the issues of robots and cyborgization today, but I believe that the essential difference between literary myths and topoi on one hand, and technological developments on the other makes such links somewhat artificial (in the negative sense of the word), even if the comparisons juxtapose representations of robots and cyborgs in contemporary art and culture.

Half way between literature and technology there lies the history of technology, and in our case the history of humanoid automata, which could be described as proto-androids. Such constructions flourished in particular in the 18th century, with the rise of works such as those by Pierre Jaquet-Droz, which I mentioned in Part One. The growth of precision mechanics coincided with the enlightenment's preference for practical displays of the power of Reason, dominating matter and transforming its laws. ${ }^{207}$ Mechanism, vitalism and the 18th-century philosophy of biology are all part of this group of issues, as they constitute important stages in the development of philosophy of the human body. This, however, decidedly exceeds the limits of this work. ${ }^{208}$

Beautifying techniques correspond with the somatic autoevolution. The theme of "artificial man" corresponds with the cyborg autoevolution. What then would be analogous with mental autoevolution?

I believe it would be the persistent theme of "spiritual transformation" and "self as a project" in the Western culture. It starts with Socrates's ethics, and is then developed within Hellenistic philosophy, especially Stoicism. It includes the

and fugitives (that is why Daedalus needed to fly out of Crete). Talos would throw stones at them or he would burn them flaring up himself. He was indestructible except for the lower part of his leg, where one of his veins ended capped with the handle. It was only the Argonauts who, with the help of Medea's magic, managed to open that vein.

207 Cf. Roland Carrera, Dominique Loiseau, Ollvier Roux, Androides. Les Automates de Jaquet-Droz (Lausanne: Scriptar, 1979); André Doyon, Lucien Liaigre, Jacques Vaucanson, mecanicien de genie (Paris: P.U.F., 1966); Alexandre Koyrè, Les Origines de la science: Les philosophes et la machine (Paris: Armand Colin, 1966); John Cohen, Les Robots humains dans le mythe et dans la science (Paris: Vrin, 1968); Philippe Breton, A l'image de l'homme. Du Golem aux realites virtuelles (Paris: Seuil, 1995).

208 In Polish, an extensive monograph of the 18th-century philosophy of biology is available: Andrzej Bednarczyk, Filozofia biologii europejskiego Oświecenia: Albrecht von Haller i jego wspótcześni (Warszawa: PWN, 1984). A very good analysis of the image of modern experimental biology in the mass culture can be found in: Jon Turney, Frankenstein's Footsteps: Science, Genetics and Popular Culture (New Haven, London: Yale University Press, 1998). 
figures of Prometheus and Faustus - the characters who break out of any subordination and who display creationist ambitions. ${ }^{209}$ (Prometheus's name comes up often in posthumanist manifestos.) Nietzschean project of an Übermensch is a crucially important stage here. All these ideas are based on an assumption of human independence from the external world, especially the cultural world, as well as on a human desire to consciously shape one's own being. This absolute existential independence is what makes all such "projects of self" resemble "mental autoevolution" in which "I" is emancipated from everything, including the body.

Nietzsche can even be seen as the founding father of posthumanism, as he is the first modern thinker to have questioned the system of values that defined modern humanism on such a grand scale. In hundreds of monographs and studies of his philosophy, scholars have traced its impact on the thought and history of the 20th century. Nietzsche's refutation of the significance of the past and institutions of humanist culture for the Übermensch not only did not lose its power - actually, as I shall try to show, today it is stronger than ever.

The "care of the self," to which Foucault devoted the third volume of The History of Sexuality and which came as such a surprise to his readers, accustomed to the vision of the "end of man," may perhaps be seen as a Nietzschean attempt to reconstruct the significance of an independent "I" in face of the poststructuralist destruction of the subject. This "I" would no longer be an issue of abstract post-Cartesian philosophical discourse, but would actually be shaped in a real project, a script for existence laid out by the ancient Stoics. ${ }^{210}$ In the time of

209 Aeschylus's Prometheus Bound grasps the essence of the motif of Prometheus. Cf. Carl Kerenyi, Prometheus: Archetypal Image of Human Existence, trans. by R. Manheim (Princeton, NJ: Princeton University Press, 1991); Louis Sechan, Le mythee de Promethee (Paris: P.U.F., 1951). The theme of Faustus (from the German folk literature, through Marlowe and Goethe, to Thomas Mann and very abstract philosophical and discursive works) has been taken up in hundreds of texts; cf. Paul A. Bates, Faust: Sources, Works, Criticism (New York: Harcourt, Brace \& World, 1969); Frank Baron, Doctor Faustus: From History to Legend (Muenchen: Wilhelm Fink, 1978); Andre Dabezies, Le mythe de Faust (Paris: Armand Colin, 1973); Harold Stein Jantz, Goethe's "Faust" as a Renaissance Man: Parallels and Prototypes (Princeton, NJ: Princeton University Press, 1951); Philip Mason Palmer, Robert Patterson More, The Sources of the Faust Tradition from Simon Magus to Lessing (New York: Frank Casa, 1936).

210 Cf. Didier Eribon, Michel Foucault, trans. by B. Wing (Cambridge, MA: Harvard University Press, 1991), chapter 3.9 "Life as a Work of Art." See also: Michel Foucault, 
posthumanism - if it ever comes - the "care of the self" will become a common duty, a necessity, as the past, history and cultural tradition, which serve as existential framework today, will cease to exist. The potential consequences of these phenomena are discussed here in Chapters 25 and 26.

"Technologies of the Self," in: Technologies of the Self: a Seminar with Michel Foucault, ed. by L. H. Martin, H. Gutman, P. H. Hutton (London: Tavistock, 1988). Nietzsche's life has been interpreted as a work of art by Alexander Nehamas. 


\title{
21 What Is Posthumanism?
}

\author{
Transhumanizing could not be expressed \\ by words; let this case, therefore, him suffice, \\ for whom Grace holds experience in reserve. \\ Dante, Paradiso, I, 70-72, trans. by Courtney Langdon
}

Unlike "autoevolution," "posthumanism" is a word widely used today. It is applied to a few different but corresponding intellectual currents: one of them born from a discussion of the impact of science and technology of the late 20th century on the social life; another from certain threads of the poststructuralist thought, while yet another is an ideology built on them. In fact, the entire posthumanist discourse is permeated by ideology. Reading posthumanist texts from the 1990s and later, it is difficult to distinguish between knowledge and information on one hand, and manifestos and declarations on the other. The reason for that is that posthumanism is an intellectual formation situating itself somewhere in-between science, philosophy and social critique, and its authors and advocates remain nearly completely oblivious of their own historical background, which I have discussed here, and generally they ignore all past in a manner typical of liberal thought. Posthumanism fulfills the criteria of utopianism, which I have described in the context of ST, and some of its premises or theses actually look like quotes from Lem. All kinds of posthumanism call for autoevolution of one of the three types listed here before, but the term "autoevolution" itself never comes up. Posthumanists prefer such terms as "post-Darwinian era." Posthumanism also attracts all sorts of believers in pseudoscientific, parareligious and "esoteric" doctrines ("cosmism," "Prometheism," "transtopia," "cosmotheism," "Church of Virus"), as well as political radicals ("anarchotranshumanism") - these phenomena will be omitted here. Again, I need to emphasize I will not be interested in posthumanism read in the context of contemporary rejection of anthropocentric positions within the academia - so, for example, I will not be referring to the many currents of animal studies.

The term "posthumanism" in the sense assumed here has a synonym - "transhumanism," but sometimes the two notions are treated as different, that is when authors take transhumanism to be an earlier stage of posthumanism, an intermediary period (trans) between humans and a completely posthuman entity. I will not, however, be using these two terms in such a way here. 
The word "transhumanism" was first used by Julian Huxley in 1957, when he vaguely defined it as a situation when "man remaining man, but transcending himself, by realizing new possibilities of and for his human nature."211 In the 1980 s though the definition changed significantly. To illustrate a typical contemporary understanding of posthumanism, we can quote Max More, the guru of Extropy Institute, who was mentioned in Part Two:

Transhumanism is a class of philosophies that seek to guide us towards a posthuman condition. Transhumanism shares many elements of humanism, including a respect for reason and science, a commitment to progress, and a valuing of human (or transhuman) existence in this life ... Transhumanism differs from humanism in recognizing and anticipating the radical alterations in the nature and possibilities of our lives resulting from various sciences and technologies.

The short quote above shows clearly the main characteristics of the entire posthumanist discourse. It is a "philosophy," but one that "tries to lead us toward a posthuman condition," so it is a philosophy of action - a type of thinking that is characteristic of most utopias of change. "It includes numerous elements of humanism," but these elements are "respect for reason and science" and "appreciation for progress," so it is clearly the humanism of the enlightenment rather than, for example, renaissance or neoclassicist humanism - so it is the only type of humanism that disregards the past. As all versions of humanism, posthumanism places man at the center of the entire system of thought and action, endowing him with supreme value, but the similarity will reveal itself as superficial as soon as we remember that the main premise of posthumanism is to go beyond the humanist understanding of humanity. It is clear that the posthumanist discourse is deeply entangled in the dilemmas of its predecessor and that its authors remain largely unaware of it. Emphasizing the role of science and technology in the process of "transhumanization" is a constant feature of posthumanists' declarations. It brings them closer with the 19th-century positivists, but, again, as was the case with the discourse of ST, the resemblance is superficial; not because of constantly distancing itself from its own arguments, as was the case with Lem, but because of posthumanists' conviction that the current psychophysiological shape of human beings is neither the only one possible nor the final one.

According to the posthumanists "there is an ethical imperative leading people to strive for progress and improvement." It is an exact, albeit unintentional, copy

211 In this context it is telling that Michel Houellebecq refers to Julian Huxley in his description of posthuman utopia at the end of his The Elementary Particles (see more on this later). 
of one of the main theses of ST, which I have described many times: that people will sooner or later fulfill their entire potential, including in technology. Further on we read: "If the human kind enters the post-Darwinian stage of existence, in which people will take over the control over their evolution, random mutations will be replaced with rational, morally and ethically justified changes." This in turn is a faithful copy of an implicit contradiction in Lem's work between what I called "the Designer's rationality" and "the pragmatics of the User." There is no necessary reason for autoevolution to follow any rules or ethical imperatives. As one would expect of utopian authors, neither Lem nor the posthumanists think about issues as prosaic as the impact of the current sociopolitical situation or even the mass culture on the practical application of their ideas.

We might be tempted to formulate a generalized proposition here. For Lem and the posthumanists, autoevolution above all involves rejecting the randomness of biological evolution, on which people have no influence, because it takes place outside the realm of human actions and human time, and that is the source of our psychophysical incapacities. This is certainly true. However, it entails a risk. Introducing autoevolution into the global social system would most likely lay it open to the threat of all destructive and random process to which all other institutions, as well as scientific and technological endeavors, are subjected. Only very naïve people still believe in the independence of science and technology from economy, politics and social issues, as well as from the impact of influential lobbies, provisional solutions and finally from passing fashions. As I have tried to show, in ST Lem ignored this entire issue, accepting implicitly that introducing "pantocreatics" will somehow solve it. This is exactly what posthumanists do today. Yet, it is quite certain that if autoevolution ever goes out of the pages of utopian musings, it will soon yield to such processes and hence it will become a random process, just as Lem described it in "The Twenty-First Voyage." The only difference is that its randomness will not come from the laws of genetics and evolution but will have its sources in the laws governing social life, and these laws, as history teaches us, override all reforms. On the other hand, it will touch not the institutions of our life, but the very material form of our existence, which will make it more dangerous than any of the previous "errors and distortions" of the civilization. This is the argument of the opponents of biotechnology.

According to Lem (as the author of both ST and Golem XIV) and the posthumanists, autoevolution will automatically mend all the evil in the world and so there is no reason to fear it. Earlier centuries have seen at least a few projects implying similar inevitability and their authors probably had the most noble of intentions. Some of them were only confined to libraries, while others 
have been implemented, taking the lives of millions of people. So it is good to retain some skepticism when studying such radical vision.

The historical beginnings of posthumanism in its technocratic version are connected with the circle of scholars and visionaries who gathered in the early 1980s at the University of California Los Angeles (UCLA). ${ }^{212}$ Apart from Max More and his extropians other important figures were, for example, Feridun M. Esfandiary and Nancie Clark (a couple in their private life), who attracted a group of enthusiastic students and followers. Esfandiary (1930-2000), a son of an Iranian diplomat, is an emblematic figure for the entire subcurrent of American posthumanism. He began as a futurologist and an author of sci-fi novels. He then moved on to prophetic reflections on the beautiful future of the human species which he laid out in a series of books, including the most famous one: Are You a Transhuman? (1989). He adopted a pen name FM-2030 and claimed that he feels "a deep nostalgia for the future." Before he died he asked to be hibernated and his body is now in a certain posthumanist center in Arizona, while his ideas are being propagated by his widow (known as Natasha Vita-More). Esfandiary's writings, just as those of his fellow posthumanists and many experts in advanced technology, are characterized by untamed enthusiasm for rapid technological progress of the late 20th century. Again, as 200 years earlier, during the industrial revolution, the swift changes in the technological sphere have produced a group of fervent followers, as well as fierce opponents, whose arguments I will recount later.

1986 is particularly important in the development of posthumanism. This is when Eric Drexler's book Engines of Creation came out, which included a description of the potential of nanotechnology which was just being born at the time. For the posthumanists it was proof that it is technically possible to fulfill their ideas. We should point out that the entire "Californian" current of posthumanism, permeated with a belief in high technology, focused on this particular type of autoevolution which I termed "the cyborg autoevolution." Its authors imagined posthuman to be a hybrid of biological body and a variety of machines, which is hardly surprising, given that they worked and thought in a close proximity to the Silicon Valley at a time when the "dominating technology" (using J. David Bolter's term) was IT, and not yet biotechnology. This was a time of intellectual osmosis between the posthumanists from the UCLA and the artificial intelligence (AI) experts from Silicon Valley - distant successors of

212 A lot about them can be learned from Erik Davis's book, TechGnosis, which I referred to in the earlier part of the book. 
Turing's idea. There is therefore a connection of sorts between the "Californian" posthumanism and the realm of $\mathrm{AI}$, and it lies in the conviction that it is possible and sensible for people to create a nonhuman form of intelligence, with the one difference (often unnoticed) that for the posthumanists these forms should be derived from human bodies ${ }^{213}$ - and replace them; whereas the theoreticians of AI, such as Marvin Minsky or Ray Kurzweil aim for a full autonomy of those forms, trying to build "intelligent machines." The difference is particularly significant if we take into account the problems with defining consciousness discussed in Part One and Part Two of this book. No one would doubt that a posthuman being will, at least in the initial stage, have a consciousness similar to ours because it would be inherited from us. At the same time no one knows for sure what kind of - if any - consciousness a computer will have (although authors such as Roger Schank believe that they know for sure what it will be like).

213 It is common among the posthumanists and AI experts to despise or even hate the human body as an aesthetically disgusting and nonfunctional lump of easily rotting organic matter. This is another thing that is similar with Lem. In AI parlance we often encounter terms such as "meatware" and "flashware" - which are again symptoms of treating the current physical form as a primitive version or an initial stage of the development of computer mechanism (in an analogy to "hardware" and "software"). See also Chapter 25. 



\section{Posthumanism as a Theoretical Discourse}

In the late 1980s the ideas of the Californian posthumanists permeated some of the American postmodern and gender discourses finding there a favorable breeding ground. The "inhuman" character of posthumanism seemed to correspond well with the poststructuralist destruction of the subject, bringing some fresh breeze of technocracy into the stale climate of academic musings about the "death of man." The deeper implications of these links are analyzed in Chapter 25. Here it is enough to briefly discuss the most representative authors. Among them, the ones who should most particularly be mentioned are, I believe, Donna Haraway, N. Katherine Hayles, Chris Hables Gray and Robert Pepperell. Each of them uses the posthumanist ideas in their own ways and connects them with different elements of the contemporary intellectual puzzle of the West. Also, each of them prefers one of the three models of autoevolution I have listed. This means that all these authors are in some sense (usually unintentionally) continuing Lem's thought, albeit with a difference, as they use the same ideas as the ones he presented but for completely different purposes.

The moment when Donna Haraway's A Cyborg Manifesto ${ }^{214}$ was published in 1985 can be seen as the moment when the idea of cyborgs shifted from the realm of technological and "technognostic" musings to the realm of imagery of postmodernism and gender studies. Haraway's text, which lies at the center of feminist polemics of the 1980s, uses the word "cyborg" as a metaphor describing the fall of the distinction between the Natural and the Artificial in science and the humanities, which implied the fall of the system of values and social roles, especially feminine social roles, founded on that distinction. According to Haraway, "a cyborg" can be a symbol of these changes, as it is a hybrid of the "natural" (body) and the "artificial" (machine), and hence, by its very existence, it dismantles the divide between these two areas.

214 Donna Haraway, “A Cyborg Manifesto: Science, Technology, and Socialist-Feminism in the Late Twentieth Century," Socialist Review, no. 90 (1985), 65-108: the essay was then included in Haraway's most famous book Simians, Cyborgs and Women: The Reinvention of Nature (1991). Early on, Donna Haraway's work focused on the imagery of biological sciences and links between natural studies and the humanities. Her published works include also, for example, Crystals, Fabrics and Fields: Metaphors of Organicism in Twentieth-Century Developmental Biology (1976). 
What can be said about the idea? Above all, Haraway, just as other authors mentioned here, pays no attention to the fact that cyborg as an advanced hybrid of a biological body and a machine has so far not gone beyond theory. Her disregard for facts and narrow interest in theoretical concepts is characteristic of the entire postmodernist thought. In this particular case, it takes an unusual shape as purely theoretical entities - which are expected to become reality in the future - are being discussed as if they were real. Moreover, we are dealing here with a complex mixture of social theory and political demands, which is also typical for many types of postmodernist thought. Yet, at the very beginning of the text, Haraway introduces the notion of irony, which implies that she is aware of the paradoxical character of her argument and she uses irony to distance herself from it.

Such description might suggest that Haraway partly talks about the same thing as Lem in ST - especially when it comes to rejecting the distinction between the Natural and the Artificial. But it is an illusion. The feminist author is not interested in either this distinction or the cyborgs for themselves, for the pure intellectual interest of probing the limits of human potential. She has no positivist faith in the independence and selflessness of science and technology. Quite the opposite: as all authors representing this type of thinking, she sees the practices of producing and distributing knowledge primarily as an element of a network of social, political and symbolic relationships, and not a leading one either. That is why the figure of a cyborg, which is nonhistorical, apolitical, nonbiological and nonsexual and free from oppression of norms, is the perfect starting point for her discussion of the social situation of women.

It needs to be added that these interpretations do not derive clearly from Haraway's text, which is written in a language that is a peculiar mix of scientific terminology and poststructuralist lingo, and most of the notions there are used as loose metaphors. These characteristics, which strongly resemble the language of social cybernetics which I have discussed in Part One, are typical of nearly all texts written by posthumanist theoreticians, and it is possible that the similarity has stronger foundations - if we accept that posthumanism plays the same role today as cybernetics did half a century earlier, and before that: organicism, evolutionism and scientism. It is a role of a mystical and utopian social ideology, based on misread scientific premises. ${ }^{215}$

215 A good example of the increasing effects of Haraway's "blurring" textual strategy in the 1990s is the article by Gary Lee Downey, Joseph Dumit, Sarah Williams, "Cyborg Anthropology," Cultural Anthropology, no. 2 (1995). "Cyborg anthropology" is to be a new incarnation of anthropological theory, located somewhere in-between an 
N. Katherine Hayles, professor of literary studies at the University of California Los Angeles (UCLA), combines posthumanism with a political discourse in a completely different manner. In her book How We Became Posthuman: Virtual Bodies in Cybernetics, Literature, and Information (1999), she tries to apply the language of the humanities to analyze the consequences of the spread of the imagery of cyberspace in the contemporary intellectual diction, especially within postmodernism. As other authors Hayles emphasizes especially the independence of cyberspace and the type of thinking about reality it entails from the methods of understanding the world available so far and developed by the Western philosophy. She claims that thinking in terms laid out by Aristotle, Descartes, Kant and Hegel, which dominated our views on the nature of reality until recently, and which was particularly impactful in shaping our understanding of our own bodies and their symbolic roles, is losing its function in light of the growing domination of thinking in terms of "IT" and "cyberspace." Bolter expressed similar views earlier in Turing's Man and both these authors refer to the same earlier thinkers (Turing, Wiener). But Bolter does not go quite as far in designing a new way of thinking, mostly because when Turing's Man was published, there was no notion of cyberspace yet. Unusually for posthumanists, Hayles points out that the growth of posthumanism as a theory and social practice will require rethinking and redefining the notion of humanity. She brings up numerous literary examples (and her book was awarded the Rene Wellek award for the best work in literary studies).

Chris Hables Gray, a professor of science studies at the University of California Santa Cruz, is the creator of "cyborg studies," one of the editors of the volume The Cyborg Handbook (1995) and the author of Cyborg Citizen: Politics in the Posthuman Age (2001). His main goal is to create a theory of a cyborg society, with the word "cyborg" used more or less the same way as Haraway uses it - as a metaphor of a certain possible social option, that is, a society of posthuman creatures devoid of historical and political tradition. Gray postulates, among other things, compiling a "Cyborg Bill of Rights," which would define their social rights, as well as those of other intelligent creatures, which are not biologically human. The idea can be placed in the context of the historical growth of rights given to different groups in modern Europe: from the Declaration of the Rights

academic discipline and social practice; "a cultural project rather than an elite academic practice." A Cyborg Manifesto has also become the founding text of a separate current on feminism called "cyberfeminism," which gained some traction at the end of the 1990s. 
of Man and of the Citizen through rights of women, people of color, children, sexual minorities and animals. If we step beyond theoretical posthumanism for a moment, we might notice that the growth of biotechnology, which is gaining pace every year, will soon force us to face a discussion of the legal status and rights of clones and genetic chimeras. ${ }^{216}$ It does not take much of an imagination to see what would be the next stage in that process: machines' rights, especially if they can be equipped (even if unintentionally) with some sort of higher intelligence. ${ }^{217}$

It all poses tremendous challenges to our established ways of thinking and therefore the ideas of Gray and other posthumanist theoreticians do indeed have some value - they may be quite fantastic, but as thought experiments they can help us understand situations in which we can find ourselves very soon. Even if we will not all become cyborgs.

In 1995 Robert Pepperell (born in 1962), a British multimedia artist, published a book titled The Posthuman Condition: Consciousness beyond the Brain, which quickly became one of the most important declarations for the entire movement. ${ }^{218}$ It includes The Posthumanist Manifesto as an appendix and it is worth it to quote a few sentences from it here. The first sentence is: "To understand how the world is changing is to change the world." For a reader acquainted with the history of utopian doctrines this will certainly bring to mind Marx's 11th thesis on Feuerbach, and indeed, in its power and concise character Pepperell's Manifesto does not fall far behind the writings of the German philosopher. Its content sums up postmodernist views, combining acceptance of extreme cultural and academic relativism with declarations borrowed from theoreticians of both "strong" and "weak" versions of artificial intelligence and general system theory. In the first part ("General Statements") it states:

1. It is now clear that humans are no longer the most important things in the universe. This is something the humanists have yet to accept....

216 Chimera is a creature that has genes of more than one biological species.

217 On this subject, see, for example: James Shreeve, "The Other Stem-Cell Debate," New York Times, April 10, 2005; Erik Baard, "Cyborg Liberation Front," The Village Voice, July 30-August 5, 2003 (article about the World Transhumanist Association Conference). The same motif can be found in Lem's fiction in "The Washing Machine Tragedy" (in Memoirs of a Space Traveler: Further Reminiscences of Ijon Tichy), the subject of which is a casuist dispute about the legal status of intelligent humanoid washing machines.

218 The book was reprinted twice and excerpts from it are now used in classrooms in many US university courses on posthumanism and artificial intelligence. 
4. Human beings, like gods, only exist inasmuch as we believe them to exist.

6. All humans are not born equal, but it is too dangerous not to pretend that they are.

7. In the posthuman era, machines will no longer be machines.

The text manipulates elements of philosophical and scientific discourse with great liberty. In the following parts of the manifesto, there are numerous statements about science and technology articulated in the same tone: they are highly ideologized, while at the same time detached from their own deeper significance. The aim of the text as a whole is to prove the main thesis of posthumanism: that human beings as products of the process of biological evolution are not the only possible form of intelligent life on Earth. Very similar phrases can be found in the 1999 Transhumanist Declaration, which also includes some intuitions as to the social and legal status of the alleged posthuman creatures:

(4) Transhumanists advocate the moral right for those who so wish to use technology to extend their mental and physical capacities and to improve their control over their own lives. We seek personal growth beyond our current biological limitations.

It is hard, however, to find texts written by post- and transhumanists that would present a higher awareness of the philosophical and social implications of their views. This is probably largely due to their own rejection of the past which is implicit to the idea of going beyond what is human. It is also significant that nearly all posthumanists are either scientists or represent the humanities, but were shaped by the anti-historical version of postmodernism - and the fact that nearly all of them are American. ${ }^{219}$

The authors quoted here are most interested in the "cyborg" autoevolution, but there are "mental" autoevolution aficionados among posthumanists too (e.g., the extropians). They pay least attention to the "somatic" type of autoevolution, probably because in their eyes it does not guarantee complete rejection of the old "biological" form of humanity.

An overview of positions ends here. The literature on posthumanism, which piled up in the last decade of the 20th century and in the early years of the current one, is vast. It includes at least a few dozens of books, hundreds of articles

219 The term "posthumanism" comes up in some of the versions of European poststructuralism, but in this case it is always linked with philosophical theories, especially the school of Foucault ("death of man") and Derrida. This version has no connection with the ideas I am discussing here and I believe it is altogether a misunderstanding to use the term in such contexts. See, for example: Stefan Herbrechter, Ivan Callus, "What's Wrong with Posthumanism?," Rhizomes: Cultural Studies in Emerging Knowledge, no. 7 (2003). 
and many more texts, which refer to the notion of posthumanism only marginally or use it for embellishment. Most of these works have been published either in renowned publishing houses or in prestigious (mostly American) journals, which should dispel any doubts there may be about the status of ideas and doctrines of posthumanism, at least in the American academia. There have been numerous conferences held there since the 1990s on posthumanism, cyborgs and other similar topics, often combined with theories of new media, gender studies, psychology of the Internet, and so on. Only time will tell the real value of these intellectual productions. 


\section{Cyborgs, Androids and Robots}

Based on the contemporary use of the word "cyborg," one could think it has always been a vague theoretical concept, a means of utopian and highly abstract musings. It would not be true, however. Before posthumanism was born, the word signified quite a concrete entity, albeit also theoretical.

As was said before, in the final part of ST, Lem mentions in passing an article about cyborgization of man, and he most likely means the founding text of the entire "cyborg studies." It is a short, few-pages-long text penned by two American scholars, Manfred E. Clynes and Nathan S. Kline, published in an issue of the journal Astronautics from September 1960, under the title "Cyborgs and Space." Referring to the laws of cybernetics (which was at its peak of popularity at the time, we should remember), the authors presented the possibility of transforming the body of an astronaut through surgery in a way that would allow him to function efficiently during space travel and on the surface of other planets. The means to that goal would be to perform surgeries to eliminate body parts, which could not function properly outside Earth (e.g., the respiratory system) and replace them with machines, which are "normally" outside the human organism. Other organs would only be supported mechanically. Let us look at this text in more detail now.

The first sentence goes as follows: "Space travel challenges mankind not only technologically but also spiritually, in that it invites man to take an active part in his own biological evolution." The similarity with Lem's thinking on autoevolution is quite clear here, but in this case autoevolution happens for utilitarian reasons: it is to facilitate space travel rather than to improve human condition, as it is meant to do for Lem. Further on the authors offer a definition of a cyborg: "For the exogenously extended organizational complex functioning as an integrated homeostatic system unconsciously, we propose the term 'Cyborg." It is followed by an expert discussion of "psychophysiological problems," such as the functioning of various senses and organs of a cyborg during space travel. These issues are largely pertinent to "normal" cosmonauts as well (long periods outside earthly gravity, psychoses, changing metabolism, etc.). There is no discussion of possible emotional changes in a cyborg, however. Interestingly enough, Lem does not ask that question either, even though the stories about Pirx the Pilot prove that he understood well the psyche of a cosmonaut exposed to loneliness in extreme conditions for long periods of time. Lem is very rarely interested in how a cyborg or any other form of "artificial life" may "feel in the world." It 
may seem odd in the context of the autoevolutionary project, but I have already tried in Part Two to show that this is really a grand-scale project. And then, Lem is generally against psychologizing, even though there are a few important exceptions to this rule.

I will return later to questions raised by psychology of posthuman creatures. Here I will only add that they can generally be seen as the opposite of Turing test. We are (potentially) in direct contact with a creature about which we know for sure that it is self-aware and intelligent. But we cannot know what their profile will be like. It will certainly differ from humans more than individual human minds differ from each other. Therefore any known standards of psychology based on conventions derived from human interactions are bound to fail us.

Clynes and Kline's article was written in the period of the highest enthusiasm about the "conquest of the universe," which soon faded away. Therefore the text became an inspiration not for science and technology but for sci-fi literature and then, as we have seen, for posthumanist theories. The evolution of the thinking on cyborgs is an interesting example of how a strictly scientific idea, marginalized by the growth of science, can gain new vigor in literature and the humanities. ${ }^{220}$

"Cyborg" is not the same as "android" or "robot." Cyborg, as is clear from above, is a creature combining elements of a biological organism and a machine system, and the machine part can consist of macroscopic servomechanisms or microchips. The word "cyborg" is a compound of "cybernetic organism." "Android" on the other hand is a machine created in the image and likeness of humans - which means it is a peculiar type of "robot" - the term covering all machines capable of movements. The word "robot" was first used by Karel Čapek in his play R.U.R. from 1920 - and the Czech neologism is now used all over the world, thanks to its pronunciation, which is easy for non-Slavs. Cyborgs, androids and robots crowd the worlds of sci-fi literature and films, but there is no need to go into detail in that regard here, even though their role in mass culture is huge and one could certainly investigate the links between them and the

220 A valuable summary of the history of the theme of cyborgs in science and art can be found, for example, in Craig M. Klugman's article "From Cyborg Fiction to Medical Reality," Literature and Medicine," no. 1 (2001). The author points out to the importance of the idea of cyborgization for medicine, especially prosthetics. He also emphasizes that the notion of a cyborg in the philosophical discourse is "non-Cartesian," which means that it is not subject to the duality of body and mind. This thesis, very popular among the posthumanists and those interested in cyborg studies, is a clever way to neutralize the "mind-body problem," which, as I have pointed out many times earlier, is the main challenge to the entire intellectual field discussed here. 
"serious" posthumanism, especially as the theoreticians of posthumanism are very often fans of science fiction.

Frederik Pohl's Man Plus, ${ }^{221}$ clearly inspired by Clynes and Kline's foundational text can serve as an example of the theme of "cyborg in literature." The protagonist of the novel is subjected to cyborgization, which is to allow him to live freely on Mars, but which also turns him into a monster resembling the medieval ideas of the devil. It is a rare version - in most cases, when the aesthetic aspect of cyborgization is taken into account, it is presented in a vision of an elegant figure of chromed steel. There is a whole separate current of "cyborg art," which draws on just such fetishizing imagery. Pohl, however, models his hero differently, as this allows him to emphasize the physical and psychological pain the transformation causes. The author's ambition is to create a psychological portrait of a man turned into a cyborg. Given the difficulties it entails, he succeed to a significant degree, even though the main source of Roger Torraway's internal conflicts lies in the fact that his wife is having an affair with his friend, who happens to be one of the people carrying out the project of cyborgization. In the end Torrawaycyborg adapts fully to the conditions on Mars and becomes its first settler, no longer missing Earth or people (Pohl hence admits that cyborg becomes a form essentially alien to man and vice versa). One interesting aspect of the novel is that it turns out that the whole plan to colonize Mars with cyborgs has been devised for people by computers, which became intelligent unnoticed, through cumulating of computing power and the growth of network. In terms of its literary value, Pohl's novel does not differ much from most US sci-fi productions, but it is an important impulse to understand, how the idea of a cyborg functioned in the mass culture of the late 1970s and early 1980s. Soon after cyborgs would become big in films, mostly through Terminator and RoboCop. This, however, goes beyond the scope of my argument. ${ }^{222}$

221 Frederik Pohl, Man Plus (New York: Baen Publishing Enterprises, 1976).

222 To complete the necessary information, I need to point out that the most famous androids of literature and cinema are the characters of Dick's novel Do Androids Dream of Electric Sheep? (1968) and its film adaptation Blade Runner (1982) directed by Ridley Scott, whereas the fullest picture of a robot was drawn by Isaac Asimov in his Foundation Series (1951-1953, and then continued in 1982-1986). In all these works the ethical, psychological and social issues connected with the existence of nonhuman protagonists are thoroughly investigated. These important texts of the late20th-century mass culture featuring cyborgs, androids and robots call for an exhaustive discussion but it would fill a separate book. Between 1980 and 1990, cyborgs often come in military contexts, as enhanced soldiers. 
Some scholars differentiate between cyborg in a sense used here before and phenomena that we can today describe as cyborgization. If we assume that any kind of enhancement of human organism by installing external devices is a form of cyborgization (and Clynes and Kline's definition allows that), then we should say every human with a pacemaker, prosthesis or even contact lenses is a cyborg. If we treat cyborgization as a form of Hall's extension - and it is acceptable given the broad scope of the latter term - then any man wearing glasses or talking on a cell phone would be a cyborg. In order to avoid such absurd conclusions, in 1995 an American scholar Alexander Chislenko came up with a word "fyborg" (a compound of "functional cyborg"), different from a "real" cyborg, and signifying a person who uses technological devices extensively in order to increase their own psychological and physical capacities. Many technology aficionados embraced the term, declaring themselves as fyborgs. ${ }^{223}$

Let me finish this topic with a brief discussion of the connection between cyborgs and cyberspace. The two terms are frequently uttered together, most often by theoreticians and critics of art engaging the modern media, who are excited by the new possibilities in that domain. I believe, however, there is a vast difference between the theory and the practice of cyberspace and cyborg or somatic autoevolution. It lies primarily in the fact that cyberspace is not tactile. Speaking about it, we usually have in mind something resembling a Platonic idea ${ }^{224}$ rather than matter; it is res cogitans rather than extensa. The only material thing a cyberspace user comes in contact with, the only sensory experience is the keyboard and the interface of the computer, occasionally with other peripheral devices, and then, if he or she is in virtual reality, they may interact with a number of simulators. Cyborgization on the other hand involves transformations

223 Kevin Warwick, a professor at Coventry University (UK), declared himself to be a real cyborg, as he had electronic chips implanted a number of times since 1998, allowing him to control some devices from a distance. Warwick became quite popular with the media and came to be an icon of cyborg studies, but his projects are often criticized as scientifically worthless tricks for publicity. His endeavors have little to do with theories discussed here. But they can contribute to progress in making the lives of people with various impairments easier.

224 See, for example: Michael Heim, “The Erotic Ontology of Cyberspace," in: idem: The Metaphysics of Virtual Reality (New York: Oxford University Press, 1993). Heim's thesis that cyberspace is "a practical incarnation" of the notion of idea in Plato's thought can only be treated as a loose metaphor. In another text Heim claims that cyberspace fulfills Leibniz's concept of monadology (strict separation of subjects, communicating solely through highly mediated codes). 
of the actual matter, not a simulated transformation. The degree of the subject's autonomy is another issue here. In cyberspace "I" can be misled freely by whoever provides the simulation of reality. We could see intuitions about the process in Dick's novels, the precise description in the chapter of ST on phantomatics, as well the cinema rendition of this in The Matrix. ${ }^{225}$ In cyborg utopia on the other hand it is the machine that is subordinated to man rather than the other way round, and ultimately man and machine are to form a harmonious one.

Given the above analysis of the two phenomena, cyberspace and cyborgization should, I believe, be carefully differentiated. The fact that all these more or less fantastic projects and ideas tend to get confused with each other comes from all of them somehow pertaining to people and having a radical transformation of man as their aim. And the most radical variant of autoevolution, which I have classified as mental autoevolution, suggests no less than to completely shift human mind into cyberspace. All these ideas are internally connected, but many authors seem unaware of the complexity of those connections and the huge intellectual difficulties they entail.

225 Slavoj Žižek offered an interesting philosophical interpretation of cyberspace in his essay The Matrix, or, the Two Sides of Perversion (1999). He sees it as a fulfillment of Malebranche's idea of occasionalism: every act of will of a subject is mediated and carried out by computer software. This and the previous footnote are examples of how many philosophical associations the notion of cyberspace can produce. 



\section{A Critique of Posthumanism}

In the last three chapters, I presented a brief description of posthumanism, its premises and how they have been put to work. I will now proceed to the charges laid against posthumanism. In Chapter 25, I will reconstruct the implicit premises of posthumanism and the contradictions they entail.

In 2006 one of the online dictionaries (www.findword.org) defined "transhumanism" as: "Transhumanism can be interpreted as a progressive libertarian ethics going beyond humanism," and then the entry continued: "In many ways transhumanism aims at fulfilling goals and hopes traditionally articulated by religion." The combination of libertarianism and quasi-religious spirituality ${ }^{226}$ (symptoms of which have already come up in previous chapters here) can be seen as an extremely dangerous coupling, resembling other social utopias in the Western thought of the last two centuries. Undoubtedly, without a second thought posthumanists accepted one of the most fateful premises of the modern worldview: that a man can be God to himself. This thought and its possible consequences haunted many a philosopher and writer - but it does not seem to bear any particular significance for posthumanists. This embracement shows for the first time that posthumanism can have something to do with contemporary theory and, more importantly, with current social practice. I will discuss that connection.

Posthumanists themselves distinguish between two types of criticism of their ideas: the practical one, targeting the possibilities of actually achieving its declared goals; and the moral one, targeting its sense. There are then two main versions of the practical critique. The advocate of the first one, Steve Jones, claims that the development of technology will never lead to the kind of potential that posthumanists talk about; there will be no such advancement that would turn us into cyborgs and transfer our minds into a network; there will not even appear a possibility to genetically enhance our bodies. This is the simplest possible charge

226 I would rather not devote much attention to the links connecting posthumanism and artificial intelligence (AI) with religion here, although there are many. The concept of the mind as a computer program, universe as a computer and consciousness "immortalized" in a computer network, finally the idea of a human "deified" into a machine clearly do tickle the religious instinct in many people. But the effects of such impulses (especially textual effects) exceed the realm of this work. The Raëlist sect has been particularly interested in posthumanism. 
and not a particularly serious one, as given the current level of technological development it is equally impossible to prove that the autoevolutionary scenario will or will not come true.

In its second version, the practical criticism is much more significant. In 1989 Max Dublin, a sociologist from the University of Toronto, published a book Futurehype: The Tyranny of Prophecy, in which he brought back a number of completely failed futurologist predictions about the development of technology. He claimed that the theses put forward by posthumanists run a risk of being equally imprecise. Indeed, there are a lot of similarities between posthumanism and futurology of the 1960s and 1970s, and it is quite likely that the technological growth in the 21 st century will go in a completely different direction than the one outlined in the autoevolutionary scenario. Yet, there are important differences between the two intellectual currents as well. Laying aside the political applications of futurology, it was essentially a science free from ideology. The futurological predictions were not meant to create utopian visions, but merely extrapolate the existing state of things. Futurologists never claimed that humanity would make a leap toward posthuman forms. There was no talk of autoevolution as means of salvation. There were no attempts to combine technological predictions with a social theory (the purpose of the predictions was practical: to regulate the functioning of the social system). Technological ideas did not become symbols in cultural and political discourse. In brief, the difference lies in intentions, even if the effects are superficially similar.

In the book I have mentioned, Dublin himself emphasizes these differences, claiming that transhumanists tend to be fanatic and nihilistic, while their views resemble religious ideologies and Marxism. Posthumanists oppose such an interpretation, pointing out that those ideologies are not consistent with rationality, which lies at the core of their entire current. Here again it becomes clear that they cannot see how rationality itself can easily become an ideology.

Sir Martin Rees, the British Astronomer Royal and the author of many splendid popular educational texts on contemporary cosmology, points out in his book Our Final Hour (2003) that the development of advanced technologies poses as many risks to our civilization as it produces benefits - which echoes the theses of the Frankfurt School created several decades earlier. Rees draws a picture of another stage of the 200-year-old argument surrounding technology. $\mathrm{He}$ calls for not so much halting its growth (which would be a utopia even less realistic than the mental autoevolution), but for a careful consideration of its effects and for limiting the openness of the structure of science. Thus he positions himself in proximity with "the principle of responsibility" of Hans Jonas and 
moderate environmentalists, making yet another attempt to somehow level the diverging currents of technology and ethics within our civilization.

The one criticism that was certainly the most important for posthumanists themselves was presented in 2000 by Bill Joy. It is important not only due to the intellectual heavy weight of arguments used, but also because the author is not one of those "ignorant" humanists, "loony" environmentalists or academic theoreticians - he comes from the very core of technocracy. William N. (Bill) Joy is a cofounder of Sun Microsystems, one of the main players of the computer industry. He is also the main developer of the very popular Java computer programming language. His essay Why the Future Doesn't Need Us came out in the prestigious IT journal Wired (April 8, 2000) and sparked a big discussion, which brought the author even bigger fame - albeit somewhat ambivalent in nature. Joy's theses mostly echo the views that many authors expressed in the 1940s and 1950s, during the discussion around the ethical implications of nuclear research and Joy invokes those arguments directly. Yet, for the posthumanists hypnotized by their own bright visions, this resonated suddenly as powerful memento. Joy wrote openly that the uncontrolled technological growth of the 21st century may lead to the destruction of our species, which will either eliminate itself accidentally, manipulating it like a sorcerer's apprentice, or it will be eliminated by AI (this option, however, is actually met with enthusiasm by many posthumanists who seem to hate humanity for many more or less idiosyncratic reasons). Joy's revelations are quite obvious for anyone who is looking at posthumanism and technophilia from the outside, but - as is evidenced by the rhetoric of his text they must have seemed quite original to Joy himself. He even quotes Nietzsche and one of his attacks on "science" and "truth," pointing out that it can be reiterated with regard to the contemporary world. He also discovers the meaning of the notion of social utopia, thanks to Jacques Attali's books on the ideals of the French Revolution. One of the last sentences of the essay is: "This all leaves me not angry but at least a bit melancholic. Henceforth, for me, progress will be somewhat bittersweet." What else can we say? ${ }^{227}$

Joy sees one more thing that none of the authors of utopias saw, not only the posthumanists, not even Lem in ST (although he did notice it in his novels). Joy writes: "And even if we scatter to the stars, isn't it likely that we may take our problems with us or find, later, that they have followed us?" This incredibly fateful sentence puts all efforts of posthumanists into question. Indeed, even if, as

227 In 2003, Joy resigned all of his positions at Sun Microsystems and announced that he was withdrawing from the IT industry. 
Lem's Golem XIV prophesized, we do make the autoevolutionary leap, in order to, "by rejecting man, save man," there is no guarantee, that what is most valuable in man, will in fact be saved. This dramatic dilemma will be discussed here again.

One more remark from Joy's essay ought to be mentioned here. At the very beginning of the text, the author juxtaposes two names and two figures of people who symbolize two opposed extreme viewpoints regarding technological progress. The first one is Ray Kurzweil, already discussed here. The other one is Teodor Kaczynski, better known as Unabomber, a terrorist, who provoked fear among US scholars in the last years of the 20th century by sending explosives to science labs. Joy claims that both these men have their point - and this must have been enough to shock most of Joy's readers - and he calls Kaczynski and other such radical opponents of technocracy "Neo-Luddites" (Kurzweil used the term too). This name, which caught on well, points to the fact that the discussion around new technologies in the late 20th and early 21 st century is yet another stage of a process that has been going on for more than 200 years, from the very beginning of the industrial revolution, which was the first among many phenomena triggered by modern science and technology and strongly affecting the social order. We could list Luddites, humanists such as Matthew Arnold (in a polemic with Thomas Henry Huxley), defenders of the classic model of education against grammar schools, Frankfurt School philosophers, those opting for the "classics" in the two cultures debate, and ideologists of the counterculture of the 1960s - all of them opposed the progress of science and technology not only because they were fearful conservatives or humanists, but also because they saw in it a risk of losing human sovereignty. It is paradoxical that the same fear can be caused by posthumanism - a theory and an ideology, which aims to ultimately elevate human beings beyond the randomness of their condition. But it is enough to remember the fate of other emancipatory ideologies, to understand how noble ideals can become the opposite.

Let us now move on to the moral critique (although Reese and Joy's criticism included numerous such elements as well). Posthumanists are aware of the problem that has been mentioned here many times already when discussing the implicit premises of ST. It is the discrepancy in the development of technology and ethics. In 2005, a Wikipedia entry on transhumanism included the following passage:

Technological solutions may be compatible with other improvements, but some worry that strong advocacy of the former might divert attention and resources from the latter. As most transhumanists support non-technological changes to society, such as the spread of political liberty, and most critics of transhumanism support technological 
advances in areas such as communications and healthcare, the difference is often a matter of emphasis.

It all seems easy then: we speak different languages, but at the end of the day we have the same goal: to make people's lives better. Posthumanists observe that there is a difference between the positive value of technological innovations themselves and the practical use to which particular people or groups put them. The polemic about technology and ethics between technophiles and Neo-Luddites is just one of the versions of the debate on human nature between liberals and conservatives. The former believe that common sense and untamed entrepreneurial spirit can guarantee the right use of technology. For the latter, unlimited technological innovations are like offering a razor to a child. At the heart of posthumanism, there lies liberal or even libertarian philosophy - although not all posthumanists realize that. Yet, for them it is obvious that technological progress - just like individual liberty - do not need to be controlled at all; and the problem of discrepancy between technology and ethics is a result of a misunderstanding or an effect of bad will on the part of some people and groups.

Another form of moral critique of posthumanism is the eugenics charge. Indeed, autoevolutionary concepts in all their versions might bring to mind the 20th-century ideas to "improve" man. It should be reminded here that in view of eugenics' creator, Francis Galton, it was meant to be a means of improving humanity as a whole. Yet, even this early premise included a seed of the later segregational and racist interpretations. Galton would admit that the aim of eugenics is to intensify the most valuable features of the species (as judged by the modern industrial society). It automatically necessitated conceptually distinguishing its "best" representatives. Does not posthumanism conceal the same risk? Likely so, but posthumanists generally reject any such affiliations. Posthumanist texts do not pose the question, who would really be subjected to autoevolution. (Perhaps posthumanists, too, imagine it to be the entire human kind). ${ }^{228}$

The third and final example of a moral critique of posthumanism is Francis Fukuyama's Our Posthuman Future, ${ }^{229}$ which accuses posthumanism of destroying the notion of human nature. Fukuyama claims that posthumanism can undermine the ideals of a liberal society, which are the very foundation of

228 There are several extremely right-wing subcurrents to posthumanism that embrace the heritage of the 20th-century segregational ideologies. But the mainstream group is definitely separating itself from such views.

229 Francis Fukuyama, Our Posthuman Future: Consequences of the Biotechnology Revolution (New York: Picador - Farrar, Straus and Giroux, 2002). 
posthumanism itself, as it calls for reframing both the notion of human nature and the premise that all people are equal. He represents a position now known as "bioconservatism," according to which every attempt at transforming the biological status of people (and thus any attempt at autoevolution, as well as cloning and other forms of biotechnology) is by necessity immoral because it has to lead to the fall of "human nature."

Fukuyama's book merits a closer look, as it is a good example of a degeneration of some versions of humanism. Francis Fukuyama and Alvin Toffler are seen in the United States and many other countries as great intellectual authorities. Their main books are Fukuyama's The End of History and the Last Man - an attempt to read the 1989 transformation through a vulgar Hegelianism - and Toffler's Future Shock - a book in which data from statistical yearbooks are to prove universalist theses on transformations of the human culture as a whole. The reasonings applied by the two authors are very similar. They use the simplest sets of notions, including popular received opinions and based on that they build interpretations of the most important civilizational dilemmas. While most contemporary European thinkers can be rightly blamed for getting stuck in academic subtleties and drowning under the burden of their philosophical tradition, Americans Fukuyama and Toffler represent the opposite extreme: their writings are depressingly straightforward. This is why Fukuyama's charges against posthumanism are probably the weakest of those invoked here, even though he is also the only critic who tries to phrase them using professional philosophical diction, which allows him to actually touch upon some truly significant issues.

How does Fukuyama understand the notion of human nature, which is to be threatened by biotechnology? For him it is not a product of any type of Western philosophy. He writes: "The definition of the term human nature I will use here is the following: human nature is the sum of the behavior and characteristics that are typical of the human species, arising from genetic rather than environmental factors" (130). This definition is taken straight from sociobiology (which, surprisingly for a European, suddenly becomes here an ally of conservatism) and it allows Fukuyama to fight posthumanism at its own game. If he defined nature the way speculative philosophy does, posthumanism could see it as pointless speculation. Choosing sociobiology as his starting point, he makes it seem like his counterarguments are backed by science. This, however, is where he is wrong because just like his opponents he treats science as if it had the power to determine the objective truth about humanity.

As I have suggested earlier, one of posthumanism's main weaknesses is the simplified treatment of what it means to "be human," which derives from naïve rationalism. Hoping to beat posthumanism at its own game, Fukuyama repeats 
the error. Moreover, his attempt to define "human nature" through behavioral and quantitative characteristics reveals a more general dangerous weakness of all attempts at "scientific" justification of general propositions about "humans" as such. We come across such attempts in every press note that starts with "Research has shown that..." followed by a thesis such as: "consuming large quantities of carrots reduces the risk of colon cancer by $17 \%$." Fukuyama tries to use similar sentences to prove that people have to retain the principles of their existence laid out by the liberal and conservative thought of the West in the last 200 years (not to mention this is for him the only possible mode of such existence), because if they stray from those principles, for instance by allowing cloning or autoevolution, they will destroy "the natural order." He does not understand that this line of argument falls apart due to its contradictions. The development of science in the 20th century created a situation in which producing general unconditional statements about the physical world (and especially man as its element) based on experimental facts is no longer possible. There are likely links between the functioning of the human organism on the genetic-molecular level and the emotional-mental one. But with the current knowledge we cannot describe them with any precision. We lack data that would allow us to say how exactly phenotype translates into someone's character and what is the impact of the external environment (in the polemic between nativism and environmentalism, Fukuyama positions himself as a nativist). We may never be able to find that out precisely, given the immense complexity of each human organism and the countless reactions and relationships that occur inside it, as well as between the organism and world. Scholars who have done research on a random sample of a few hundred people and claim that listening to Wagner's operas has negative impact on blood levels of hemoglobin (and the lack of any qualifiers suggests the thesis is to pertain to the population at large) are simply ridiculous. Fukuyama, who uses similar arguments to support conservative social policies, is just sad. It is as if a chef calculated ingredients for dishes in millimoles, hoping such precision would produce better flavors.

The problem with Fukuyama's book is that while his arguments are weak, the problems he takes up are vital. Fukuyama is better than Silicon Valley technophiles at seeing dangers that come with the growing potential for implementing autoevolution. In his own naïve and naturalistic way, he is trying to warn against the same thing Lem was warning against in his own internal polemic with the autoevolutionary project in ST. He sees the utopianism of autoevolutionary ideas. He is also right to notice that within the perimeters he has himself laid out it is possible to manipulate "human nature" just wish pharmaceutics. But by grounding his notion of "human nature" and "dignity" 
in sociobiological premises, he deprives his own arguments of any value and reduces them to the kind of rationalist utopia he was trying to avoid.

Fukuyama's fear is not merely a conservative's fear facing the fall of morality caused by technocracy and permissiveness. He is asking about humanity not only in the context of evolutionarily determined genotype and phenotype. He is also interested in historical characteristics, which determine humanism in the posthumanist context. He is trying to answer whether autoevolution would turn us into the characters from Brave New World or 1984. In brief, again we hear anxiety about whether posthumans will retain what is best in people: free will, subjectivity and self-determination. Will they not lose what made their predecessors human, once they improve their bodies? In other words, will they become the Nietzschean Übermensch? (Fukuyama resents Nietzsche for his bold rejection of tradition.) Posthumanists do not ask themselves this strictly philosophical question, because even when they do use such old-fashioned terms as "free will," they see it as a product of an oppressive social system, or an old-fashioned metaphysics at best. Lem on the other hand, who understood the significance of such notions much better (and who showed the consequences of "castrating improvement" in Return from the Stars), saw them as always linked with the painful and irrefutable dilemmas of the human condition, from which he hoped to liberate us. Golem's message, which I have quoted in Chapter 19, is clear: whatever we become, it will be better than what we have been so far, it cannot be any worse. Even if we take up a form in which the categories of old anthropology will lose their meaning, they will be replaced by a "better existential system," although we may not be able to imagine it now.

We can see here that the discussion about the ethical determinants of human and posthuman existence is theoretically unsolvable. Questions about the ethnicity of these two forms of existence most clearly show how radically different from each other they are. It is easier to produce visions of a cyborg society or a humanity "downloaded" to a computer than to answer questions about emotions, which will organize their world. It is in fact a matter of faith rather than knowledge, because - and it needs to be stated clearly - we are dealing with transcendence here. The posthuman world can be either paradise or hell, but only those who enter it will know. This is one of the reasons why posthumanists avoid such questions - they realize their "rational" ideas will acquire characteristics of religious faith. 


\section{Hidden Premises Behind Posthumanism}

The subject of this chapter has already_been started on the final pages of Chapter 24. But it is not the hidden similarity between posthumanism and religious faith that is the most important in order to understand the crucial problems of the doctrine. On the following pages, I will further develop the discussion of philosophical, social and psychological problems implicit to posthumanism and autoevolution.

\section{Philosophy}

If posthumanists read Kant, or at least Isaiah Berlin, they would probably say: "Since the crooked timber of humanity cannot be fixed, it ought to be cut down, rooted out, and then new planted. The new one will certainly be straight." The posthumanist utopia is extremely liberal, and its critique is a conservative critique. It is obvious and it is equally obvious what are the main characteristics of liberal and conservative thinking, seen very clearly in the discussion I have just described here. But it is worth it to investigate closer some characteristics, which, I believe, are peculiar to posthumanism only, or at least of all the contemporary types of thinking about the society here they are most evidently present.

Posthumanism unconditionally rejects historicity of the human condition. It rejects the notion of identity of an individual as correlate to tradition and history. In brief, it rejects the historical temporality of human existence. In that respect, it resembles other liberal currents, but it is more radical in one regard. This is because of autoevolution, of course - none of the liberal doctrines assumes that people will reject their history so much, that they will cease to be people. What is it then that is happening with the earlier definitions of human identity?

The notion of Übermensch in Nietzsche is connected with a rejection of the past. Übermensch constructs his identity on his own, with no reference to tradition, social and moral norms or any kind of models derived from the past. His "amoralism" does not imply a lack of rules, but adopting rules he himself sets up, independently of the consensually determined social norms. Nietzsche was not interested in the possible social consequences of the idea of Übermensch nor in the intellectual challenges it poses.

An amoral Übermensch is thus also antisocial, because his rules are not created in communication with other people. "A society of Übermensch" is a contradiction in terms, because there is no agreement between them about the form of 
social existence, which would only be a constraint. If culture is to be understood as correlate to interpersonal communication - Übermensch have no culture. They are strictly monadic.

Being an Übermensch poses immense intellectual and ethical challenges for anyone who would like to become one. An Übermensch needs to create himself anew, build his identity with no support from the outside and independently from the entire "methodology of identity" so far, based on layers of the past. And once he achieves that, all that remains is absolute loneliness. Unless he realizes the gravity of these challenges, his self-determination will be merely a caricature of Nietzsche's ideas.

At the end of the 20th century, Pierre Hadot, a French historian of philosophy, suggested an understanding of the ancient philosophy, especially Stoicism, as an "existential project." In his book What is Ancient Philosophy? (2002), he claimed that it was only the emergence of Christianity that led to philosophy no longer being treated as a "way of life" and becoming an abstract discourse. The Hellenistic philosophy, understood in the way suggested by Hadot, offers an existential project that is similar to the Nietzschean project of Übermensch. In both cases, human identity is understood as task, not a heritage. In Hellenistic thought, this detachment from past models was caused by a vast change in the condition of existence after the conquests of Alexander the Great and the creation of a universalist monarchy, and then of Hellenistic states. These developments destroyed the Greek notion of social life, shaped by the classical period, almost entirely.

This way Nietzsche and the Stoics are placed on the same continuum: they all call for man to design his own identity independently from any external circumstances, which could determine it. These philosophies are radically antisocial and this is the difference between them and the 19th- and 20th-century emancipatory doctrines, which were to achieve their goals through rules pertaining to the community at large.

What does it all have to do with Lem and posthumanism? I believe that the project of autoevolution is in some ways similar to these philosophies. Completely neglecting the past, tradition and historicity makes posthumans the equivalent of Nietzschean Übermensch - if they are to have any identity other than the physical one, they need to create it themselves, with no reference to the external factors. I will leave the question whether an ex nihilo identity is possible at all unsolved - it goes beyond the sphere of discourse available here.

Posthumanism can then be described as the most radical emancipatory project. Through it, not only people are to be liberated from the constraints of 
history and social norms, but they will also be free from Culture and Nature, and eventually from being human altogether. Deification and self-salvation will happen through renunciation of humanity. It is implicitly assumed that the only way to eliminate the kind of issues that are inherent to human condition is to give up on being human. However, as the veracity (or falsity) of this proposition can only be determined in actu, the utopian character of posthumanism seems all the stronger.

In a famous opening passage of Politics, Aristotle writes that animals and gods live in solitude, while people have to live in a group, because this is their nature. Posthumanism confirms this view in a peculiar way. As I have tried to show posthuman beings will be unable to live in a group, because rejecting tradition, past and history - and, consequently, rejecting culture and society as well precludes any kind of group mode of existence. This isolation is not caused by closing oneself in cyberspace, as it was predicted by some popular thinkers (and which Lem describes with more subtlety in his analysis of phantomatics), but by the very core principles of posthumanism. It seems, however, that posthumanists are unaware of these consequences.

What can we compare this state to? Is Stoic "ataraxia," the eternal "present" without time known to mystics or the Buddhist nirvana something similar? I believe such speculations are pointless. We can have no idea what a self-aware, rational being detached from any past or community would be like. Our entire existence depends on them.

Polish sociologist Jan Strzelecki opens his book Próby świadectwa with the following: "If we were - ultimately, with no appeal, no chance and no one to save us - a product of a meaningless explosion of existence bustling in a thousand forms; if we were pure existence..." Contemporary science led us to just such state. This is what we are exactly in science's light. People thinking in terms of science cannot understand what a work on sense is - and this is what Strzelecki believed to be the most important goal of our existence. But they do understand that man - whether a purely biological creature, or maybe even a product of history and its meanings - is certainly imperfect and does not fulfill the ideals humanity placed in front of him; a man is torn by contradictions that are the essence of humanity. All utopias were born from this perspective. But the posthumanist utopia is unique - because it is science that is to lead to salvation; the very science that first took away the meaning of our existence. The deification is to happen in a machine. Thus scientism becomes mysticism: cyborgs will step out on the banks of the river of time. They will forget Homer, Kant and the Second World War. Forty centuries will still look down on them, but they will no longer be feeling the weight of that gaze. 


\section{Society}

It would not be true to say that all authors interested in posthumanism agree on such radical consequences I have described earlier as entailed by its hidden premises. They are a result of somewhat irresponsible thinking of some theoreticians who treat autoevolution as a process independent from external factors. Many authors try to outline those factors. Because of how "fanatic" posthumanism generally tends to be, most such attempts happen within sci-fi literature. Such writers as James Gunn, Greg Egan or Jacek Dukaj think about the possible social stratification autoevolution may lead to. The question is simple: who will be affected? What social groups will have the possibility and willingness to subject themselves to autoevolution and what social tensions may result from that? The problem can be seen as another stage of biopolitics (similar to what Lem describes in parody in "The Twenty-first Voyage"). Some such intuitions can be found in Fukuyama as well, when he considers the negative economic results of biotechnology.

It seems clear that if autoevolution happens in practice on a bigger scale, the first level to be involved will be economy; simply speaking: the costs. At least at the beginning it will be a luxury available only to the wealthiest. As there will gradually be more and more posthuman beings, there will certainly occur a difficult legal and public discussion on their legal status in coexistence with people. All the social process that took place when introducing any important technological innovation will take place. Autoevolution will shift from a purely rational idea (which it is both in ST and in posthumanist texts and which in its pure form could lead to what I have described earlier) to the level of social practice, brimming with random difficulties I have mentioned.

James Gunn (born in 1923), an admired American sci-fi writer, is the author of the novel The Immortals (1964), which develops the theme of advanced somatic autoevolution, limited to political and financial elites, isolated from the rest of the society. The most sought-after social role is working in the biotechnological and medical sectors. As a result of the elites' isolation, the social order is disrupted and individuals mutated through flawed autoevolutionary interventions form a cast of outlaws and criminals. At some point in the novel, it turns out that the members of the social elite did not achieve any kind of perfection through autoevolution - quite the opposite; just like Lem's H.P.L.D.'s and Borges's immortals, they became mentally and physically degenerated by the feeling of their omnipotence.

Jacek Dukaj presents a completely different version of events in his book Perfekcyjna niedoskonałość (2004). ${ }^{230}$ The complex novel is set in the 29th century

230 Jacek Dukaj, Perfekcyjna niedoskonałość. Pierwsza tercja progresu (Kraków: WL, 2004). 
in the world in which people and posthuman forms coexist in relative harmony within a technosphere permeated by nanomatic devices and controlled by computer software. There is a network of connections between living creatures and computer programs, which allows for complete virtualization of reality. Dukaj gives detailed descriptions of social hierarchies and economic and status competition between the stahs (standard Homo sapiens) and phoebes (posthuman being; the names are honorific). Phoebes can program their personality and forms of existence at will. There are higher autoevolutionary forms in this world as well: inclusions, similar to the old notion of omnipotent gods. Within my typology they correspond to the category of advanced mental autoevolution. In the novel it is often emphasized that the consciousness and the experiences of the phoebes (not to mention inclusions) are unavailable to stahs. Undergoing autoevolution depends on financial capacity, which is only available to a small percentage of people, and the conventions governing that reality have been laid out 600 years earlier by the industrial and political establishment. Posthuman beings do not fulfill the definition of gender, and Dukaj created a special grammatical conjugation for them. ${ }^{231}$ Lem's influence is clearly visible in Dukaj's prose, including Perfekcyjna niedoskonałość, but there is no place here for a detailed textual analysis to prove it. Yet the vision of autoevolution in this novel can be seen as a literary rendition of the discursive project of ST; the difference is that Dukaj is fully aware how this project is impacted by other factors (i.e., economy, rivalry between individual subjects in fight for higher stages of development, the politics of symbols, etc.). In Dukaj's text, the element of the "ultimate" version of autoevolution, which I have described earlier, takes up the form of complete inaccessibility of the internal life of posthuman beings to people. The problem of retaining identity in a situation when it is possible to shape and transfer it with no limit is illustrated here by the characters' meticulous use of proper forms and rituals.

Ray Kurzweil also allows for dividing people into humans and posthumans. In his The Age of Spiritual Machines, he outlines a scenario of how civilization will develop in the 21st century, and under the year 2099, he puts the emergence of a cast called MOSH (Most Original Substrate Human) - as a relic of sorts. The 800 years between Kurzweil's and Dukaj's versions is no accident. The former, in a manner characteristic of American posthumanists, does not

231 It brings to mind Lem's teasing descriptions from "The Twenty-First Voyage," but the problem is completely serious for Dukaj, which is something that connects him with queer theory. 
think much about the persisting social issues that have been troubling civilization from the very beginning. So for him, it is not impossible that we will deal with ignorance, poverty and violence within one century. Despite appearances, Dukaj is more of a realist and assumes it will take eight times longer, and even then for him autoevolution will only apply to a small section of the population.

Australian writer Greg Egan (born in 1961) also elaborates on themes of autoevolution in his works. He is currently highly admired in the sci-fi and posthumanist circles (accidentally, Dukaj is a fan as well). His fourth novel Distress (1995) ${ }^{232}$ is set in 2055, when as a result of advanced somatic and cyborg autoevolution, as well as advanced biopolitics, human population is divided into seven biotechnologically modeled sexes. These are: $\mathrm{u}-, \mathrm{n}$ - and imen; $\mathrm{u}-, \mathrm{n}-\mathrm{and}$ iwomen (prefixes meaning, respectively, "ultra," "normal" and "infra"); the seventh sex consists of asexes - individuals renouncing sexual life to avoid being entangled in the "politics of gender," determining social life. The plot focuses on the announcement of the final version of the physical Theory of Everything and related cognitive complications. Egan weaves into the plot a number of thorough descriptions of political and social conflicts, which occur in the context of advanced biotechnology, "migration of sexes" and possible cultural factors impacting science. The image of the struggle of "two cultures," which I have described in Part Two of the work, is here led to its radical consequences, and the author strongly opposes the old humanism. Proponents of "traditional" culture are a group of demagogue extremists in Egan's world. Similarly to posthumanists, but with more understanding of the complex nature of the world, Egan is convinced that the forms of humanism, which have framed our understanding of ourselves for centuries, fail completely when we gain the possibility to determine our identity through pharmacology, surgery and nanotechnology. It is the exact same problem that Fukuyama warned against, except Egan treats it as obvious (just as the rejection of old norms is obvious). In other works, Egan often describes the world of mental autoevolution.

I should also mention an author who is far from science fiction in his work, but who offers his own version of autoevolution. I mean Michel Houellebecq and his novel The Elementary Particles (Les particules elementaires 1998), ${ }^{233}$

232 Greg Egan, Distress (New York: Harper Prism, 1995).

233 Michel Houellebecq, Atomised, trans. by F. Wynne (London: Heinemann, 1999); published in the United States as The Elementary Particles (New York: Vintage, 2001). Quotes from: The Elementary Particles... 
which triggered a discussion in Europe on a subject that can be described as follows: are the ideals of modern Western civilization irrevocably over, or can they still be raised from the dead? Houellebecq himself believes the first option to be true and that is why one of the protagonists of the novel, a distinguished biochemist, is working on a project of a "genetic reform" of the human species, after which people would stop reproducing sexually. The project is implemented in the epilogue.

Houellebecq's novel is interesting to me for a number of reasons, although the project of autoevolution as such has a marginal role in the plot. The asexual utopia of the French writer is a type of cri de coeur, inspired by the complete emptiness of the emotional life of the inhabitants of postindustrial Europe; and Houellebecq is deeply convinced that this is the state of Europe. The Elementary particles is the only case of a literary description of autoevolution (a somatic one here, with an emphasis on physiology rather than morphology) that is not set in a science fiction environment, but in a tradition of realist novels. The disgust with body and sexuality constantly demonstrated by the narrator and the characters makes Houellebecq resemble Lem and Turing with their obsession of human existence freed of the bodily aspect. (It is no accident that Slavoj Žižek begins his 2001 essay "No Sex, Please, We're Post-human!" by invoking Houellebecq, Foucault and Turing. Similarly to my own argument, Žižek emphasizes that humanity and human identity are rooted in notions such as historicity, trauma and Heideggerian temporality.) A conversation between two brothers is also significant - the two protagonists of the novel - in brothers Julian and Aldous Huxley. The former, we should remember, is the author of the term "transhumanism," and the latter - the author of one of the most famous antiutopias based on the concept of technological improvement of man. Houellebecq suggests that both these thinkers were right in predicting a spiritual crisis in the postmodern society and the possibility of overcoming it through autoevolution. In the novel, he includes a number of statements on reducing the role of the past and the disappearance of the sense of existential and cultural continuity in contemporary society, which is to be a harbinger of the posthuman era. Finally, the epilogue tells the story of implementing the project of autoevolution, under the aegis of UNESCO, ending with a success in 2029. The posthuman narrator says around 2075:

There remain some humans of the old species ... Their reproductive levels fall year by year, however, and at present their extinction seems inevitable. Contrary to the doomsayers, this extinction is taking place peaceably ... It has been surprising to note the meekness, resignation, perhaps even secret relief with which humans have consented to their own passing. 
Having broken the filial chain that linked us to humanity ... Men consider us to be happy; it is certainly true that we have succeeded in overcoming the forces of egotism, cruelty and anger which they could not ... Science and art are still a part of our society; but without the stimulus of personal vanity, the pursuit of Truth and Beauty has taken on a less urgent aspect. To humans of the old species, our world seems a paradise. (263)

All posthumanists would likely second those words that grasp the very essence of the utopian dreams of autoevolution.

\section{Psychology}

We can now ask what psychological premises stand behind posthumanist thought? Why some people want to stop being human so much that they write books about it and come up with entire theories? What is the psychological background of posthumanism and autoevolution?

I believe there are at least six possible impulses for the development of such thought. I shall list them starting with the ones I deem most important:

1. Hatred of one's own species, caused by its imperfect physical and spiritual form. I have tried to trace it in Lem and Turing. It is also visible in many authors writing on artificial intelligence (AI) and information technology (IT). These are "Turing's men" in a sense proposed by Bolter, accustomed to the precision and "purity" of machines. The "blurriness" of human mind, the indeterminate emotions and all bodily experiences (from illnesses, through age and death, to everyday soiling and secretions) must seem most disgusting to those people, and they often express that. A hundred years ago they would not even have theoretical chances to go outside their race and "oppose nature," but the progress of technology, which made the project of autoevolution possible, also allowed for an "inhuman" plan to free them from the abominable "meat machine." It brings to mind a comparison with the anachorites of the late antiquity who tortured their bodies in a way that would have seemed pathological to us, because they deemed them an obstacle on their way to sanctity. Again, posthumanism becomes an analogue of religious mysticism.

2. Powerlessness, or a sense of powerlessness rather. It is caused by a Pascalian disproportion between our bodies and minds and the scale of the physical reality that was unveiled to us by the 20th century science (see Chapter 11). This feeling is most visible in authors who draw visions of omnipotence of posthuman beings (Jacek Dukaj is among them).

3. Frustration. The source of it is the sense of ultimate waning of the life force in the Western civilization and a conviction that there is no "normal" way out of the situation. It is most visible in Houellebecq's work. It is also connected 
with a sense of fatigue with the questions of body and sexuality in the postindustrial era, as for Elfriede Jelinek who "asked whether she would rather have a different body [hating her own], responds: 'No, I wouldn't want a dick like men either. I wish I didn't have anything. Angels don't have genitals too.' "234

4. Curiosity - as is well known, it has always been one of the main impulses driving the civilization's growth. Today, too, it pushes authors to think about "what will happen, when we stop being human?"

5. Play. The motif can be found in the writings of some American posthumanists. If technology allows us to carry out autoevolution - let us do it, "just for fun." Such thinking comes from a complete ignorance about all the issues related to autoevolution, which I have been discussing here. Clearly, the fact that AI experts mostly see people as "meat," as do gender studies authors (to which I will return again) is mostly a result of a rejection of historicity. ${ }^{235}$ If the network of symbols through which we have been explaining our existence to ourselves for centuries has no more meaning, all that is left is the body, that is, as the poet Sekułowski observed in Hospital of the Transfiguration, "a pile of meat."

6. Fatigue. This motif is similar to the previous one, but it derives more from an unpleasant feeling that people have already fulfilled their entire existential potential and, if they do not do something spectacular with themselves, they will be facing an eternity of ennui. Such approach is typical for people who are constantly hungry for new experiences. This hunger is intensified by most

234 Anna Rubinowicz-Gründler, "Elfriede Jelinek. 'Nie umiem się niczym cieszyćc", Wysokie Obcasy, October 23-24, 2004.

235 A particularly telling example of such ahistorical (and psychologically ignorant) thinking can be found in Kurzweil's The Age of Spiritual Machines (163-166). He writes about "cybernetic poetry," that is, poems generated by computer programs. For Kurzweil such poems are in no way different from poetry written by people. It means that he does not understand the role of cultural tradition and the psyche in the creative process that goes into producing a work of art (which could ingratiate him with extreme structuralists). And Roger Schank, a distinguished expert in AI, writes: "I've been able to find remarks on the subject by Thomas Aquinas, Montaigne and Aristotle... These people have a vague, hand-waving notion of what consciousness is about, with a religious tinge to it. Their work wouldn't fly at all in modern academics" (Third Culture..., 28). Schank's arrogance is made even deeper by his certainty that is it him and his colleagues, for example, Daniel Dennett, have actually discovered the essence of consciousness. (By the way, if Schank did not underestimate the old authors so much, he might have a little less regard for his own achievements.) 
kinds of contemporary mass culture, which imposes on consumers a desire for ever-new experiences.

This list could go on, but I believe that the six psychological motifs are enough to answer the question posed.

Why does Lem create the project of autoevolution? I believe the first four motifs are the most important for him, and most particularly the first two. This should be clear from the analyses included in Part Two of this book. The question about deeper psychological reasons will have to remain unanswered. Lem is careful to obliterate traces of his own biography and psyche. Yet, some traces can be found in his earliest works and in the novel Wysoki Zamek. His negative way of seeing humanity was certainly influenced by his wartime experiences and his medical studies.

Here I end the analysis of the hidden premises behind posthumanism. In Chapter 26, I will be showing the links between posthumanism and some types of postmodernist thinking. 


\section{Posthumanism and Gender}

In the multitude of contemporary intellectual currents, gender studies are now among them most important. As I have suggested a number of times already, placing sex, gender and human body at the center of philosophical and social thought may be caused by the fall of metaphysics and historicism. "Body," both "sex" and "gender," as well as "sexuality" are used in this discourse as primary terms describing fundamental elements of the human condition. A full account of gender studies or even its intellectual genesis, even a brief one, goes beyond the scope of this work. By "gender studies," I mean some types of contemporary feminism - LGBTQ+ studies and queer theory. I believe the way these social theories conceive of history and identity is very similar to how posthumanism understands them. How is it so?

One of the main theses of the gender studies discourse since at least the early 1990s is the "construction of gender," best laid out by Judith Butler. The thesis is that gender and even biological sex is not a given characteristic we are born with (a "core" of our condition), but a product of complicated norms, conventions and social roles implemented through performance; it is not an element of "nature" and can therefore be modified in all sorts of ways. ${ }^{236}$ To prove the thesis, Butler and other authors focus on those forms of human sexuality which have so far never been mentioned or have been treated as odd exceptions because they did not abide by those norms, roles and conventions, by violating and confusing them. This includes above all some "borderline" forms: androgyny; homo-, biand transsexuality; hermaphrodites; transvestites; including especially camp and drag - as cultural phenomena; and also all "non-standard" sexual behaviors described medically as paraphilias. Gender studies' authors analyze these phenomena in detail on many levels (sociology, psychology, political studies, literary studies, media studies, etc.). The fact that "gender games" are the focus of gender studies is the inevitable result of making body, sex and gender main instances of human identity understood in a Nietzschean way. Just as in posthumanism, we are dealing here with the task of constructing an identity without reference to

236 This premise implicitly contains the thesis about invalidation of the opposition between what is Natural and Artificial - and it may be no accident that it is so (if we accept Donna Haraway's influence on Judith Butler). Thirty years earlier Erving Goffman wrote that social being is a perfromance, but it probably never occured to him that this perspective could include biological sex... 
tradition, which has been rejected as a source of limitations and repression. If so, if identity is no longer determined by cultural past - it cannot be built with the existing set of cultural symbols (which was still done by early postmodernists), and the only available means of constructing identity is sexuality, especially those kinds of sexuality which were forbidden before. Gender studies can be seen as a "quest for the limits of humanity," but the quest only happens in the absolutized sphere of sexuality (just as in Sade's works interpreted by Bataille), because the "spiritual" sphere, which had determined the shape of the Western civilization for at least thirty centuries, was pronounced to be a construction governed by hegemonic discourses, which ultimately boil down to body and sexuality too. In light of gender studies, the only reality directly available to us is the materiality of our bodies (and especially the surface of our bodies) and sensory experiences; and this reality is "most real" when it is vague and is not governed by any norms.

Of all subfields of gender studies, I believe the queer theory is most similar to posthumanism. In this theory, first created in the 1990s, mostly through Judith Butler's inspiration, both principal premises of gender - that sexuality determined our identity and that sexuality is not conditioned in any way - are developed to the limits of their consequences. Queer theory rejects both the notion of heterosexuality and homosexuality - both are equally fictitious and do not represent the infinite complexity of the real libido. They are replaced by the concept of identity as a continuous process, with final form as its goal. According to theoreticians of queer, human identity should be constantly changing, never fully graspable, always in statu nascendi. On the discursive level, this is represented by using the methods of deconstruction in the analysis of the social reality.

How does such premise translate into practice? Can normative identity be truly rejected? It seems that a man who would do that would also face the same problem that appeared when we were considering the consequences of the notion of Übermensch and posthuman: how to create oneself anew? How to be more than a desiring surface of a body? And just as in the other cases, "a queer human" should have an immense intellectual and spiritual potential in order to face the existential challenge of a "self-made man" and not reduce their odyssey of continuously creating identity to what we see today in mass culture: thoughtlessly adopting the newest ephemeral trends and "serial individualism." Life as a work of art is a much harder task than one would think. Few can afford to fulfill this ideal. ${ }^{237}$

237 In "The Twenty-First Voyage" by Lem, which I have analyzed here, there is a sentence that describes one of the stages of autoevolution of Dichoticans, which expresses the 
The assumptions behind the queer theory are the same as the theses of the noblest liberalism: each individual should have a right to freely search and shape their identity. But in a situation when the process of shaping can never end; when each individual is to have their very own, unique identity (and blurred at the same time); when there is no norm pertaining to many, nor even any scale for comparison; finally, when identity is to be constructed based on "blurred" bodies and sexes only, then the very notion of identity loses its meaning. The protagonist of Dukaj's Perfekcyjna niedoskonałość talks about just that when he is speaking about posthuman forms:

These phoebes, who modify themselves... How does it happen? They decide that they'd rather be different and reprogram themselves. And having reprogramed themselves, with the new network of fears and desires, they choose yet another type of phren. And so on, and so on, with no end; and all very honestly. Can they predict and simulate the state of their minds after $\mathrm{X}$ modifications? When in the state $\mathrm{N}$ they hope for $\mathrm{N}+1$, but do they also want $\mathrm{N}+1-, \mathrm{N}+100$ ? ... Where is identity in this process? Or maybe it is no longer a state but the process itself? (363; translated by OK)

And Greg Egan describes asexes as follows:

Asex was really nothing but an umbrella term for a broad group of philosophies, styles of dress, cosmetic-surgical changes, and deep-biological alterations. The only thing that one asex person necessarily had in common with another was the view that vis gender parameters ... were the business of no one but verself ... What a person actually did in response to that attitude could range from as little as ticking the ' $\mathrm{A}$ ' box on census forms, to choosing an asex name ... all the way to full physical and/or neural asexuality, hermaphroditism, or exoticism. (34-35)

Theoreticians of queer intended to create a model that would best fit the infinitely complex social reality. But when the authors of queer theory started to confuse theory with social activism, they forgot about the difference between a description and the phenomenon described, and about Max Weber's remark that no theory can describe any reality in full and thinking otherwise is one of the biggest mistakes that can be made in the humanities. Just like gender studies, posthumanism and partly like Lem in ST, queer theory forgets that lesson. And, as I have tried to show, in all these cases forgetting it has the same effect of confusing theory and practice, thought and a manifesto, philosophy and ideology and with best intentions. This is why the anthropological premises adopted by those authors, their belief in the existential independence of an individual, lead

issue well: "when you can be anyone and have any conviction, then you are no one and have no conviction." 
to such extraordinary consequences. Posthumanism, gender studies and queer theory all represent the challenge of absolute egoism: negating all forms of social existence combined with fetishism of individual beings. The result is a loose group of monads.

Authors such as Dukaj and Egan realize what kind of problems are caused by constructing identity independently from all tradition, based only on gender - or lack thereof - and biotechnology. But in their novels they carefully avoid describing the internal life of posthuman beings, especially those aspects of it which for humans are shaped by nonbiological factors. They do not suggest that posthumans are determined solely by their physiological qualities, however imaginatively designed. Hence they produce an impression in the readers that posthuman identity is just as diverse as ours, except it is not revealed in full. But the theoreticians of queer want to grasp identity in its totality - and that is how, without realizing it, they contradict themselves.

The practical aspect of the queer theory is occasionally reduced to complex plastic surgeries today, changing sex or combining male and female features. Of course, in many cases, this is a life-saving option for people who are transsexual and whose "body" is tragically unfit for their "soul." Sometimes, however, it is more about manifesting one's power over one's body, a liberty in shaping it and hence a liberty to shape the most basic elements of identity at will. ${ }^{238}$ "Selfcreation" even includes sex here (although the word "even" suggests a traditional humanist point of view - in light of the queer theory there is not much more left to be shaped). Another type of such practice is voluntary castration ${ }^{239}$ or asexuality - a complete rejection of sexual life caused by a lack of sex drive or a lack of a desire to follow it. ${ }^{240}$ The emancipatory quality of the queer theory invites such

238 For example, Pedro Álmodovar's films illustrate the transgender problematic. Among such "manifestations of power over one's body," we could also mention plastic surgeries in general, especially the radical cases, such as "human lizard" (with green skin and split tongue), "human cat" (with moon-shaped pupils and fur) or "human enigma" (with skin covered in a checkered pattern). This is probably a passing trend, but the very fact it occurred has a lot to do with the theories I am discussing here.

239 This is the subject of a documentary American Eunuchs, Italy 2003, directed by Gian Claudio Guiducci. It shows that a significant number of men are getting voluntarily castrated in the United States (a few hundred every year). The main cause is fatigue with one's sex drive.

240 So far it remains unclear whether asexuality is a psychosomatic disorder, or fourth sexual orientation (although the theoreticians of queer would reject both terms and would likely see it as just a point on the continuum of sexual identities). Egan describes it as one of the forms of existence. It might include cases that would have been 
experiments and it is clear we are dealing with a specific type of autoevolution here, limited to surgical and hormonal treatments, and certainly primitive in eyes of "serious" posthumanists. It turns out they were not the only ones who came to the conclusion that it is time for freedom from the chains of biology.

It may seem somewhat surprising that the technological utopia of Stanisław Lem and gender theories have something in common. These two very different areas of thought are dominated by the same conviction that, just as Baron von Münchhausen, we can pull ourselves by hair from the swamp of humanity.

Philosophical and social theories that have been discussed here have their equivalent in visual arts. Body art has existed since the 1960s and the late 1980s brought abject art, the "art of disgust." Human body, body of an artist or dead body of an anonymous human is the material of art in these currents. Bodies are injured, cut, subjected to all kinds of mechanical and surgical treatments, exhibited as anatomic preparations and finally combined with machine installations. Art theoreticians emphasize the rich intellectual background of such works, derived, among other sources, from accepting body as the only foundation of human condition as imposed by gender studies.

Thus we reach an interesting paradox - a strong desire to become independent from our "natural" conditions leads to a focus on a body deprived of a cultural meaning, treated as a lump of matter - so a focus on this element which is the most "natural" in us. The most abstract philosophical discourse takes as its subject the most material being, rejecting the richness of mediating symbols created by the Western culture. Is it not similar to the "wild" autoevolution, deprived of any supreme meaning, of the Dichoticans in "The Twenty-First Voyage," where the faith in transcendence was rejected at the beginning?

In the conversations with Stanisław Bereś Lem, lamenting the fall of contemporary art, he said that soon galleries would be exhibiting human stomachs.

described as "frigidity" in the past. J. M. Barrie (the author of Peter Pan), Salvador Dali, Glenn Gould, Maurice Ravel, Immanuel Kant, Isaac Newton, John Ruskin, Nikola Tesla and Antonio Salazar are among historical figures deemed today to have been asexual. "Asexuality" is another term that introduced into discourse a phenomenon that had existed in reality for a long time. There are many such terms in contemporary social discourse, including "domestic violence," "sexual harassment," "pedophilia," etc. A thorough analysis of their evolution, similar to what Foucault did for the 18th and 19th centuries, could give us a valuable image of the mutual influence between social and theoretical reality of the late 20th century, of how new notions "discover" previously unnoticed phenomena, and of the extent to which these "discoveries" are projected back on history, impacting the social theory as well. 
As usual, this was a correct prophecy. He did not take into account the truly shocking fact that these stomachs will be a result of premises not very different from his own. We may only wonder where the deep belief in our own power of self-creation may lead us. ${ }^{241}$

241 Another possible interpretation of these phenomena is that they signify finally accepting the body as the last element of "nature" in the context of the "artificial" world, or treating it as a sphere of struggle between Nature and Culture. The problem of the body in the Western philosophy dates back, of course, at least to Descartes, and becomes particularly poignant in Merleau-Ponty's phenomenology. However in this continuum, "body" is the link between the external and the internal world of man, not the center of human identity. 


\section{Posthumanism and Bioethics}

There are a number of dilemmas in the contemporary social theory and practice that can be read through the terms proposed by posthumanism. They are ethical issues related to euthanasia, cloning and all other forms of genetic engineering, as well as gay marriages, and, to some extent, abortion and suicide (although these are much older than the other ones and, like gay marriages, are not a result of technological growth). ${ }^{242}$ All these practices imply a deep intervention into human identity, as it has been understood in the Western philosophy so far. Following the debates between proponents and opponents of cloning people, one can notice that the main arguments against these practices focus on the question whether people are entitled to determine who is human. Conservative humanists such as Fukuyama claim that the very possibility that such a line could be drawn should be rejected, because human identity is a given determined by the supreme laws of biology. The discussion about abortion is similar in that regard, although the question is somewhat narrower in this case and it is as follows: when does a human embryo receive an individual identity (the extreme position is that it happens the moment a spermatozoon enters an egg cell). In the case of euthanasia ${ }^{243}$ and suicide, the discussion is whether people can decide when to end the life of other people (or their own) - it again touches on the issue of individual human identity, as it entails assuming that at some point in life, as a result of physical or spiritual suffering, the existence itself (i.e., continuing an individual's identity) loses its supreme value. Gay marriages on the other hand (as opposed to civil unions) undermine sexual identity in a way similar to what I have described in Chapter 26, because their very existence deprives the traditional understanding of it and its meaning as a union of two people of opposite sexes.

I have already mentioned here that some of these issues arise from the juxtaposition of new technologies with traditional ethical norms rooted in the historical process. In an article that was quoted here at the end of Chapter 19, Lem described this juxtaposition as a "collision between faith and empiricism." It is

242 I am treating all these issues only peripherally here. Therefore I am not going into any more specific distinctions (e.g., between passive and active euthanasia).

243 For an overview of various perspectives on the subject, see: Marta Zimniak-Hałajko, "Bez bólu. O dobrej śmierci," in: Ból (Gdańsk: słowo/obraz terytoria, 2004), 271-276 (it includes a variety of references). 
probably best seen in the cases of euthanasia and cloning. Now these problems can also be described in terms of posthumanism: procedures such as cloning or euthanasia radically undermine the meaning of identity as known so far. One could even claim that the entire cultural heritage does not provide us with clues on how to classify them. And this is not because we do not have enough exempla of these procedures - they are abundant in both history and literature - but because they undermine the very categories this culture has come up with. The "prefigurative" quality of our culture (in a sense proposed by Margaret Mead) touches on the most fundamental categories here: What is a human? Who is human? What does it mean to be human? Of course, those questions have always been asked - but only in a purely philosophical way. These were often decided in practice too - but always arbitrarily. Now, we are expected to answer them practically in a democratic and liberal discussion and procedure. And history cannot help in that, because in the first two centuries of its existence liberal democracy has never taken up those issues either as a philosophy or in policy.

I would suggest that the ethical dilemmas discussed here are a result of the collision of humanism and posthumanism. The default understanding of human identity presented by the supporters of cloning, euthanasia and gay marriages (as well as suicide conceived as a morally neutral deed) is in my view fully posthumanist. The implicit assumption is that individual's identity is self-created, that it is independent from external factors (and especially from social and moral norms) and that autarchic identity can be freely shaped, created or destroyed with arbitrary convention or individual will - without looking back on the group, intersubjective or social sphere.

I do not wish to limit these issues to pure theory though. In the recent years, there have been many cases when euthanasia was not just a matter of conservative or liberal understanding of identity, but of an actual deep suffering. For example, in 2000, a 20-year-old French fireman Vincent Humbert was paralyzed as a result of a car crash; he also lost sight and ability to speak. However, he remained completely conscious (apart from a few months in a coma). With his right-hand fingers (which were the only ones he could still move), he wrote a book Je vous demante le droit de la mort, ${ }^{244}$ in which he was arguing for his right to terminate his own life. The authorities refused to allow this, but in 2003 Humbert was killed by his own mother (who was subsequently treated in a psychiatric hospital), which sparked a national discussion in France on the admissibility

244 Vincent Humbert, Je vous demante le droit de la mort (Paris: Le Grand livre du mois, 2003). 
of euthanasia. This case, as many other similar situations, shows that the technological advancement of medicine as an art of keeping people alive is actually in conflict with its own ethical principles - and it has been so for a long time, but up until a few years ago, such cases were not a subject of a broad discussion, because, as with asexuality, there had been no term that would make the discussion of the phenomenon possible. ${ }^{245}$ Perhaps it is a temporary situation and we will soon achieve the kind of knowledge that will allow us to return power over their bodies to people who suffer from paralysis (but will we return youthfulness to the elderly without stepping on the way toward cyborg autoevolution?). But even then the dilemmas born on the borderline between humanism and posthumanism will not disappear. They are not just connected to the state of technology, but are a result of how we understand our existence and its limits.

For Aristotle, an object combining categorial features of a few different objects was monstrous. The mythological chimera was an example of such a monster for him - but so was woman. We can now observe this monstrosity on other examples: cyborgs, transgenders, clone, genetic chimeras - the entire posthumanism in theory and in practice is about constantly mixing categories hoping for new better ones to emerge. I will invoke Dukaj here again. His other novel Inne pieśni (2002) is set in a world governed by Aristotelian ontology. The protagonists of the novel start a war with adynatoses - creatures combining opposite categories in a way inconceivable for "regular" people (hence their name: "adynatos" in Greek means "impossible"). Is it not a grand metaphor of the conflict between humanism and posthumanism? James Shreeve, an American writer in biotechnology, wrote in an article about genetic chimeras: "When we start to blend the edges of things, we're uneasy." ${ }^{246}$

Here I finish this overview of the possible links between posthumanism and social problems connected with postmodernist thought and bioethics. It is merely an outline of the problematic that can direct further interpretations.

245 Even this drama can be found reflected in Lem's works (although it may seem cynical to look for literary expressions of the issue). In Memoirs of a Space Traveler: Further Reminiscences of Ijon Tichy, there is a story of a scholar who, hoping to achieve immortality for his dead wife, put her "soul" in a small box. Ijon Tichy, mortified by the idea of an active consciousness petrified in eternal immobility and darkness, destroys this monument. (Philosophically, it is a reductio ad absurdum of the idea of immortality of the soul.)

246 James Shreeve, “The Other Stem-Cell Debate," New York Times, April 10, 2005. 



\section{Final Remarks}

I started this part of the book by discussing the vision of autoevolution in Lem's works (the project as laid out in the final chapter of ST and in two pieces of fiction: the "serious" Golem XIV and the "grotesque" version in "The Twenty-first Voyage"). I then tried to read this project as an example of a liberal rational utopia. The following chapters were devoted to discussion and critique of posthumanism - a social and scientific theory and ideology that emerged in the 1980s. I was arguing that the premises behind posthumanism are very similar to the ones adopted by Lem in ST. In the final chapters, I offered an interpretation of posthumanism and other contemporary emancipatory ideas as fulfilling the Nietzschean motif of Übermensch, who rejects the past and the norms derived from it in order to create a brand new identity. I also showed the contradiction and difficulties entailed by radical consequences of such ideas. Most of my analyses were based on revealing hidden premises of these concepts.

The discussion of premises, consequences and affinities of Lem's project of autoevolution led me toward various peculiar areas, but also to some of the major problems of contemporary civilization. I have tried to prove the thesis laid out at the beginning of this part: that Lem's essays, especially Dialogues and Summa Technologiae, are devoted exactly to these issues, even though they are not explicitly the subject of discussion.

Was Lem a posthumanist? No, but unwillingly he became a precursor of the current. Compared with ST, the entire posthumanist discourse is very simple and entangled in social ideologies, which Lem managed to avoid by carefully separating his project from social issues. Lem and posthumanists are very general in their musings on the human condition. Despite planning to change, they are not in the least bit interested in current problems; there is only a rejection of those issues with one swiping move as problems that posthumanism and autoevolution will immediately solve - as utopias do. I need to emphasize that both Lem and posthumanists have the best intentions. They all honestly hope to improve our condition - even at the price of eradicating our humanity. 



\section{Conclusion}

One plump schoolgirl (she looked about fifteen), peering inquisitively over her spectacles abruptly asked: "And what is it for?"

Solaris, chapter "The Monsters"

Humanists ought not hide behind a distaste for ideaologies to avoid participating in the processes of creating, shaping and fading of ideologies, unless they wish these processes to turn again them and their values.

Leszek Kołakowski, "Wielkie i Małe Kompleksy Humanistów," in: Kultura i Fetysze

In his once controversial essay "Tragizm i maski tragizmu," Jan Kott described the works of Conrad and Malraux in terms of tragedy that is defined by characters facing a world devoid of meaning. Kott claimed that tragedy is overcome when individuals enter the world of communal values. The characters in Lem's novels are tragic in a very similar sense, but they do not find a similar solution. They are unable to find meaning in culturally sanctioned activities because culture barely exists in their world. Culture as a reservoir of the past, history and their symbols cultivated in social communication has no place in Lem's novels. That is why their protagonists are absolutely lonely. Their only haven is science, reason and - especially in his early works - the ethos of male friendship rooted in the former two. But Lem frequently undermines all these sources of meaning. It seems that the very possibility of communication between people, based either on shared symbols or simple empathy, is highly problematic in his eyes. Perhaps this is why it was easy for him to come up with plans of autoevolution and was so eager to dive into the world of machines. For Lem, technology neutralizes culture and history.

Who is Lem as the author of "technological" essays? Is he really a positivist, as many of his critics see him? To answer this question, we should look at the four basic characteristics of positivist thinking, as laid out by Leszek Kołakowski ${ }^{247}$ :

1. The rule of phenomenalism. "This may be briefly formulated as follows: there is no real difference between 'essence' and 'phenomenon' ... We are entitled

247 Leszek Kołakowski, "An Over-all View of Positivism," in: The Alienation of Reason. A History of Positivist Thought, trans. by N. Guterman (Garden City, NY: Doubleday and Company Inc., 1968), Chapter 1, 1-11. 
to record only that which is actually manifested in experience; opinions concerning occult entities of which experienced things are supposedly the manifestations are untrustworthy. Disagreements over questions that go beyond the domain of experience are purely verbal in character" (3).

This is, of course, about ridding the discourse of unnecessary speculative terms, following the principle entia non sunt multiplicanda praeter necessitatem. Does Lem follow this rule? When reading Dialogues and ST superficially, it may seem so, especially if we believe his own declaration of loyalty to it and hostility toward speculative metaphysics. But a problem occurs when we ask whether the subject of his own inquiries abides by this principle. If we assume that the main topic of ST is the project of autoevolution, seen as correlate to human rationality (and I have devoted much of the present work to argue that it is indeed so), then we should also accept that among Lem's implicit premises there is also at least one that refers to a notion that cannot be empirically verified - the idea of rationality itself. Moreover, in Lem's theoretical writings there are a number of statements that allow for a possibility of there being an element of human existence that could not be reduced to empirical notions, and some of his novels (Solaris, His Master's Voice) actually have this possibility as their main theme. It violates the rule of phenomenalism. I would rather say then that the whole of Lem's thought is more of a proof that he may have intended to be faithful to the rule, but he was not able to fulfill that intention, because throughout most of his creative biography he was struggling with his own "metaphysical temptation."

2. The rule of nominalism. "[It] comes down to the statement that we may not assume that any insight formulated in general terms can have any real referents other than individual concrete objects" (5).

Lem breaks this rule all the time. In ST there are a number of terms that are used as general terms, even though they have no concrete referents, even though they play a vital part in the book's argument. It is enough to mention "Nature," "Science" or "Designer." At the beginning of Part Two, I showed how Lem mixes elements of an academic text and an informal essay. The tendency to use such terms is among those characteristics of his writings that qualify them as informal essays.

3. The rule "that denies cognitive value to value judgments and normative statements" (7). In ST there are dozens of such statements (and I have quoted many of them here). It is hard to say with absolute certainty whether Lem sees any cognitive values in them. It is clear, however, that he uses them as arguments. The validity of the project of autoevolution is based on them. 
4. The rule of unity of the scientific method. It is about "the belief that the methods for acquiring valid knowledge, and the main stages in elaborating experience through theoretical reflection, are essentially the same in all spheres of experience" (9). Practically it entails subordinating the humanities to science, which we know well from the history of these two fields. Lem does not share such approach at all. In Dialogues and ST, which are the subject of my inquiry here, humanities are omitted altogether. They include no methodological declarations on acquiring knowledge of the non-physiological sphere of human existence (except cybernetic sociology in Dialogues, but even that is treated with some skepticism). I see this absence as a proof that Lem realized that positivism was helpless in that regard. In The Philosophy of Chance and Science Fiction and Futurology, Lem tried to build a theory of literature based on scientific premises, but he admitted the effects of those attempts were fruitless (that is the content of those books does not constitute a scientific theory in a strict sense). It is another proof of the difference between Lem's declared positivism and his concrete thinking on human and biological reality. We should also remember that structuralism, which was originally meant to be a "scientific" theory of culture, was strongly criticized by Lem from the very beginning for its senseless use of scientific terms for the analysis of works of literature and art.

So Lem does not follow any of the four main rules of positivism. Or, to be more precise, he does not follow any of them unconditionally. His writings are so rich and diverse that there is enough material in it to prove the opposite thesis too. I have quoted Lem's sentences that any genuine scientist could claim as theirs. But I think it would not be fair to see Lem merely as a positivist, as it would require omitting many themes of his works which I deem the most important. As a writer he was aware that there is a sphere of human existence which cannot be reduced to positive knowledge. ${ }^{248}$ The thing is that he opposes the existence of this sphere, as he believes it to be the source of insufferable and unavoidable contradictions of our condition. In that sense Lem, just as Tolstoy, is a fox who wants to be a hedgehog in Isaiah Berlin's terms. He knows about the irreducible diversity of the world, but despite his better judgment, he wants to find a Grand Rule that would govern and explain it. As I have pointed out a number of times

248 Jerzy Jarzębski emphasizes this duality in his essay Przypadek $i$ wartości ["Chance and values"], which presents a thorough analysis of Lem the scientist and Lem the humanist. 
already, the project of autoevolution is a means to overcome these contradictions, and as such it is among many noble utopias that present a vision of man who saved himself from his own flaws. In Lem's version (and in its simplified version that is posthumanism), posthuman beings achieve such level of perfection that the entire struggle between Nature and Culture, which plagues our current social and mental existence, becomes as distant as the polemics between Monophysites and Monothelites. In Lem's view, autoevolution is to give us the opportunity to tame the horses in the Platonic chariot and achieve a dream balance of existence, even if it requires rejecting the heritage of a few dozen centuries of culture, philosophy, art and religion, the achievements of which are but a testimony to this hopeless struggle. In this uncompromising vision, humanity is but a sad episode. The autoevolutionary utopia is only a dream of liberation from "the terrible burden of being human." 249

We could shrug it off and just say: what kind of fantasies are these? Would it not be better to do something useful? Probably, yes. But I believe - and I am highly aware this judgment is not particularly significant - that the work of Stanisław Lem is one of the most beautiful adventures of human mind.

249 Maria Janion uses this phrase when discussing Zbignier Kubiak's Mitologia Greków i Rzymian in her volume Żyjąc tracimy życie (Warszawa: W.A.B., 2003). 


\section{Bibliography}

Adams, Frank and Greg Laughlin. The Five Ages of the Universe: Inside the Physics of the Eternity. New York: Free Press, 1999.

Arbib, Michael A. The Metaphorical Brain. An Introduction to Cybernetics as Artificial Intelligence and Brain Theory.

New York-London-Sydney-Toronto: Wiley, 1972.

Ashby, William Ross. An Introduction to Cybernetics. London: Chapman \& Hall, 1958.

Baard, Erik. "Cyborg Liberation Front." The Village Voice. July 30-August 5, 2003, https://www.villagevoice.com/2003/07/29/cyborg-liberation-front/, accessed 9.06.2018.

Bolter, J. David. Turing's Man: Western Culture in the Computer Age. Chapel Hill: The University of North Carolina Press, 2014.

Boulanger, G. R. "Prologue: What is Cybernetics?” In Survey of Cybernetics.

A Tribute to Dr Norbert Wiener, edited by John Rose. London: Illiffe Books Ltd, 1969.

Brockman, John (ed.), The Third Culture, New York: Simon \& Schuster, 1995.

Castells Manuel. The Information Age: Economy, Society and Culture, vol.

1: The Rise of the Network Society, vol. 2: The Power of Identity, vol. 3: End of Millenium. 2nd edition. Oxford: Blackwell, 2000.

Cetwiński, Olgierd. Między buntem a pokorą. Warszawa: KiW, 1986.

Clynes, Manfred E. and Nathan S. Kline. "Cyborgs and Space." Astronautics, no. 9 (1960), 26-27, 74-76.

Cohen, John. Les Robots humains dans le mythe et dans la science. Paris: Vrin, 1968.

Davies, Paul. The Last Three Minutes: Conjectures about the Ultimate Fate of the Universe. London: Weidenfeld \& Nicolson, 1994.

Davis, Erik. TechGnosis: Myth, Magic and Mysticism in the Age of Information. London: Serpents Tail, 2004.

Downey, Gary Lee, Joseph Dumit and Sarah Williams. "Cyborg Anthropology." Cultural Anthropology, no. 2 (1995), 264-269.

Dukaj, Jacek. Inne pieśni. Kraków: WL, 2002.

Dukaj, Jacek. Perfekcyjna niedoskonałość. Pierwsza tercja progresu.

Kraków: WL, 2004. 
Dyson, Freeman John. “Time without End: Physics and Biology in an Open Universe.” Review of Modern Physics, no. 51 (1979), 447-460.

Egan, Greg. Distress. New York: HarperPrism, 1995.

Foucault, Michel. “Technologies of the Self." In Technologies of the Self: A

Seminar with Michel Foucault, edited by Luther H. Martin, Huck Gutman and Patrick H. Hutton. London: Tavistock, 1988.

Fromm, Erich. To Have or to Be? New York: Bloomsbury, 2013.

Fukuyama, Francis. Our Posthuman Future: Consequences of the Biotechnology

Revolution. New York: Picador - Farrar, Straus and Giroux, 2002.

Gibson, William. Neuromancer. New York: Berkley Publishing Group, 1988.

Greniewski,Henryk. Cybernetyka z lotu ptaka. Warszawa: KiW, 1959.

Greniewski,Henryk. Elementy cybernetyki sposobem niematematycznym wyłożone. Warszawa: PWN, 1959.

Greniewski,Henryk. Cybernetyka niematematyczna. Warszawa: PWN, 1969.

Haraway, Donna. “A Cyborg Manifesto: Science, Technology, and SocialistFeminism in the Late Twentieth Century." Socialist Review, no. 90 (1985), 65-107.

Hayles, N. Katharine. Chaos Bound: Orderly Disorder in Contemporary Literature and Science. Ithaca-London: Cornell University Press, 1990.

Hayles, N. Katharine. How We Become Posthuman: Virtual Bodies in Cybernetics, Literature and Information. Chicago: University of Chicago Press, 1999.

Heim, Michael. “The Erotic Ontology of Cyberspace.” In idem, The Metaphysics of Virtual Reality. New York: Oxford University Press, 1993.

Herbrechter, Stefan and Ivan Callus. "What's Wrong with Posthumanism?" Rhizomes. Cultural Studies in Emerging Knowledge, no. 7 (2003), http://www. rhizomes.net/issue7/callus.htm, accessed 9.06.2018.

Hodges, Andrew. Alan Turing: The Enigma. London: Burnett Books, 1983.

Hodges, Andrew. Turing. New York: Routledge, 1999.

Horgan, John. The End of Science. Facing the Limits of Knowledge in the Twilight of the Scientific Age. New York: Basic Books, 2015.

Houellebecq, Michel. Elementary Particles, translated by Frank Wynne.

New York: Vintage, 2001.

Hoyle, Fred. The Black Cloud. London: Heinemann, 1957.

Humbert, Vincent. Je vous demante le droit de la mort. Paris: Le Grand livre du mois, 2003. 
Jacques, Monod. Chance and Necessity, translated by Austryn Wainhouse. London: Fontana, 1974.v

Jarzębski, Jerzy. “'Summa technologiae' i jej potomstwo.” In Stanisław Lem. Summa technologiae. Dzieła zebrane. Kraków: WL, 2000.

Jarzębski, Jerzy. “Lata młodzieńcze i dojrzałość cybernetyki." In Stanisław Lem. Dialogi. Dzieła zebrane. Kraków: WL, 2001.

Jarzębski, Jerzy. Wszechświat Lema. Kraków: WL, 2003.

Joy, Bill. "Why the Future Doesn't Need Us." Wired, April 10, 2000, https://www. wired.com/2000/04/joy-2/, accessed 9.06.2018.

Klugman, Craig M. "From Cyborg Fiction to Medical Reality." Literature and Medicine, no. 1 (2001), 39-54.

Kołakowski, Leszek. “Informacja i utopia.” Twórczość, no. 11 (1964), p. 115-123.

Kołakowski, Leszek. The Alienation of Reason. A History of Positivist Thought, translated by Norbert Guterman. Garden City, NY: Doubleday and Company Inc.,1968.

Kołakowski, Leszek. “Lemowi.” Wiedza i Życie, no. 12 (1991), p. 71-72.

Konieczny, Józef. Cybernetyka walki. Warszawa: PWN, 1971.

Kossecki, Józef. Cybernetyka kultury. Warszawa: PIW, 1974.

Kossecki, Józef. Cybernetyka społeczna. Warszawa: PWN, 1981.

Koyrè, Alexandre. Les Origines de la science: Les philosophes et la machine.

Paris: Armand Colin, 1966.

Kunicki-Goldfinger, Władysław J. H. Znikąd donikąd. Warszawa: PIW, 1993.

Kurzweil, Ray. The Age of Spiritual Machines: When Computers Exceed Human Intelligence. New York: Penguin, 2000.

Lange, Oskar. Dzieła, vol. 7: Cybernetyka. Warszawa: Państwowe Wydawnictwo Ekonomiczne, 1977.

Lem, Stanisław. "Autoewolucja." Argumenty, no. 34 (1969), p. 7, 14.

Lem, Stanisław. Refleksje 1974. In idem, Rozprawy i szkice. Kraków: Wyd. Literackie, 1975.

Lem, Stanisław. [Response to a polemic]. Znak, no. 291 (1978), p. 1148.

Lem, Stanisław. Dialogi. 3rd edition. Kraków: WL, 1984.

Lem, Stanisław. “Trzydzieści lat później”. Wiedza i Życie, no. 6 (1991), p. 10-23.

Lem, Stanisław. Tajemnica chińskiego pokoju. Kraków: Znak, 1996.

Lem, Stanisław. Summa technologiae. Dzieła zebrane. Kraków: WL, 2000.

Lem, Stanisław. Listy albo opór materii, edited by Jerzy Jarzębski. Kraków: Wyd. Literackie, 2002. 
Lem, Stanisław. Mój pogląd na literaturę. Dzieła zebrane. Kraków: WL, 2003.

Lem, Stanisław. Summa Technologiae, translated by Joanna Żylińska.

Minneapolis: University of Minneapolis Press, 2013.

LemStanisław, BereśStanisław, Tako rzecze...Lem. Ze Stanisławem Lemem rozmawia Stanisław Bereś. Kraków: WL, 2001.

Manuel, Frank Edward. A portrait of Isaac Newton. Cambridge, MA: Belknap, 1968.

Mazur, Marian. Cybernetyka i charakter. Warszawa: PIW, 1976.

Nagel, Thomas. “What Is It Like To Be a Bat?” In: Thomas Nagel, Mortal Questions. Cambridge: Cambridge University Press, 1979, 165-180.

Penrose, Roger. The Emperor's New Mind: Concerning Computers, Minds and the Laws of Physics. London: Vintage, 1990.

Penrose, Roger. The Large, the Small and the Human Mind. Cambridge: Cambridge University Press, 1997.

Pepperell, Robert. The Posthuman Condition: Consciousness Beyond the Brain. London: Intellect, 1995.

Pierce, John R. An Introduction to Information Theory. Symbols, Signals \& Noise. New York: Dover Publications, Inc., 1980.

Pohl, Frederik. Man Plus. New York: Baen Publishing Enterprises, 1976.

Putnam, Hilary. Reason, Truth, and History. Cambridge: Cambridge University Press, 1981.

Rubinowicz-Gründler, Anna. "Elfriede Jelinek. 'Nie umiem się niczym cieszyć.” Wysokie Obcasy, no. 287, October, 23-24, 2004, 5-9.

Ruyer, Raymond. La Gnose de Princeton. Paris: Fayard, 1974.

Scholem, Gershom. On the Kabbalah and Its Symbolics, translated by Ralph Manheim. London: Routledge and Kegan Paul, 1965.

Searle, John. "Minds, Brains and Programs." Behavioral and Brain Sciences, no. 3 (1980), 417-457.

Sherwin, Byron L. The Golem Legend: Origin and Implications. Lanham, MD: University Press of America, 1985.

Shreeve, James. “The Other Stem-Cell Debate.” New York Times, April 10, 2005.

Snow, Charles Percy. The Two Cultures. London: Cambridge University Press, 1969.

Steinbuch, Karl. Automat und Mensch. 4th edition.

Berlin: Springer-Verlag, 1961.

Szacki, Jerzy. Historia myśli socjologicznej. Warszawa: PWN, 2003. 
Szpakowska, Małgorzata. “Ucieczka Stanisława Lema.” Teksty, no. 3 (1972), p. 75-90.

Szpakowska, Małgorzata. Dyskusje ze Stanisławem Lemem. Warszawa: OPEN, 1997.

Świętochowski, Aleksander. Utopie w rozwoju historycznym. Warszawa: Gebethner i S-ka, 1910.

Taranienko, Zbigniew. "O biosferyczny parlament świata. Rozmowa ze Stanisławem Lemem.” Argumenty, no. 38 (1970), 5-8.

Thompson, D’Arcy Wentworth. On Growth and Form. Cambridge: Cambridge University Press, 1992.

Thorndike, Lynn. A History of Magic and Experimental Science, 8 volumes. New York: Macmillan, 1923-1958.

Turing, Alan M. “Computing Machinery and Intelligence." Mind, no. 59 (1950), p. 433-460.

Wiener, Norbert. The Human Use of Human Beings. Cybernetics and Society. Boston: Houghton Mifflin, 1950.

Wiener, Norbert. Cybernetics, or the Control and Communication in the Animal and the Machine. Cambridge, MA: MIT, 1965.

Zimniak-Hałajko, Marta. “Bez bólu. O dobrej śmierci.” In Ból. Gdańsk: Słowo/ Obraz Terytoria, 2004.

Žižek, Slavoj. No Sex, Please, We're Post-human, http://www.lacan.com/nosex. htm, accessed 9.06.2018.

Žižek, Slavoj. The Matrix, or, the Two Sides of Perversion, http://www.lacan.com/ zizek-matrix.htm, accessed 9.06.2018. 



\section{Index of Names}

A

Adams Fred 141, 233

Aeschylus 16, 179

Alexander the Great 208

Álmodovar Pedro 220

Arbib Michael 18, 233

Archimedes 164

Arnold Matthew 202

Aristotle 189, 209, 215, 225

Ashby William Ross 18, 23, 24, 28, 34, 55, 97, 233

Asimov Isaac 195

Attali Jacques 201

Augustine 31

B

Baard Erik 190, 233

Baltes Paul 20

Barlow John Perry 123

Baron Frank 179

Barrie James Matthew 221

Barthes Roland 64

Bataille Georges 218

Bates Paul A. 179

Bateson Gregory 20, 33

Baudrillard Jean 129

Bednarczyk Andrzej 178

Bejan Adrian 88

Bereś Stanisław 16, 41, 56, 121, 221, 236

Berkeley George 42, 101

Berlin Isaiah 207, 231

Bertalanffy Ludwig van 19

Bloom Allan 136

Bogusławski Stanisław 24

Bohr Niels Henrik 93

Bolter Jay David 34, 37, 38, 110,

$184,189,214,233$
Boltzmann Ludwig 17

Borges Jorge Luis 46, 139, 175, 210

Boulanger Georges R. 18, 233

Brandes Bernd 172

Breton Philippe 178

Brockman John 88, 233

Brown Robert 58

Buffon Georges Leclerc de 64

Bunsen Robert Wilhelm 94

Butler Judith 171, 217, 218

C

Callus Ivan 191, 234

Čapek Karel 194

Capra Fritjof 93, 135

Carrera R. 178

Castells Manuel 123, 233

Cetwiński Olgierd 29, 233

Caesar (Caius Iulius Caesar) 28

Champollion Jean François 17

Chislenko Alexander 196

Choynowski Mieczysław 16

Clark Nancie 184

Clynes Manfred E. 156, 193-196, 233

Cohen John 178, 233

Comte Auguste 94

Conrad Joseph 229

Crick Francis 89

Cromwell Oliver 28

Cronenberg David 173

Cugnot Nicolas Joseph 70

Cunningham Chris 173

D

Dabezies Andre 179

Daeniken Erich von 89

Dali Salvador 221 
Damiens Robert 172

Dante Alighieri 87, 181

Darwin Charles 19, 64, 165, 181, 183

Davies Paul 141, 233

Davis Erik 123, 124, 184, 233

Dawkins Richard 57

Dedal, see Kijowski Andrzej 40

Dennett Daniel 215

Derrida Jacques 191

Dick Philip K. 195, 197

Dostoyevsky Fyodor 47

Drexler Eric 184

Dublin Max 200

Dukaj Jacek 125, 210-212, 214, 219 , 220, 225, 233

Dumit Joseph 188, 233

Dyson Freeman 141, 234

E

Eco Umberto 40

Eddington Arthur Stanley 115

Edison Thomas 89, 91

Egan Greg 210, 212, 219, 220, 234

Eigen Manfred 133

Einstein Albert 87, 93

Eribon Didier 179

Esfandiary Feridun

M. (FM-2030) 184

F

Faraday Michael 19, 86

Faulkner William 9

Feuerbach Ludwig 190

Feynman Richard 134

Fisher Ronald Aylmer 18

Flaubert Gustave 9

FM-2030, see Esfandiary

Feridun M. 184

Foerster Heinz von 20

Foucault Michel 110, 172, 173, 179, $180,191,213,221,234$
Frege Gottlob 160

Fromm Erich 110, 234

Fukuyama Francis 203-206, 210, 212, 223, 234

G

Galton Francis 203

Gauss Carl Friedrich 19

Gehlen Arnold 53

Gibbs Josiah Willard 17

Gibson William 125, 234

Goethe Johann Wolfgang 179

Goffman Erving 217

Gomułka Władysław 136

Gosiewski Anatol 24

Gould Glenn 221

Gould Stephen Jay 87, 88

Gray Chris Hables $187,189,190$

Greniewski Henryk 18, 23-25, 27, $35,41,49,234$

Guiducci Gian Claudio 220

Gunn James 210

H

Hadot Pierre 208

Haraway Donna 187-189, 217, 234

Harpprecht Klaus 9

Hayles N. Katharine 105, 159, 187, 189,234

Hegel Georg Wilhelm Friedrich 9, 81, 189, 204

Heidegger Martin 213

Heim Michael 196, 234

Herbrechter Stefan 191, 234

Herschel Frederick William 91

Hodges Andrew 102, 105, 234

Hoerner von 90

Homer 16, 209

Horace (Quintus Horatius

Flaccus) 28

Horgan John 36, 234 
Houellebecq Michel 136, 182, 212-214, 234

Hoyle Fred 89, 141, 142, 234

Humbert Vincent 224, 234

Huxley Aldous 213

Huxley Julian 63, 182

Huxley Thomas Henry 202

\section{J}

Jaquet-Droz Pierre 17, 178

Janion Maria 232

Jarzębski Jerzy 40-42, 59, 60, 67, $73,74,78,80,-82,92,109,162$, 231,235

Jeans James 115

Jelinek Elfriede 215, 236

Jonas Hans 200

Jones Steve 199

Joy William N. (Bill) 201, 202, 235

Joyce James 40

Judin Paweł 23

Jung Carl Gustav 89

K

Kaczynski Teodor 202

Caligula (Caius Iulius Caesar

Germanicus Caligula) 28

Kandel Michael 67, 85, 108, 111,

$126,131,168$

Kant Immanuel 189, 207, 209, 221

Descartes (właśc. Rene

Descartes) 31, 37, 91, 189, 222

Kaufmann Stuart 21

Kempisty Maria 18, 23, 26

Kerényi Károly 179

Kępczyńska Danuta 39

Kijowski Andrzej (Dedal) 40

Kirchhoff Gustav Robert 94

Kline Nathan S. 156, 193-196, 233

Klugman Craig M. 194, 235

Kobyliński Szymon 119
Kołakowski Leszek 69-71, 73, 77, $80,109,125,153,229,235$

Kolmogorov Andrey 18, 23

Konieczny Józef 26, 235

Kossecki Józef 28-30, 34, 49, 55, 235

Kotarbiński Tadeusz 23

Kott Jan 229

Koyré Alexandre 178, 235

Krauss Lawrence M. 127

Kubiak Zbignier 232

Kuhn Thomas 131

Kunicki-Goldfinger Władysław Jerzy H. 235

Kurzweil Raymond (Ray) 185, 202, $211,215,235$

L

Lamarck Jean Baptiste de Monet de 64

Lange Oskar 25, 27, 28, 235

Laplace Pierre Simon de 61

Laughlin Greg 141, 233

Lee Downey Gary 188, 233

Lefebvre Henri 110

Leibniz Gottfried Wilhelm 17, 19, 31, 118, 196

Leonardo da Vinci 87

Lessing Lawrence 179

Leś Mariusz 40, 162

Liddell Henry George 16

Llull Ramon 17

Locke John 37

Loiseau D. 178

Luhmann Niklas 20, 134

Lukács György 9

Lucian 42

M

Malebranche Nicolas 197

Malraux André 229

Mann Thomas 9, 179 
Manuel Frank E. 236

Markov Andrey 58

Marlowe Christopher 179

Marx Karl 24, 25, 190, 200

Mason Palmer P. 179

Maturana Humberto 20, 134

Mazur Marian 27-30, 34, 52, 55,236

McCarthy John 99

Mead Margaret 20, 33, 224

Meiwes Armin 172, 173

Mendeleev Dmitri 87

Merleau-Ponty Maurice 70, 222

Minsky Marvin 99, 125, 185

Monod Jacques 87, 235

Montaigne Michel de 215

Moravec Hans 125

More Max 124, 182, 184

Morgenstern Oskar 33

$\mathbf{N}$

Nagel Thomas 90, 236

Napoleon Bonaparte 120, 212

Nehamas Alexander 180

Neumann John von $16,18,32,33$, 100,134

Newton Isaac 31, 34, 221, 236

Nietzsche Friedrich 124, 179, 180 , 201, 206-208, 217, 227

Nordenskjöld Nils 86

O

Oramus Marek 40

Osuchowska Barbara 24

$\mathbf{P}$

Pascal Blaise 17, 94, 138, 214

Pasteur Louis 86

Patterson More R. 179

Pavlov Iwan 23

Peary Edward 86

Penrose Roger 43, 236
Pepperell Robert 187, 190, 236

Petronius (Caisu Petronius) 28

Pierce John 36, 37, 236

Plato 16, 33, 42, 161, 196, 232

Plessner Helmuth 53

Pohl Frederik 195, 236

Prigogine Ilya 21

Proust Marcel 28

Pseudo-Dionizy Areopagita 138

Pushkin Alexander 58

Putnam Hilary 100, 101, 236

$\mathbf{R}$

Ravel Maurice 221

Rees Martin 200, 202

Roentgen Wilhelm 87

Rose J. 18, 233

Roussel Raymond 108

Routledge N. A. 102, 105, 234, 236

Roux O. 178, 203, 234

Rozental Mark 23

Rubinowicz-Gründler Anna 215, 236

Ruskin John 221

Ruyer Raymond 135, 236

\section{S}

Sade Donatien Alphonse François de 218

Sadkowski Wacław 40

Sagan Carl 89

Salazar Antonio 221

Sartre Jean Paul 9

Schank Roger 185, 215

Scheler Max 53

Schneirla Theodore Christian 33

Scholem Gershom 236

Scott Ridley 195

Scott Robert 16

Searle John 100, 236

Sechan Louis 179 
Shannon Claude 17, 24, 36, 37, 44

Sherwin Byron L. 236

Shreeve James 190, 225, 236

Siemek Marek J. 9

Sienkiewicz Henryk 28

Sienkiewicz Piotr 30

Skłodowska-Curie Maria 87

Smelser Neil 20

Smith Adam 25, 212

Snow Charles Percy 34, 236

Spielberg Steven 89

Stanley Henry Morton 86

Stein Jantz H. 179

Steinbuch Karl 31

Stoczkowski Wiktor 89

Strzelecki Jan 209

Szacki Jerzy 161, 236

Szapiro Jerzy 24

$\hat{S}$

Świętochowski Aleksander 161, 237

T

Taranienko Zbigniew 66, 237

Teilhard de Chardin Pierre 137

Tesla Nikola 221

Thompson D' Arcy Wentworth 87, 88,237

Thorndike Lynn 237

Tipler Frank 137

Toffler Alvin 204

Turing Alan Mathison 18, 31, 34, $37,38,46,65,73,88,99-110,121$,
$170,175,185,189,194,195,213$, 214, 233, 234, 237

Turney Jon 178

V

Varela Francisco 20, 134

Vita-More Natasha 184

W

Wachowscy Andy and Larry 121

Wagner Richard 205

Warwick Kevin 196

Watson James 155

Weber Max 219

Weinberg Steven 141

Wellek René 189

Wells Herbert George 161

White Hayden 154

Wiener Norbert 15-21, 23, 24, 26-28, 31-38, 44, 55, 93, 189, 233, 237

Wierciński Andrzej 28

Williams Sarah 188, 233

Wilson Edward O. 57

Winkler Ruthild 133

Wittgenstein Ludwig von 94, 101

Wolfram Stephan 88

Wright Orville and Wilbur 86

Z

Zimniak-Hałajko Marta 223, 237

Žižek Slavoj 105, 197, 213, 237

Znaniecki Florian 128 



\section{Modernity in Question Studies in Philosophy, Sociology and History of Ideas}

Edited by Małgorzata Kowalska

Volume 1 Andrzej Leder: The Changing Guise of Myths. Philosophical Essays. 2013.

Volume 2 Mateusz Salwa: Illusion in Painting. An Attempt at Philosophical Interpretation. Translated by Katarzyna Pisarek. 2013.

Volume 3 Małgorzata Kowalska (éd.): Morales et politiques postmodernes. 2014.

Volume 4 Waśkiewicz, Andrzej: Strangers by Choice. An Asocial Philosophy of Life. Translated by Tul'si Bambry and Agnieska Waśkiewicz. 2015.

Volume 5 Jacek Migasiński: Toward Metaphysics. New Tendencies in French Philosophy in the Middle of the Twentieth Century. Translated by Jan Pytalski. 2014.

Volume 6 Przemysław Czapliński: The Remnants of Modernity. Two Essays on Sarmatism and .Utopia in Polish Contemporary Literature. Translated by Thomas Anessi. 2015.

Volume 7 Bartosz Kuźniarz: Farewell to Postmodernism. Social Theories of the Late Left. Translated by Bill Stanley. 2015.

Volume 8 Małgorzata Kowalska: Dialectics Beyond Dialectics. Essay on Totality and Difference. Translated by Cain Elliott and Jan Burzyński. 2015.

Volume 9 Jacek Dobrowolski: The Rise and Fall of Modern Man. Translated by Simon Loeb and Joanna Guzowska. 2017.

Volume 10 Paweł Majewski: Between an Animal and a Machine. Stanisław Lem's Technological Utopia. 2018.

www.peterlang.com 